\title{
AN INTEGRATED PLANNING FRAMEWORK FOR URBAN STORMWATER MANAGEMENT: A ONE WATER APPROACH
}

\author{
by \\ James Kirk Hager \\ BSc (Geology), Mount Royal University, 2015 \\ A THESIS SUBMITTED IN PARTIAL FULFILLMENT OF \\ THE REQUIREMENTS FOR THE DEGREE OF \\ MASTER OF APPLIED SCIENCE \\ in
}

THE COLLEGE OF GRADUATE STUDIES

(Civil Engineering)

THE UNIVERSITY OF BRITISH COLUMBIA

(Okanagan)

April 2019

(C) James Kirk Hager, 2019 
The following individuals certify that they have read, and recommend to the College of Graduate Studies for acceptance a thesis/dissertation entitled:

\section{AN INTEGRATED PLANNING FRAMEWORK FOR URBAN STORMWATER MANAGEMENT: A ONE WATER APPROACH}

Submitted by James Kirk Hager in partial fulfillment of the requirements of the degree of Master of Applied Science.

Dr. Rehan Sadiq, School of Engineering

\section{Supervisor}

Dr. Kasun Hewage, School of Engineering

\section{Co-Supervisor}

Dr. Zheng Liu, School of Engineering

\section{Supervisory Committee Member}

Dr. Shahria Alam, School of Engineering

\section{Supervisory Committee Member}

Dr. Homayoun Najjaran, School of Engineering

\section{University Examiner}




\section{Abstract}

Flooded streets and homes, polluted surface water bodies, degraded aquatic habitats, stressed aquifers, and expensive drainage infrastructure are evidence that Canada's current approach to stormwater management is not financially or environmentally sustainable. Although there are several decision support tools and frameworks for stormwater management planning that have been developed in the past decade, few are suited to the specific needs of long-term communitylevel urban stormwater management planning in Canada's diverse and extreme climates. To address the abovementioned challenges, the development of a modern community-level urban stormwater decision support framework was proposed. The framework is capable of adapting to suit the needs of resilient stormwater infrastructure planning in Canada. The framework will assess low impact development infrastructure, traditional stormwater infrastructure, and communitylevel stormwater reuse schemes to identify the optimal resilient stormwater management strategy for a new urban community development in Canada based on the community's water footprint. The proposed framework incorporates stochastic variation in natural processes (e.g., inter- and intra-annual variability in precipitation patterns) to predict a community's water footprint using the "one water approach". The one water approach is an integrated planning framework for managing all water resources (including stormwater, wastewater, and drinking water). A climate change sensitivity analysis is also incorporated to test any proposed stormwater systems for resiliency to Canada's changing climate. The framework relies on two multi-criteria, multi-period decision-making methods to optimize a community's stormwater infrastructure based on constraints defined by community planners. The proposed framework will allow new-community developers and planners to reduce a community's long-term water footprint by identifying the optimal combination of resilient and cost-effective stormwater infrastructure. Two case studies were performed to highlight the capabilities of the developed framework. The results indicate that the optimal mix of stormwater infrastructure is heavily influenced by decision makers' priorities, inter- and intra-annual weather patterns, site conditions, and regional predictions of climate change. 


\section{Lay Summary}

Flooded streets and homes, polluted surface water bodies, degraded aquatic habitats, stressed aquifers, and expensive drainage infrastructure are evidence that Canada's current approach for stormwater management is not economically or environmentally sustainable. Projected urbanization is expected to increase the area of drainage basins covered in non-permeable surfaces, increasing urban stormwater runoff volumes, surface water pollution, and urban flooding. Also, existing infrastructure is being overwhelmed by changing weather patterns, increasing the risk to people and property associated with urban stormwater flows. To address these challenges, a community-level urban stormwater planning framework was developed. The framework assesses low impact development stormwater management technologies, traditional stormwater infrastructure, and community-level stormwater reuse schemes to optimize a resilient stormwater management plan for a new Canadian urban community development. This research will allow developers and planners to reduce a community's water footprint by identifying the optimal mix of resilient and cost-effective stormwater infrastructure. 


\section{Preface}

All model development and validation was conducted by Mr. Hager under the supervision of Drs. Rehan Sadiq and Kasun Hewage.

A manuscript titled "Performance of low impact development best management practices: a critical review" has been published in the journal Environmental Reviews. That paper was comprised of parts of Chapter 2 of this thesis. The paper was written by James Hager under the supervision of Drs. Rehan Sadiq and Kasun Hewage. Dr. Guangji Hu was also an author on this paper due to his contributions during the paper writing process, including help with paper layout and technical reviews.

A version of Chapters 3 and 4 was also presented as a poster at the 2018 Environmental Flow Needs Conference, Kelowna, BC, Canada, on October 17, 2018. The conference was hosted by the Canadian Water Resource Association, the Okanagan Basin Water Board, and the Okanagan Nation Alliance. The poster was titled "Optimization of urban stormwater management strategy to support environmental flow needs".

A different version of Chapters 2, 3 and 4 have also been submitted to the Journal of Water Resources Planning and Management, titled "Integrated planning framework for urban stormwater management: one water approach." The paper was written by James Hager under the supervision of Drs. Rehan Sadiq and Kasun Hewage. Dr. Haroon Mian and Dr. Guangji Hu were also authors on this paper due to their contributions during the paper writing process. Dr. Hu was a co-contributor in performing the fuzzy clustering analysis and creating all relevant figures and tables and helped in interpreting the results. Dr. Mian contributed in the form of review and editing of the paper layout and provided meaningful technical reviews.

The full references for all submitted and published works as a result of this thesis are as follows:

Hager, J., Hewage, K. and Sadiq, R. (2018). "Optimization of urban stormwater management strategy to support environmental flow needs." Poster presented at Environmental Flow Needs Conference 2018: Science, Policy \& Practice, Okanagan Basin Water Board and the Canadian Water Resources Association, Kelowna, BC. 
Hager, J., Hu, G., Hewage, K., \& Sadiq, R. (2018). "Performance of low-impact development best management practices: A critical review." Environmental Reviews, 00: 1-26. doi:10.1139/er-2018-0048

Hager, J., Mian, H. R., Hu, G., Sadiq, R., and Hewage, K. (2019). “Integrated planning framework for urban stormwater management: one water approach." Journal of Water Resources Planning and Management. Manuscript submitted for publication. 


\section{Table of Contents}

ABSTRACT ................................................................................................................................................... iii

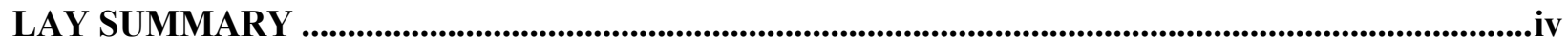

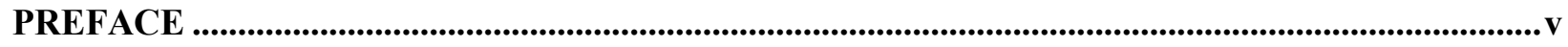

TABLE OF CONTENTS ...................................................................................................................................vii

LIST OF TABLES...................................................................................................................................................

LIST OF FIGURES......................................................................................................................................................

LIST OF SYMBOLS AND ABBREVIATIONS..........................................................................................

ACKNOWLEDGEMENTS ..........................................................................................................................

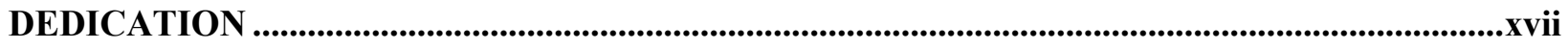

1 INTRODUCTION ................................................................................................................. 1

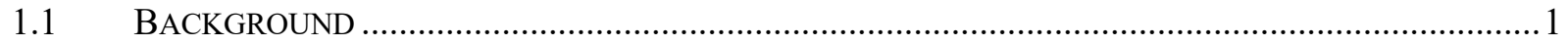

1.2 RESEARCH OBJECTIVES......................................................................................

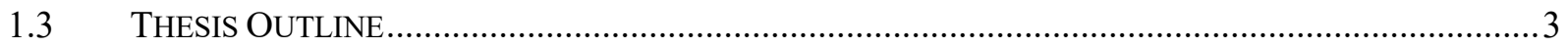

2 LITERATURE REVIEW ........................................................................................................4

2.1 Performance of Low Impact DeVELOPMENT: A CRitical REVIEW of Best MANAGEMENT

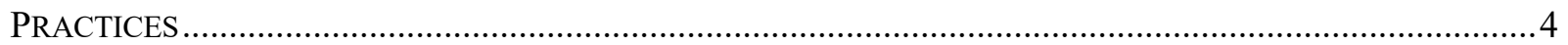

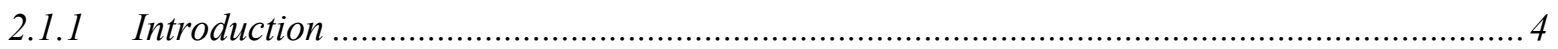

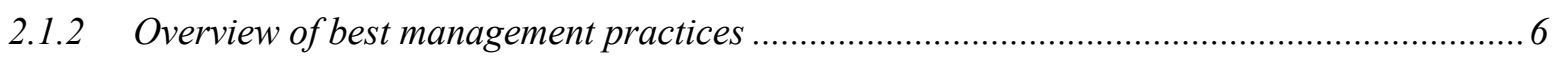

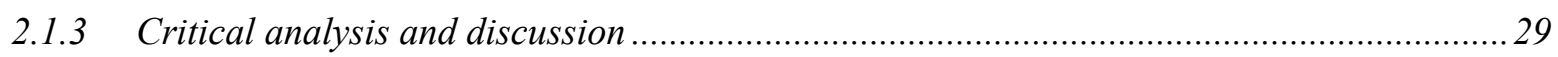

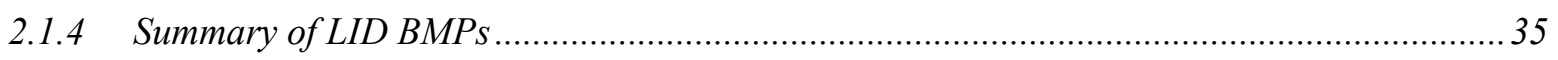

2.2 STORMWATER MANAGEMENT PLANNING FRAMEWORKS AND TOOLS .........................................35

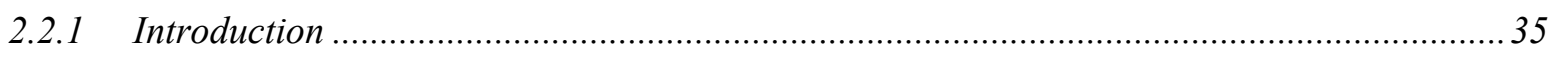

2.2.2 Existing decision support tools for stormwater management.............................................. 38

2.2.3 Summary of existing tools and frameworks .................................................................. 41

3 ONE WATER STORMWATER PLANNING FRAMEWORK.....................................................43

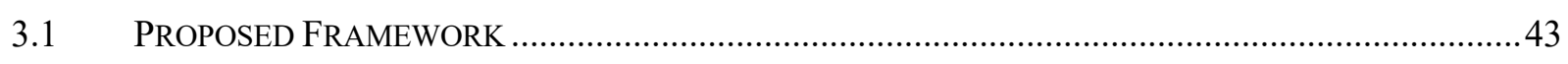

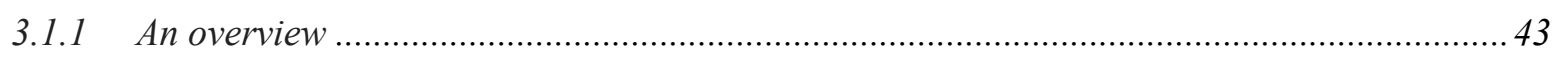




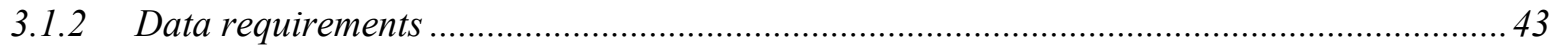

3.1.3 Runoff, evapotranspiration, and infiltration models ........................................................ 46

3.1.4 Meteorology and climate change modules .................................................................... 51

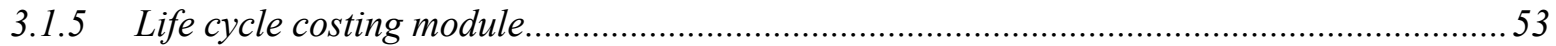

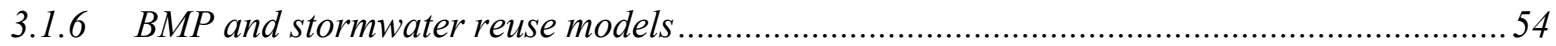

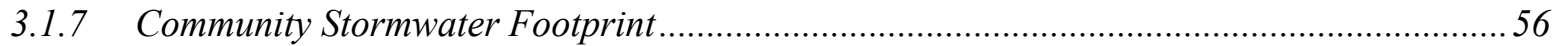

3.1.8 Representative stormwater infrastructure scenarios ...................................................... 60

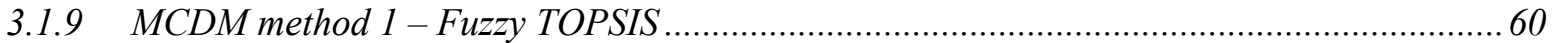

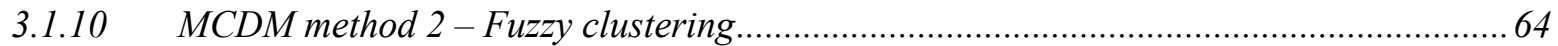

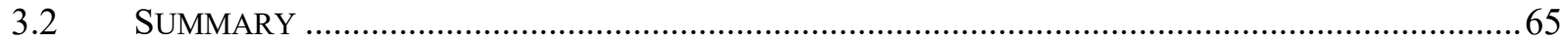

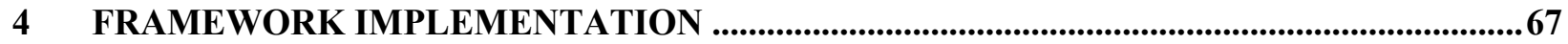

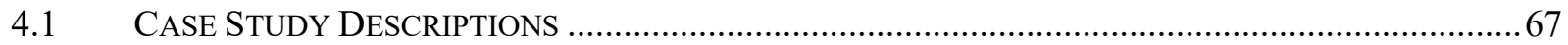

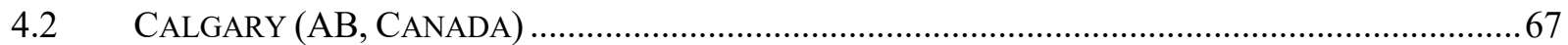

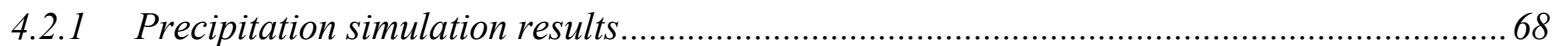

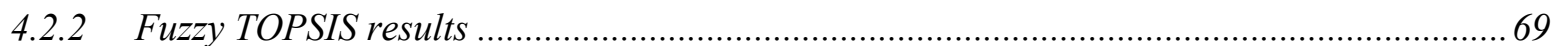

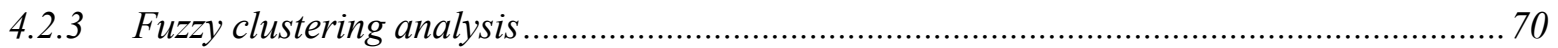

4.2.4 Aggregate fuzzy decision making.......................................................................................... 72

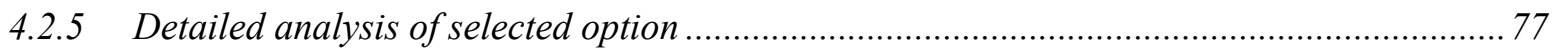

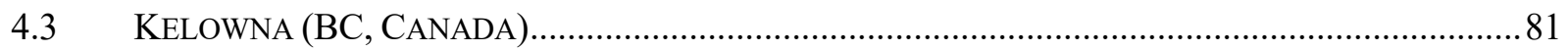

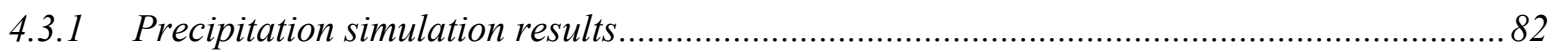

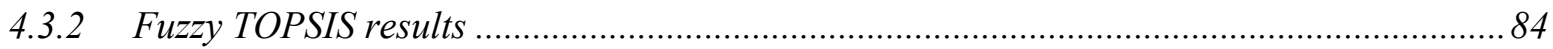

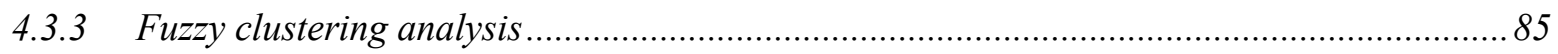

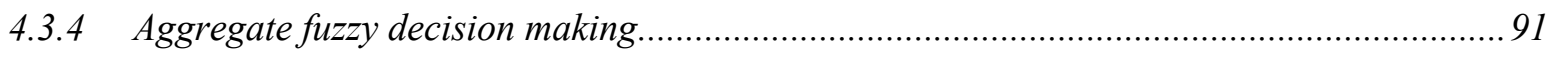

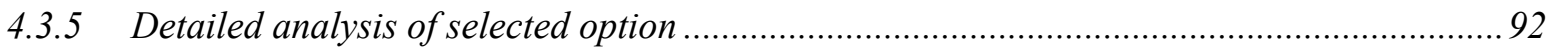

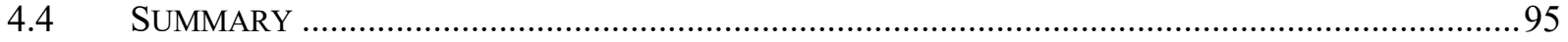

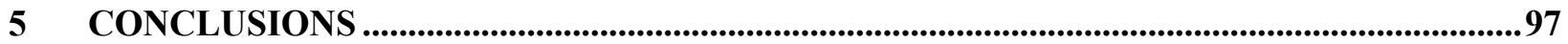

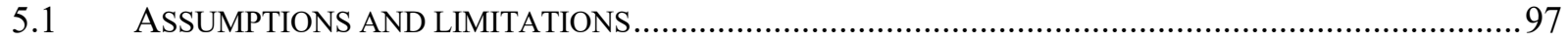

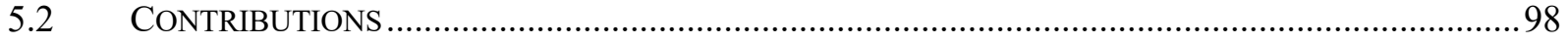

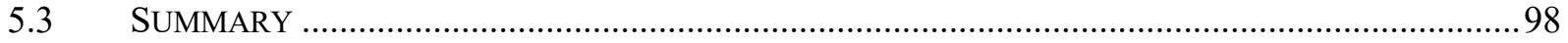

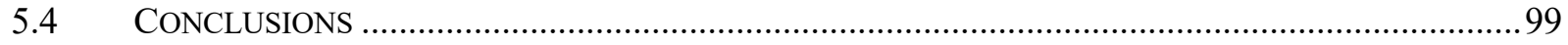

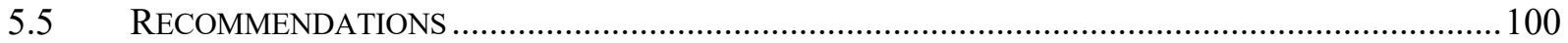

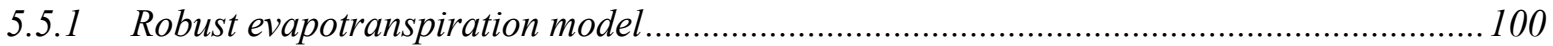

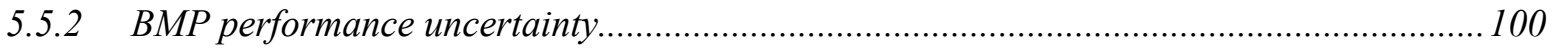




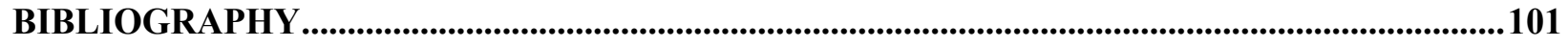

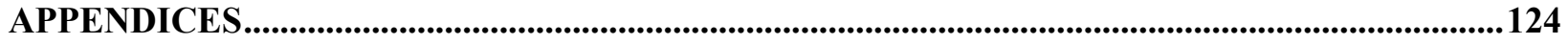

APPENDIX A: DETAILED REPORTS OF REVIEWED LID BMP STUDIES............................................... 124

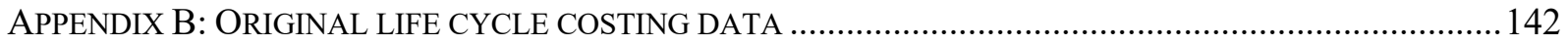

APPENDIX C: CASE STUDY DEMONSTRATION - DETAILED DATA …................................................. 143 


\section{List of Tables}

Table 2-1: Urban stormwater parameters and categories reviewed in this study........................7

Table 2-2: Number of studies investigating each parameter for each BMP..............................30

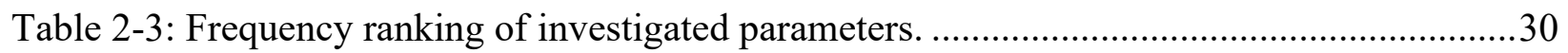

Table 2-4: Nonparametric statistics of the reviewed literature for the top-ranked parameters for

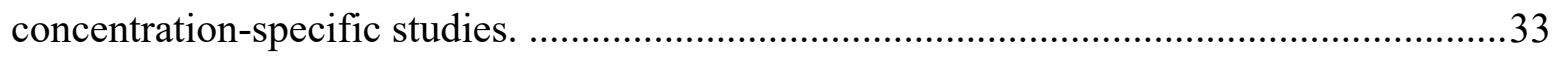

Table 2-5: BMPs and their nutrient exportation potential.....................................................33

Table 2-6: Summary of features of existing urban stormwater decision support tools and

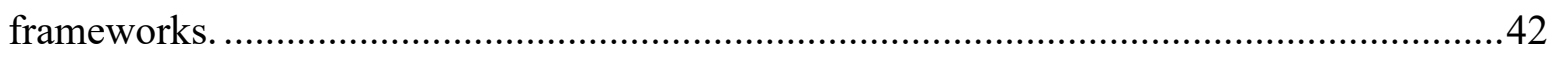

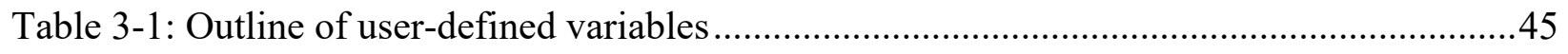

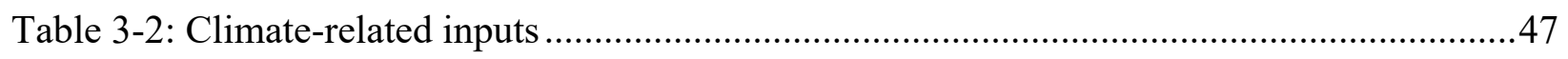

Table 3-3: Best management practice and stormwater reuse control variables .........................48

Table 3-4: Runoff curve numbers for undeveloped areas. ...................................................49

Table 3-5: Runoff curve numbers for urban areas.................................................................49

Table 3-6: Mean daily percentage of annual daytime hours for the month based on latitude.......50

Table 3-7: Relationships of soil texture classification, infiltration rate, and soil group type........51

Table 3-8: Upper and lower bounds for driving the Monte Carlo-based LCC module................53

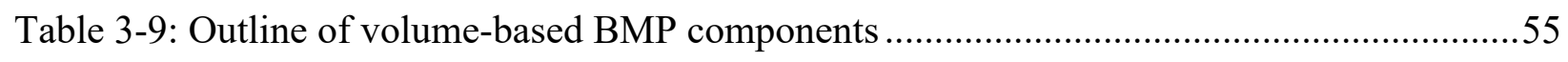

Table 3-10: Urban stormwater pollutant concentrations by source area.................................58

Table 3-11: LID BMP pollutant reduction performance ......................................................58

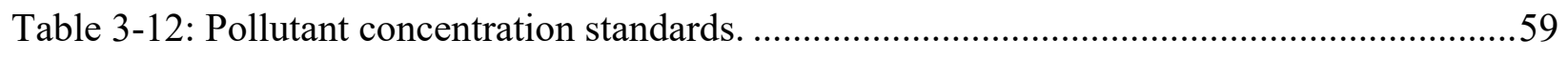

Table 3-14: Sources of fuzzy number values in the OWSWPF. .........................................61

Table 3-13: Representative stormwater infrastructure scenarios ........................................62

Table 4-1: Annual precipitation statistics for precipitation simulations based on historical data. 68

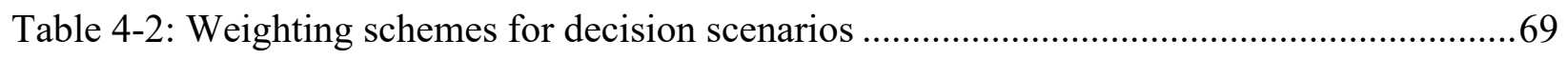

Table 4-3: Infrastructure mix rankings and closeness coefficients for different weighting scenarios

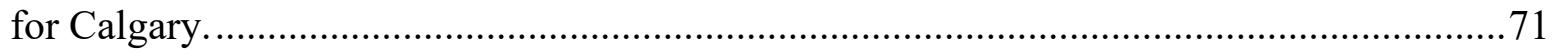

Table 4-4: Data required for performing aggregate decision making considering both FCA and Fuzzy-TOPSIS results and resiliency for Calgary ................................................... 73

Table 4-5: Levels of performance corresponding to different index ranges. .............................74

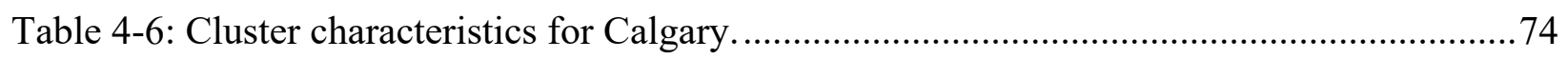


Table 4-7:Average monthly climate normals for Calgary and Kelowna (1981-2010). .82

Table 4-8: Annual precipitation statistics for precipitation simulations based on historical data. 83

Table 4-9: Infrastructure mix rankings and closeness coefficients for different weighting scenarios

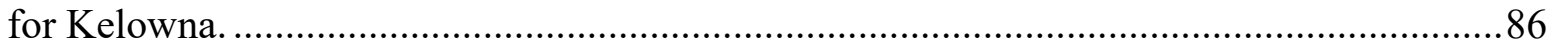

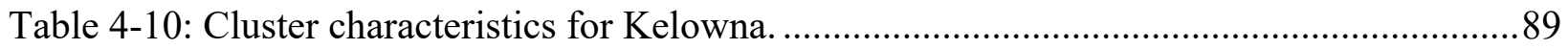

Table 4-11: Advantages and disadvantages of associated with MCDM algorithms used in this study.

Table 4-12: Data required for performing aggregate decision making considering both FCA and Fuzzy-TOPSIS results and resiliency for Kelowna....................................................... 91 


\section{List of Figures}

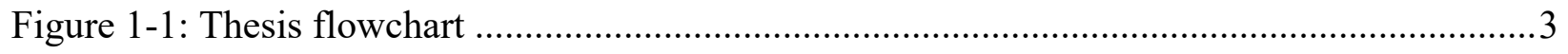

Figure 2-1: Classification of reviewed BMPs. ................................................................. 6

Figure 2-2: Cross-section schematic of a permeable pavement system ................................... 7

Figure 2-3: Cross-section schematic of an infiltration trench ............................................. 9

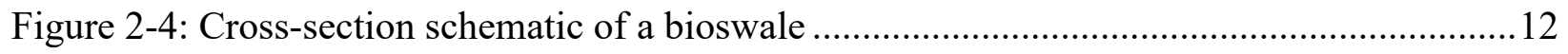

Figure 2-5: Cross-section schematic of a bioretention cell ....................................................... 14

Figure 2-6: Cross-section schematic of a buffer/filter strip............................................... 17

Figure 2-7: Cross section schematic of a constructed stormwater wetland................................19

Figure 2-8: Cross-section schematic of a home with disconnected downspout directed to a raingarden and a separate downspout connected to the sewer system .............................22

Figure 2-9: Cross-section schematic of a building with underground rainwater storage and an aboveground rain barrel. Adapted from O'Hogain et al. (2011)......................................24

Figure 2-10: Cross-section schematic of a typical intensive green roof system .......................26

Figure 2-11: Box-and-whisker plots comparing the runoff reduction and treatment efficiencies of BMPs .32

Figure 2-12: Change in average precipitation based on multi-model mean projections for 20812100 relative to 1986-2005 under the representative concentration pathway (RCP) 2.6 (left) and RCP 8.5 (right) scenarios.

Figure 3-1: One Water StormWater Planning Framework overview.....................................44

Figure 3-2:Graphical representation of assumed runoff treatment train for the OWSWPF.........46

Figure 3-3: Bioretention cell schematic showing water inflows and outflows ..........................55

Figure 3-4: OWSWPF scope of pre-development stormwater footprint...................................59

Figure 3-5: OWSWPF scope of post-development stormwater footprint .................................59

Figure 4-1:Closeness coefficients for stormwater infrastructure scenarios in Calgary...............69

Figure 4-2:Change in ranking results for all infrastructure and weighting scenarios for Calgary.

Figure 4-3:The kernel density estimation (KDE) of (a) life cycle costs (LCC); (b) grey water footprints; and (c) blue water footprints for the Calgary case study demonstration .75

Figure 4-4: The variation of within-group sum of squares (SS) with change in cluster number for Calgary. 
Figure 4-5: Matrix scatterplot of FCA for Calgary. .76

Figure 4-6: Visual representation of WBEs for historical climate norms (a) and RCP 8.5 (b) for Calgary. .78

Figure 4-7: Total annual water footprint vs. total annual rainfall for Calgary ..............................79

Figure 4-8: Annual GWF vs. total annual precipitation for Calgary............................................8 80

Figure 4-9: Boxplots of Monte Carlo-based life cycle costs for Calgary......................................81

Figure 4-10: Average monthly precipitation values generated by the OWSWPF for current (Historical) and predicted climate change (RCP 2.6 and RCP 8.5) and observed historical averages (Observed) for Calgary.

Figure 4-11: Average monthly precipitation values generated by the OWSWPF for current (Historical) and predicted climate change (RCP 2.6 and RCP 8.5) and observed historical averages (Observed) for Kelowna. .84

Figure 4-12: Closeness coefficients for stormwater infrastructure scenarios in Kelowna. .84

Figure 4-13: Change in ranking results for all infrastructure and weighting scenarios for Kelowna.

Figure 4-14: The kernel density estimation (KDE) of (a) life cycle costs (LCC); (b) grey water footprints; and (c) blue water footprints for the Kelowna case study demonstration. .88

Figure 4-15: The variation of within-group sum of squares (SS) with change in cluster number for Kelowna. .89

Figure 4-16: Matrix scatterplot of FCA for Kelowna. .90

Figure 4-17: Visual representation of WBEs for historical climate norms (a) and RCP 8.5 (b) for

Kelowna..... .92

Figure 4-18:Total annual water footprint vs. total annual rainfall for Kelowna. .94

Figure 4-19: Annual grey water footprint vs. total annual precipitation for Kelowna. .94

Figure 4-20: Boxplots of Monte Carlo-based life cycle costs for Kelowna. .95 


\section{List of Symbols and Abbreviations}

$\begin{array}{ll}\text { AB } & \text { Alberta } \\ \text { BC } & \text { British Columbia } \\ \text { BMP } & \text { best management practice } \\ \text { BWF } & \text { blue water footprint } \\ \text { DDSS } & \text { Diagnostic Decision Support System } \\ \text { DOM } & \text { degree of membership } \\ \text { FCA } & \text { fuzzy clustering analysis } \\ \text { FNIS } & \text { fuzzy negative ideal solution } \\ \text { FPIS } & \text { fuzzy positive ideal solution } \\ \text { GCM } & \text { generalized circulation model } \\ \text { GHG } & \text { greenhouse gas } \\ \text { GWF } & \text { green water footprint } \\ \text { GyWF } & \text { grey water footprint } \\ \text { IPCC } & \text { Intergovernmental Panel on Climate Change } \\ \text { ISO } & \text { International Standards Organization } \\ \text { LCC } & \text { life cycle costing } \\ \text { LID } & \text { low impact development } \\ \text { MCDM } & \text { multi-criteria decision making } \\ \text { NPC } & \text { net present cost } \\ \text { NPS } & \text { nonpoint source } \\ \text { NSC } & \text { National Stormwater Calculator } \\ \text { OECD } & \text { Organization for Economic Co-operation and Development } \\ \text { OWSWPF } & \text { One Water StormWater Planning Framework } \\ \text { RCP } & \text { representative concentration pathway } \\ \text { SCS } & \text { Soil Conservation Service } \\ \text { SUSTAIN } & \text { System for Urban Stormwater Treatment and Analysis Integration } \\ \text { SWE } & \text { Stormwater equivalent } \\ \text { SWMM } & \text { Storm Water Management Model } \\ \text { SWR } & \end{array}$


TOPSIS

$\mathrm{TP}$

TSS

TTT

USDS

USEPA technique for order of preference by similarity to ideal solution total phosphorous

total suspended solids

Treatment Train Tool

urban stormwater drainage system

United States Environmental Protection Agency 


\section{Acknowledgements}

First, I would like to thank Dr. Rehan Sadiq for his support and encouragement as a graduate student supervisor. Dr. Sadiq's guidance during my time at UBC-O helped me define a thesis topic for which I was passionate and that had real-world implications. Dr. Sadiq provided me with the perfect balance of academic freedom, direction, and funding opportunities.

I would also like to acknowledge my Co-Supervisor, Dr. Kasun Hewage, for ensuring that I received the "full package" during my time with UBC-O and the Life Cycle Management Laboratory (LCML). Thanks to the applied research projects pursued by the LCML team, I have gained an understanding of decision making, life cycle thinking, and project planning that I never could have expected.

I will never forget the friendships that I have made during my time with the LCML. Although I have yet to travel the world, I feel as though I have a global network of meaningful relationships thanks to the LCML. Special thanks to the Water Warriors and the Energy Fighters. You have all taught me so very much.

I would also like to thank the Natural Sciences and Engineering Research Council of Canada for awarding me the Alexander Graham Bell Canadian Graduate Scholarship - Master's Program. 


\section{Dedication}

This thesis is dedicated to my family and friends, but most importantly to the love of my life, Cassie. Thanks to all of you for your love and support. I couldn't have done it without you.

"A man has made at least a start on discovering the meaning of human life when he plants shade trees under which he knows full well he will never sit."

- D. Elton Trueblood 


\section{INTRODUCTION}

\subsection{Background}

The combined impacts of climate change (IPCC 2014), increasing urbanization (United Nations 2014), and population growth (UNEP 2016) are causing costly urban stormwater drainage systems (USDS) around the globe to be overwhelmed. The improper management of urban stormwater results in greater non-point source (NPS) pollutant loads being directed to ground and surface waters (USEPA 2016a), increasing rates of catastrophic urban flooding (UNEP 2016), and changes to the natural water balance (Kenway et al. 2011) that regulates the environmental flow needs of water resources.

Along with impacts to drainage basins associated with increased urbanization, growing populations in urban environments also withdraw increasing amounts of water from ground and surface waters for anthropogenic activities (Domene and Saur1 2006). Increases to consumption and use of water resources combined with the stresses placed on these resources by urban NPS pollution can result in water scarcity (OECD 2015). The Organization for Economic Co-operation and Development (OECD) defines water scarcity as "the management of four water risks: scarcity, floods, pollution, and freshwater ecosystem resilience" (OECD 2013). The OECD predicts that by 2150 , over $40 \%$ of the world's population will live under severe water stress (OECD 2013).

The proper management of urban stormwater runoff has the unique ability to affect each of the four water risks of water scarcity. In recent years, low impact development (LID) and stormwater reuse schemes have been adopted to respond to the risks of water scarcity. However, these infrastructures have often been adopted in an ad-hoc basis, with their construction instigated in response to increasing severe weather events (e.g., droughts and floods). Another modern movement in water resource management is the one water approach. The one water approach is an integrated planning approach for managing all water resources (including stormwater, wastewater, and drinking water) (Paulson et al. 2017). According to the Water Research Foundation, the adoption of a one water-based framework for infrastructure planning can support the effective development of: drinking water supply reliability plans; wastewater and recycled water master plans; climate change adaptation plans; infrastructure resilience plans; and stormwater and green infrastructure management plans (Paulson et al. 2017). 
Currently, there is no holistic framework to support the integrated planning of multiple water utilities (e.g., drinking water and stormwater) while simultaneously considering the impacts on local water resources in terms of both quantity and quality. Therefore, it is important to develop a planning framework to identify the best stormwater management strategy for a newly proposed community that considers a holistic view of water resources.

\subsection{Research Objectives}

This primary objective of this thesis was to develop a holistic planning framework for urban developers to identify the optimal mix of stormwater infrastructure for a new community during the planning stage. The framework has been dubbed the One Water StormWater Planning Framework (OWSWPF) and relies on two multi-criteria, multi-period decision making algorithms to identify optimal stormwater management strategies. The framework considers local climate conditions, site-specific soil conditions, intended land-use practices, and local water use practices to calculate the community's stormwater footprint. The OWSWPF considers uncertainty related to precipitation patterns, predicted climate changes, and life cycle costing. The OWSWPF provides urban stormwater planners with a planning framework to identify the most cost-effective stormwater management plan to reduce a community's stormwater footprint using a One Water perspective.

The chapters and objectives of this thesis are arranged in a logical order to promote the completion and demonstration of the primary objective. The specific sub-objectives are outlined below:

1. Perform and in-depth and state-of-the-art literature review on modern stormwater management strategies (LID BMPs) from across the globe. The results from this review provided the stormwater pollutant treatment efficiencies of various BMPs for use in the proposed framework.

2. Develop a stormwater management planning framework that addresses contemporary issues of urban nonpoint source pollutants, water scarcity, climate change, and project economics. This framework was developed to provide community planners with a method of identifying the optimal high-level mix of stormwater infrastructure in a new community.

3. Perform case study demonstrations of the developed framework to highlight its benefits and contributions to the applied science community. The case studies were performed to assess the practicality and real-world implications of the developed framework in two 
Canadian cities with different water management priorities, annual precipitation patterns, and climate change predictions.

\subsection{Thesis Outline}

This thesis is organized into five chapters. Following this introduction, Chapter 2 (LITERATURE REVIEW) is divided into two sections. The first section presents a literature review of common LID best management practices (BMPs) and their pollutant treatment efficiencies as per results of academic research articles. The second section of Chapter 2 outlines the current state of urban stormwater planning tools, identifies the current knowledge gaps in planning frameworks and describes the need for a new planning framework Chapter 3 describes the development of the OWSWPF. In Chapter 4, the OWSWPF was customized for a hypothetical 80-hectare residentialcommercial development in Calgary $(\mathrm{AB})$ and Kelowna $(\mathrm{BC})$; the results are interpreted and recommendations are made. Chapter 5 includes discussion, conclusions, and recommendations for future research.

Figure 1-1 is a flowchart demonstrating the relationships between thesis chapters and objectives.

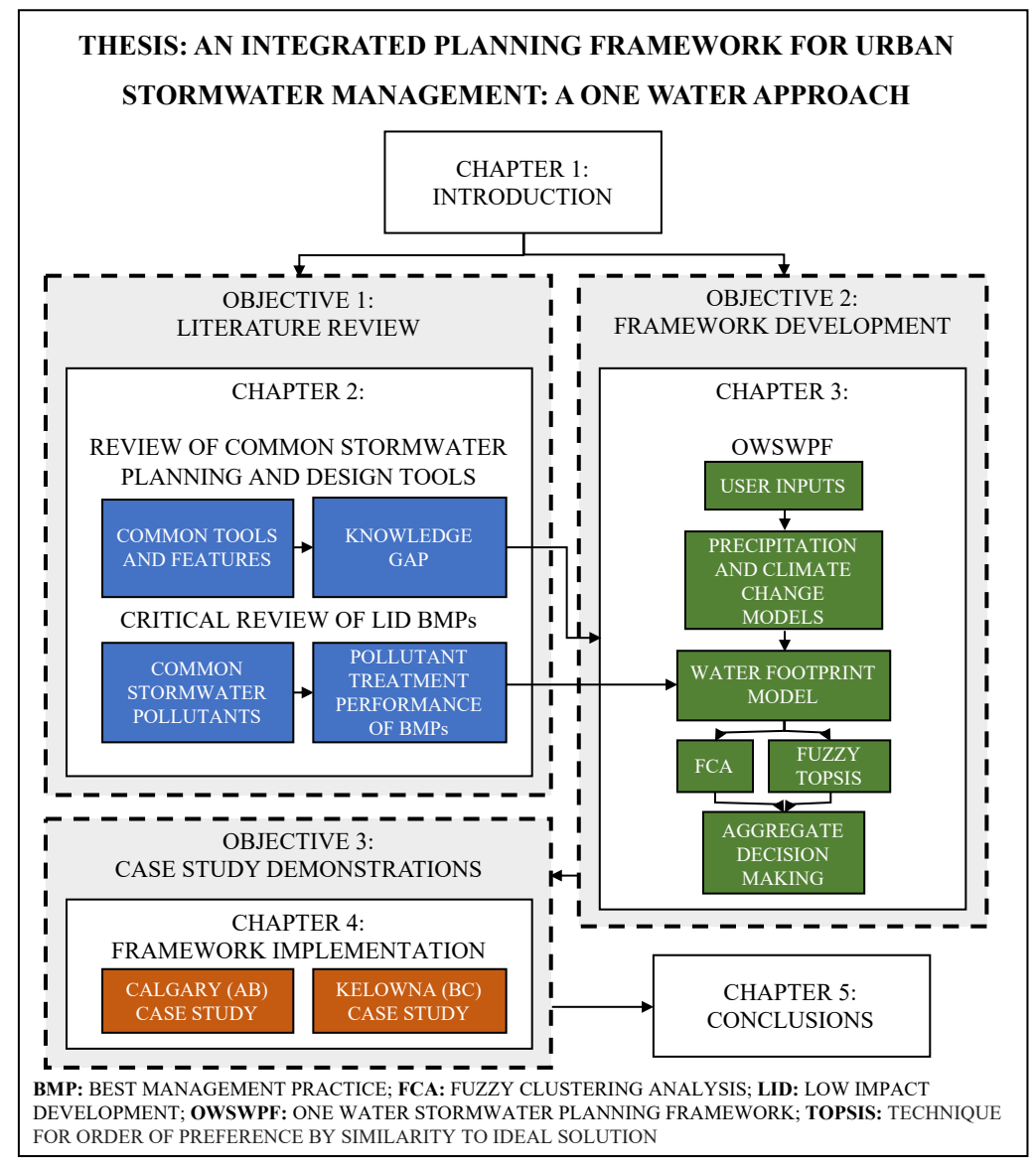

Figure 1-1: Thesis flowchart 


\section{LITERATURE REVIEW}

This chapter is divided into two broad topics of review. The first topic (section 2.1) is a critical review of LID BMP pollutant treatment performance literature. The second topic (2.2) is a review of common contemporary stormwater planning and design tools and frameworks. The review of both topics was necessary to identify the knowledge gaps in existing stormwater management decision support tools and frameworks, identify pollutants of interest for calculating stormwater footprints, and determining pollutant removal performance of various LID BMPs.

\subsection{Performance of Low Impact Development: A Critical Review of Best Management Practices}

\subsubsection{Introduction}

Rapid urbanization is one of the phenomena responsible for stormwater quantity and quality challenges faced by sustainable stormwater management practitioners across the globe (Abebe et al. 2018; Fletcher et al. 2013). Sprawling urbanization is creating large swaths of connected impervious cover and dramatically affecting the natural hydrology of neighborhoods proximal to surface water bodies. The principal effects of urbanization on stormwater management include changes to urban hydrology, altered geomorphology, unstable water chemistry, loss of riparian habitat, barriers to stormwater runoff movement, and altered terrestrial inputs (Wenger et al. 2009). These changes to natural hydrology can result in increased pollutant delivery, flooding, and erosion, and can also decrease groundwater recharge (USEPA 2017a). As a result of rapid urbanization, traditional detention and conveyance-based urban stormwater infrastructure is becoming insufficient for communities' stormwater management needs.

In recent years, the term low impact development (LID) has been used to describe a set of best management practices (BMPs) that are employed to manage urban stormwater in terms of both quantity and quality. LID BMPs are manmade features that rely on natural processes (i.e., green infrastructure) to manage the quantity and quality of stormwater. Ultimately, BMPs are adopted to achieve LID's goal of mimicking a site's pre-development hydrology (USEPA 2017b). LID BMPs can be broadly classified into two categories: infiltration-based technologies and retention-based technologies. Infiltration-based technologies assist in increasing the volume of water infiltrated into the ground, supporting recharge, and retention-based technologies are designed to retain 
stormwater by either attenuating stormwater flows and/or increasing evapotranspiration, and capture and reuse possibilities (Fletcher et al. 2013).

Owing to their promising stormwater management potential, BMPs have been the topic of many stormwater management-related studies. Several review articles have been published related to BMP technology development. Ahiablame et al. (2012) reviewed several BMPs, including bioretention units, permeable pavement systems (PPSs), green roofs, and swale systems, to highlight the benefits of adopting LID. Based on the review, the authors recommended the adoption of suitable BMPs in different urban environments characterized by different climatic conditions, geographic locations, and stormwater characteristics. Shafique and Kim (2015) reviewed LID practices across the globe to highlight the beneficial uses of BMPs. Research related to bioretention systems, green roofs, PPSs, and swale systems were reviewed and performance of each BMP discussed. Dietz (2007) also reviewed PPSs, bioretention units, and green roofs and compared the treatment performance of the three BMPs for several pollutants. Although these reviews addressed many of the important parameters of effective BMP adoption, none of the reviews provide readers with a quantitative statistical summary of BMP performance in terms of runoff reduction and treatment performance for a wide range of stormwater pollutants. To promote resilient and reliable LID planning, there is a need for a systematic review of state-of-the-art academic studies on BMP performance in terms of runoff reduction and pollutant treatment performance, ultimately producing practical, reasonable, and quantified ranges for hydraulic and water quality performance of each BMP.

This review of LID BMPs contains two major components; the first component is a comprehensive introduction to nine BMPs; the second component is a critical discussion of the reviewed BMPs in the context of modern stormwater management. BMP selection was based on frequent referencing in various North American municipal stormwater management guideline documents and the LID controls outlined in Volume III of the Storm Water Management Model Reference Manual (USEPA 2016). In Section 2, recent studies related to nine commonly-adopted BMPs were reviewed. The components and stormwater treatment mechanisms of each BMP were elucidated. In Section 3, literature related to each BMP's treatment performance in terms of urban stormwater quality and quantity were thoroughly investigated and nonparametric statistics were produced based on the results of the reviewed literature. Relying on the results of the reviewed BMP studies, the authors then compared reported BMP performance to the intended objectives of LID. This 
review provides urban stormwater planners and the research community with typical ranges of BMP performance for an array of LID planning metrics (e.g., runoff reduction, pollutant treatment performance).

\subsubsection{Overview of best management practices}

In this section of Chapter 2, recent studies (after the year 2008) related to nine commonly-adopted BMPs (permeable pavements systems (PPS), infiltration trenches (IT), bioswales (BS), bioretention (BR) cells, buffer/filter strips (BFS), constructed stormwater wetlands (CSW), raingardens and downspout disconnections, rain harvesting $(\mathrm{RH})$, and green roofs $(\mathrm{GR})$ ) were investigated. Over 250 academic research articles were reviewed and 102 were selected for producing nonparametric summary statistics related to runoff quantity and quality. The BMPs reviewed in this study can be classified into two main categories: infiltration or retention-based technologies (Figure 2-1) (Fletcher et al. 2013). Although many jurisdictions have guidelines or regulations for stormwater discharge volumes and pollutant concentration limits, there is no universal agreement on which pollutants should be regulated. Based on this review, 21 urban stormwater parameters of concern were identified (Table 2-1).

\subsubsection{Permeable pavement systems}

The term permeable pavement system (PPS) refers to a suite of pavement systems (interlocking pavers, porous asphalt, and porous concrete) relying on a variety of materials and techniques to increase the surface infiltration capacity of stormwater through traditionally impermeable surfaces. The adoption and installation of permeable surfaces results in the reduction of surface water runoff

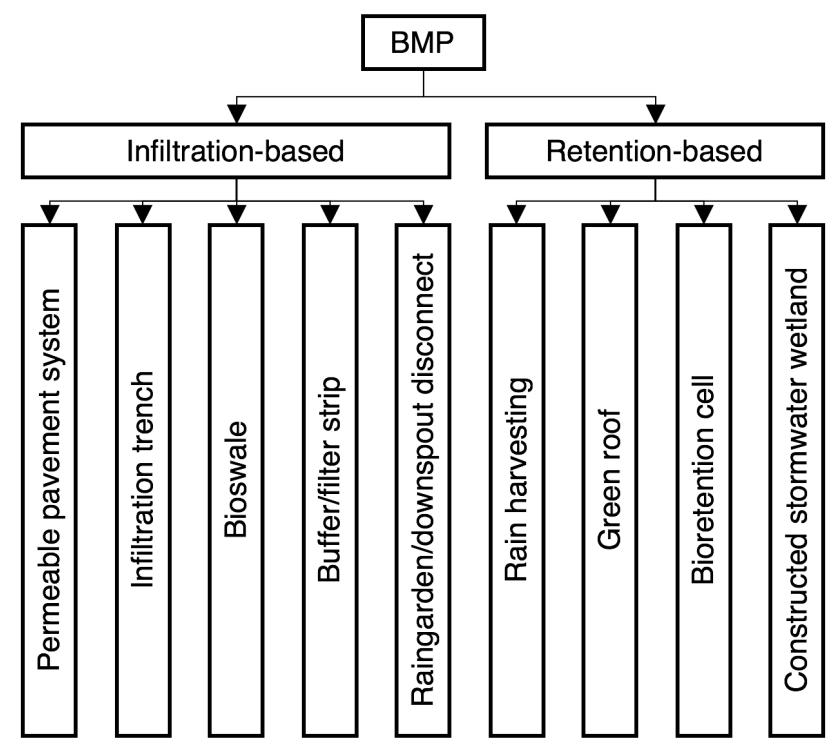

Figure 2-1: Classification of reviewed BMPs. 
from storm events and filtration of stormwater contaminants. PPSs offer an effective and simple solution for decreasing impervious surfaces in urban areas while maintaining the usability of vehicle and pedestrian traffic (Imran et al. 2013; Sansalone et al. 2012). The thickness of a PPS varies depending on the load to be carried over the permeable surface (i.e., vehicles or pedestrians), but generally ranges from 0.5 to $2 \mathrm{~m}$. Figure $2-2$ is a simplified schematic of a typical PPS.

Table 2-1: Urban stormwater parameters and categories reviewed in this study.

\begin{tabular}{|c|c|}
\hline Category & Parameter \\
\hline Runoff Volume & Surface Runoff \\
\hline \multirow[t]{2}{*}{ Solids } & Total suspended solids (TSS) \\
\hline & Total dissolved solids (TDS) \\
\hline \multirow[t]{3}{*}{ Metals } & Lead $(\mathrm{Pb})$ \\
\hline & Copper $(\mathrm{Cu})$ \\
\hline & Zinc $(\mathrm{Zn})$ \\
\hline \multirow[t]{9}{*}{ Nutrients } & Nitrogen \\
\hline & - total nitrogen $(\mathrm{TN})$ \\
\hline & - total Kjeldahl nitrogen (TKN) \\
\hline & - $\quad$ nitrate nitrogen $\left(\mathrm{NO}_{3}-\mathrm{N}\right)$ \\
\hline & - $\quad$ nitrite nitrogen $\left(\mathrm{NO}_{2}-\mathrm{N}\right)$ \\
\hline & - $\quad$ ammoniacal nitrogen $\left(\mathrm{NH}_{3}-\mathrm{N}\right)$ \\
\hline & Phosphorous \\
\hline & - $\quad$ total phosphorous (TP) \\
\hline & - orthophosphate (OPP) \\
\hline \multirow[t]{2}{*}{ Hydrocarbons } & Total petroleum hydrocarbons (TPH) \\
\hline & Polycyclic aromatic hydrocarbons (PAH) \\
\hline Dissolved Ions & Chloride $\left(\mathrm{Cl}^{-}\right)$ \\
\hline \multirow[t]{2}{*}{ Oxidizing Pollutants } & Biological oxygen demand (BOD) \\
\hline & Chemical oxygen demand (COD) \\
\hline \multirow[t]{3}{*}{ Pathogens } & Total coliforms (TC) \\
\hline & Fecal coliforms (FC) \\
\hline & Escherichia coli (E. coli) \\
\hline
\end{tabular}

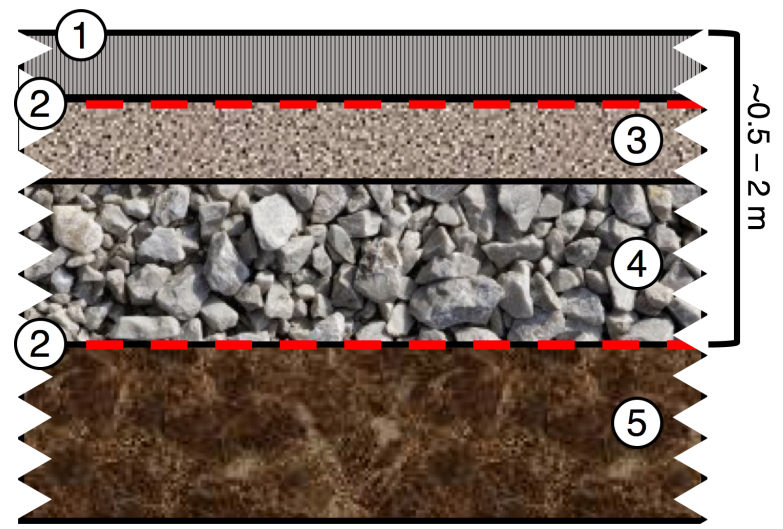

Figure 2-2: Cross-section schematic of a permeable pavement system. 1) Permeable surface; 2) Optional geotextile layer(s); 3) Medium base layer; 4) Coarse base layer; 5) Existing subgrade. 
Permeable pavement systems have been found to be effective at infiltrating stormwater runoff and improving stormwater quality in all seasons (including freezing winter months) in many climate scenarios (Drake et al. 2014a; Huang et al. 2016; Roseen et al. 2012). Roseen et al. (2012) examined the effectiveness of a PPS in coastal New Hampshire, USA, where six months of subfreezing temperatures generally occur. The authors concluded that due to high drainage rate of the installed PPS, issues related to frost penetration-induced freezing (i.e., reduced infiltration due to clogging from frozen water in pores of PPS) were minimized and statistically significant declines in hydraulic performance were not observed (Roseen et al. 2012). Huang et al. (2016) also found that peak runoff reduction volumes were not statistically different for three types of PPS (permeable interlocking pavers, porous asphalt, and porous concrete) in winter conditions when compared to warm-weather runoff reduction volumes. The authors also tested the robustness of the PPSs by repeatedly sanding and then pressure washing the systems to test the effects of regular use on the hydraulic performance of PPSs. It was found that heavy sanding greatly reduced the hydraulic performance of the PPSs, but pressure washing was shown to adequately restore the lost performance (Huang et al. 2016).

Permeable pavement systems have been proven to be effective at removing many pollutants (e.g., $\mathrm{Cu}, \mathrm{Zn}, \mathrm{Pb}$, cadmium $(\mathrm{Cd})$, petroleum pollutants, animal and vegetable oil, BOD, $\mathrm{COD}, \mathrm{NH}_{4}-\mathrm{N}_{\text {, }}$ and TP) to varying degrees (see Appendix A) due to the interception and retention of pollutants in the porous materials (Jiang et al. 2015). Huang et al. (2016) also suggested that the formation of biofilm (a group of microorganisms that grow on and stick to surfaces) within the pores of the PPS one year after installation of the PPS could increase TN removal rates. Chowdhury et al. (2016) found that PPS was ineffective in reducing total aerobic and total coliform bacteria.

The key benefits of PPS include runoff reduction, improved groundwater recharge, reduced pollution through natural filtration of biological processes (e.g., biofilm), less need for curbing and storm sewers, low land requirements (i.e., PPS replaces traditional paved surfaces), management of the heat island effect due to lighter colours of most PPSs, and increased road safety due to better skid resistance (Alsubih et al. 2017; Thorpe and Zhuge 2010; USEPA 1999). The main disadvantages of PPSs are potential clogging if not properly maintained, less durability compared to traditional paving systems, some building codes may not allow installation, microbiological decomposition of pollutants may be impeded if soils are not able to dry out between storm events, and installation complexity (Thorpe and Zhuge 2010; USEPA 1999). The factors that most affect 
the performance of PPS are considered to be surface infiltration rate, shape and volume of the PPS, infiltration and exfiltration capacity of the system, stormwater sediment discharge characteristics, and construction and maintenance techniques (Brown and Borst 2015). Table A-1 in Appendix A outlines the results of the reviewed studies related to the quantitative and qualitative effects of PPSs on urban stormwater runoff.

\subsubsection{Infiltration trenches}

Infiltration trenches (ITs) are subsurface trenches filled with porous and permeable material, increasing subsurface infiltration capacities. As Figure 2-3 shows, ITs are generally linear trenches and often installed with perforated pipes running through the trench to increase infiltration rate. An optional geotextile material can be installed during construction to reduce sediment-induced clogging. ITs are able to reduce land area requirements for infiltration while simultaneously increasing the quality of infiltrated waters (Yu et al. 2013). Gravel, sand, and their mixtures are commonly used as the permeable material in ITs (Chahar et al. 2012; Segismundo et al. 2017). More recently, other materials with high sorption capacities, such as ash, have been used to fill ITs to increase infiltration rates and reduce pollutant levels of infiltrated waters (Segismundo et al. 2017). The width of ITs varies, but is generally on the scale of one to a few metres. The required depth of ITs is dependent on the depth of the frost line. ITs have been found to function properly throughout winter months as long as the maximum effective depth of the trench is below the frost line (Minnesota Pollution Control Agency 2000).

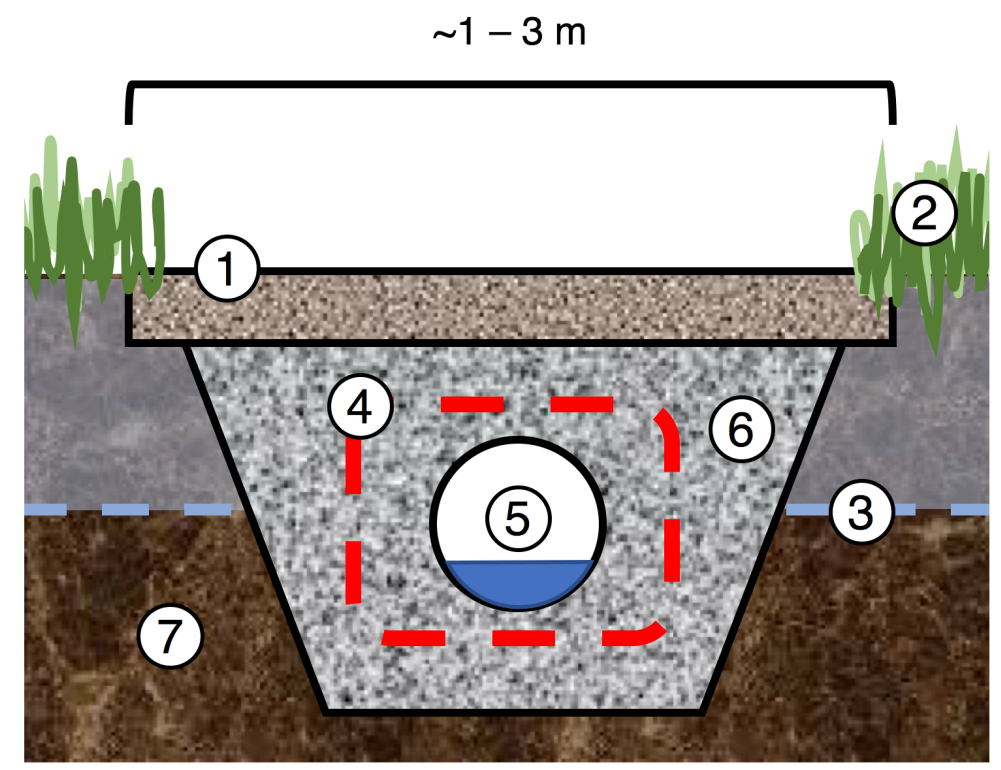

Figure 2-3: Cross-section schematic of an infiltration trench. 1) Infiltrating surface; 2) Vegetation; 3) Frost line; 4) Optional geotextile material; 5) Perforated pipe; 6) Porous and permeable material; 7) Existing subgrade. 
Infiltration trenches offer multiple functions, such as the reduction of stormwater runoff volumes, increased groundwater recharge, and improved quality of infiltrated waters (Emerson et al. 2010). Like many other infiltration-based BMPs, the use of ITs can be limited in regions with high groundwater tables and soils with low hydraulic conductivity (Locatelli et al. 2015). Clogging due to poor maintenance can greatly affect IT performance and is considered to be a significant limitation for ITs (Chahar et al. 2012; Emerson et al. 2010; Lewellyn et al. 2015; Maniquiz et al. 2010; Muller 2017; Nilsson and Stigsson 2012). Heilweil and Watt (2011) compared two types of infiltration methods, including an IT and an infiltration pond, in terms of infiltration capacity into an underlying sandstone unit in Utah, USA. The results showed that the IT infiltration rates were an order of magnitude higher than the rates of the infiltration pond (Heilweil and Watt 2011). The authors contributed the comparatively higher infiltration rates to the combined effects of: the geometry of the seepage face; removal of lower permeability soil deposits; maintaining warmer isothermal conditions; minimized clogging by silt, carbonate mineral, and biofilm layers; and minimized effects of trapped gas bubbles (Heilweil and Watt 2011). After performing a sensitivity analysis for 11 IT design factors, Locatelli et al. (2015) found that hydraulic conductivity and unsaturated soil depth, and area/storage ratio were the most influential parameters affecting IT hydraulic performance. Other factors affecting performance of ITs are: stormwater quality, rainfall characteristics, maintenance practices, water table depths, soil characteristics, and surrounding topography (Nilsson and Stigsson 2012; Petit-Boix et al. 2015).

Other recent studies have shown that ITs are capable of capturing many conventional pollutants, including: TSS, heavy metals, BOD, and COD (Emerson et al. 2010; Maniquiz-Redillas and Kim 2016; Maniquiz et al. 2010; Muller 2017; Norrstrom 2005; Scholz and Yazdi 2009; Segismundo et al. 2017; Yu et al. 2013). As shown in Table A-2 of Appendix A, moderate nutrient removal by ITs has also been confirmed by several studies (Maniquiz et al. 2010; Scholz and Yazdi 2009; Yu et al. 2013). Norrström (2005) completed a laboratory study on the effects of metal mobility through ITs due to simulated de-icing solutions (high salinity). The author tested the leachate from an IT that had previously infiltrated simulated de-icing solutions. The author concluded that roadside soils impacted by $\mathrm{NaCl}$ (de-icing salts) can also contribute to increased $\mathrm{Pb}$ leaching into groundwater and stated that increased infiltration rates of ITs can increase the impacts of groundwater contamination compared to regular soils (Norrstrom 2005). 
The most commonly reported advantages of ITs are: reduced runoff volumes; excellent removal of sediment, metals, nutrients, bacteria, and oxidizing pollutants; increased groundwater recharge; appropriate for small sites; and minimal land requirements due to narrow dimensions (Emerson et al. 2010; Lewellyn et al. 2015; Minnesota Pollution Control Agency 2000; Muller 2017). The main limitations of ITs are related to design complexity, potential need for pretreatment to mitigate clogging (depending on runoff characteristics); poor performance in areas with low soil conductivity and high water tables; possible groundwater contamination if infiltrated waters are polluted; susceptible to clogging; and frequent inspection and maintenance requirements (Lewellyn et al. 2015; Minnesota Pollution Control Agency 2000).

\subsubsection{Bioswales}

Bioswales (BSs) (or vegetative swales) are linear depressions that act as drainage courses with sloped sides that trap, transport, and treat stormwater runoff (Figure 2-4). BSs are generally trapezoidal or triangular in cross section (Winston et al. 2012). BSs are one of the most basic, costeffective, and simple to implement BMPs, often replacing traditional curb-and-gutter drainage systems in urban areas (Lucke et al. 2014). BSs can be installed adjacent to roadways, sidewalks, bridge decks, irrigated urban landscapes, and parking lots to reduce pollutant loads during conveyance (Leroy et al. 2016; Melville 2016; Winston et al. 2010b; Xiao et al. 2017). Typically, BSs are covered in grass to enhance water quality treatment performance, but more diverse assemblages of vegetation (e.g., shrubs, trees, and a variety of tall grasses) can also be incorporated to increase treatment efficiency and aesthetics (Winston et al. 2012; Xiao et al. 2017). BSs are not

generally used to reduce stormwater runoff volumes, but rather as means of simultaneously treating stormwater and reducing flow velocities (Lucke et al. 2014). One of the best practices for BS design involves the incorporation of a freeboard depth, a design feature that increases the depth of the BS to accommodate unexpected flow volumes (Department of Environmental Quality 2003). The vegetation in BSs is responsible for the majority of pollutant removal, which is primarily attributed to physical filtration by vegetation, plant uptake of nutrient pollutants, increased sedimentation, and chemical and biological interactions with soil (Tang et al. 2016; Winston et al. 2012). 


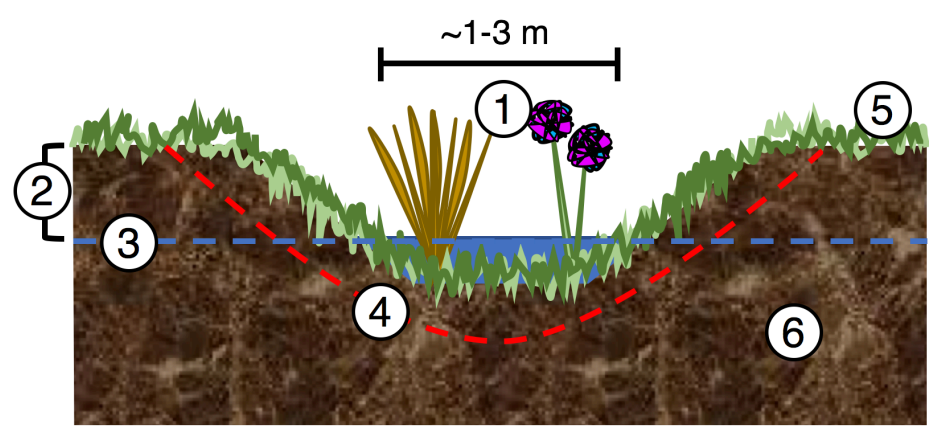

Figure 2-4: Cross-section schematic of a bioswale. 1) Native vegetation; 2) Freeboard; 3) Max water level; 4) Optional geotextile fabric; 5) Optional filter strip (extended beyond schematic); 6) Existing subgrade.

Recent studies have tested the impacts of different natural and engineered materials on the water quality treatment performance of BSs. Some of the materials tested in these studies include: blast furnace slag, straw wattles, engineered soils, biosorption activated media (BAM), mycorrhizal treatments, and biochar (Hood et al. 2013; Li et al. 2016; Melville 2016; Winston et al. 2010b; Xiao and McPherson 2011). Hood et al. (2013) evaluated the effectiveness of BAM in various BS systems and found that the BSs underlain with BAM could remove $71 \%$ of total phosphorous and 95\% soluble phosphorous. Li et al. (2016) assessed the effectiveness of incorporating sand, soil, humus, fly ash, sand, and blast furnace slag as packing materials in BSs for treating various pollutants $\left(\mathrm{NH}_{4}-\mathrm{N}, \mathrm{NH}_{3}-\mathrm{N}, \mathrm{TN}, \mathrm{SRP}, \mathrm{TP}, \mathrm{COD}, \mathrm{Zn}, \mathrm{Cd}\right)$. The authors found that blast furnace slag had the best removal of nitrogen, phosphorous, and heavy metals ( $\mathrm{Zn}$ ) under low inflow concentrations ( $\mathrm{Li}$ et al. 2016). Melville (2016) studied the effects of applying a mycorrhizal fungi treatment to a BS in an urbanized area. The author found that the application of the mycorrhizal treatment contributed to $\mathrm{Zn}$ reductions between $24-26 \%$, as compared to the $23-39 \%$ increase in extractable $\mathrm{Zn}$ observed in the control BS without the mycorrhizal treatment (Table A-3 in Appendix A). The mycorrhizal treated BS also demonstrated significant reductions in runoff phosphorous levels, with the non-treated BS showed increases in phosphorous levels. For all measured pollutants $(\mathrm{Pb}, \mathrm{Cu}, \mathrm{Zn}, \mathrm{TP}$, and $\mathrm{COD})$, the mycorrhizal treatment resulted in removal efficiencies between $67 \%$ and 100\%. Winston et al. (2012) compared the treatment performance of dry swales and BSs in terms of runoff quantity and quality at four sites along a 48-km stretch of highway. The authors found that the BSs provided greater TN removal as compared to dry swales, with effluents of 1.02-1.03 mg/L TN and 1.50-1.63 mg/L TN, respectively. The authors attributed this difference in performance to the greater number of nutrient removal mechanisms available in the BSs. Winston et al. (2012) also found that maintenance of swales (especially dry 
swales) was shown to be very important, with an eroded dry swale producing effluent TSS concentrations as high as $70 \mathrm{mg} / \mathrm{L}$ (up to three times greater than other reported TSS concentration values). Due to fertilization requirements, BSs have also been identified as a nutrient pollutant exporter (i.e., nitrogen and phosphorous effluent concentrations higher than influent) (Leroy et al. 2016; Melville 2016; Stagge et al. 2012; Winston et al. 2010b). Under the assumption that de-icing salts are the sole source of chloride, Stagge et al. (2012) found that although road salting activities generally only occur during winter months, chloride concentrations discharged from roadside BSs remained elevated throughout the year. As a result, the authors found that the BSs exported chloride, rather than removing it, resulting in negative chloride removal rates ranging from -104 to $-78 \%$ (Stagge et al. 2012).

The mechanisms involved in pollutant removal of BSs are sedimentation, filtration by vegetation, infiltration into the subsurface zone, and bio-chemical processes (Lucke et al. 2014). Studies have shown that these processes can be affected by swale length and width, slope, vegetation cover (type and density), soil type and characteristics, pollutant properties (e.g., sediment particle size distribution, concentrations), ratio of catchment area to BS area, filter media (e.g., sand, biochar, blast furnace slag), and maintenance practices (Li et al. 2016; Lucke et al. 2014; Tang et al. 2016; Winston et al. 2012).

The key benefits of BSs are: the ability to convey runoff while simultaneously reducing pollutant concentrations, reduced runoff velocities, very basic design requirements, cost-effective (lower cost than traditional curb-and-gutter systems); low maintenance requirements; ease of siting; ability to perform in areas with low soil conductivity and high water tables; and to a lesser extent, the ability to infiltrate small volumes of runoff during conveyance (Leroy et al. 2016; Lucke et al. 2014; Melville 2016; Stagge 2006; Winston et al. 2010b; Xiao et al. 2017).

\subsubsection{Bioretention cells}

Bioretention (BR) cells are subterraneous short-term storage areas that are designed to exploit the benefits of stormwater flow attenuation and water quality improvements by natural processes. As seen in Figure 2-5, BR cells are a type of plant and soil-based green infrastructure, consisting of a basin filled with porous cell media to promote infiltration and a porous growing media layer topped with dense vegetation and mulch (Khan et al. 2012a). For optimal results, native vegetation is generally selected based on its water and pollutant tolerance (DeBusk and Wynn 2011). Stormwater runoff is directed through BR cells where it pools during larger storm events prior to 
infiltrating the porous media layer. As waters pass through the BR cell basin, various physical, chemical, and biological processes are responsible for pollutant removal (Hsieh and Davis 2005). Percolated runoff is then infiltrated into surrounding soils or directed via perforated pipes to traditional stormwater infrastructure integrated into the BR cell's design (Khan et al. 2012a) (Figure 2-5). Coarse drainage layers can also be incorporated at the base of BR cells to promote infiltration into surrounding soils. Overflow systems are also often incorporated to ensure flooding does not occur should the system become clogged or overloaded (Forasteé and Hirschman 2010). DeBusk et al. (2011) found that BR cells can enable urban hydrology to behave comparably to natural watersheds in terms of flow rates and flow volumes. BR cells have been shown to effectively manage runoff from many urban surfaces, including: roads, roofs, driveways, lawns and yards, parking lots, and other impermeable surfaces (Li et al. 2011; Liu and Davis 2014; Mangangka et al. 2015a; McIntyre et al. 2016; Paus et al. 2015).

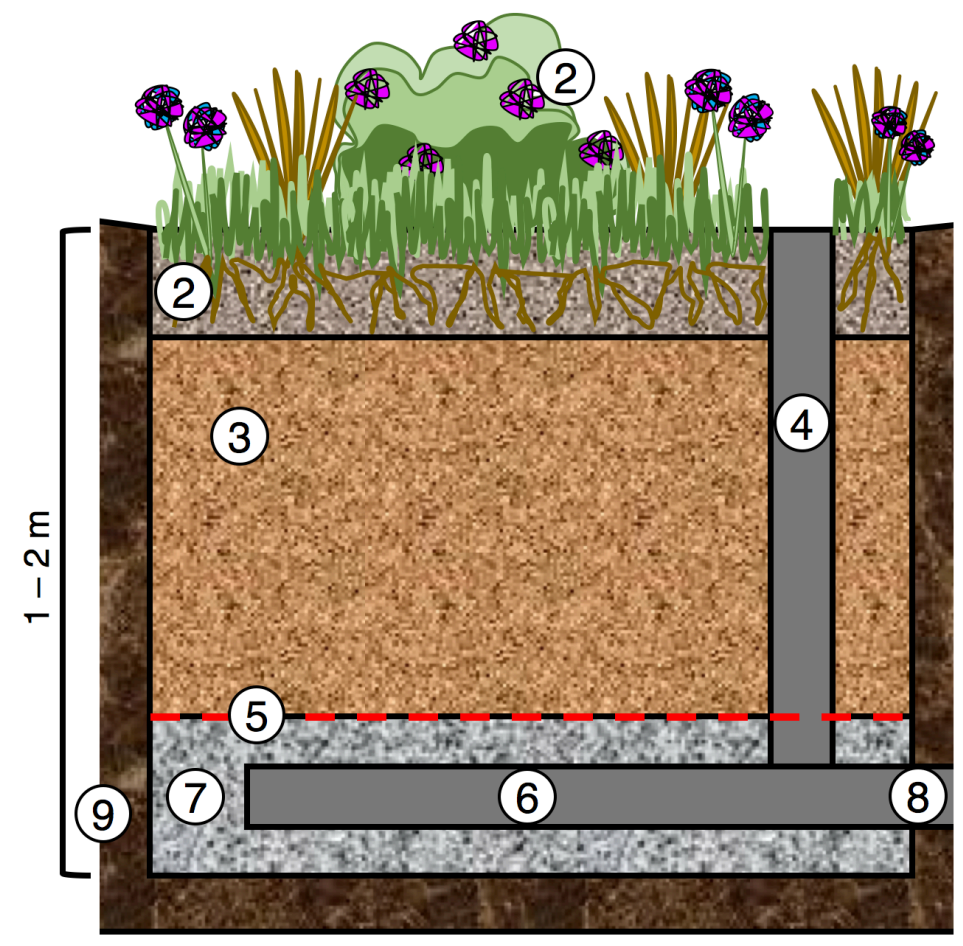

Figure 2-5: Cross-section schematic of a bioretention cell. 1) Native vegetation; 2) Root zone in porous medium; 3) Media layer; 4) Overflow conduit; 5) Optional geotextile layer; 6) perforated piping; 7) Coarse drainage layer; 8) Outlet to storm sewer; 9) Existing subgrade.

Bioretention cell media is selected based on the engineered purposes of each soil layer. A high porosity surficial layer hosts the roots of the vegetation in the BR cell, while a lower media layer acts as temporary storage, facilitating infiltration of stored runoff into surrounding soils (Hunt et 
al. 2012). Sand, gravel, compost, and biochar have been used to produce engineered soils for BR cells with mixed results (Brown and Hunt 2011; Carpenter and Hallam 2010; Iqbal et al. 2015; Zhang and Guo 2014). Due to the common practice of incorporating compost and fertilizing requirements, BR cells have been found to be net nutrient exporters (Forasteé and Hirschman 2010; Li et al. 2011; Randall and Bradford 2013; Winston et al. 2010b). Brown and Hunt (2011) tested the hydrologic and pollutant treatment performance of two $(0.6 \mathrm{~m}$ depth and $0.9 \mathrm{~m}$ depth $)$ loamysand-filled BR cells. The authors found that infiltrated volume was much higher in the deeper BR cell. The authors presumed the higher infiltration capacity was attributed to the greater storage volume in the media and more exposure to side walls. Carpenter and Hallam (2010) observed an increase in nitrogen removal by BR cells from $22 \%$ to $87 \%$ once vegetation was firmly established and healthy. The authors concluded that there exists an initial phase of vegetation development prior to optimal nutrient removal functionality. Iqbal et al (2015) tested the effects of two compostbiochar mixtures (one of biochar and mature compost, and the other of composted biochar and mature compost) on the leaching of carbon, nitrogen, and phosphorous from BR cells. The authors incorporated the mixtures into the medial layer of BR cells and found that there was no significant difference between the effects of both types of compost-biochar mixtures on nutrient leaching. The authors found that a compost-sand mixture was more effective at reducing nitrate and phosphorous leaching when compared to the biochar mixtures, with the optimal compost-sand mixture nitrogen and phosphorous pollutant loads at least $\sim 50 \%$ lower than the biochar mixtures (Iqbal et al. 2015). Currently, there is no consensus in literature as to whether cold climate conditions affect the hydrologic performance of BR cells. DeBusk et al. (2011) found that cold climate conditions had no significant impact on the hydrologic performance of BR cells in both field and column experiments, while Khan et al. (2012b) found that cold conditions significantly impacted the performance of the BR cells for high-volume storm events and determined that a partially frozen surface layer was the cause of the poor hydrologic performance.

Factors affecting the hydrologic and pollutant treatment performance of BR cells are storage volume, maintenance practices, rainfall characteristics, inflow characteristics, number of antecedent dry days, vegetation type, clogging due to high sediments loads in inflow, and road salting activities (Brown and Hunt 2011; Hartung 2017; Kim et al. 2012; Mangangka et al. 2015a; Paus et al. 2015). 
Bioretention cells have many potential benefits, including: high tolerance to changing hydrologic regimes, ability to significantly reduce stormwater volumes through infiltration and evapotranspiration, ease of integration in urban environments, stormwater retention and treatment capabilities, relatively fast draining periods (i.e., hours for some designs), and the aesthetic benefits of incorporating green infrastructure (Forasteé and Hirschman 2010; Roy-Poirier et al. 2010).

Bioretention units are plagued by the same long-term performance issues as many other infiltration-based BMPs, most notably clogging (Brown and Hunt 2011; David et al. 2015; Hunt et al. 2012; Khan et al. 2012b; Roy-Poirier et al. 2010) and labour-intensive maintenance to maintain performance (Brown and Hunt 2011; David et al. 2015; Forasteé and Hirschman 2010; Hunt et al. 2012; Li et al. 2011). Kratky et al. (2017) found that once clogged, if not repaired, the accumulated pollutants may breakthrough and result in the BR cell leaching pollutants back into the environment. Table A-4 in Appendix A outlines the results of various studies related to the volumetric and qualitative effects of BR cells on urban stormwater runoff.

\subsubsection{Buffer/filter strips}

Buffer/filter strips (BFSs), are gently sloped surfaces (ideally with a slope of $<20 \%$ (Müller et al. 2004) covered in dense perennial vegetation that act as a barrier between areas of non-point source pollution and natural water bodies (Figure 2-6). Most commonly, BFSs are simply covered in grasses, but trees, shrubs, and other plants can be incorporated as well (Unger et al. 2013; Winston et al. 2011b). Topsoil used in BFSs can range in composition, but best results are achieved with the use of loam or sandy loam (Choi et al. 2016; Larson and Safferman 2012; Stagge et al. 2012). To further increase treatment efficiencies, researchers have incorporated materials like ochre and aluminum-based water treatment residuals into the topsoil of BFSs (Habibiandehkordi et al. 2014). Runoff from a variety of surfaces have been directed across BFSs, including: roads and streets, construction sites, driveways, rooftops, sidewalks, asphalt parking areas, bridge decks, and forestland (Flanagan et al. 2017; Fulazzaky et al. 2013; Hunt et al. 2010; Knight et al. 2013; Peak and Gil 2016; Winston et al. 2015). Aside from urban stormwater runoff, BFSs are commonly used for treating agricultural runoff (Choi et al. 2016; Helmers et al. 2012). BFSs can slow runoff flow velocities, promote sediment settling, increase infiltration, and increase nutrient uptake by plants (Choi et al. 2016; García-Serrana et al. 2017; Helmers et al. 2012). Level spreaders are often installed at the top of BFSs to induce even sheetflows across the vegetated slope and increase effectiveness (Winston et al. 2011a). 


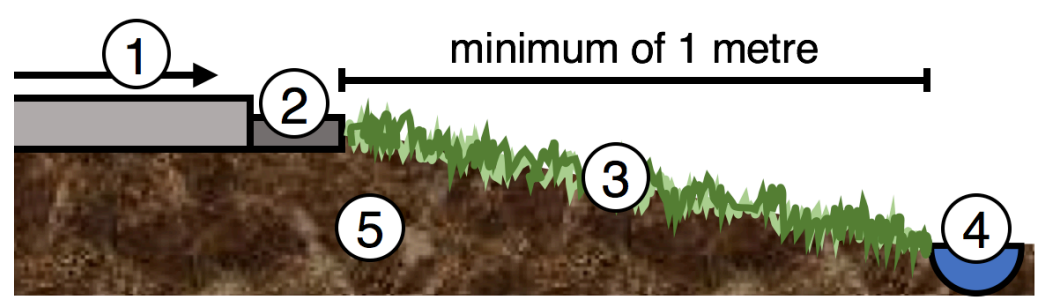

Figure 2-6: Cross-section schematic of a buffer/filter strip. 1) Flow from impervious surface; 2) Optional level spreader; 3) Grassed or vegetated surface; 4) Optional outlet trench; 5) Existing subgrade.

Studies have identified vegetation coverage, length, cross-sectional shape, retention time, slope, design flow rate, type of vegetation, soil conductivity, and width as the primary design factors affecting the efficiency of BFSs (Choi et al. 2016; Flanagan et al. 2017; García-Serrana et al. 2017; Lafrance et al. 2013; Peak and Gil 2016; Winston et al. 2010a).

Sensitivity analysis results show that rainfall intensity and soil hydraulic conductivity are the most sensitive factors influencing whether water is infiltrated or is maintained as runoff. As a consequence, systems of similar geometry located in different climates or having different soil types, may function very differently (Flanagan et al. 2017). García-Serrana et al. (2017) performed a series of tests over three seasons at four different highway locations to analyze the infiltration performance of roadside BFSs. Although BFSs are not generally designed to infiltrate large amounts of runoff, the authors calculated an average percentage infiltration for moderate road runoff rates ranging between 70 and $85 \%$, roughly $47 \%$ for high runoff rates, and roughly $69 \%$ for low runoff rates (García-Serrana et al. 2017) Habibiandehkordi et al. (2014) investigated enhanced soluble phosphorous removal from agricultural runoff by incorporating ochre and aluminum-based water treatment residuals in the topsoil of BFSs. The authors completed a series of kinetic sorptiondesorption experiments alongside kinetic modelling to understand the rate and the mechanisms of phosphorous removal. The authors found that when applied to BFSs, aluminum-based water treatment residuals and ochre could be applied at rates of $<30 \mathrm{~g} / \mathrm{kg}$ soil to increase phosphorous sorption without any adverse environmental impacts. The researchers found that incorporating these widely available materials can be a cost-effective approach to minimizing soluble phosphorous exportation from BFSs .

In terms of cold-weather performance, the results of Stagge et al. (2012) concerning chloride release from BSs following winter de-icing practices (previously mentioned in Section 2.1.2.3) are echoed for BFSs due to the similar functionality of the two BMPs. Nutrient uptake by plants is also diminished during cold seasons due to reduced biological activity (Minnesota Pollution 
Control Agency 2016). When installed in areas experiencing seasonal snowfall, BFSs can act as a storage area for snow. Increased maintenance practices may be required to clear debris accumulated during winter months and to replace vegetation damaged by road de-icing salts (Minnesota Pollution Control Agency 2016).

Buffer/filter strips are not only effective in managing urban stormwater runoff (both in terms of pollutant reduction and conveyance (Winston et al. 2017)), but have also been heralded for their ease of installation and design, low construction and maintenance costs, and diversity of possible siting locations (Hunt et al. 2010; Winston et al. 2011a). Because infiltration occurs at the ground surface in BFSs, this BMP has been proven to work efficiently in areas with high water tables (Knight et al. 2013). Stagge et al. (2012) proposed that the cost-effective benefits of BFSs could be used to pre-treat runoff prior to being directed to other BMPs. The adoption of BFSs can also provide habitat for a diversity of animals (Lafrance et al. 2013).

Other than limited infiltration capacities, limitations are not often cited for BFSs due to their low costs, ease of maintenance, and simultaneous conveyance capabilities. It can also be inferred that due to their similar functionalities, BFSs share the same limitations as BSs (i.e., low infiltration rates, potential nutrient and chloride exporter, steep and low grades both reduce functionality). Table A-5 in Appendix A outlines the results of various studies related to the quantitative and qualitative effects of BFSs on urban stormwater runoff.

\subsubsection{Constructed stormwater wetlands}

In the context of this research, a constructed stormwater wetland (CSW) is any artificial waterbased ecosystem constructed to simultaneously store and treat stormwater runoff using vegetative filtration (including floating treatment wetlands (FTWs), horizontal/vertical subsurface constructed wetlands (H/VSSF CW), free water surface constructed wetlands, and CSWs). Although there are many possible configurations of CSWs, Figure 2-7 is an example of a CSW containing the features of FTWs, H/VSSFs, and free water surface CSWs. CSWs can also be built as a series of smaller wetland units designed as a natural treatment train. CSWs generally consist of an inlet zone (often coupled with a forebay to promote settling), a macrophyte zone (of dense aquatic vegetation), and an optional bypass channel for high volume storm events. 


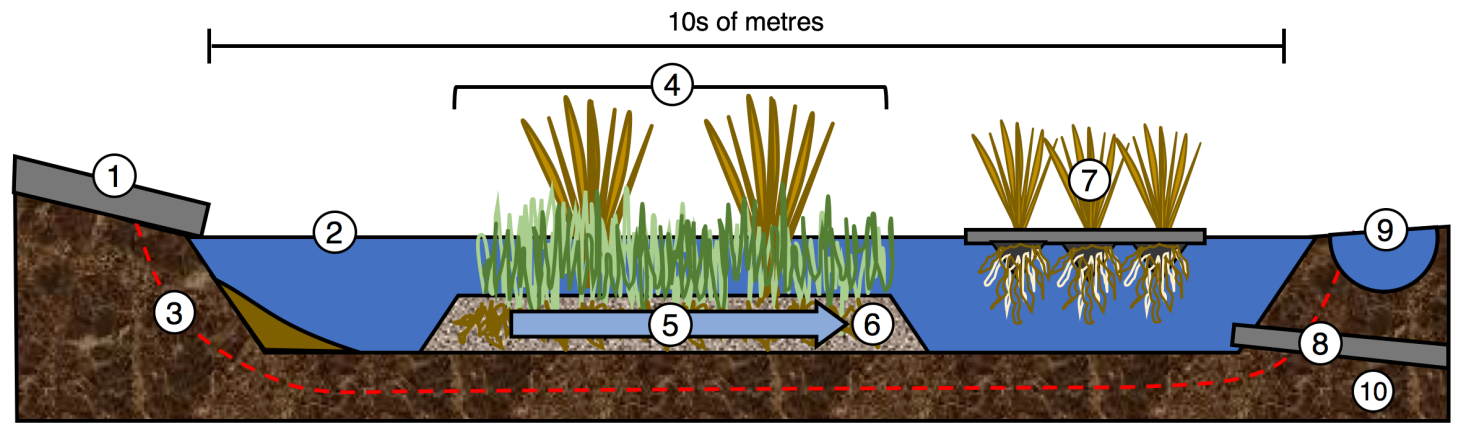

Figure 2-7: Cross section schematic of a constructed stormwater wetland. 1) Inlet; 2) Free water and forebay; 3) Optional liner; 4) Macrophyte zone; 5) Horizontal subsurface flow; 6) Root zone in porous medium; 7) Floating treatment wetland; 8) Outlet; 9) Optional bypass channel; 10) Existing subgrade.

Constructed stormwater wetlands can provide several benefits that traditional stormwater infrastructure cannot, such as: creating a habitat for wildlife, recharging groundwater (when wetland liners are not installed), and attenuating large volumes of stormwater runoff. As a retention-based BMP, CSWs are capable of treating larger volumes of stormwater as compared to other infiltration-oriented BMPs (e.g., ITs, raingardens, PPSs) (Mitsch and Gosselink 2001). The processes responsible for the abovementioned benefits include settling of sediments and particulates, physical filtration, absorption, biological uptake of pollutants, and biological decomposition (Mangangka 2017).

Different primary media have been tested as base layer materials for CSWs, including: loamy sand, gravel, and blast furnace slag (Lucas and Babatunde 2017). Furthermore, additional engineered and natural sorption media can be integrated into various parts of a CSW's design. These media may include sawdust, peat, compost, zeolite, wheat straw, newspaper, sand limestone, expanded clay, wood chips, wood fibers, mulch, glass, ash pumice, bentonite, tire crumb, expanded shale, oyster shell, and soy meal hull (Hossain et al. 2009). As with any other plant-dependent BMP, vegetation type is selected based on the locally tolerant species.

Constructed stormwater wetlands have been successfully adopted for treating runoff from a variety of catchments, including: residential communities, industrial/commercial areas, roadways, institutional campuses, apartment complexes, parking lots, stormwater retention ponds, and even to treat combined sewer discharge (Al-Rubaei et al. 2016; Ávila et al. 2013; Forgione 2015; Humphrey et al. 2014; Lynch et al. 2015; Mangangka et al. 2015b). CSWs can treat a variety of stormwater pollutants, but studies have shown they preform exceptionally well at removing 
nutrient pollutants (Al-Rubaei et al. 2016; Ávila et al. 2013; Chang et al. 2012; Humphrey et al. 2014; Lucas et al. 2015; Lucas and Babatunde 2017; Schmitt et al. 2015).

Researchers have identified multiple factors potentially affecting the performance of CSWs, including: antecedent dry days, system configuration, hydraulic conditions, influent quality parameters, primary media, soil types, vegetation, and retention time (Lucas and Babatunde 2017; Lynch et al. 2015; Walker et al. 2017; Yu et al. 2012). Lucas and Babatunde (2017) performed a study to investigate the effects of various CSW design configurations and operating variables on pollutant removal performance of laboratory-scale CSWs. The authors found that TSS concentrations were generally decreased by roughly $85 \%$ irrespective of CSW design (Lucas and Babatunde 2017). The authors also found that nutrient pollutant removal was highly variable, and performance was dictated by wet and dry periods (for nitrogen) and the primary media (phosphorous).

Although CSWs are generally designed with a minimum surface area of 5\% of the serviced runoff area, Walker et al. (2017) showed that even with a wetland area of $<1 \%$ of the serviced runoff area, significant removal of TSS and TP can still be achieved. Lucas and Babatunde (2017) also found no correlation between pollutant removal efficiency and wetland-to-watershed ratio. Floating treatment wetlands are a relatively new technology for CSWs, but recent studies have shown their efficacy in stormwater nutrient pollutant removal, even with as low as 5\% surface water coverage (Chang et al. 2012; Lynch et al. 2015; Walker et al. 2017).

Lucas et al. (2015) completed a review of the literature on the functionality of CSWs. The authors reviewed the literature and reports with regards to cold climate performance and found that CSWs have been shown to perform effectively with negligible or no negative effects in much colder regions (e.g., Norway, Minnesota, Switzerland).

Constructed stormwater wetlands can provide many benefits, including: reductions in peak flows and runoff volumes (specifically for larger volume runoff events), water quality improvements, provide a thriving ecological habitat, abilities to maintain continuous flows (both base flows and storm flows), more flood protection than lower volume BMPs, groundwater recharge (when liners are not installed), mechanically simple design, and the ability to perform well with relatively limited operating and maintenance requirements (Forgione 2015; Humphrey et al. 2014; Mackintosh et al. 2015; Tang et al. 2017; Vacca et al. 2016; Zounemat-Kermani et al. 2015). 
Al-Rubaei et al. (2016) studied whether the lack of long-term maintenance affected the performance of a CSW. The only maintenance the studied CSW had received over a period of 19 years was the removal of sediments from the forebay (Al-Rubaei et al. 2016). The authors found that despite a lack of regular maintenance, the CSW performed similarly to its expected design performance. Based on the results, the authors concluded that CSWs can perform well for several decades with minimal maintenance (Al-Rubaei et al. 2016).

The primary disadvantage of the adoption of CSWs are associated with land requirements (Chang et al. 2012; Forgione 2015; Zounemat-Kermani et al. 2015). Due to the large land requirements for CSWs, there are many stakeholder requirements to satisfy (including planning authorities, regulatory bodies, and landowners), ultimately increasing the complexity of permitting and adoption of CSWs (Lucas et al. 2015). Aside from the limitations associated with land requirements, other CSW disadvantages are as follows: large volume flows may have to be bypassed to preserve vegetation, resulting in untreated stormwater runoff; lack of flexibility in system retrofitting once constructed; and potential habitat for pollutant-tolerant insects (Chang et al. 2012; Lucas et al. 2015; Mackintosh et al. 2015).

Table A-6 in Appendix A outlines the results of various studies related to the quantitative and qualitative effects of CSWs on urban stormwater runoff.

\subsubsection{Raingardens and downspout disconnections}

Raingardens and downspout disconnections are discussed together in this chapter as they are both lot-level BMPs and both require very little engineering and essentially accomplish the same stormwater management goals (i.e., increased infiltration, reduced runoff, and mitigation of sewer overflow). Runoff from conventional roofs can deliver a large volume of water if directly sent to stormwater sewers. This results in no opportunity for infiltration, evapotranspiration, or treatment of roof runoff prior to entering the utility system and ultimately ending up in nearby surface waters or in a wastewater treatment plant.

To address the abovementioned challenges, two simple lot-level BMPs can be adopted to minimize runoff from individual lots, disconnection of downspouts and the adoption of raingardens. Downspouts are often directed onto impermeable surfaces (e.g., driveways) or directly attached to storm sewer networks, and inevitably result in increased burdens on stormwater or wastewater (in the case of combined sewer systems) infrastructure. Downspout disconnection is the simple action 
of redirecting roof runoff onto vegetated surfaces, like grass lawns or raingardens, where roof runoff can be infiltrated into the ground.

In the context of this thesis, the following distinction is made between BR cells and raingardens:

Raingarden: a lot-level BMP designed to capture roof rainwater and redirect it into a shallow depression in the native soil. Depressions are filled with engineered soils and planted with native plants that are drought resistant and water tolerant (Richards et al. 2015). Coarse drainage layers of gravel are often installed at the base of raingardens to promote infiltration (Figure 2-8).

Bioretention cell: a heavily engineered piece of public infrastructure designed to capture stormwater runoff from a variety of surfaces to promote infiltration and evapotranspiration and decrease runoff volumes and peak flows. Refer to section 2.1.2.4 for more information on BR cells.

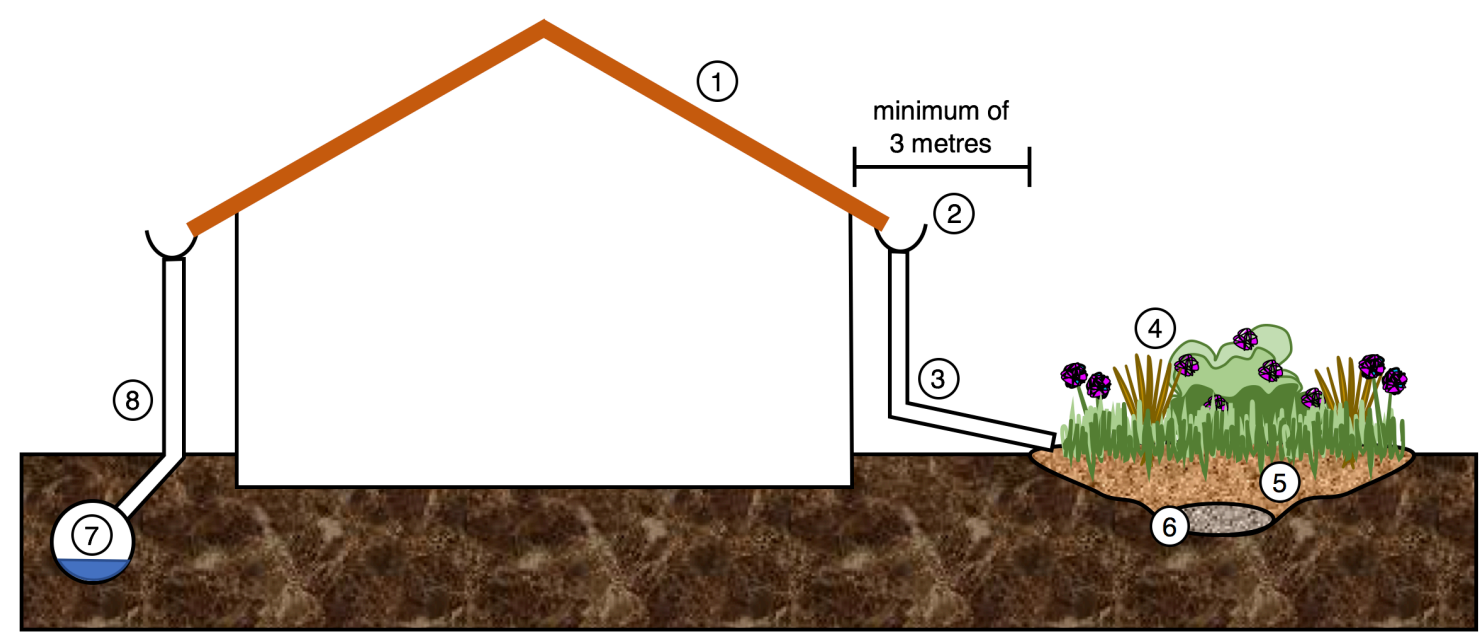

Figure 2-8: Cross-section schematic of a home with disconnected downspout directed to a raingarden and a separate downspout connected to the sewer system. 1) Roof collection area; 2) Gutter; 3) Raingarden downspout; 4) Raingarden; 5) Engineered soil; 6) Coarse drainage layer; 7) Storm sewer; 8) Connected downspout.

Although raingardens are designed to offer the same functionality as BR cells, they are generally on a smaller scale and require much less engineering of components.

Due to the lot-level nature of raingardens and downspout disconnections, very few studies have investigated the quantified treatment efficiencies of either of these BMPs. Although there are many studies that have quantified the effects of raingardens, many of the BMPs described in these studies are defined as BR cells under the nomenclature of this thesis (Elliott et al. 2011; Guo and Luu 2015; Yergeau and Obropta 2013). 
Many municipalities in Canada (e.g., City of Toronto and the City of Windsor) and states in the USA (e.g., Connecticut, Maine, Massachusetts, and Vermont) have adopted downspout disconnection programs to reduce stormwater runoff volumes from entering their sewer systems (City of Toronto 2017; City of Windsor 2017; USEPA 2017c). In areas with combined sewer systems, disconnected downspouts can reduce the amount of combined flow requiring treatment and also mitigates the risk of combined sewer overflows (Canada Mortgage and Housing Corporation 2017). Ma (2013) studied the impacts of a sponsored raingarden program in the metropolitan area of Kansas City. The author found that stormwater sewer flows were decreased by $64 \%$ after only installing 135 raingardens in the study area (Ma 2013). According to the Canada Mortgage and Housing Corporation (2017), considering an average rainfall of $700 \mathrm{~mm}$ (which is typical for Toronto, Ontario) and a roof area of $140 \mathrm{~m}^{2}$, a home with a disconnected downspout can divert roughly $100,000 \mathrm{~L}$ per year from the sewer system.

Downspout disconnections have been heralded by many jurisdictions for their low cost of implementation (especially when compared to other BMPs), simplicity of installation, and immediate benefits (Canada Mortgage and Housing Corporation 2017). As an extra benefit, the functionality of raingardens as a source of food was studied by Richards et al. (2015). The authors found that raingardens are not only capable of fulfilling their stormwater management functionalities, but can simultaneously serve as vegetable gardens (Richards et al. 2015).

Many of the key factors affecting the performance of downspout disconnections also result in some of the BMPs limitations. When considering a downspout disconnection the property owner or consultant must consider the size of the lot (requires enough area to allow runoff to infiltrate without pooling); the perviousness of the soil; the grade of the property (too low and the water will pool, too high and water will not infiltrate); and proximity of disconnection to buildings (potential for foundation damage or flooding) (Canada Mortgage and Housing Corporation 2017).

\subsubsection{Rainwater harvesting}

The harvesting of rainwater collected from urban rooftops can assist municipalities in achieving effective stormwater management and also serve as a resource for domestic water supplies (Shuster et al. 2013). Water harvested and stored from rainwater harvesting (RH) systems is generally used in residential applications for irrigation, clothes washing, and toilet flushing (USEPA 2013). It is important to make the following distinction between rainwater and stormwater; rainwater consists 
of rain collected from roofs, and stormwater runoff flows come from a combination of other surfaces (e.g., driveways, roads, lawns), also including roofs.

The most basic RH setup consists of a catchment surface (generally the roof of a building), a rain gutter, a piping network connecting the catchment surface to the storage unit, a storage unit, and a means for diverting overflow volumes (Isoken and Osemwengie 2016) (Figure 2-9). Some RH systems may also include a filter system or first flush device. First-flush devices are often incorporated into RH systems to increase harvested water quality. First flush devices are used to divert the initial runoff volume from catchment surfaces to wash away pollutants that have accumulated since the previous harvestable rainfall. Mendez et al. (2011) found that water quality was greatly improved by diverting the first $38 \mathrm{~L}$ for every $93 \mathrm{~m}^{2}$ of catchment area with a firstflush device. O'Hogain et al. (2011) studied the quality of harvested rainwater from a pilot residential facility in Ireland and found that even with a very basic filter, all harvested rainwater samples were in compliance with local bathing water regulations. Most commonly, residential rainwater storage units consist of polyethylene barrels no larger than $300 \mathrm{~L}$ (Shuster et al. 2013), but larger commercial units (both aboveground and belowground) are also available (USEPA 2013).

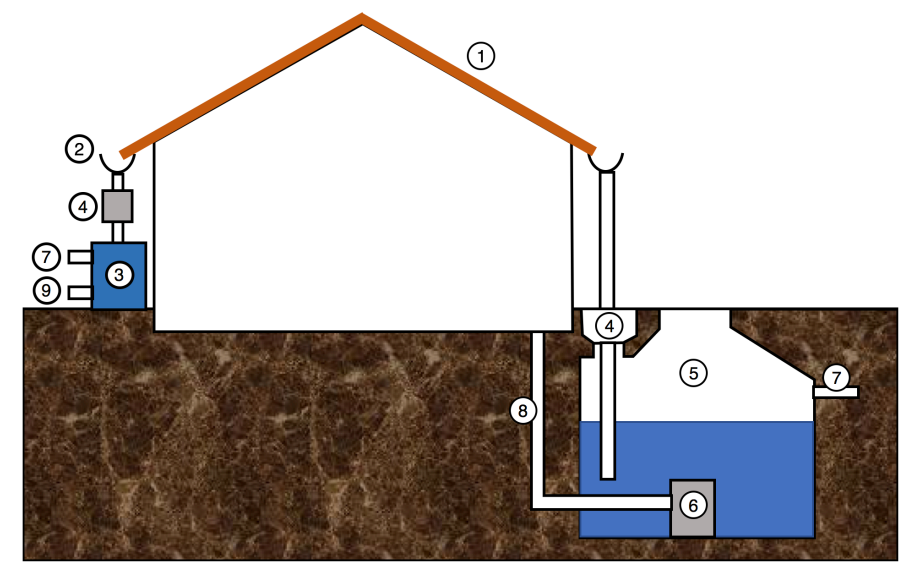

Figure 2-9: Cross-section schematic of a building with underground rainwater storage and an aboveground rain barrel. Adapted from O'Hogain et al. (2011). 1) Roof collection area; 2) Gutter; 3) Rain barrel; 4) First flush diverter/filter; 5) Belowground cistern; 6) Pump; 7) Overflow outlet; 8) Piping to residence; 9) Outlet for irrigation.

Variability in harvested rainwater quality has been attributed to: land use practices, weather patterns, storage system material, roof slope, roofing material, and maintenance practices (Farreny et al. 2011; Gwenzi et al. 2015; Lee et al. 2012b; Morales-Pinzón et al. 2015; Zhang et al. 2014). Physiochemical properties of rainwater are controlled via atmospheric deposition, leaching and 
weathering of roofing materials, faecal contamination, and storage and conveyance systems (Gwenzi et al. 2015). Mendez et al. (2011) examined the effects of conventional roofing materials (i.e., concrete tile, metal, and asphalt fibreglass shingles) and alternative roofing materials (i.e., cool and green roofs) on the quality of harvested rainwater. The authors found that, regardless of roofing material, rainwater harvested from roofing surfaces requires, at minimum, first-flush diversion, filtration, and disinfection to ensure potable quality. Morales-Pinzón et al. (2015) evaluated the quality of rainwater and its relation to selected variables (piping material, roofing material, deposits, and amount of precipitation) for six different buildings. The authors found that, regardless of differences in the selected variables, the sampled water was suitable for many nonpotable uses (Morales-Pinzón et al. 2015). Farreny et al. (2011) completed a study on roof selection criteria for RH systems. The authors studied the water quality from roofs with four different types of materials and slopes. The authors concluded that sloped smooth roofs perform better in terms of water quantity (volume harvested) and quality (physiochemical parameters) than rough flat roofs (Farreny et al. 2011).

In areas experiencing freezing temperatures during winter months, RW storage systems are generally decommissioned during winter months (including draining water from the system to avoid any damage due to freezing) (Shuster et al. 2013).

When compared to the maintenance requirements of infrastructure-based BMPs, maintenance for RH systems is very minimal, but it is important to consider that the onerous for maintenance is shifted toward the property owner. For some property owners, RH system maintenance may either deter them from adopting the system or result in the system's poor performance. To study residents' experiences with RH, Shuster et al. (2015) distributed a set of owner-user surveys to residents with rain barrels in Cincinnati, Ohio. Although overall experience with RH was either "good" or "fair," maintenance issues were cited by many of the respondents (Shuster et al. 2013). In general, RH maintenance activities include cleaning of storage tanks, gutters, and catchment areas (Amin et al. 2013; Meera and Mansoor Ahammed 2006; Rahman et al. 2014). Although some sort of periodic roof cleaning is often suggested, Farreny et al. (2011) found that, despite a lack of maintenance and cleaning of roofs, water quality analyses indicated low pollutant loads in terms of TSS and total organic carbon, and fell in the "low concern" range for conductivity and $\mathrm{pH}$. 
There are many advantages associated with small-scale RH systems cited in literature. The most commonly referenced advantages are: reduced burden on public water supplies; low cost of installation and maintenance; ability to reduce water expenses; and simple deployment of untreated water for non-potable uses (Farreny et al. 2011; Rahman et al. 2014). Morales-Pinzón et al. (2015) also suggest that the use of unconvential residential water sources (e.g., rainwater and greywater) should be considered as a component of any sustainable housing analysis (Morales-Pinzón et al. 2015).

Rainwater harvesting systems are limited by two primary disadvantages, storage constraints and water quality risks (De Kwaadsteniet et al. 2013; USEPA 2013). Regional climate conditions play an important role in the water quantity performance of RH systems. In areas of seasonal rainfall patterns, RH water availability will be restricted to the wet part of the year. Ideally, matching supply (rainfall) with user demand will result in the greatest water savings (USEPA 2013), but this is often quite difficult. De Kwaadsteniet et al. (2013) also make the argument that there is a lack of research on the role of social factors on the widespread acceptance and use of RH.

Table A-7 in Appendix A outlines the results of various studies related to the concentrations of pollutants in RH storage vessels.

\subsubsection{Green roofs}

A green roof (GR), or vegetative, roof is a term for a roof that has been constructed to accommodate a living layer of plants, as opposed to traditional high runoff coefficient materials (e.g., asphalt tile, metal, clay tile, etc.). Figure 2-10 is a simplified schematic of a typical GR.

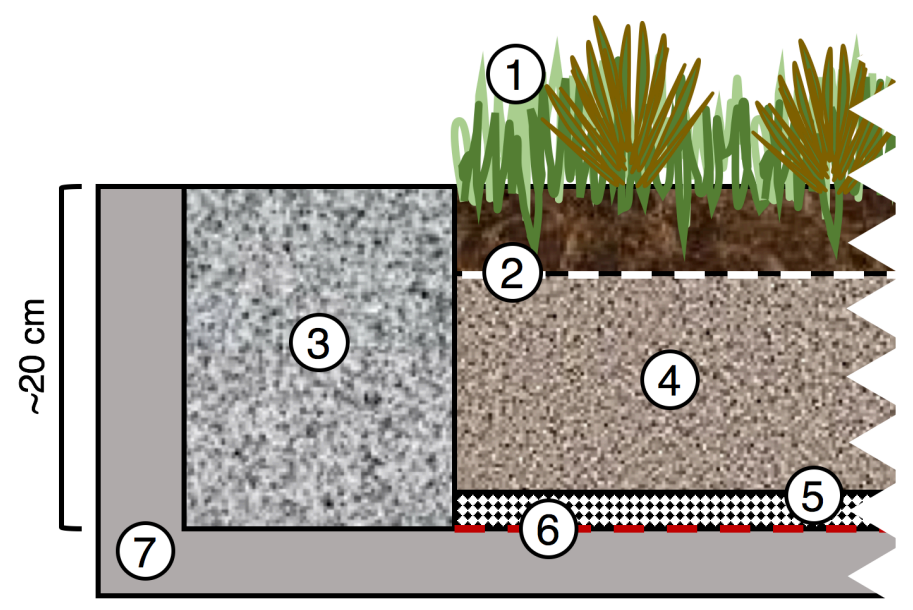

Figure 2-10: Cross-section schematic of a typical intensive green roof system. 1) Vegetative layer; 2) Geotextile fabric; 3) Peripheral drainage; 4) Substrate layer; 5) Storage and drainage layer; 6) Waterproof membrane; 7) Building. 
The choice of GR vegetation is dependent on region, but succulents and herbaceous perennials are often planted (Dvorak and Volder 2010). Underlying roof materials can be conventional asphalt, gravel ballast, or white membrane roofing material (Buffam et al. 2016; Sims et al. 2016). Ideal substrates for GRs should have low bulk density, provide structurally sound anchorage for plant roots, be able to supply and store plant nutrients, leach minimal pollutants, remain stable in all climate conditions, have good aeration, and have a high water retention capacity (Nagase and Dunnett 2011). Drainage layers can be composed of natural and recycled building materials (e.g., gravel, crushed rock, crushed lava, crushed brick, shredded tires, tumbled glass) or fabricated products (e.g., plastic sheets with cups, Rockwool, Pollytag®, LECA (lightweight expanded clay aggregate)) (Karczmarczyk et al. 2014). GRs store rainwater in the substrate layer and the vegetation canopy. Water is held in the pore spaces of the growth medium and is then transpired through vegetation and evaporated. GRs are capable of reducing runoff under unsaturated media conditions, but once storage capacity is reached, typical roof runoff volumes will occur.

After reviewing the available literature, the following factors affecting GR performance were repeatedly reported: choice of substrate, number of layers, substrate thickness, type of vegetation, percentage of roof covered by GR, roof slope, weather conditions (number of antecedent dry days, rainfall characteristics), and the presence of a drainage/storage layer (Dvorak and Volder 2010; Garofalo et al. 2016; Nagase and Dunnett 2011; Vanuytrecht et al. 2014).

Due to the limited storage capacities of GRs, a larger portion of rainfall volumes for smaller storm events are retained by GRs as opposed to smaller portions for larger storm events (Sims et al. 2016). Sims et al. (2016) studied the runoff retention of GRs in varying climates in Canada (Calgary, London, and Halifax, Canada). The authors found that drier climates had a significantly higher cumulative retention (67\%) than wetter climates (34\%). Garofalo et al. (2016) found that when single event precipitation values were above $10 \mathrm{~mm}$, the runoff reduction from GRs ranged from $0-20 \%$. Even in semi-arid environments, GRs have been shown to be a sustainable and effective approach for managing roof runoff (Dabbaghain et al. 2013).

Although GRs are an effective option for reducing roof runoff volumes, research shows that concentrations of nutrient pollutants (i.e., nitrogen and phosphorous) in stormwater runoff can be increased by GR runoff, attributed to soils, plants, and fertilizers (Buffam et al. 2016; Kuoppamäki et al. 2016; Morgan et al. 2013; Teemusk and Mander 2011; Vijayaraghavan and Badavane 2017). 
Maintenance requirements (e.g., fertilizing) will vary depending on the vegetation planted on the GR and is therefore highly dependent on region and design. Ascione et al. (2013) describes the typical division of GRs into two categories: intensive; and extensive (Ascione et al. 2013). Intensive GRs require complex substrates and put a significant amount of mechanical stress on the host building. These designs are generally more costly and have higher maintenance requirements (Ascione et al. 2013). Extensive GRs on the other hand require lower initial costs, less substrate (i.e., less thickness and weight), and have lower operating costs and maintenance requirements (Ascione et al. 2013).

The durability of GRs is greatly dependent on materials used in the drainage layer. Gwózdź et al. (2016) evaluated the effects of freeze-thaw cycles on the hydraulic effectiveness of GRs using different aggregate materials for the drainage layer. The authors found that even after 30 freezethaw cycles, hydraulic conductivity can be maintained when using appropriate materials (e.g., travertine or crushed brick), but could be decreased by as much as $67 \%$ for inappropriate materials (e.g., crushed granite, LECA, and chalcedony).

Green roofs not only offer several advantages to stormwater management (e.g., the ability to retain and detain stormwater), but can also counteract the effects of urban heat islands, reduce building energy consumption by insulating roofs, increase urban aesthetics, and increase urban biodiversity by offering a habitat for animals and plants (Ascione et al. 2013; Morgan et al. 2013; Vijayaraghavan et al. 2012; Vijayaraghavan and Badavane 2017). As rooftops generally make up 40-50\% of impervious surface areas in urban environments (Dunnett and Kingsbury 2004), GRs as a form of urban stormwater runoff management are often a practical solution. The high captial and maintenance costs of GRs (Vijayaraghavan et al. 2012) are often not enough to deter their adoption. Other disadvantages to using a GR as opposed to a traditional impermeable roof are: the structural limitations of buildings in terms of load capacity; potential for nutrient exportation during overflow events; and issues with improper selection of vegetation (resulting in higher maintenance costs and potential need of supplementary watering) (Nagase and Dunnett 2011; Vijayaraghavan et al. 2012). Table A-8 outlines the results of various studies related to the concentrations of pollutants in GR runoff and the quantitative and qualitative effects of GRs on urban stormwater runoff. 
Table A-9 in Appendix A provides a summary of the primary function, pros, cons, factors affecting performance, land requirements, maintenance requirements, potential for nutrient pollutant exportation, and cold climate functionality for each reviewed BMP.

\subsubsection{Critical analysis and discussion}

Based on the reviewed literature, five recurring themes were observed in regards to knowledge gaps and conflicting objectives in LID and BMP research. These five themes are as follows:

- Lack of consensus on which parameters to measure for effective BMP and LID adoption

- High variability in reported BMP performance

- Many BMPs are known exporters of nutrient pollutants

- Lack of cold weather performance-specific studies for individual BMPs

- Lack of human pathogen-related stormwater quality studies for individual BMPs

Prior to systematically comparing the treatment performance of the nine investigated BMPS, the parameters for comparison must be selected. The authors performed a frequency analysis of the 21 parameters (Table 2-1) relevant to BMP studies and identified the most frequently investigated parameters. It is important to note that no single reviewed study examined all 21 parameters. Table 2-2 outlines the number of studies investigating each parameter for each BMP and the ranking results based on the total number of studies investigating each parameter across all BMPs. Although BMPs can be combined or integrated with other water treatment and storage technologies to increase functionality and performance (Brown et al. 2012; Jia et al. 2015; TotaMaharaj and Scholz 2010; Xu et al. 2017), the analysis of BMP performance is based on individual systems without integration of other BMPs.

With no global consensus from regulators on which pollutants to monitor, a lack of consistency in BMP research across the globe has been identified. BMP experiments are often designed so the results meet the needs of a certain jurisdiction or watershed. Although this customized approach can be beneficial for site-specific planning research, this leaves the global community of stormwater researchers at a disadvantage in terms of knowledge sharing.

As shown in Table 2-2, the top-six most frequently investigated parameters were found to be: TSS, $\mathrm{TP}, \mathrm{TN}$, runoff volume, $\mathrm{Zn}$, and $\mathrm{NO}_{3}-\mathrm{N}$. These six parameters cover aspects of urban stormwater runoff related to solid loads, nutrient pollutants, runoff volumes, and metals. Moreover, a division 
between parameters measured in percentage reduction-specific studies and concentration specificstudies (i.e., GRs and RH) was noted. The top-ranked parameters based on the further sub-divided frequency analysis are outlined in Table 2-3. Although a consensus on investigated parameter ranking was identified for percentage reduction-based studies, no such consensus was observed

Table 2-2: Number of studies investigating each parameter for each BMP.

\begin{tabular}{|c|c|c|c|c|c|c|c|c|c|c|c|c|c|c|c|c|c|c|c|c|c|}
\hline Number of Studies & Runoff & TSS & TDS & $\mathbf{P b}$ & $\mathrm{Cu}$ & $\mathrm{Zn}$ & TN & TKN & $\mathrm{NO}_{2}-\mathrm{N}$ & $\mathrm{NO}_{3}-\mathrm{N}$ & NH3-N & TP & OPP & TPH & PAH & Cl- $\mathrm{T}$ & TC $\mathbf{r}$ & FC & E. coli & BOD & COD \\
\hline Permeable Pavement Systems (13) & 8 & 8 & 1 & 4 & 5 & 6 & 4 & 0 & 0 & 4 & 5 & 6 & 2 & 4 & 0 & 3 & 1 & 2 & 2 & 2 & 2 \\
\hline Infiltration Trenches (10) & 5 & 6 & 1 & 3 & 1 & 3 & 2 & 4 & 0 & 1 & 0 & 2 & 1 & 1 & 0 & 1 & 0 & 0 & 0 & 2 & 2 \\
\hline Bioswales (12) & 4 & 9 & 1 & 5 & 4 & 7 & 6 & 4 & 3 & 5 & 4 & 9 & 0 & 2 & 1 & 1 & 0 & 0 & 0 & 2 & 4 \\
\hline Bioretention (17) & 6 & 10 & 0 & 2 & 3 & 4 & 8 & 2 & 3 & 4 & 4 & 11 & 3 & 1 & 1 & 1 & 0 & 0 & 1 & 1 & 1 \\
\hline Buffer/Filter Strips (17) & 6 & 8 & 0 & 1 & 1 & 2 & 6 & 3 & 3 & 3 & 2 & 6 & 3 & 0 & 0 & 1 & 0 & 0 & 1 & 3 & 3 \\
\hline $\begin{array}{c}\text { Constructed Stormwater } \\
\text { Wetlands (15) }\end{array}$ & 2 & 9 & 0 & 2 & 2 & 3 & 11 & 3 & 3 & 5 & 4 & 10 & 6 & 0 & 1 & 1 & 0 & 1 & 2 & 3 & 4 \\
\hline Green Roofs* (13) & 7 & 1 & 3 & 3 & 3 & 3 & 2 & 0 & 0 & 4 & 2 & 3 & 2 & 0 & 0 & 1 & 1 & 0 & 1 & 1 & 1 \\
\hline Rain Harvesting* (10) & 0 & 4 & 4 & 6 & 3 & 4 & 1 & 0 & 3 & 6 & 6 & 3 & 3 & 0 & 0 & 3 & 7 & 5 & 3 & 2 & 1 \\
\hline Sum & 38 & 55 & 10 & 26 & 22 & 32 & 40 & 16 & 15 & 32 & 27 & 50 & 20 & 8 & 3 & 12 & 9 & 8 & 10 & 16 & 18 \\
\hline Rank & 4 & 1 & 16 & 8 & 9 & 5 & 3 & 12 & 14 & 5 & 7 & 2 & 10 & 19 & 21 & 151 & 181 & 19 & 16 & 12 & 11 \\
\hline
\end{tabular}

Note: colours indicate the parameter ranking in terms of each respective BMP. Green indicates more studies for that particular BMP investigated that parameter, while red indicates very few or no studies investigated that parameter. The Rank row indicates the final ranking based on the sum of the number of studies investigating each parameter across all BMPs. Numbers in parentheses represent the number of studies used to create the summary statistics. Values in parentheses are the number of studies used to create summary statistics.

* Both concentration and percentage reduction-based studies included in sum.

for the concentration-based studies. The difference in parameter rankings between the two types of studies is interpreted to be influenced by the differences in influent data (i.e., rain water). For example, those studies that reported results in terms of percent reduction had to measure influent stormwater runoff and effluent. On the other hand, those studies reporting results in terms of concentration did not measure influent and solely measured effluent concentrations. The mostcommonly studied parameters for GRs and RH reflect the greatest risks posed by these two technologies, i.e., nutrient pollutant exportation from GRs $\left(\mathrm{NO}_{3}-\mathrm{N}, \mathrm{OPP}, \mathrm{TN}, \mathrm{TP}\right)$ and adverse human health effects for RH (TC, Pb, E. coli).

Table 2-3: Frequency ranking of investigated parameters.

\begin{tabular}{|c|c|c|c|c|c|c|c|c|}
\hline \multirow{2}{*}{\multicolumn{3}{|c|}{ Reduction-specific studies }} & \multicolumn{6}{|c|}{ Concentration-specific studies } \\
\hline & & & \multicolumn{3}{|c|}{ Green roof studies } & \multicolumn{3}{|c|}{ Rain harvesting studies } \\
\hline Parameter & $\begin{array}{c}\text { Number of } \\
\text { Studies }\end{array}$ & Rank & Parameter & $\begin{array}{c}\begin{array}{c}\text { Number of } \\
\text { Studies }\end{array} \\
\end{array}$ & Rank & Parameter & $\begin{array}{l}\text { Number } \\
\text { of Studies }\end{array}$ & Rank \\
\hline TSS & 50 & 1 & $\mathrm{NO}_{3}-\mathrm{N}$ & 4 & 1 & TC & 7 & 1 \\
\hline TP & 44 & 2 & OPP & 3 & 2 & $\mathrm{NO}_{3}-\mathrm{N}$ & 6 & 3 \\
\hline $\mathbf{T N}$ & 37 & 3 & TDS & 2 & 7 & $\mathbf{N H}_{3}-\mathbf{N}$ & 6 & 3 \\
\hline Runoff & 31 & 4 & $\mathbf{C u}$ & 2 & 7 & $\mathbf{P b}$ & 5 & 5 \\
\hline \multirow[t]{3}{*}{ Zn } & 25 & 5 & Zn & 2 & 7 & E. coli & 5 & 5 \\
\hline & & & $\mathbf{T N}$ & 2 & 7 & & & \\
\hline & & & TP & 2 & 7 & & & \\
\hline
\end{tabular}


To compare the performance of individual BMPs in terms of the top-ranked parameters, nonparametric statistics were created from the data in Tables A-1 to A-8 in Appendix A. Nonparametric univariate statistics were used due to the fact that the type of data collected in this chapter was highly dependent on the results formatting for each individual study. The treatment efficiency data collected in this literature review was presented in a variety of statistics (e.g., minimum, maximum, mean, median, standard deviations). Figure 2-11 compares the runoff reduction and treatment efficiencies of BMPs reported in reduction-specific studies. As Figure 2-11 shows, BMP treatment performance varies over a large range for most parameters. These ranges are attributed to differences in the factors affecting performance outlined for each BMP (Table A-9 in Appendix A). Table 2-4 outlines the nonparametric statistics of the reviewed literature for the top-ranked parameters for concentration-specific studies. For most parameters in Table 2-4, the minimum and maximum values for concentration can vary between two to three orders of magnitude, with some ranges being as large as five orders of magnitude (TC for rain harvesting). Based on the observed variations in BMP performance seen in Figure 2-11 and Table 2-4, decision makers will experience great challenges in developing effective urban watershedscale stormwater management plans to promote the adoption of various BMPs and LID. More critically, some BMPs were found to commonly export nutrient pollutants via runoff. A negative treatment efficiency of a BMP for a certain pollutant means that the BMP exports that pollutant. As observed in Figure 2-11 (only reduction-based studies), many of the investigated BMPs are shown to export both TN and TP. Based on the data available for those BMPs and by further investigating the reported values for $\mathrm{NO}_{3}-\mathrm{N}$, ITs are the only BMP not identified as a potential nutrient exporter

Table 2-5). However, as only three studies investigated nutrient concentrations, in terms of TN, $\mathrm{TP}$, and $\mathrm{NO}_{3}-\mathrm{N}$, in the runoff from ITs (Maniquiz et al. 2010; Scholz and Yazdi 2009; Yu et al. 2013), the reported data is still not adequate to identify ITs as a source of nutrient exportation. These broad generalizations of nutrient exportation potential of BMPs cannot be inferred to those BMPs lacking sufficient reduction-based empirical evidence (i.e., GRs, RWH, and downspout disconnections).

One of the primary reported benefits of LID is the reduction of pollutants discharged to ground and surface waters. The nutrient pollutant exportation potential of some BMPs contradicts the pollutant load reduction goals of LID, potentially resulting in poor community-scale watershed 
LID performance. When high concentrations of nutrient pollutants accumulate in surface waters (eutrophication), algal blooms can occur, resulting in degradation of aquatic ecosystem health (Liu et al. 2017). To address the issues of nutrient exportation from BMPs, researchers have investigated the effects of using engineered materials (Iqbal et al. 2015; Karczmarczyk et al. 2014; Kuoppamäki et al. 2016; Melville 2016; Morgan et al. 2013; Vijayaraghavan and Badavane 2017) and designing BMP treatment trains to take advantage of each BMPs' treatment strengths (Brown et al. 2012; Jia et al. 2015; Xu et al. 2017). Although these studies investigated possible mechanisms for reducing nutrient exportation from BMPs, until these technologies become more widely adopted, urban stormwater planners will require more information to quantify the optimal mix of LID and traditional stormwater infrastructure.
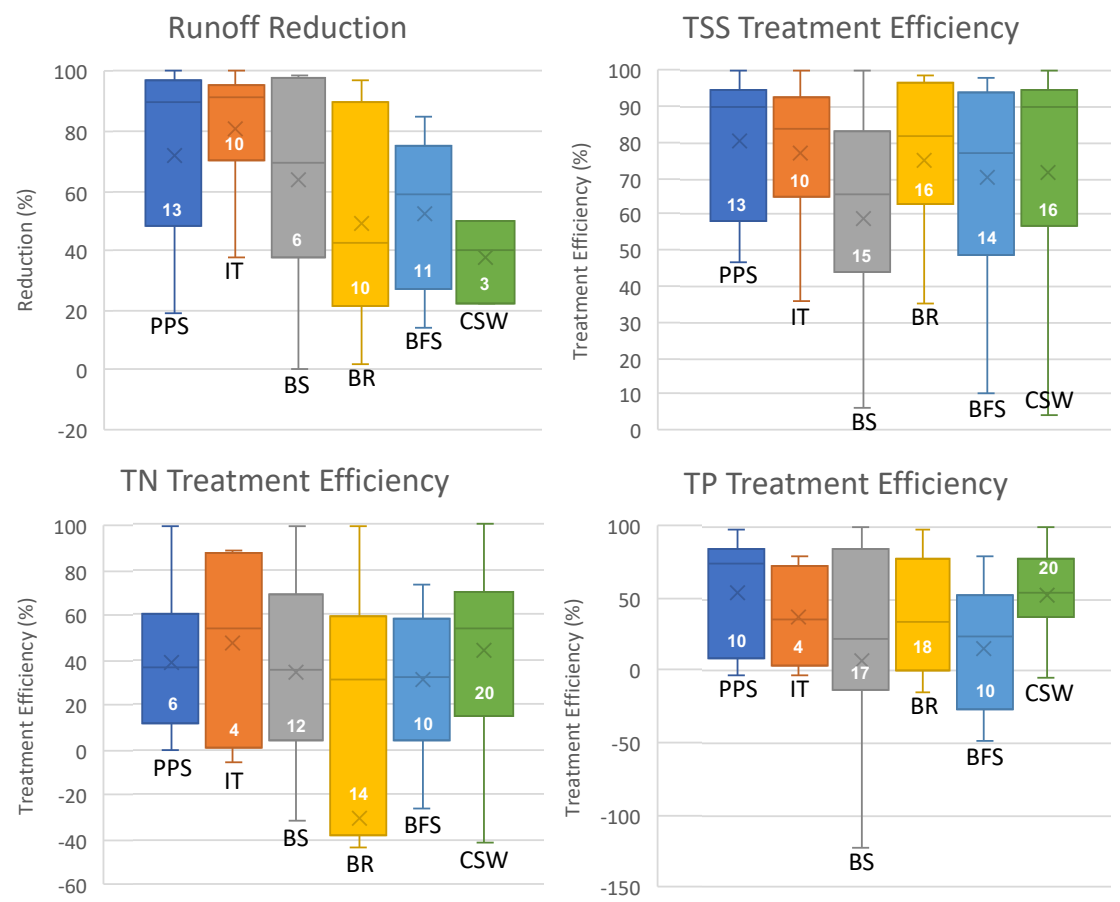

Zn Treatment Efficiency

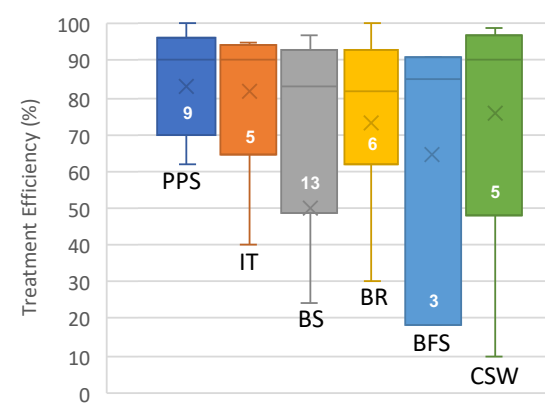

Figure 2-11: Box-and-whisker plots comparing the runoff reduction and treatment efficiencies of BMPs. Note: outliers are not shown in plots. Values displayed in plots represent the sample size for each parameter. PPS: permeable pavement system; IT: infiltration trench; BS: bioswale; BR: bioretention; BFS: buffer/filter strip; CSW: constructed stormwater wetland. 
Table 2-4: Nonparametric statistics of the reviewed literature for the top-ranked parameters for concentration-specific studies.

\begin{tabular}{|c|c|c|c|c|c|c|c|c|c|c|c|}
\hline \multirow[b]{2}{*}{ Parameter } & \multicolumn{5}{|c|}{ Green Roofs } & \multirow[b]{2}{*}{ Parameter } & \multicolumn{5}{|c|}{ Rain Harvesting } \\
\hline & Min & Q1 & Q2 & Q3 & Max & & Min & Q1 & $\mathrm{Q} 2$ & Q3 & $\operatorname{Max}$ \\
\hline $\mathrm{NO}_{3}-\mathrm{N}(\mathrm{mg} / \mathrm{L})$ & 0.1 & 0.28 & 0.86 & 8.1 & 70 & TC (cfu/100mL) & 0 & 11 & 141 & 493 & 112000 \\
\hline OPP (mg/L) & 0.25 & 1.05 & 2.7 & 15.9 & 40 & $\mathrm{NO}_{3}-\mathrm{N}(\mathrm{mg} / \mathrm{L})$ & 0.10 & 0.96 & 1.93 & 5.05 & 14.2 \\
\hline TDS (mg/L) & 505 & 514 & 546 & 576 & 577 & $\mathrm{NH}_{3}-\mathrm{N}(\mathrm{mg} / \mathrm{L})$ & 0 & 0.09 & 0.26 & 0.55 & 1.4 \\
\hline $\mathrm{Cu}(\mathrm{mg} / \mathrm{L})$ & 0.004 & 0.008 & 0.025 & 0.045 & 0.060 & $\mathrm{~Pb}(\mathrm{mg} / \mathrm{L})$ & 0 & 0.005 & 0.012 & 0.038 & 0.055 \\
\hline $\mathrm{Zn}(\mathrm{mg} / \mathrm{L})$ & 0.04 & 0.10 & 0.22 & 0.69 & 1.81 & E. $\operatorname{coli}(\mathrm{cfu} / 100 \mathrm{~mL})$ & 0 & 0.3 & 3.1 & 123 & 8300 \\
\hline TN (mg/L) & 1.7 & 2.4 & 3.0 & 5.0 & 7.0 & & & & & & \\
\hline TP (mg/L) & 0.27 & 0.39 & 0.5 & 1.05 & 1.6 & & & & & & \\
\hline
\end{tabular}

Note: Q1 = first quartile; Q2 = second quartile or median; Q3 = third quartile; Min = minimum value; Max = maximum value

Table 2-5: BMPs and their nutrient exportation potential.

\begin{tabular}{lll|ll|ll}
\hline BMP & $\begin{array}{l}\text { Exports } \\
\text { TN? }\end{array}$ & $\begin{array}{l}\text { Min value } \\
(\%)\end{array}$ & $\begin{array}{l}\text { Exports } \\
\text { TP? }\end{array}$ & $\begin{array}{l}\text { Min value } \\
(\%)\end{array}$ & $\begin{array}{l}\text { Exports } \\
\text { NO}_{3}-\mathbf{N} ?\end{array}$ & $\begin{array}{l}\text { Min value } \\
(\%)\end{array}$ \\
\hline PPS & N & 0 & N & -3 & Y & -50 \\
IT & N & -6 & N & -3 & N & 32 \\
BS & Y & -31 & Y & -311 & N & -10 \\
BR & Y & -480 & Y & -3251 & Y & -118 \\
BFS & Y & -26 & Y & -49 & Y & -12 \\
CSW & Y & -41 & N & -5 & Y & -94 \\
\hline
\end{tabular}

Note: BMPs are deemed potential nutrient exporters if the minimum reported value is below $-10 \%$. The authors selected $-10 \%$ as a cut-off to account for uncertainty in measurements and calculations of reported values. $\mathrm{Min}=$ minimum.

It is important to note that temporal variations in BMP performance were not tracked throughout this review. It has been reported that nutrient exportation potential can change as BMPs age (Kamali et al. 2017). The nutrient exportation data compiled in this chapter were collected from studies focusing on BMPs with different ages, ranging from multi-day laboratory experiments to field investigations of BMPs that have been in service for over a decade. Hence, there is a potential data bias in terms of length of studies and age of BMPs.

This research also revealed that the performance of BMPs was not sufficiently understood under cold climate conditions. Of the 102 studies used to produce nonparametric statistics, only eight reported results for BMP functionality during cold weather conditions. With LID being adopted in diverse and extreme climate regions across the globe, urban stormwater planners require cold climate-specific data to address the regional needs and limitations of their jurisdictions. Although researchers have studied the performance of LID BMPs in countries experiencing cold winter climates, including Norway, Sweden, Canada, and Iceland (Ascione et al. 2013; Khan et al. 2012b; Lucas et al. 2015; Roy-Poirier et al. 2010), there is still a great need for more data to address the uncertainty with LID adoption in these regions.

With urban stormwater reuse an emerging global trend, and an urban community's energy needs strongly connected to its water use (Chhipi-shrestha et al. 2017), stormwater reuse can 
simultaneously provide an alternative source of water and address energy use, greenhouse gas emissions, a community's water footprint, non-point source pollution, and ecosystem management. Various technologies, such as underground storage systems for stormwater reuse and LID BMPs, have already been integrated with urban stormwater reuse systems in Australia and the USA (Chen et al. 2016a). The integration of LID and stormwater reuse offers community planners an opportunity to address water scarcity and non-point source pollution challenges related to increased urbanization. One of the possible challenges to deploying both LID and urban stormwater reuse is the lack of data required for performing a human health risk assessment for urban stormwater reuse (e.g., large ranges or non-existent information on pathogen, metal, and TDS removal via BMPs). Common methods and metrics, such as quantitative microbial risk assessment and disability-adjusted life years, would be difficult to perform and calculate without data related to the human pathogen removal efficiency of BMPs. In the reviewed literature, only 16 studies reported the treatment efficiency of human pathogens (total coliforms, fecal coliforms, and E. coli) for BMPs. Of the 16 studies investigating human pathogens, seven studies were related to rain harvesting.

This literature review specifically targets studies originating from academic sources, $96 \%$ of which are published in peer-reviewed scientific journals and $4 \%$ are from graduate theses. The work presented here is by no means the largest collection of LID BMP performance data. The International Stormwater BMP Database (ISBMPD) contains data for $\sim 560$ standardized performance studies (non-academic) for a larger variety of BMPs and stormwater pollutants. Annual reports and robust summary statistics are produced for the ISBMPD, providing urban stormwater planners with an up-to-date overview of the database's current results. In the most recent annual report from the ISBMPD (Clary et al. 2017), the authors provided four conclusions based on the summary statistics:

1. All evaluated BMPs demonstrated statistically significant reduction in TSS

2. Data related to fecal indicator bacteria data for EPA-recommended fecal indicators remains limited

3. Some BMPs were found to be nutrient pollutant exporters

4. All evaluated BMPs showed statistically significant reduction of total copper, lead and zinc 
It is interesting to note the overlap between the findings of this academic-based review and those of the ISBMPD Summary Statistics Report. The results of this study are generally consistent with the conclusions of the latest annual report, despite using different sets of data.

\subsubsection{Summary of LID BMPs}

In this section, recent academic literature (after the year 2008) related to nine LID BMPs was reviewed to highlight the most-commonly investigated pollutants and ranges in treatment performance for 21 parameters. A frequency analysis of the reviewed parameters showed that TSS, $\mathrm{TP}$, TN, runoff reduction, and $\mathrm{Zn}$ were the most frequently investigated stormwater runoff parameters. Nonparametric statistics were created from the reviewed literature and large ranges in BMP treatment efficiencies were highlighted. The work completed in this section involved compiling existing recent data and revealed that temporal, geographic, and design factors result in significant variations in BMP treatment performance. As BMPs are dynamic systems, often incorporating their own small ecosystems, their effectiveness is dependent on stormwater runoff quality, climate, seasonality, soil conditions, as well as their design and maintenance practices. To address these variations in performance, researchers should address uncertainty for all processes (stormwater runoff quality, weather patterns, seasonality, treatment efficiencies, and maintenance) into stormwater infrastructure planning models.

Based on a lack of consistency in investigated stormwater quality parameters, there is a need to identify key parameters for BMP pollutant monitoring activities across the globe to promote knowledge sharing and deployment of results for urban stormwater regulators and planners.

\subsection{Stormwater management planning frameworks and tools}

\subsubsection{Introduction}

\subsubsection{Impacts of increasing urbanization}

According to the United Nations, $54 \%$ of the world's population lives in urban areas. This number has increased sharply from 1950, when only 30\% lived in urban areas, and is expected to grow to $66 \%$ by the year 2050 (United Nations 2014). With the expansion of urban areas increasing at an average rate twice that of urban population growth, the Intergovernmental Panel on Climate Change (IPCC) predicts that increases to urban land cover in the first three decades of the $21^{\text {st }}$ century will be greater than the cumulative urban expansion in all anthropogenic history, with some estimates predicting increases up to $310 \%$ (Seto et al. 2014). Although urban centres only account for roughly $5 \%$ of the Earth's landmass, heavily-urbanized areas exert immense pressure 
on natural environments, and can accelerate environmental degradation (Scientific and Technical Advisory Panel of the Global Environment Facility 2014). Given the prevailing containment paradigm for urban planning (i.e., greater urban density to fight urban sprawl) (Angel et al. 2011), built environments across the globe will continue to increasingly affect their surrounding natural environments.

One of the greatest impacts of increased urbanization culminates in the form of changes to a drainage basin's natural water cycle and water balance. Urbanized basins can be distinguished from natural drainage basins by their relatively small size, modified boundaries (enforced through artificial drainage systems and land slopes), a large proportion of impervious areas, relatively low overland roughness, and presence of an artificial system of channels and collectors (Olechnowicz and Weinerowska-Bords 2014). As a result, the processes dominating the water cycle in natural drainage basins, such as interception, evapotranspiration, infiltration, and natural surface retention, are reduced, ultimately producing greater volumes of stormwater runoff (Olechnowicz and Weinerowska-Bords 2014). The increase of direct conversion from rainfall to runoff attributed to urbanization can also result in increased runoff speeds, runoff intensities, and decreased lag times, resulting in urban flooding, stream channel scouring and erosion, and increased pollutant transportation to receiving water bodies (Rhea et al. 2015; Zhang et al. 2017).

Nonpoint source pollution (NPS) is distinguished from point source pollution (e.g., industrial and sewage treatment plants) by the many diffuse sources of pollutants. NPS is attributed to the natural and human-made pollutants transported by rainfall or snowmelt travelling over and through the ground (Chen et al. 2018; USEPA 2016a). The fate of NPS pollutants is often to be discharged into surface water bodies and groundwater (USEPA 2016a). In the United States alone, roughly 215 million people (70\% of the population) live within two miles of a polluted surface water body, with $80-85 \%$ of these impaired water bodies attributed to NPS pollution (USEPA 2016a). Urban NPS pollution is capable of deteriorating the water quality of surface and ground waters, and can result in eutrophication, toxicity, destruction of natural habitats, and decreased source quality for drinking water (Al Bakri et al. 2008; Chen et al. 2018; Zhang et al. 2017).

Along with impacts to a drainage basin associated with increased development of urbanized areas, growing populations in urban environments also withdraw increasing amounts of water from ground and surface waters for anthropogenic activities (Domene and Saur1 2006). Increases to consumption and use of water resources combined with the stresses placed on these resources by 
urban NPS pollution can result in water scarcity (OECD 2015). The Organization for Economic Co-operation and Development (OECD) defines water scarcity as "the management of four water risks: scarcity, floods, pollution, and freshwater ecosystem resilience." (OECD 2013) The OECD predicts that by 2150 , over $40 \%$ of the world's population will live under severe water stress (OECD 2013).

\subsubsection{Modern stormwater management strategies}

The proper management of urban stormwater runoff has the unique ability to affect each of the four water risks of water scarcity (scarcity, floods, pollution, and freshwater ecosystem resilience). In recent years, low impact development (LID), a set of best management practices (BMPs) that are employed to manage urban stormwater in terms of both quantity and quality, has been adopted by land developers and planners across the world to manage urban stormwater runoff. The intent of LID is to mimic a site's natural hydrology with the incorporation of features that induce natural stormwater infiltration, evapotranspiration, and runoff processes (USEPA 2017b), by creating a "functionally equivalent hydrologic landscape" (U.S. Environmental Protection Agency 2000). Ultimately, the focus of LID is on decreasing impervious areas and maintaining natural environments in urbanized areas (Fletcher et al. 2015). Low impact development is often regarded as a more sustainable solution for stormwater management in urban areas as opposed to traditional impervious urban drainage systems (Qin et al. 2013). Traditional urban stormwater infrastructure generally consists of detention, retention, and conveyance-based infrastructure (Maniquiz et al. 2010). LID provides opportunities to address water scarcity risks related to flooding (via stormwater runoff volume reduction), pollution (via increased stormwater urban stormwater runoff quality), and freshwater ecosystem resilience (via reduced pollutant transport to receiving surface and groundwater sources). Previous research has identified difficulties in quantifying the benefits provided by green infrastructure (Wild et al. 2017), but the adoption of LID BMPs has proven to be worthwhile to cities and developers time and time again (Olechnowicz and Weinerowska-Bords 2014; Rhea et al. 2015).

As another means of addressing the water scarcity risks outlined by the OECD, stormwater capture, treatment, and reuse is being increasingly adopted across the globe. Unlike LID, stormwater reuse (SWR) has the potential to address all four types of water scarcity risks outlined by the OECD (scarcity, flooding, pollution, and freshwater ecosystem resilience). SWR is a new phenomenon in urban stormwater planning that has been triggered by long-term droughts and 
chronic water scarcity across the globe. Stormwater is seen by some as the last untapped source of potentially useable water (Chong et al. 2013). Modern literature offers examples of SWR schemes in Australia, Japan, the United States, Europe, and the Middle East (Chen et al. 2016b). The United States Environmental Protection Agency (USEPA) has identified several forward-thinking communities in water-limited regions that have recognized that green stormwater infrastructure (including SWR) is a viable and cost-effective approach to stormwater management despite their limited annual precipitation (USEPA 2009). Modern SWR schemes in North America have been adopted at both community and regional scales and have been used to provide supplemental nonpotable water, irrigation water, and groundwater recharge (National Academies of Sciences 2016). With an urban community's energy needs strongly connected to its water use (Chhipi-shrestha et al. 2017; Government of Canada 2017a), SWR can simultaneously provide an alternative source of water and address energy use, greenhouse gas emissions, a community's water footprint, NPS pollution, human health, and ecosystem management.

\subsubsection{Climate Change}

To further exacerbate the previously outlined dilemmas, urban stormwater management planners must consider that climates across the globe are changing, and with this change comes a diverse range in possible scenarios for future precipitation patterns. The IPCC predicts that it is very likely that extreme precipitation events will become more intense and more frequent in many regions across the globe throughout the $21^{\text {st }}$ century (IPCC 2014). The risks associated with these more frequent and intense events are compounded in heavily developed urban areas, with increased risk to people, assets, economies, and ecosystems (IPCC 2014). These predicted changes in precipitation have forced forward-thinking urban planners to adopt climate change into their decision-making frameworks (Abebe et al. 2018). Figure 2-12 outlines the predicted global change in average precipitation between 1986-2005 and 2081-2100 for representative concentration pathways (RCP) 2.6 and 8.5 scenarios.

\subsubsection{Existing decision support tools for stormwater management}

When developing a community's stormwater management plan, decision makers must first address the drivers (scarcity, floods, pollution, and freshwater ecosystem resilience) for management system selection. The importance of these four drivers play a role not only in the details of the selected management strategy, but these often-conflicting drivers (National Academies of Sciences 2016) can result in planners choosing to go with either a LID or SWR-based strategy during the 
project planning phase. The currently available tools do not offer a robust method to help decision makers in deciding between LID, SWR, or a mix of both management systems when developing a community's urban stormwater management plan.

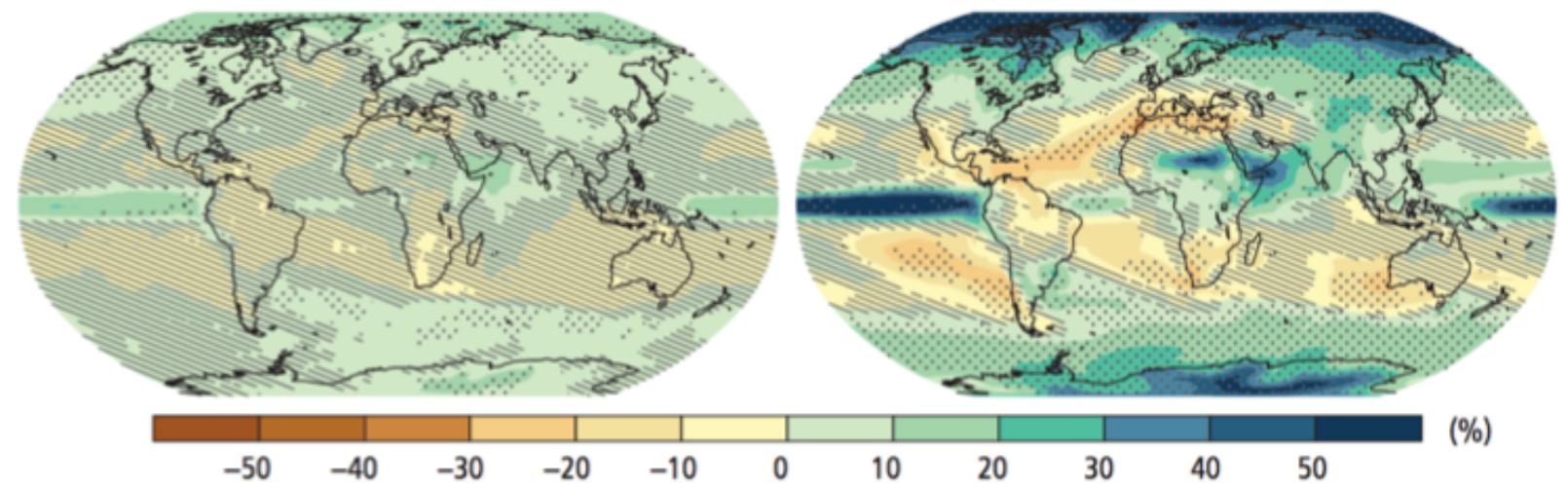

Figure 2-12: Change in average precipitation based on multi-model mean projections for 2081-2100 relative to 1986-2005 under the representative concentration pathway $(R C P) 2.6$ (left) and $R C P 8.5$ (right) scenarios. Dotted areas represent regions where the projected change is large compared to natural internal variability and at least $90 \%$ of models agree on the sign of change. Diagonal lines represent regions where the projected change is less than one standard deviation of the natural internal variability. Taken from (IPCC 2014).

Planners are equipped with several software tools to aid in the design of urban stormwater systems and management plans. Individually, these tools are capable of simulating multiple stormwater management technologies, including: LID BMPs, traditional stormwater infrastructure, and stormwater reuse infrastructure. Most of the existing software has been developed to estimate urban stormwater runoff and evaluate stormwater infrastructure performance from a water quantity and/or quality point of view (Morales-Torres et al. 2016a). Morales-Torres et al. (2016) completed a review of available frameworks and software tools to compare capabilities with $\mathrm{E}^{2} \mathrm{Stormed}$, a decision support tool that incorporates the energy efficiency and environmental criteria in the urban stormwater management decision-making process. The authors compared the available tools and frameworks in terms of: hydraulic performance (both quantity and quality); estimates of ecosystem services; estimates of costs, energy consumption, and $\mathrm{CO}_{2}$ emissions; flood protection, rainwater harvesting, and building insulation potential; multi-criteria decision analysis capabilities; and the quality of the graphical user interface and ease of use/interpretation. The authors identified a lack of integration between stormwater infrastructure and energy infrastructure planning tools and thus created $E^{2}$ Stormed. Although Morales-Torres et al.'s (2016) review is 
comprehensive and fit for their research, the compared software/frameworks and their capabilities are not relevant to this research, thus a review and comparison of available stormwater planning tools more relevant to this research was conducted.

The USEPA's Storm Water Management Model (SWMM) (USEPA 2018a) is a hydrologyhydraulic water quality simulation model. SWMM can produce both single-event or long-term (continuous) simulations of urban stormwater runoff quantity and quality. Stormwater runoff calculations operate in terms of sub-catchment areas that receive precipitation and generate runoff and associated pollutant loads. SWMM tracks flow rates, flow depths, and quality of water throughout the designed system during simulations made of multiple time steps. SWMM can model the impacts of various LID BMPs and can estimate the pollutant loads associated with stormwater runoff. SWMM can be used by planners and designers with extensive knowledge of urban stormwater infrastructure engineering.

The USEPA's National Stormwater Calculator (NSC) (USEPA 2018b) is a software application capable of estimating annual rainwater volumes and frequency of runoff from a specific site. Estimates are based on local soil conditions, land cover, and historic rainfall records. The NSC is designed to be used by anyone interested in reducing runoff from a property, including: site developers, landscape architects, urban planners, and homeowners. The NSC is most appropriate for completing a screening level analysis of small footprint sites (up to several dozen acres in size) with uniform soil conditions. NSC's primary focus is for informing site developers and property owners on how well they can meet a desired stormwater retention target.

The main objective of the MED Programme's E2STORMED (Morales-Torres et al. 2016b) decision support tool is to include energy efficiency and environmental criteria in urban stormwater management planning, promoting innovative sustainable solutions. ${ }^{2}$ STORMED quantifies the economic costs, savings, energy consumption, and $\mathrm{CO}_{2}$ emissions of different drainage scenarios and compares them using a multi-criteria decision analysis. $E^{2}$ STORMED was originally designed for stormwater management planners in Mediterranean countries but the data inputs can be manipulated to function in other regions, as long as the impacts of snow accumulation are not to be considered.

The LID Treatment Train Tool (TTT) (LSRCA 2016), developed by the Lake Simcoe Region Conservation Authority, Credit Valley, and Toronto and Region Conservation Authorities, and powered by the USEPA SWMM5 engine, assesses runoff volume control targets, and pollutant 
reduction targets (TSS and TP) for annual and event-based scenarios. The LID TTT also provides users with a preliminary water balance analysis (i.e., surface evapotranspiration, infiltration, surface runoff). The LID TTT was created to help developers, consultants, municipalities and landowners better understand, plan, and implement sustainable stormwater management practices. The USEPA contracted with Tetra Tech to develop the System for Urban Stormwater Treatment and Analysis Integration (SUSTAIN) watershed-scale decision-support system (Lee et al. 2012a). The SUSTAIN model provides process-based simulations of flow and pollutant behavior for a wide range of structural drainage systems. It is focused on stormwater water quality processes but is also capable of infrastructure cost estimates. SUSTAIN is intended to support the decision making of users who have a fundamental understanding of watershed and BMP modeling processes (Lee et al. 2012a).

The Diagnostic Decision Support System (DDSS) (Wang et al. 2017) was developed by a group of researchers from the University of Maryland to identify and locate the most critical NPS pollution areas within a watershed at a high spatial resolution. The DDSS provides a series of spatially distributed small-scale BMPs to treat NPS. The DDSS includes three components: a hotspots identifier; a diagnostic expert system; and a prescriptive expert system. The DDSS allows researchers and policy makers to achieve a better understanding of urban watershed hydrology and the most effective BMPs for a given watershed.

To compare the capabilities of existing stormwater infrastructure planning tools relevant to the proposed OWSWPF, the outlined available tools and frameworks are compared (Table 2-6) in terms of the following categories: hydraulic performance evaluation; types of stormwater infrastructure; climate change forecasting; uncertainty analysis; cost estimating; multi-criteria decision making (MCDM); life cycle costing; ease of use; optimization capabilities; and geographic area of use.

\subsubsection{Summary of existing tools and frameworks}

To address the challenges outlined in this chapter and fill in the knowledge gaps in current urban stormwater planning tools, the One Water StormWater Planning Framework (OWSWPF) is proposed. The OWSWPF provides urban stormwater planners with a project planning framework to identify the most cost-effective stormwater management plan to reduce a community's stormwater footprint. The key to providing decision makers with a holistic decision support framework for community-level stormwater management plans lies in the integration of the one 
water approach and a community's stormwater footprint. The OWSWPF takes a multi-criteria, multi-period approach to account for many of the uncertainties in stormwater planning, including: precipitation patterns, climate change, and cost estimating.

Table 2-6: Summary of features of existing urban stormwater decision support tools and frameworks.

\begin{tabular}{|c|c|c|c|c|c|c|c|}
\hline & $\begin{array}{l}\text { USEPA } \\
\text { SWMM }\end{array}$ & $\begin{array}{l}\text { USEPA } \\
\text { NSC }\end{array}$ & $\mathrm{E}^{2}$ Stormed & $\begin{array}{l}\text { LID } \\
\text { TTT }\end{array}$ & $\begin{array}{c}\text { USEPA } \\
\text { SUSTAIN }\end{array}$ & DDSS & OWSWPF \\
\hline \multicolumn{8}{|c|}{ Hydraulic Performance Evaluation } \\
\hline Quantity & $\checkmark$ & $\checkmark$ & $\checkmark$ & $\checkmark$ & $\checkmark$ & $\checkmark$ & $\checkmark$ \\
\hline Quality & $\checkmark$ & $x$ & $\checkmark$ & $\checkmark$ & $\checkmark$ & $\checkmark$ & $\checkmark$ \\
\hline Snow-water equivalent & $\checkmark$ & $x$ & $x$ & $\checkmark$ & $\checkmark$ & $x$ & $\checkmark$ \\
\hline \multicolumn{8}{|c|}{ Stormwater Infrastructure } \\
\hline LID & $\checkmark$ & $\checkmark$ & $\checkmark$ & $\checkmark$ & $\checkmark$ & $\checkmark$ & $\checkmark$ \\
\hline SW Reuse & $\checkmark$ & $x$ & $\checkmark$ & $x$ & $x$ & $x$ & $\checkmark$ \\
\hline Traditional & $\checkmark$ & $x$ & \multicolumn{4}{|c|}{ Climate Change } & $x$ \\
\hline Various RCP Scenarios & $x$ & $x$ & $x$ & $x$ & $x$ & $x$ & $\checkmark$ \\
\hline Factor/percent change & \multicolumn{6}{|c|}{ Cost Estimating } & $x$ \\
\hline LCC & $x$ & $x$ & $\checkmark$ & $x$ & $x$ & $x$ & $\checkmark$ \\
\hline Capital & $x$ & $\checkmark$ & $\checkmark$ & $x$ & $\checkmark$ & $x$ & $\checkmark$ \\
\hline $\begin{array}{l}\text { Operation and } \\
\text { maintenance }\end{array}$ & $x$ & $\checkmark$ & $\checkmark$ & $x$ & $\checkmark$ & $x$ & $\checkmark$ \\
\hline \multicolumn{8}{|c|}{ Uncertainty } \\
\hline Precipitation & $\checkmark$ & $x$ & $x$ & $x$ & $x$ & $x$ & $\checkmark$ \\
\hline Climate change & $x$ & $x$ & $x$ & $x$ & $x$ & $x$ & $\checkmark$ \\
\hline LCC costs & $x$ & $x$ & $x$ & $x$ & $x$ & $x$ & $\checkmark$ \\
\hline \multicolumn{8}{|c|}{ Multi-Criteria Decision Making } \\
\hline Crisp values & $x$ & $x$ & $\checkmark$ & $x$ & $\checkmark$ & $x$ & $x$ \\
\hline Fuzzy values & $x$ & $x$ & $x$ & $x$ & $x$ & $x$ & $\checkmark$ \\
\hline $\begin{array}{l}\text { Integration with other } \\
\text { water utilities (one water } \\
\text { approach) }\end{array}$ & $x$ & $x$ & $\checkmark$ & $x$ & $x$ & $x$ & $\checkmark$ \\
\hline Energy simulation & $x$ & $x$ & $\begin{array}{l}\checkmark \\
\text { Ease of Us }\end{array}$ & $x$ & $x$ & $x$ & $x$ \\
\hline $\begin{array}{l}\text { Functional with limited } \\
\text { data }\end{array}$ & $x$ & $\checkmark$ & $\checkmark$ & $x$ & $x$ & $x$ & $\checkmark$ \\
\hline $\begin{array}{l}\text { Does not require } \\
\text { advanced knowledge }\end{array}$ & $x$ & $\checkmark$ & $\checkmark$ & $x$ & $x$ & $x$ & $\checkmark$ \\
\hline \multicolumn{8}{|c|}{ Optimization Capabilities } \\
\hline Optimization algorithm & $x$ & $x$ & $x$ & $x$ & $\checkmark$ & $x$ & $\checkmark$ \\
\hline $\begin{array}{l}\text { Functional unit for } \\
\text { optimization }\end{array}$ & N/A & $\mathrm{N} / \mathrm{A}$ & N/A & N/A & $\begin{array}{l}\text { User-defined } \\
\text { criteria }\end{array}$ & N/A & $\begin{array}{l}\text { Community water } \\
\text { footprint; life cycle } \\
\text { costs }\end{array}$ \\
\hline Geographic extent & Global & USA & $\begin{array}{c}\text { Other } \\
\text { Mediterranean }\end{array}$ & Canada & USA & USA & Canada \\
\hline
\end{tabular}




\section{ONE WATER STORMWATER PLANNING FRAMEWORK}

\subsection{Proposed Framework}

Based on the knowledge gaps identified in Section 2 of Chapter 2 of this thesis, a new stormwater management planning framework was developed. The framework has been dubbed the One Water StormWater Planning Framework (OWSWPF). This chapter outlines the development of the OWSWPF.

\subsubsection{An overview}

Based on the OECD's definition of water availability, Canada is home to multiple catchment areas under severe water stress, i.e., where more than $40 \%$ of available freshwater is being used for anthropogenic activities (Government of Canada 2017b). Although various technologies, such as underground storage systems and LID BMPs, have already been integrated with urban SWR systems in parts of Australia and the USA (Chen et al. 2016b), these technologies have yet to be integrated with SWR systems in Canada. With large Canadian cities like Vancouver developing integrated rainwater managements plans that treat rain as a resource as opposed to a liability (City of Vancouver 2018), Canadian stormwater planners require effective frameworks to help them identify the optimal mix between LID, SWR, and traditional stormwater infrastructure.

The main objective of the OWSWPF is to provide urban developers, community planners, and regulators with an integrated solution to identifying the optimal mix of stormwater infrastructure during the planning stages of development of an urban community. The OWSWPF offers users the ability to identify the various stormwater management technologies and their relative sizes (e.g., volume, areal coverage, penetration) that best meet the needs of the proposed community given certain geographic, climatic, and economic limitations. The OWSWPF was specifically designed with the needs of Canadian urban stormwater planners in mind and therefore, each step in the methodology is supported by Canadian-specific data and examples. A high-level description of the OWSWPF methodology is outlined in this paper (Figure 3-1).

\subsubsection{Data requirements}

To address the fact that project planners are often plagued with data limitations, the OWSWPF relies on easy-to-acquire data that a community planner or developer would have during the project planning phase. The required inputs are divided into three categories: community specifications; 


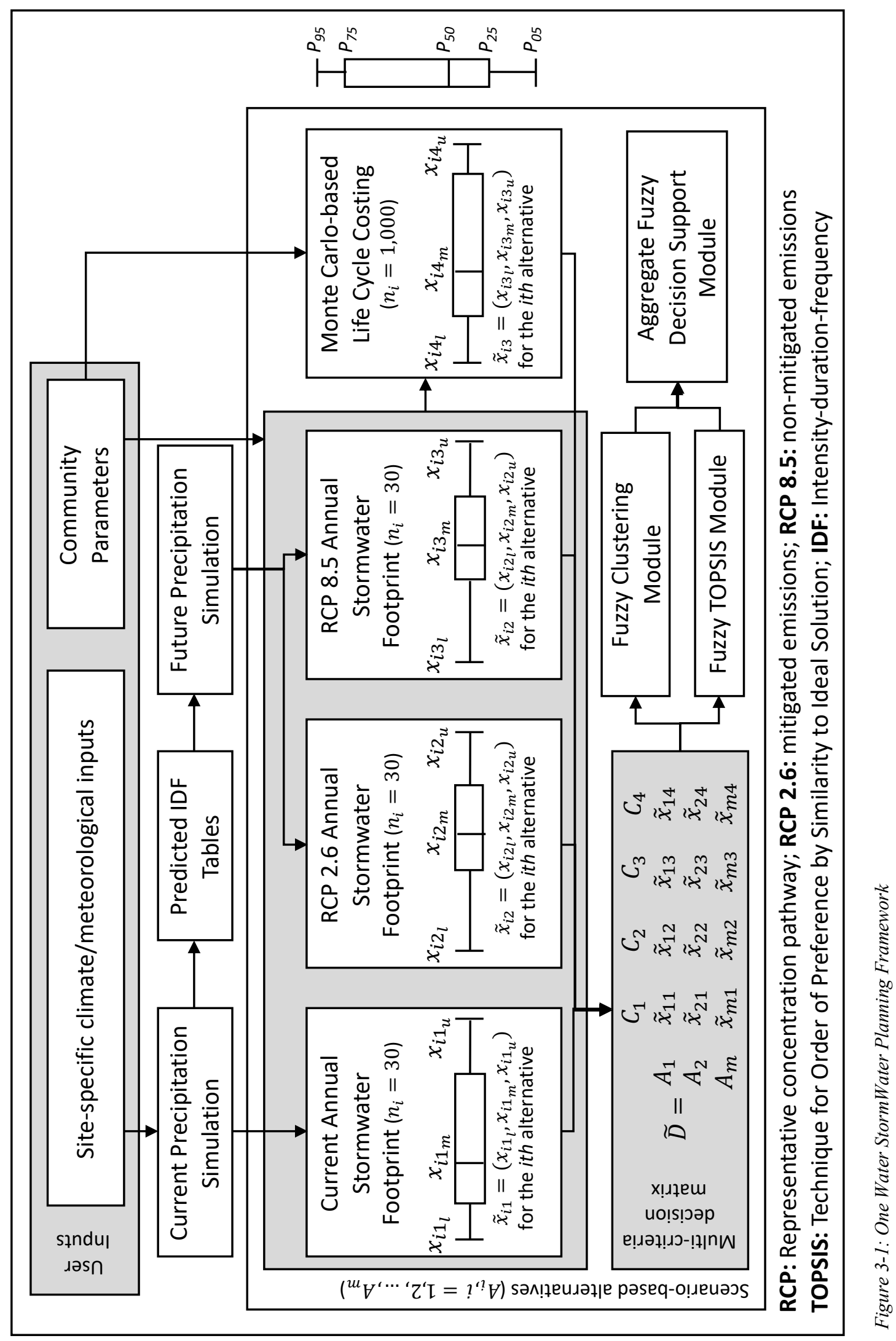


Table 3-1: Outline of user-defined variables

\begin{tabular}{|c|c|c|c|}
\hline \multicolumn{2}{|c|}{ Community inputs } & \multicolumn{2}{|c|}{ Pre-development inputs } \\
\hline $\begin{array}{l}\text { User-defined control } \\
\text { variable }\end{array}$ & Unit & $\begin{array}{l}\text { User-defined observed } \\
\text { variables }\end{array}$ & Unit \\
\hline $\begin{array}{l}\text { Total areal size of } \\
\text { community }\end{array}$ & Hectares & Land cover description & $\begin{array}{l}\text { Cover type; based } \\
\text { on (USDA 1986) }\end{array}$ \\
\hline $\begin{array}{l}\text { Community residential lot } \\
\text { coverage }\end{array}$ & $\%$ & Average grade & $\begin{array}{l}\text { Flat }\left(<2^{\circ}\right) \text {; Average } \\
\left(2^{\circ}-7^{\circ}\right) \text {; Steep }\left(>7^{\circ}\right)\end{array}$ \\
\hline $\begin{array}{l}\text { Community surface waters } \\
\text { (excluding BMPs) coverage }\end{array}$ & $\%$ & \multicolumn{2}{|c|}{ Residential lot inputs } \\
\hline $\begin{array}{l}\text { Community roadways and } \\
\text { walkways coverage }\end{array}$ & $\%$ & $\begin{array}{l}\text { User-defined control } \\
\text { variable }\end{array}$ & Unit \\
\hline $\begin{array}{l}\text { Community parking lot } \\
\text { coverage }\end{array}$ & $\%$ & $\begin{array}{l}\text { Number of residential } \\
\text { lots }\end{array}$ & Integer \\
\hline $\begin{array}{l}\text { Community commercial } \\
\text { area coverage }\end{array}$ & $\%$ & $\begin{array}{l}\text { Percent of lots covered } \\
\text { in buildings }\end{array}$ & $\%$ \\
\hline $\begin{array}{l}\text { Community green space } \\
\text { coverage }\end{array}$ & $\%$ & $\begin{array}{l}\text { Percent of lots covered } \\
\text { in impermeable } \\
\text { surfaces }\end{array}$ & $\%$ \\
\hline $\begin{array}{l}\text { Percent of green spaces } \\
\text { available for water-based } \\
\text { infrastructure }\end{array}$ & $\%$ & $\begin{array}{l}\text { Percent of lot covered } \\
\text { in lawns/gardens }\end{array}$ & $\%$ \\
\hline $\begin{array}{l}\text { Community Stormwater } \\
\text { Reuse Volume Profile }\end{array}$ & Litres/day/month & $\begin{array}{l}\text { Average rain harvesting } \\
\text { volume }\end{array}$ & Litres \\
\hline $\begin{array}{l}\text { User-defined observed } \\
\text { variables }\end{array}$ & Unit & $\begin{array}{l}\text { Number of dry days } \\
\text { before watering lawn }\end{array}$ & Days \\
\hline Soil type & $\begin{array}{l}\text { USDA Soil Texture } \\
\text { Classification }\end{array}$ & $\begin{array}{l}\text { Residential daily water } \\
\text { use }\end{array}$ & $\begin{array}{l}\text { Monthly - } \\
\text { litres/household/ } \\
\text { /day }\end{array}$ \\
\hline \multicolumn{2}{|c|}{ Commercial lot inputs } & \multicolumn{2}{|c|}{ Runoff capture and distribution inputs } \\
\hline $\begin{array}{l}\text { User-defined control } \\
\text { variable }\end{array}$ & Unit & $\begin{array}{l}\text { User-defined control } \\
\text { variable }\end{array}$ & Unit \\
\hline $\begin{array}{l}\text { Number of commercial } \\
\text { units }\end{array}$ & Integer & $\begin{array}{l}\text { Percent of post-lot } \\
\text { runoff directed to } \\
\text { streets/walkways }\end{array}$ & $\%$ \\
\hline $\begin{array}{l}\text { Percent of lots covered in } \\
\text { buildings }\end{array}$ & $\%$ & $\begin{array}{l}\text { Percent of post-lot } \\
\text { runoff directed directly } \\
\text { to sewers }\end{array}$ & $\%$ \\
\hline $\begin{array}{l}\text { Percent of lots covered in } \\
\text { impermeable surfaces }\end{array}$ & $\%$ & $\begin{array}{l}\text { Percent of pretreatment } \\
\text { train runoff directed to } \\
\text { constructed stormwater } \\
\text { wetland }\end{array}$ & $\%$ \\
\hline Commercial daily water use & $\begin{array}{l}\text { Monthly - } \\
\text { litres/business/day }\end{array}$ & $\begin{array}{l}\text { Percent of pretreatment } \\
\text { train runoff directed to } \\
\text { stormwater reuse } \\
\text { scheme }\end{array}$ & $\%$ \\
\hline
\end{tabular}

site-specific meteorological and climate statistics; and BMP and SWR control parameters. These three categories can be further subdivided into control variables; observed variables; and decision variables (Table 3-1). Moreover, Figure 3-2 is a graphical representation of the assumed runoff treatment train for all modeled infrastructure scenarios.

The OWSWPF also requires a number of observed and predicted inputs in terms of climate and meteorological inputs. The OWSWPF relies on open-source data to provide site-specific climate 
and metrological inputs. This data is made freely available by government-funded agencies and is specific to a given site. Historical weather data and projected average precipitation changes data are made available by Environment and Climate Change Canada (Environment and Climate Change Canada 2018). Historical and projected site-specific intensity-duration-frequency (IDF) curves are made available by the Institute for Catastrophic Loss Reduction of Western University in London, Ontario (Simonovic et al. 2018). Table 3-2 outlines the data sources for the required user inputs. The data from these sources are used to drive the equations outlined in Section 3.1.3 of this paper.

The inputs related to BMP and stormwater reuse control parameters are used to drive the stormwater runoff simulations integrated within the OWSWPF. The stormwater runoff simulation is further explained in Section 3.1.3 of this paper. Table 3-3 outlines the control variables for LID BMPs and SWR schemes.

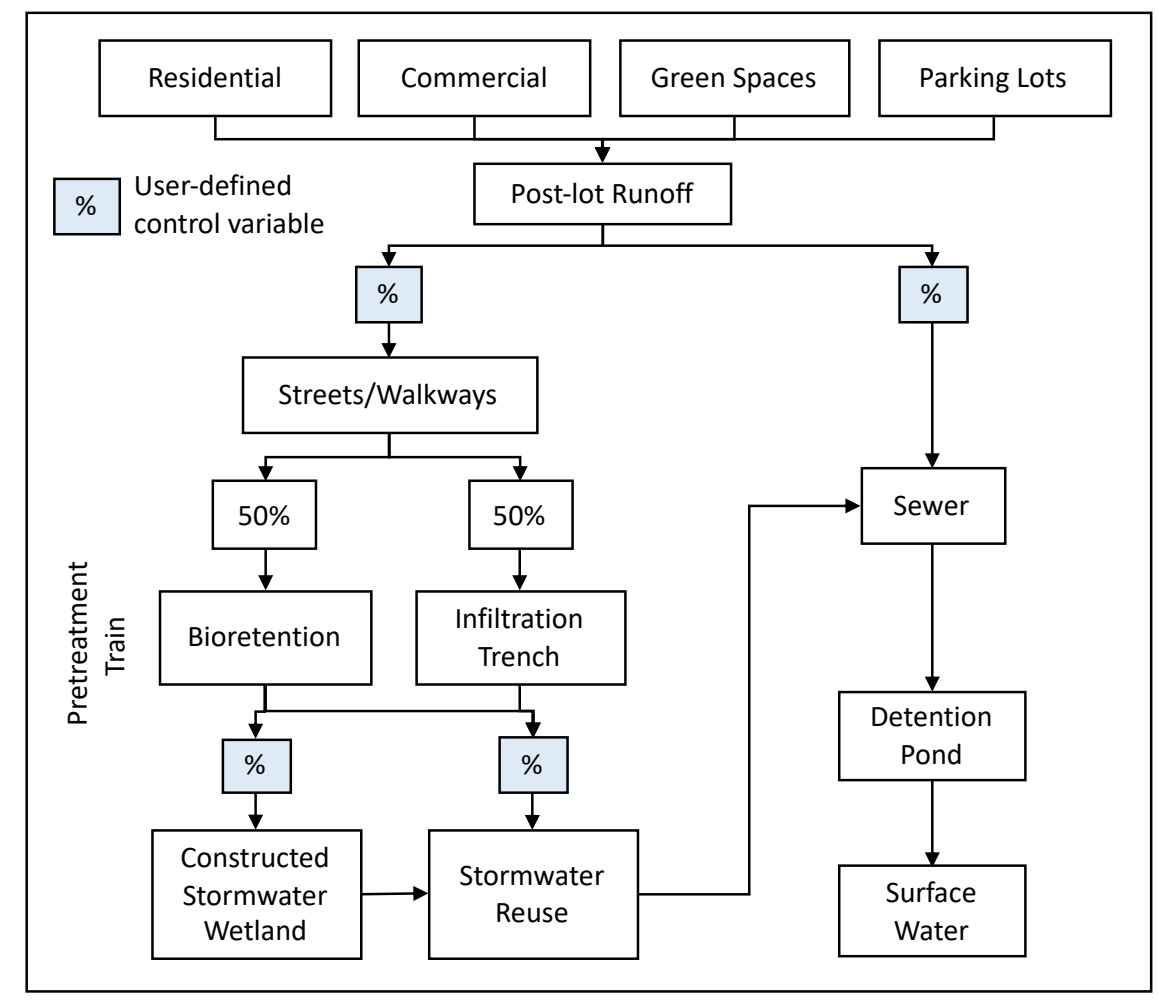

Figure 3-2: Graphical representation of assumed runoff treatment train for the OWSWPF.

\subsubsection{Runoff, evapotranspiration, and infiltration models}

The OWSWPF relies on the on the Soil Conservation Service (SCS) curve number method (USDA 1986) for estimating runoff. The United States Department of Agriculture (USDA) continues to 
promote this method for the use of estimating stormwater runoff. Equation 3-1outlines the curve number method for calculating runoff in an undeveloped area.

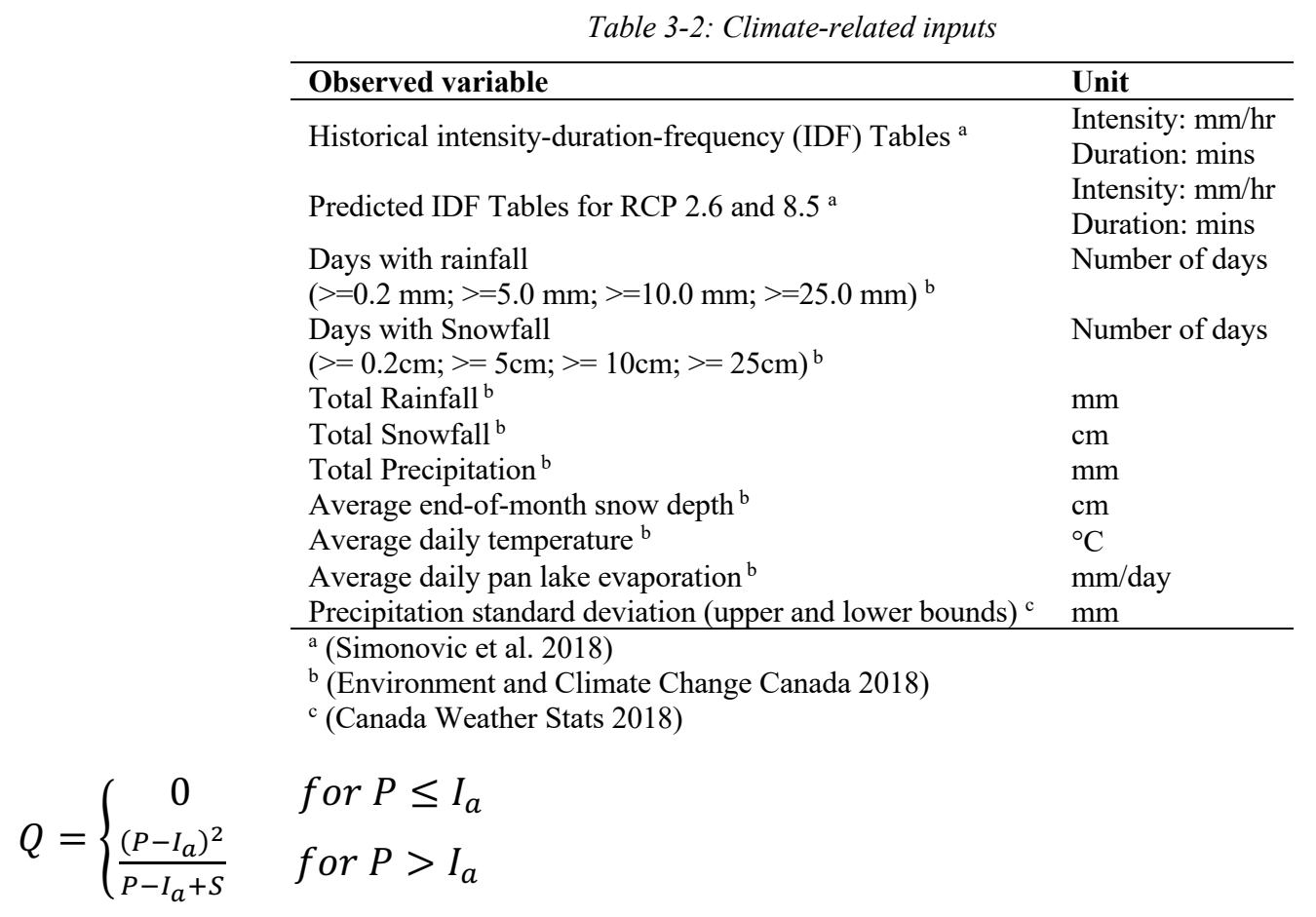

Equation 3-1

where $Q$ is runoff $(\mathrm{mm}), P$ is the precipitation depth $(\mathrm{mm}), S$ is the potential maximum soil moisture retention after runoff begins (mm) (Equation 3-2), and $I_{a}$ is the initial abstraction (mm) (calculated as $0.2 S$ ).

$$
S=\frac{1000}{C N}-10
$$

where $C N$ is the curve number. Curve numbers for undeveloped areas are based on the predevelopment land cover description defined by the user. Table 3-4 outlines the curve numbers associated with various types of pre-development land cover (USDA 1986). Equation 3-3 outlines the curve number method for calculating runoff in an urbanized area.

$$
Q=\left\{\begin{array}{cc}
0 & \text { for } P \leq 0.05 S \\
\frac{\left(P-0.05 S_{0.05}\right)^{2}}{P+0.95 S_{0.05}+S} & \text { for } P>0.05 S
\end{array}\right.
$$

Equation 3-3

where $Q$ is runoff $(\mathrm{mm}), P$ is the precipitation depth $(\mathrm{mm})$, and $S_{0.05}$ is the potential maximum soil moisture retention after runoff begins $(\mathrm{mm})$ - corrected for urban developments based on (Lim et al. 2006). $S_{0.05}$ is directly related to curve number $(\mathrm{CN})$ and is calculated using the $\mathrm{CN}$ values from Table 3-5, Equation 3-4, and Equation 3-5. 
$S_{0.20}=\frac{1000}{C N}-10$

Equation 3-5

Table 3-3: Best management practice and stormwater reuse control variables

\begin{tabular}{|c|c|c|c|c|c|}
\hline \multicolumn{2}{|l|}{ Permeable pavement systems } & \multicolumn{2}{|l|}{ Infiltration trenches } & \multicolumn{2}{|l|}{ Green Roofs } \\
\hline Parameter & Unit & Parameter & Unit & Parameter & Unit \\
\hline Maximum time to drain & hours & Maximum time to drain & hours & $\begin{array}{l}\text { Percentage of green roofs } \\
\text { composed of traditional roof }\end{array}$ & $\%$ \\
\hline $\begin{array}{l}\text { Subbase reservoir void } \\
\text { fraction* }\end{array}$ & $\begin{array}{l}\text { volume } \\
\text { faction - } \\
\text { unitless }\end{array}$ & $\begin{array}{l}\text { Maximum storage layer } \\
\text { thickness* }\end{array}$ & $\mathrm{mm}$ & Soil layer thickness* & $\mathrm{mm}$ \\
\hline \multirow[t]{3}{*}{$\begin{array}{l}\text { Percent of impermeable } \\
\text { pavement directed to } \\
\text { permeable pavement }\end{array}$} & $\%$ & $\begin{array}{l}\text { Storage layer void } \\
\text { fraction* }\end{array}$ & $\begin{array}{l}\text { volume } \\
\text { faction - } \\
\text { unitless }\end{array}$ & Soil Porosity* & $\begin{array}{l}\text { volume ratio - } \\
\text { unitless }\end{array}$ \\
\hline & & & & Wilting point* & $\begin{array}{l}\text { volume ratio - } \\
\text { unitless }\end{array}$ \\
\hline & & & & Field capacity* & $\begin{array}{l}\text { volume ratio - } \\
\text { unitless }\end{array}$ \\
\hline \multicolumn{2}{|l|}{ Assumption } & \multicolumn{2}{|l|}{ Assumption } & \multicolumn{2}{|l|}{ Assumption } \\
\hline \multicolumn{2}{|c|}{$\begin{array}{l}\text { PPS surface functionality is equivalent to } \\
\text { other impermeable surfaces (e.g., } \\
\text { traditional pavement) }\end{array}$} & \multicolumn{2}{|l|}{-} & \multicolumn{2}{|c|}{$\begin{array}{l}\text { Irrigation is initiated once soil moisture reaches } \\
\text { wilting point. }\end{array}$} \\
\hline \multicolumn{2}{|l|}{ Bioretention cells } & \multicolumn{2}{|l|}{ Rain Harvesting } & \multicolumn{2}{|c|}{ Constructed Stormwater Wetland } \\
\hline Parameter & Unit & Parameter & Unit & Parameter & Unit \\
\hline Maximum time to drain & hours & $\begin{array}{l}\text { Average size of rain } \\
\text { barrels }\end{array}$ & Litre & Permanent pool requirements & $\mathrm{m}^{3} / \mathrm{ha}$ \\
\hline Soil layer thickness* & $\mathrm{mm}$ & $\begin{array}{l}\text { Monthly average daily } \\
\text { rain barrel water use }\end{array}$ & Litre & Maximum outflow rate & $\mathrm{m}^{3} / \mathrm{s} / \mathrm{ha}$ \\
\hline Soil porosity* & $\begin{array}{l}\text { volume } \\
\text { ratio - } \\
\text { unitless }\end{array}$ & & & & \\
\hline $\begin{array}{l}\text { Maximum storage layer } \\
\text { thickness }\end{array}$ & $\mathrm{mm}$ & & & & \\
\hline Storage layer void fraction* & $\begin{array}{l}\text { volume } \\
\text { ratio - } \\
\text { unitless }\end{array}$ & & & & \\
\hline Soil layer wilting point* & $\begin{array}{l}\text { volume } \\
\text { ratio - } \\
\text { unitless }\end{array}$ & & & & \\
\hline Soil layer field capacity* & $\begin{array}{l}\text { volume } \\
\text { ratio - } \\
\text { unitless }\end{array}$ & & & & \\
\hline \multicolumn{2}{|l|}{ Assumption } & \multicolumn{2}{|l|}{ Assumption } & \multicolumn{2}{|l|}{ Assumption } \\
\hline \multicolumn{2}{|c|}{$\begin{array}{l}\text { Irrigation is initiated once soil moisture } \\
\text { reaches wilting point. }\end{array}$} & \multicolumn{2}{|c|}{$\begin{array}{l}\text { Rain barrels are drained and not used } \\
\text { during months with average daily } \\
\text { temperatures below } 0^{\circ} \mathrm{C} \text {. }\end{array}$} & \multicolumn{2}{|c|}{$\begin{array}{l}\text { Permanent pool sized based on catchment area } \\
\text { of inflow. Maximum outflow rate based on } \\
\text { calculated permanent pool area. }\end{array}$} \\
\hline \multicolumn{2}{|c|}{ Community Stormwater reuse } & \multicolumn{2}{|l|}{ Detention Pond Sizing } & & \\
\hline Parameter & Unit & Parameter & Unit & & \\
\hline \multirow[t]{4}{*}{$\begin{array}{l}\text { Monthly reuse volume } \\
\text { profile }\end{array}$} & L/day & $\begin{array}{l}\text { Maximum drawdown } \\
\text { time }\end{array}$ & hours & & \\
\hline & & Storm depth for sizing & $\mathrm{mm}$ & & \\
\hline & & Maximum outflow rate & $\mathrm{m}^{3} / \mathrm{s} / \mathrm{ha}$ & & \\
\hline & & Maximum depth & $\mathrm{m}$ & & \\
\hline \multirow{2}{*}{\multicolumn{2}{|c|}{$\begin{array}{l}\text { Assumption } \\
\text { Community has procured a client for } \\
\text { stormwater reuse volumes }\end{array}$}} & \multicolumn{2}{|l|}{ Assumption } & & \\
\hline & & - & & & \\
\hline
\end{tabular}


Table 3-4: Runoff curve numbers for undeveloped areas.

\begin{tabular}{|c|c|c|c|c|c|}
\hline \multirow{2}{*}{ Cover Description } & & \multicolumn{4}{|c|}{ Curve numbers for hydrologic soil group } \\
\hline & & A & $\mathrm{B}$ & $\mathrm{C}$ & $\mathrm{D}$ \\
\hline \multirow{3}{*}{ Pasture, grassland, or range - continuous forage for grazing a } & Poor & 68 & 79 & 86 & 89 \\
\hline & Fair & 49 & 69 & 79 & 84 \\
\hline & Good & 39 & 61 & 74 & 80 \\
\hline $\begin{array}{l}\text { Meadow - continuous grass, protected from grazing and generally } \\
\text { mowed for hay }\end{array}$ & - & 30 & 58 & 71 & 78 \\
\hline \multirow[b]{2}{*}{ Brush - brush-weed-grass mixture with brush as the major element ${ }^{b}$} & Poor & 48 & 67 & 77 & 83 \\
\hline & Fair & 35 & 56 & 70 & 77 \\
\hline & Good & $30^{\mathrm{c}}$ & 48 & 65 & 73 \\
\hline \multirow{3}{*}{ Woods - grass combination (orchard or tree farm) ${ }^{d}$} & Poor & 57 & 73 & 82 & 86 \\
\hline & Fair & 43 & 65 & 76 & 82 \\
\hline & Good & 32 & 58 & 72 & 79 \\
\hline \multirow{3}{*}{ Woods ${ }^{\mathrm{e}}$} & Poor & 45 & 66 & 77 & 83 \\
\hline & Fair & 36 & 60 & 73 & 79 \\
\hline & Good & 30 & 55 & 70 & 77 \\
\hline Farmsteads - buildings, lanes, driveways, and surrounding lots & - & 59 & 74 & 82 & 86 \\
\hline
\end{tabular}

a) Poor: $<50 \%$ ground cover or heavily grazed with no mulch; Fair: 50-75\% ground cover and not heavily grazed; Good: $>75 \%$ ground cover and light or only occasionally grazed.

b) Poor: $<50 \%$ ground cover; Fair: 50-75\% ground cover; Good: $>75 \%$ ground cover.

c) Actual curve number is less than 30 ; use $\mathrm{CN}=30$ for runoff computation.

d) CN's shown were computed for areas with 50\% woods and 50\% grass (pasture) cover. Other combinations of conditions may be computed from the CN's for woods and pasture.

e) Poor: Forest litter, small trees, and brush are destroyed by heavy grazing or regular burning; Fair: Woods are grazed but not burned, and some forest litter covers the soil; Good: Woods are protected from grazing, and litter and brush adequately cover the soil.

Table 3-5: Runoff curve numbers for urban areas

\begin{tabular}{|c|c|c|c|c|c|}
\hline & \multirow[t]{2}{*}{ Cover Description } & \multicolumn{4}{|c|}{$\begin{array}{l}\text { Curve numbers for } \\
\text { hydrologic soil group }\end{array}$} \\
\hline & & $\mathrm{A}$ & $\mathrm{B}$ & $\mathrm{C}$ & $\mathrm{D}$ \\
\hline \multirow{3}{*}{$\begin{array}{l}\text { Open space (lawns, parks, golf } \\
\text { courses, cemeteries, etc.) }\end{array}$} & Poor condition (grass cover $<50 \%$ ) & 68 & 79 & 86 & 89 \\
\hline & Fair condition (grass cover 50 to $75 \%$ ) & 49 & 69 & 79 & 84 \\
\hline & Good condition (grass cover $>75 \%$ ) & 39 & 61 & 74 & 80 \\
\hline Impervious areas & $\begin{array}{r}\text { Paved parking lots, roofs, driveways, etc. (excluding right- } \\
\text { of-way) }\end{array}$ & 98 & 98 & 98 & 98 \\
\hline \multirow{4}{*}{ Street and roads } & Paved; curbs and storm sewers (excluding right-of-way) & 98 & 98 & 98 & 98 \\
\hline & Paved; open ditches (including right-of-way) & 83 & 89 & 92 & 93 \\
\hline & Gravel (including right-of-way) & 76 & 85 & 89 & 91 \\
\hline & Dirt (including right-of-way) & 27 & 82 & 87 & 89 \\
\hline \multirow[b]{2}{*}{ Western desert urban areas } & Natural desert landscaping (pervious area only) & 63 & 77 & 85 & 88 \\
\hline & $\begin{array}{r}\text { Artificial desert landscaping (impervious weed barrier, } \\
\text { desert shrub with 1-2 inch sand or gravel mulch and basin } \\
\text { borders) }\end{array}$ & 96 & 96 & 96 & 96 \\
\hline \multirow{4}{*}{ Urban districts } & Commercial and business ( $85 \%$ imp.) & 89 & 92 & 94 & 96 \\
\hline & Industrial ( $72 \%$ imp.) & 81 & 88 & 91 & 93 \\
\hline & $1 / 8$ acre or less (town houses) ( $65 \%$ imp.) & 77 & 85 & 90 & 92 \\
\hline & $1 / 4$ acre $(38 \%$ imp.) & 61 & 75 & 83 & 87 \\
\hline Residential districts by average & $1 / 3$ acre $(30 \%$ imp. $)$ & 57 & 72 & 81 & 86 \\
\hline \multirow[t]{3}{*}{ lot size } & $1 / 2$ acre $(25 \% \mathrm{imp})$. & 54 & 70 & 80 & 85 \\
\hline & 1 acre $(20 \%$ imp.) & 51 & 68 & 79 & 84 \\
\hline & 2 acres ( $12 \%$ imp.) & 46 & 65 & 77 & 82 \\
\hline
\end{tabular}

Taken from United States Department of Agriculture's Urban Hydrology for Small Watersheds (TR-55) (USDA 1986) The Blaney-Criddle method was used to estimate evapotranspiration from all green spaces for each time step (daily). The Blaney-Criddle method is a simplistic latitude and temperature-based 
estimation of daily evapotranspiration. The Food and Agriculture Organization of the United States uses the Blaney-Criddle method to provide broadly accurate (orders of magnitude) estimates for evapotranspiration (Food and Agriculture Organization of the United States n.d.). The method relies on limited data - daily average air temperature and the mean daily percentage of annual sunshine hours based on latitude, as seen in Equation 3-6:

$$
E T_{o}=p\left(0.46 T_{\text {avg }}+8\right)
$$

Equation 3-6

where $E T_{o}$ is the reference crop evapotranspiration (mm/day) average for the month, $p$ is the mean daily percentage of annual daytime hours for the month (Table 3-6), and $T_{a v g}$ is the mean daily temperature $\left({ }^{\circ} \mathrm{C}\right)$ for the month.

Pan lake evaporation $\left(\mathrm{mm} / \mathrm{day} / \mathrm{m}^{2}\right)$ is used to calculate evaporation from surface water bodies (e.g., lakes, constructed stormwater wetlands, detention facilities).

For non-BMP surfaces (e.g., lawns, parks, roadways), infiltration is equal to the rainfall volume minus evapotranspirated volumes, and runoff volumes, daily infiltration values can be calculated (Equation 3-7).

$$
I=P-E V T-Q
$$

where $I$ is the infiltration $(\mathrm{mm}), P$ is precipitation $(\mathrm{mm}), E V T$ is the evapotranspiration $(\mathrm{mm})$ (calculated using the evapotranspiration estimation module), and $Q$ is runoff $(\mathrm{mm})$.

The daily infiltration rates of the BMPs containing an infiltration component are calculated based on the defined soil texture classification (Table 3-7). The relationships between hydrologic soil groups, soil texture classifications, and infiltration rates are outlined in Table 3-7.

Table 3-6: Mean daily percentage of annual daytime hours for the month based on latitude

\begin{tabular}{lllllllllllll}
\hline Latitude $\left({ }^{\circ}\right.$ North) & Jan & Feb & Mar & Apr & May & Jun & Jul & Aug & Sept & Oct & Nov & Dec \\
\hline 60 & 0.15 & 0.2 & 0.26 & 0.32 & 0.38 & 0.41 & 0.4 & 0.34 & 0.28 & 0.22 & 0.17 & 0.13 \\
50 & 0.19 & 0.23 & 0.27 & 0.31 & 0.34 & 0.36 & 0.35 & 0.32 & 0.28 & 0.24 & 0.2 & 0.18 \\
40 & 0.22 & 0.24 & 0.27 & 0.3 & 0.32 & 0.34 & 0.33 & 0.31 & 0.28 & 0.25 & 0.22 & 0.21 \\
35 & 0.23 & 0.25 & 0.27 & 0.29 & 0.31 & 0.32 & 0.32 & 0.3 & 0.28 & 0.25 & 0.23 & 0.22 \\
30 & 0.24 & 0.25 & 0.27 & 0.29 & 0.31 & 0.32 & 0.31 & 0.3 & 0.28 & 0.26 & 0.24 & 0.23 \\
25 & 0.24 & 0.26 & 0.27 & 0.29 & 0.3 & 0.31 & 0.31 & 0.29 & 0.28 & 0.26 & 0.25 & 0.24 \\
20 & 0.25 & 0.26 & 0.27 & 0.28 & 0.29 & 0.3 & 0.3 & 0.29 & 0.28 & 0.26 & 0.25 & 0.25 \\
15 & 0.26 & 0.26 & 0.27 & 0.28 & 0.29 & 0.29 & 0.29 & 0.28 & 0.28 & 0.27 & 0.26 & 0.25 \\
10 & 0.26 & 0.27 & 0.27 & 0.28 & 0.28 & 0.29 & 0.29 & 0.28 & 0.28 & 0.27 & 0.26 & 0.26 \\
0 & 0.27 & 0.27 & 0.27 & 0.27 & 0.27 & 0.27 & 0.27 & 0.27 & 0.27 & 0.27 & 0.27 & 0.27 \\
\hline
\end{tabular}

Taken from (Food and Agriculture Organization of the United States n.d.) 
Table 3-7: Relationships of soil texture classification, infiltration rate, and soil group type.

\begin{tabular}{lll}
\hline Hydrologic soil group & Soil Texture Classification & Infiltration rate (mm/hour) \\
\hline A & gravel & 41.4 \\
& sandy gravel & 41.4 \\
& silty gravels & 41.4 \\
& sand & 20.3 \\
& loamy sand & 20.3 \\
& sandy loam & 20.3 \\
B & loam & 7.6 \\
& silty loam & 7.6 \\
C & sandy clay loam & 5.1 \\
D & clay loam & 1.5 \\
& silty clay loam & 1.5 \\
& sandy clay & 1.5 \\
& silty clay & 1.5 \\
& clay & 1.5 \\
\hline Hydrologic soil group info from (Minnesota Environment and Natural Resources Trust Fund \\
2013). Infiltration rate info from (Minnesota Pollution Control Agency 2018a).
\end{tabular}

\subsubsection{Meteorology and climate change modules}

The OWSWPF accounts for uncertainty due to both aleatoric and epistemic uncertainty. System parameters contributing to aleatoric uncertainty are those related to meteorology and climate. The first step of the OWSWPF is to produce the required annual daily precipitation simulations, given past precipitation statistics. These precipitation simulations are later used to drive the water balance models. The precipitation simulations rely on historical monthly probabilities of precipitation $(\mathrm{mm})$ and end-of-month snow pack $(\mathrm{cm})$ to simulate runoff volumes. Snow-water equivalent (SWE) data are created using one of two methods: by dividing the measured amount of snow $(\mathrm{cm})$ by 10 (ordinary stations); or by melting the snow that falls into the measurement gauges to calculate a correction factor (primary stations) (Government of Canada 2018a). As a result, snow water equivalent (SWE) volumes are calculated using Equation 3-8.

$$
S W E f_{i}=\frac{P_{i}-R_{i}}{S_{i} \times 10 \frac{\mathrm{mm}}{\mathrm{cm}}}
$$

where $S W E f_{i}$ is the SWE correction factor for month $i, P_{i}$ is the historical monthly precipitation average for month $i$ in $\mathrm{mm}, R_{i}$ is the historical monthly rainfall average for month $i$ in $\mathrm{mm}$, and $S_{i}$ is the historical monthly precipitation average for month $i$ in $\mathrm{cm}$. 
An iterative algorithm generates 30 annual runoff simulations with a daily temporal scale. Each annual precipitation simulation is validated with historical precipitation norms to ensure that the simulated year's precipitation falls within reason for the given location (i.e., the sum of differences between simulated monthly precipitation and historical monthly precipitation values for the entire year is no greater than a defined cutoff; and the standard deviation of the monthly differences is no greater than a separate defined cutoff). These cutoffs can be adjusted to account for inter- and intra-monthly variability between simulated and observed precipitation values.

In total, the OWSWPF simulates urban runoff for a total of 10,950 days (365 $\frac{\text { days }}{\text { year }} x 30$ years), ultimately amounting to a type of Monte Carlo simulation. With more than 10,000 simulated days, it is assumed that variability in historical precipitation patterns is captured and uncertainty due to aleatoric variability is considered for historical runoff volumes. For each simulated runoff event, a return period (years) and duration (minutes) is identified based on empirical IDF tables. These return period and duration values are the key to performing the predicted climate change runoff simulations.

To develop adaptation and mitigation strategies, many researchers and decision makers have relied on evaluation of the impacts of climate chang using general circulation models (GCMs) based on alternative future scenarios (O’Neill et al. 2016). These mathematical climate models are driven by the physical principles that govern the circulation of a planet's atmosphere and oceans. To project future climate change, GCMs rely on representative concentration pathways (RCPs), a range of possibilites in future anthropogenic greenhouse gas emissions, measured in terms of $\mathrm{CO}_{2}$ equivalents. The atmospheric greenhouse gas concentrations are then converted to increases in the radiative forces of the earth's atmosphere (watts $/ \mathrm{m}^{2}$ ). Two of the most common RCP scenarios are RCP 2.6 and RCP 8.5, representing an increase in atmospheric radiative forces of 2.6 and 8.5 watts $/ \mathrm{m}^{2}$ respectively. The RCP 2.6 scenario represents a stringent emissions reduction scenario, and RCP 8.5 represents a scenario with essentially unmitigated GHG emissions (IPCC 2014). The IDF_CC Tool 3.0 (Simonovic et al. 2018) created by the Institute for Catastrophic Loss Reduction at Western University is capable of generating local IDF curve information that accounts for the possible impacts of climate change. The IDF_CC tool relies on a user-friendly GIS interface and provides precipitation accumulation depths for a variety of return periods $(2,5$, 10, 25, 50 and 100 years) and durations (5, 10, 15 and 30 minutes and 1, 2, 6, 12 and 24 hours), thus allowing users to generate both historical and future total precipitation IDF curves. The 
IDF_CC tool allows users to select from multiple RCP scenarios and apply results from a selection 24 GCMs and nine downscaled GCMs that simulate various future climate conditions.

The Government of Canada has made available a series of maps showing quarterly changes in precipitation and snow thickness under RCP scenarios 2.6, 4.5, and 8.5 (Government of Canada 2017c). These maps are computed from the multi-model ensemble of the Coupled Model Intercomparison Project Phase 5 (CMIP5). Using the predicted IDF tables and the predicted changes to rainfall, snowfall, and snowpack, daily precipitation values are then modified for all 30 years of simulated runoff for RCP 2.6 and RCP 8.5 for the specific location of the proposed urban development.

\subsubsection{Life cycle costing module}

The OWSWPF accounts for epistemic uncertainty based on the outputs of a life cycle costing (LCC) Monte Carlo simulation. Upper and lower limits for capital costs, operation and maintenance costs, time to rehabilitation, rehabilitation costs, and decommissioning costs for each Table 3-8: Upper and lower bounds for driving the Monte Carlo-based LCC module.

\begin{tabular}{|c|c|c|c|c|c|c|c|c|c|c|c|}
\hline & \multirow[b]{2}{*}{$\begin{array}{l}\text { Infrastructure } \\
\text { component }\end{array}$} & \multicolumn{2}{|c|}{ Capital Costs } & \multicolumn{2}{|c|}{$\begin{array}{c}\text { Annual } \\
\text { Operation and } \\
\text { Maintenance } \\
\text { Costs }\end{array}$} & \multicolumn{2}{|c|}{$\begin{array}{l}\text { Rehabilitation } \\
\text { Costs }\end{array}$} & \multicolumn{2}{|c|}{$\begin{array}{c}\text { Time to } \\
\text { Rehabilitation } \\
\text { (years) }\end{array}$} & \multicolumn{2}{|c|}{$\begin{array}{c}\text { Decommissioning } \\
\text { Costs (as \% of } \\
\text { Capital costs) }\end{array}$} \\
\hline & & Low & High & Low & High & Low & High & Low & High & Low & High \\
\hline \multirow{2}{*}{ 索总 } & $\begin{array}{ll}\text { Green } & \text { Roofs } \\
\left(\$ / \mathrm{m}^{2}\right) & \end{array}$ & 34.08 & 172.98 & 0.89 & 1.16 & 63.27 & 214.78 & 36 & 44 & 31.5 & 38.5 \\
\hline & $\begin{array}{l}\text { Rain Barrels } \\
(\$ / L)\end{array}$ & 0.29 & 1.13 & 0.00 & 0.10 & 0.29 & 1.13 & 18 & 22 & 0.0 & 0.0 \\
\hline \multirow[b]{2}{*}{ 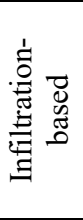 } & Permeable & 16.68 & 73.75 & 0.38 & 0.87 & 47.64 & 58.22 & 27 & 33 & 31.5 & 38.5 \\
\hline & $\begin{array}{l}\text { Pavement } \\
\left(\$ / \mathrm{m}^{2}\right) \\
\text { Infiltration } \\
\text { Trenches } \\
\left(\$ / \mathrm{m}^{2}\right)\end{array}$ & 310.82 & 513.25 & 0.84 & 14.39 & $242.44^{*}$ & $400.34^{*}$ & 27 & 33 & 31.5 & 38.5 \\
\hline \multirow{5}{*}{ 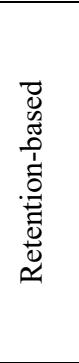 } & Bioretention & 71.36 & 366.83 & 8.36 & 17.19 & 59.72 & 73.00 & 22.5 & 27.5 & 35.1 & 42.9 \\
\hline & $\begin{array}{l}\text { Cells } \\
\left(\$ / \mathrm{m}^{2}\right)\end{array}$ & & & & & & & & & & \\
\hline & $\begin{array}{l}\text { Constructed } \\
\text { Stormwater }\end{array}$ & 30.20 & 36.92 & 0.09 & 1.08 & 23.56 & 28.80 & 45 & 55 & 34.2 & 41.8 \\
\hline & $\begin{array}{l}\text { Wetlands } \\
\left(\$ / \mathrm{m}^{2}\right)\end{array}$ & & & & & & & & & & \\
\hline & $\begin{array}{l}\text { Stormwater } \\
\text { Reuse } \\
\left(\$ / \mathrm{m}^{3}\right)\end{array}$ & 270.00 & $2,361.32$ & 20.00 & 37.17 & $268.60^{*}$ & $328.28^{*}$ & 20 & 50 & 31.5 & 38.5 \\
\hline 莺 & $\begin{array}{l}\text { Detention } \\
\text { Basin } \\
\left(\$ / \mathrm{m}^{2}\right)\end{array}$ & 34.58 & 42.26 & 0.53 & 0.84 & $26.97^{*}$ & $32.96^{*}$ & 45 & 55 & 31.5 & 38.5 \\
\hline
\end{tabular}

\footnotetext{
Note: All values are in 2018 CAD. Values are adjusted by converting into 2018 values and then converting to CAD.
}

* Based on $78 \%$ of capital costs. Same ratio of rehab/capital costs of permeable pavement. 
system component are used to account for epistemic uncertainty intrinsic in calculating life cycle costs. Default upper and lower bounds for driving the LCC Monte Carlo Simulation are outlined in Table 3-8.

For each infrastructure scenario, the OWSWPF produces 1,000 LCC simulations for 50 years. This expected service life is based on the mid value of the oldest of the top-three age categories for stormwater infrastructure as per the 2016 Canadian Infrastructure Report Card (Canadian Society of Civil Engineers 2016). All costs are converted to net present costs (NPC) to ensure meaningful comparison (Equation 3-9).

$$
N P C_{j}=\left(\sum_{t=1}^{n} \frac{N C O_{t}}{(1+r)^{t}}\right)-\text { Initial Investment }
$$

where $N P C_{j}$ is the NPC for the $j t h$ infrastructure scenario in dollars, $t$ is the time in years, $N C O_{t}$ is the net cash outflow for year $t, r$ is the discount or interest rate, and $n$ is the anticipated service life of the infrastructure in years. The initial investment is calculated as the sum of the capital costs of all stormwater infrastructure components covered under the scope of the LCC module. It is important to note that the value of the reusable stormwater is considered as a component of the annual operation and maintenance costs for the SWR schemes (Furlong et al. 2017).

As the OWSWPF is a planning framework, there are several design specifications that are not available to planners at this stage, most notably, the detailed design of the storm sewer conveyance system. To address this lack of data, the scope of the LCCs are in terms of additional modifications that can be added to a baseline system consisting of conveyance components (e.g., pipes). The infrastructure components and life cycle phases included in the scope of the LCC module are outlined in Table 3-8.

\subsubsection{BMP and stormwater reuse models}

Green roofs, permeable pavement systems, bioretention cells, infiltration trenches, rain barrels, SWR schemes rely on simple volume-based models for calculating runoff, storage, infiltration, and evapotranspiration. Table 3-9 outlines the volume-based BMPs and their components. Figure 3-3 provides a schematic representation of a bioretention cell (the only BMP containing all four components). 
Table 3-9: Outline of volume-based BMP components

\begin{tabular}{lcccc}
\hline BMP & Surface layer & Soil layer & Storage layer & Infiltration surface \\
\hline Green roof & $x$ & $\checkmark$ & $\checkmark$ & $x$ \\
Permeable pavement system & $x$ & $x$ & $\checkmark$ & $\checkmark$ \\
Bioretention cell & $\checkmark$ & $\checkmark$ & $\checkmark$ & $\checkmark$ \\
Infiltration trench & $\checkmark$ & $x$ & $\checkmark$ & $x$ \\
Rain barrels* & $x$ & $x$ & $\checkmark$ & $x$ \\
Stormwater reuse scheme & $x$ & \multicolumn{2}{c}{. }
\end{tabular}

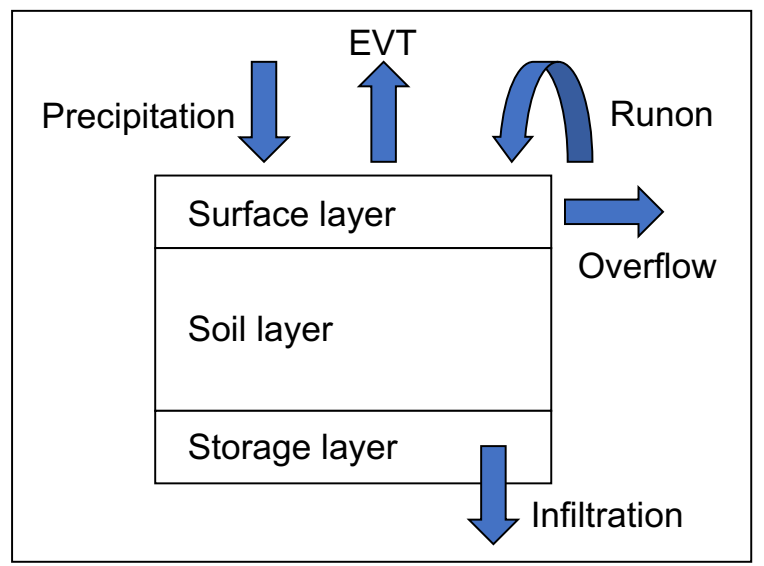

Figure 3-3: Bioretention cell schematic showing water inflows and outflows

Storage layers are sized based on a user-defined maximum drainage time. The maximum drainage time is then used to calculate the storage reservoir volume based on the daily infiltration rate of the selected soil type (Equation 3-10).

$$
V=A f t \emptyset
$$

Equation 3-10

where $V$ is the effective storage volume of the storage layer in $\mathrm{m}^{3}, A$ is the surface area of the infiltration surface in $\mathrm{m}^{2}, f$ is the daily infiltration rate of the soil in $\mathrm{m} /$ day, $t$ is the maximum time to drain in days, and $\varnothing$ is the storage area void fraction.

Daily soil moisture content is updated in BMP soil layers by subtracting daily losses of evapotranspiration (as per Blaney-Criddle) and percolation. The difference between the saturated soil moisture content and the field capacity moisture content is assumed to transferred to the storage unit via percolation after evapotranspiration losses are considered. As per the same assumptions as SWMM, when soil moisture content $(\theta)$ drops below the field capacity moisture level $\left(\theta_{\mathrm{FC}}\right)$, percolation rates becomes zero (USEPA 2016b). 
Constructed stormwater wetland volumes are calculated using a surface area to catchment area method. As outlined by the Minnesota Stormwater Manual (Minnesota Pollution Control Agency 2018b), constructed stormwater wetland volumes are calculated using Equation 3-11.

$$
V_{t s}=V_{p p}+V_{w q}
$$

Equation 3-11

where $V_{t s}$ is the total storage volume of the constructed stormwater wetland $\left(\mathrm{m}^{3}\right), V_{p p}$ is the permanent pool volume $\left(\mathrm{m}^{3}\right)$ (Equation 3-12), and $V_{w q}$ is the water quality volume $\left(\mathrm{m}^{3}\right)$ (Equation 3-13).

$$
\begin{array}{lr}
V_{p p}=\rho A_{d} & \text { Equation 3-12 } \\
V_{w q}=0.062 * A_{\text {imp }} & \text { Equation 3-13 }
\end{array}
$$

where $\rho$ is the permanent pool volume-drainage area ratio $\left(\mathrm{m}^{3} / \mathrm{ha}\right), A_{d}$ is the drainage area (ha), where 0.062 represents $2.5 \mathrm{~cm}$ of runoff for every impervious hectare $(\mathrm{m} / \mathrm{ha})$, and $A_{\text {imp }}$ is the impervious drainage area $\left(\mathrm{m}^{2}\right)$. The default value for $\rho$ is $125.8 \mathrm{~m}^{3} /$ ha (Minnesota Pollution Control Agency 2018b).

Once volumes are calculated, dimensions (surface area and depth) are calculated based on the defined restrictions for available area and minimum/maximum depth of $V_{p p}$ (with default values of $0.9 \mathrm{~m}$ and $3.0 \mathrm{~m}$, respectively). Once sized, the constructed stormwater wetland model consists of a permanent pool and water quality volume. It is assumed that all constructed stormwater wetlands are installed with an impervious liner. Therefore, wetland water losses can only be achieved via evapotranspiration and overflow. A maximum outlet flow rate of $0.3962 \mathrm{~m} 3 / \mathrm{s} / \mathrm{ha}$ of permanent pool volume will not be exceeded (Minnesota Pollution Control Agency 2018b). Daily evapotranspiration is calculated based on historical daily pan lake evaporation values.

\subsubsection{Community Stormwater Footprint}

The International Standards Organization (ISO) developed a standard for water footprinting in 2014 (ISO 14046 2014) (International Organization for Standardardization 2014). The ISO 14046 standard aims at "providing transparency, consistency, and credibility for assessing water footprint and reporting water footprint results of products, processes or organizations" (International Organization for Standardardization 2014). The water footprint assessment should be a comprehensive analysis comprising water availability and water pollution aspects. When calculating a water footprint, if only a single aspect of a more comprehensive life cycle assessment 
analysis is considered, this should be reflected in the name of the study (Berger et al. 2016) (e.g., "community stormwater footprint").

It is common for authors to divide a water footprint into three categories: blue, green, and grey. The following terminology is used to describe blue, green, and grey water in the OWSWPF.

Blue water footprint: The total volume of ground and surface water consumed by the community. Total stormwater reuse volumes and conveyed water volumes are subtracted from total utility water volumes to calculate the total volume of water consumed by the community (Equation 3-14).

$$
B W F=A W U-S W R-C W-I
$$

Equation 3-14

where $B W F$ is the community's annual blue water footprint in $\mathrm{m}^{3}, A W U$ is the community's anthropogenic utility water use in $\mathrm{m}^{3}, S W R$ is the volume of stormwater available for reuse in $\mathrm{m}^{3}$, $C W$ is the volume of conveyed water (i.e., returned to either ground or surface waters) in $\mathrm{m}^{3}$, and $I$ is the volume of infiltrated stormwater in $\mathrm{m}^{3}$.

By accounting for decreases in utility water use, the OWSWPF adopts the one water approach for calculating the community's stormwater footprint. The one water approach is an integrated planning approach for managing all water resources (including stormwater, wastewater, and drinking water) (Paulson et al. 2017). According to the Water Research Foundation, the adoption of a one water-based framework for infrastructure planning can support the effective development of: drinking water supply reliability plans; wastewater and recycled water master plans; climate change adaptation plans; infrastructure resilience plans; and stormwater and green infrastructure management plans (Paulson et al. 2017).

Green water footprint: Volume of water lost to evapotranspiration and rainwater consumed by the flora in the community.

Grey water footprint: Although the water returned to surface and ground water via infiltration and conveyance is subtracted from the blue water footprint volumes, this water is of lesser quality (due to urban stormwater pollution). To reflect this change in quality, the grey water footprint represents a virtual volume of water required to dilute polluted waters to an acceptable quality (Equation 3-15).

$$
G W F=\sum_{i=1}^{m} \sum_{j=1}^{n} \frac{B W F_{i} x[\text { Poll }]_{j}}{B W F_{i} \times\left[\text { Poll limit }_{j}\right.} B W F_{i}
$$


where $G W F$ is the grey water footprint in $\mathrm{m}^{3}, B W F_{i}$ is the blue water footprint for area $i$ in $\mathrm{m}^{3}$, and $[\mathrm{Poll}]_{j}$ is the concentration of pollutant $j$ in the conveyed stormwater in $\mathrm{mg} / \mathrm{L}$, and $\left[\right.$ Poll limit $_{j}$ is the pollutant concentration limit in $\mathrm{mg} / \mathrm{L}$ for pollutant $j$ (i.e., an acceptable pollutant concentration as defined by the user). The community's total stormwater footprint is calculated as a sum of the blue, green, and grey water footprints.

The OWSWPF relies on well-established land-use specific pollutant concentrations to calculate annual pollutant loads (Table 3-10).

Table 3-10: Urban stormwater pollutant concentrations by source area.

\begin{tabular}{|c|c|c|c|c|}
\hline Land Use & TSS & $\mathrm{TN}$ & $\mathrm{TP}$ & $\mathrm{Zn}$ \\
\hline Residential Roof & $19 \mathrm{mg} / \mathrm{L}^{\mathrm{a}}$ & $1.5 \mathrm{mg} / \mathrm{L}^{\mathrm{a}}$ & $0.11 \mathrm{mg} / \mathrm{L}^{\mathrm{a}}$ & $0.312 \mathrm{mg} / \mathrm{L}^{\mathrm{a}}$ \\
\hline Commercial Roof & $9 \mathrm{mg} / \mathrm{L}^{\mathrm{a}}$ & $2.1 \mathrm{mg} / \mathrm{L}^{\mathrm{a}}$ & $0.14 \mathrm{mg} / \mathrm{L}^{\mathrm{a}}$ & $0.256 \mathrm{mg} / \mathrm{L}^{\mathrm{a}}$ \\
\hline Green Roof & $118 \mathrm{mg} / \mathrm{L}^{\mathrm{d}}$ & $3.0 \mathrm{mg} / \mathrm{L}^{\mathrm{c}}$ & $0.5 \mathrm{mg} / \mathrm{L}^{\mathrm{c}}$ & $0.22 \mathrm{mg} / \mathrm{L}^{\mathrm{c}}$ \\
\hline Lawns & $602 \mathrm{mg} / \mathrm{L}^{\mathrm{a}}$ & $9.1 \mathrm{mg} / \mathrm{L}^{\mathrm{a}}$ & $2.1 \mathrm{mg} / \mathrm{L}^{\mathrm{a}}$ & $0.050 \mathrm{mg} / \mathrm{L}^{\mathrm{a}}$ \\
\hline Res Imp Areas & $173 \mathrm{mg} / \mathrm{L}^{\mathrm{a}}$ & $2.1 \mathrm{mg} / \mathrm{L}^{\mathrm{a}}$ & $0.56 \mathrm{mg} / \mathrm{L}^{\mathrm{a}}$ & $0.107 \mathrm{mg} / \mathrm{L}^{\mathrm{a}}$ \\
\hline Commercial Imp Areas & $69 \mathrm{mg} / \mathrm{L}^{\mathrm{b}}$ & $1.9 \mathrm{mg} / \mathrm{L}^{\mathrm{a}}$ & $0.201 \mathrm{mg} / \mathrm{L}^{\mathrm{b}}$ & $0.226 \mathrm{mg} / \mathrm{L}^{\mathrm{b}}$ \\
\hline Parking Lots & $27 \mathrm{mg} / \mathrm{L}^{\mathrm{a}}$ & $1.9 \mathrm{mg} / \mathrm{L}^{\mathrm{a}}$ & $0.15 \mathrm{mg} / \mathrm{L}^{\mathrm{a}}$ & $0.139 \mathrm{mg} / \mathrm{L}^{\mathrm{a}}$ \\
\hline Public Green Spaces & $602 \mathrm{mg} / \mathrm{L}^{\mathrm{a}}$ & $9.1 \mathrm{mg} / \mathrm{L}^{\mathrm{a}}$ & $2.1 \mathrm{mg} / \mathrm{L}^{\mathrm{a}}$ & $0.050 \mathrm{mg} / \mathrm{L}^{\mathrm{a}}$ \\
\hline Roads/Walkways & $172 \mathrm{mg} / \mathrm{L}^{\mathrm{a}}$ & $1.4 \mathrm{mg} / \mathrm{L}^{\mathrm{a}}$ & $0.55 \mathrm{mg} / \mathrm{L}^{\mathrm{a}}$ & $0.173 \mathrm{mg} / \mathrm{L}^{\mathrm{a}}$ \\
\hline
\end{tabular}

LID BMP pollutant reduction concentrations are based on the results of the critical review completed by Hager et al. (2018), i.e., Chapter 2 of this thesis (Table 3-11).

Table 3-11: LID BMP pollutant reduction performance.

\begin{tabular}{ccccc}
\hline BMP & TSS & TN & TP & Zn \\
\hline Permeable Pavement System & $90 \%$ & $37 \%$ & $75 \%$ & $90 \%$ \\
Infiltration Trench/Basin & $85 \%$ & $55 \%$ & $40 \%$ & $90 \%$ \\
Bioretention Cells & $82 \%$ & $35 \%$ & $30 \%$ & $82 \%$ \\
Constructed Stormwater Wetland & $90 \%$ & $53 \%$ & $55 \%$ & $90 \%$ \\
\hline
\end{tabular}

The OWSWPF calculates pollutant loads based on an optimal scenario of $50 \%$ reduction in pollutant loadings from typical residential urban areas. The values in Table 3-12 are 50\% of typical pollutant loadings in runoff from medium-density residential urban areas (USEPA 2016b). The pollutant reduction as a percentage of load per acre-year metric has been adopted by the Toronto 
and Region Conservation Authority, and has been used and promoted for urban planning in Canadian municipalities (Toronto and Region Conservation Authority 2012).

Table 3-12: Pollutant concentration standards.

\begin{tabular}{|c|c|c|c|c|}
\hline Pollutant & TSS & $\mathrm{TN}$ & TP & $\mathrm{Zn}$ \\
\hline Concentration Limit & $107 \mathrm{~kg} / \mathrm{ha}$-year & $2.4 \mathrm{~kg} / \mathrm{ha}$-year* & $0.3 \mathrm{~kg} /$ ha-year & $0.1 \mathrm{~kg} / \mathrm{ha}$-year \\
\hline
\end{tabular}

Figure 3-4 and Figure 3-5 provide a schematic representation of the community stormwater footprint scope of the OWSWPF.

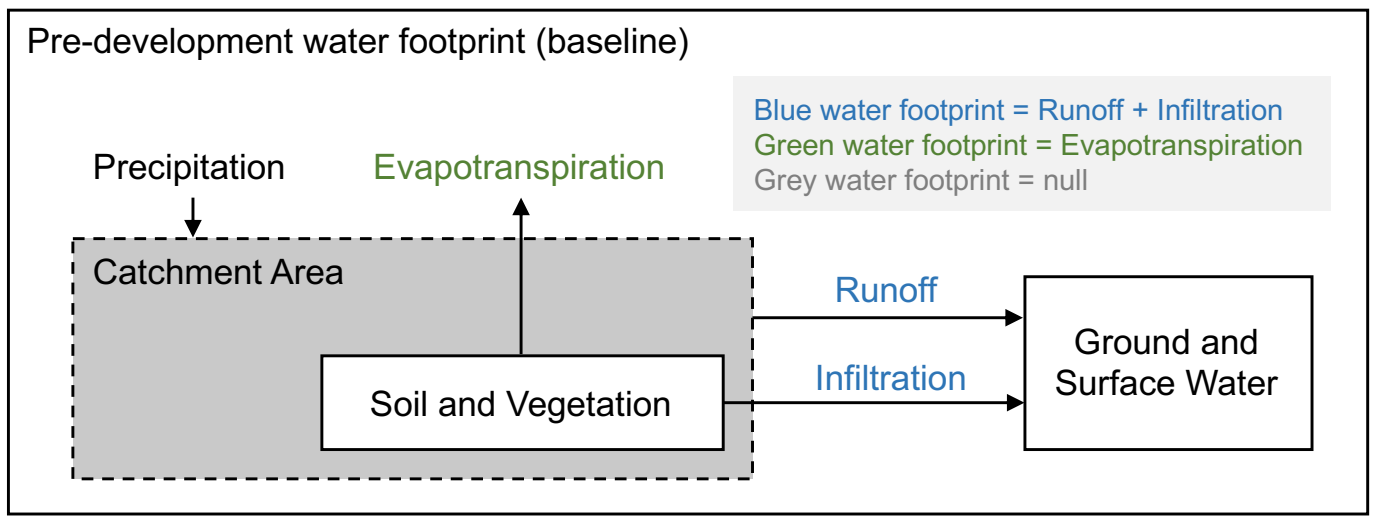

Figure 3-4: OWSWPF scope of pre-development stormwater footprint

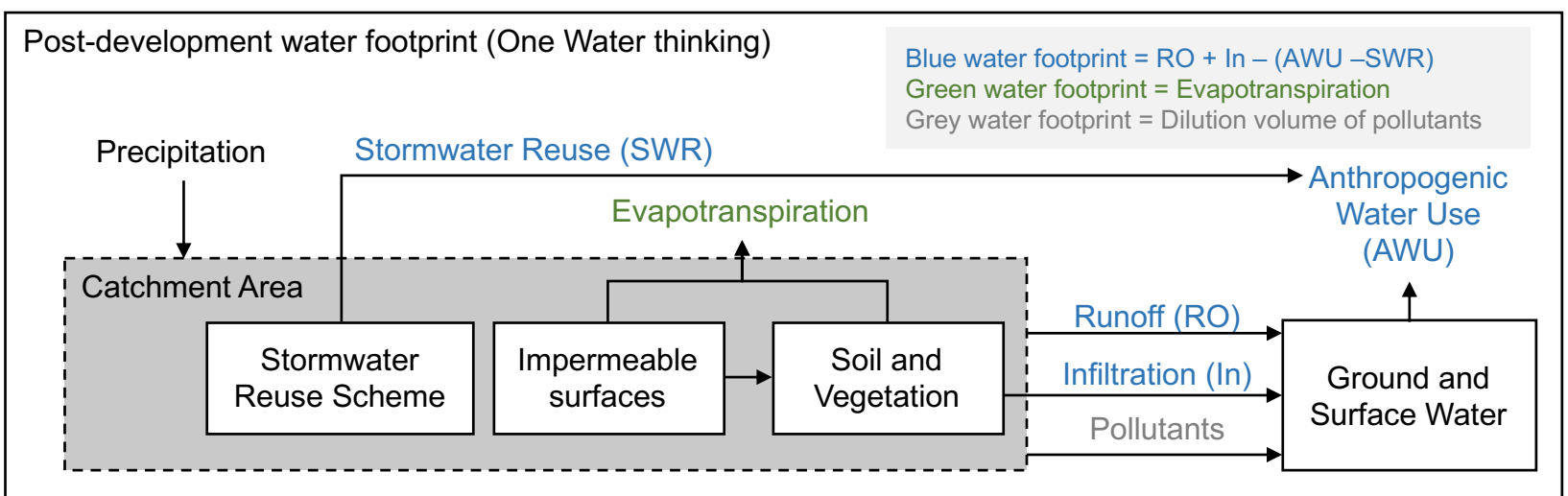

Figure 3-5: OWSWPF scope of post-development stormwater footprint

As a means of accounting for the baseline infiltration, runoff, and evapotranspiration requirements (i.e., environmental flow needs) of the pre-developed land, pre-development stormwater footprints are subtracted from post-development stormwater footprints for each year and scenario (Equation 3-16 to Equation 3-18). 


$$
\begin{aligned}
& B W F_{i j}=B W F_{\text {post }_{i j}}-B W F_{\text {pre }_{j}} \\
& G W F_{i j}=G W F_{\text {post }_{i j}}-G W F_{\text {pre }_{j}} \\
& G y W F_{i j}=G y W F_{\text {post }_{i j}}-G y W F_{\text {pre }_{j}}
\end{aligned}
$$

where $B W F_{i j}$ is the blue water footprint for the $i$ th infrastructure scenario and the $j$ th year, $B W F_{\text {post }_{i j}}$ is the post-development blue water footprint for the $i$ th infrastructure scenario and the $j$ th year, $B W F_{\text {pre }}$ is the pre-development blue water footprint for the $j$ th year, $G W F_{i j}$ is the green water footprint for the $i$ th infrastructure scenario and the $j$ th year, $G W F_{p o s t}$ ij the postdevelopment green water footprint for the $i$ th infrastructure scenario and the $j$ th year, $G W F_{p r e_{j}}$ is the pre-development green water footprint for the $j$ th year, $G y W F_{i j}$ is the grey water footprint for the $i$ th infrastructure scenario and the $j$ th year, $G y W F_{p_{o s t}}$ is the post-development grey water footprint for the $i$ th infrastructure scenario and the $j$ th year, and $G y W F_{\text {pre }_{j}}$ is the pre-development grey water footprint for the $j$ th year.

\subsubsection{Representative stormwater infrastructure scenarios}

The OWSWPF calculates the annual community stormwater footprint and life cycle costs for 35 representative management configurations based on the limitations defined by the user in section 3.1.2. Table 3-14 outlines the decision variables used for each stormwater system component and the values used to define each possible system configuration. The OWSWPF simulates 35 possible system configurations at a daily time resolution for three climate scenarios (historical, RCP 2.6, and RCP 8.5 ) and calculates a community stormwater footprint for each of the 30 simulated years, resulting in 3,150 annual stormwater footprints. The 35 infrastructure scenarios represent various mixes and penetrations of LID (retention- and detention-based), SWR, and traditional infrastructure.

\subsubsection{MCDM method 1 - Fuzzy TOPSIS}

To identify the optimal stormwater system configuration based on the results of the stormwater system simulations, two MCDM methods were adopted, fuzzy-TOPSIS and fuzzy-clustering. The intent of adopting two MCDM methods is to offer decision makers with two perspectives on decision support. As a result, framework adopters will be able to perform an aggregate decision making exercise using the two MCDM methods. The OWSWPF relies on a four-dimensional 
fuzzy-TOPSIS algorithm to rank system configurations. The four dimensions evaluated by this MCDM method are the historical stormwater footprint, two climate change scenario (RCP 2.6 and RCP 8.5) stormwater footprints, and the life cycle costs of each system. To address uncertainty intrinsic to each of these dimensions, fuzzy numbers are used. Fuzzy approaches for considering uncertainty in stormwater management planning have been adopted by many authors (Bick et al. 2018; Gouri and Srinivas 2017; Jato-Espino et al. 2014) and fuzzy logic has been used for many other types of infrastructure decision making as well (Haider et al. 2018; Liu et al. 2016; Pan et al. 2018; Ruparathna et al. 2017). The Technique for Order Performance by Similarity to Ideal Solution (TOPSIS) was first developed by Hwang and Yoon in 1981 (Hwang and Yoon 1981). Chen later combined the TOPSIS methodology with triangular fuzzy numbers, and outlined a method for calculating the distance between two triangular fuzzy numbers (Chen 2000). This fuzzy-TOPSIS methodology enables decision makers to evaluate multiple alternatives under multiple criteria while considering uncertainty, linguistic, or imprecise data.

A fuzzy multi-criteria decision making problem can be expressed in matrix format as:

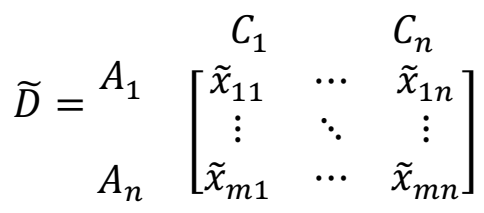

Equation 3-19

where for all $\tilde{x}_{i j}, i=1,2, \ldots, \mathrm{m} ; \mathrm{j}=1,2, \ldots, \mathrm{n}$. Here $\tilde{x}_{i j}=\left(a_{i j}, b_{i j}, c_{i j}\right)$ are triangular fuzzy numbers for alternatives $A_{1}-A_{n}$ with criteria $C_{1}-C_{n}$. Alternatives in the OWSWPF representing all the possible combinations of stormwater management plans (as outlined in Table 3-14). The sources for each alternative and the sources for their fuzzy numbers are outlined in Table 3-13.

Table 3-13: Sources of fuzzy number values in the OWSWPF.

\begin{tabular}{llllll}
\hline Criteria & Name & unit & lower & middle & upper \\
\hline $\mathrm{C}_{1}$ & Current stormwater & $\mathrm{m}^{3}$ & $5^{\text {th }}$ percentile of & $50^{\text {th }}$ percentile of & $95^{\text {th }}$ percentile of \\
& footprint & & simulations & simulations & simulations \\
$\mathrm{C}_{2}$ & RCP 2.6 stormwater & $\mathrm{m}^{3}$ & $5^{\text {th }}$ percentile of & $50^{\text {th }}$ percentile of & $95^{\text {th }}$ percentile of \\
& footprint & & simulations & simulations & simulations \\
$\mathrm{C}_{3}$ & RCP 8.5 stormwater & $\mathrm{m}^{3}$ & $5^{\text {th }}$ percentile of & $50^{\text {th }}$ percentile of & $95^{\text {th }}$ percentile of \\
& footprint & & simulations & simulations & simulations \\
$\mathrm{C}_{4}$ & Life cycle costs & \multirow{2}{*}{ CAD } & $5^{\text {th }}$ percentile of LCC & $50^{\text {th }}$ percentile of LCC & $95^{\text {th }}$ percentile of LCC \\
\hline
\end{tabular}

The historical stormwater footprint fuzzy numbers are based on the $5^{\text {th }}$ percentile, median, and $95^{\text {th }}$ percentile of stormwater footprints calculated for each system configuration over all 30 simulated years. 
Table 3-14: Representative stormwater infrastructure scenarios

\begin{tabular}{|c|c|c|c|c|c|c|c|c|}
\hline \multirow{2}{*}{$\begin{array}{l}\text { Function } \\
\text { Scenario Name }\end{array}$} & \multicolumn{2}{|c|}{$\begin{array}{l}\text { Infiltration- } \\
\text { based }\end{array}$} & \multicolumn{2}{|c|}{$\begin{array}{l}\text { Retention- } \\
\text { based }\end{array}$} & \multicolumn{2}{|c|}{ Lot-level } & \multirow{2}{*}{$\begin{array}{l}\text { Reuse } \\
\text { SWR }^{g} \\
(\mathrm{~mm})\end{array}$} & \multirow{2}{*}{$\begin{array}{c}\text { Detain } \\
\text { Detention }^{\mathrm{h}}(\mathrm{mm})\end{array}$} \\
\hline & $\begin{array}{l}\text { PPS }^{\mathrm{a}} \\
(\%)\end{array}$ & $\begin{array}{l}\mathrm{IT}^{\mathrm{b}} \\
(\%)\end{array}$ & $\begin{array}{l}\mathrm{BR}^{\mathrm{c}} \\
(\%)\end{array}$ & $\begin{array}{c}\mathrm{CSW}^{\mathrm{d}} \\
(\%)\end{array}$ & $\begin{array}{l}\mathrm{GR}^{\mathrm{e}} \\
(\%)\end{array}$ & $\begin{array}{l}\mathrm{RH}^{\mathrm{f}} \\
(\%)\end{array}$ & & \\
\hline Traditional (SWR 0) & 0 & 0 & 0 & 0 & 0 & 0 & 0 & 100-yr, 1440-min \\
\hline Traditional (SWR 1) & 0 & 0 & 0 & 0 & 0 & 0 & $2-y r, 5-\min$ & $100-y r, 1440-\mathrm{min}$ \\
\hline Traditional (SWR 2) & 0 & 0 & 0 & 0 & 0 & 0 & $5-\mathrm{yr}, 10-\mathrm{min}$ & 100-yr, 1440-min \\
\hline Traditional + (SWR 3) & 0 & 0 & 0 & 0 & 0 & 0 & $10-y r, 15-\min$ & $100-y r, 1440-\min$ \\
\hline Traditional + (SWR 4) & 0 & 0 & 0 & 0 & 0 & 0 & $25-\mathrm{yr}, 30-\mathrm{min}$ & $100-\mathrm{yr}, 1440-\mathrm{min}$ \\
\hline Traditional + LID (Inf-med) (SWR0) & 20 & 50 & 0 & 0 & 10 & 33 & 0 & $100-y r, 1440-\min$ \\
\hline Traditional + LID (Inf-med) (SWR1) & 20 & 50 & 0 & 0 & 10 & 33 & 2-yr, 5-min & $100-\mathrm{yr}, 1440-\mathrm{min}$ \\
\hline Traditional + LID (Inf-med) (SWR2) & 20 & 50 & 0 & 0 & 10 & 33 & $5-\mathrm{yr}, 10-\mathrm{min}$ & 100-yr, 1440-min \\
\hline Traditional + LID (Inf-med) (SWR3) & 20 & 50 & 0 & 0 & 10 & 33 & $10-y r, 15-\min$ & 100-yr, 1440-min \\
\hline Traditional + LID (Inf-med) (SWR4) & 20 & 50 & 0 & 0 & 10 & 33 & 25-yr, 30-min & $100-\mathrm{yr}, 1440-\mathrm{min}$ \\
\hline Traditional + LID (Inf-high) (SWR0) & 40 & 100 & 0 & 0 & 20 & 66 & 0 & 100-yr, 1440-min \\
\hline Traditional + LID (Inf-high) (SWR1) & 40 & 100 & 0 & 0 & 20 & 66 & $2-y r, 5-\min$ & $100-y r, 1440-\mathrm{min}$ \\
\hline Traditional + LID (Inf-high) (SWR2) & 40 & 100 & 0 & 0 & 20 & 66 & 5 -yr, 10-min & 100-yr, 1440-min \\
\hline Traditional + LID (Inf-high) (SWR3) & 40 & 100 & 0 & 0 & 20 & 66 & $10-y r, 15-\min$ & 100-yr, 1440-min \\
\hline Traditional + LID (Inf-high) (SWR4) & 40 & 100 & 0 & 0 & 20 & 66 & $25-\mathrm{yr}, 30-\mathrm{min}$ & 100-yr, 1440-min \\
\hline Traditional + LID (Ret-med) (SWR0) & 0 & 0 & 50 & 50 & 10 & 33 & 0 & 100-yr, 1440-min \\
\hline Traditional + LID (Ret-med) (SWR1) & 0 & 0 & 50 & 50 & 10 & 33 & $2-\mathrm{yr}, 5-\mathrm{min}$ & $100-y r, 1440-\min$ \\
\hline Traditional + LID (Ret-med) (SWR2) & 0 & 0 & 50 & 50 & 10 & 33 & $5-\mathrm{yr}, 10-\mathrm{min}$ & $100-y r, 1440-\min$ \\
\hline Traditional + LID (Ret-med) (SWR3) & 0 & 0 & 50 & 50 & 10 & 33 & $10-y r, 15-\min$ & 100-yr, 1440-min \\
\hline Traditional + LID (Ret-med) (SWR4) & 0 & 0 & 50 & 50 & 10 & 33 & 25-yr, 30-min & $100-\mathrm{yr}, 1440-\mathrm{min}$ \\
\hline Traditional + LID (Ret-high) (SWR0) & 0 & 0 & 100 & 100 & 10 & 66 & 0 & 100-yr, 1440-min \\
\hline Traditional + LID (Ret-high) (SWR1) & 0 & 0 & 100 & 100 & 20 & 66 & $2-\mathrm{yr}, 5-\mathrm{min}$ & $100-\mathrm{yr}, 1440-\mathrm{min}$ \\
\hline Traditional + LID (Ret-high) (SWR2) & 0 & 0 & 100 & 100 & 20 & 66 & $5-\mathrm{yr}, 10-\mathrm{min}$ & 100-yr, 1440-min \\
\hline Traditional + LID (Ret-high) (SWR3) & 0 & 0 & 100 & 100 & 20 & 66 & $10-y r, 15-\min$ & $100-y r, 1440-\min$ \\
\hline Traditional + LID (Ret-high) (SWR4) & 0 & 0 & 100 & 100 & 20 & 66 & $25-\mathrm{yr}, 30-\mathrm{min}$ & 100-yr, 1440-min \\
\hline Traditional + LID (Mix-med) (SWR0) & 20 & 25 & 255 & 50 & 10 & 33 & 0 & 100-yr, 1440-min \\
\hline Traditional + LID (Mix-med) (SWR1) & 20 & 25 & 2 & 50 & 10 & 33 & 2-yr, 5-min & $100-\mathrm{yr}, 1440-\mathrm{min}$ \\
\hline Traditional + LID (Mix-med) (SWR2) & 20 & 25 & 25 & 50 & 10 & 33 & $5-\mathrm{yr}, 10-\mathrm{min}$ & $100-\mathrm{yr}, 1440-\mathrm{min}$ \\
\hline Traditional + LID (Mix-med) (SWR3) & 20 & 25 & 25 & 50 & 10 & 33 & $10-y r, 15-\min$ & 100-yr, 1440-min \\
\hline Traditional + LID (Mix-med) (SWR4) & 20 & 25 & 25 & 50 & 10 & 33 & 25-yr, 30-min & $100-y r, 1440-\min$ \\
\hline Traditional + LID (Mix-high) (SWR0) & 40 & 50 & 50 & 100 & 20 & 66 & 0 & 100-yr, 1440-min \\
\hline Traditional + LID (Mix-high) (SWR1) & 40 & 50 & 50 & 100 & 20 & 66 & $2-y r, 5-m i n$ & $100-y r, 1440-\min$ \\
\hline Traditional + LID (Mix-high) (SWR2) & 40 & 50 & 50 & 100 & 20 & 66 & $5-\mathrm{yr}, 10-\mathrm{min}$ & 100-yr, 1440-min \\
\hline Traditional + LID (Mix-high) (SWR3) & 40 & 50 & 50 & 100 & 20 & 66 & $10-y r, 15-\min$ & 100-yr, 1440-min \\
\hline Traditional + LID (Mix-high) (SWR4) & 40 & 50 & 50 & 100 & 20 & 66 & $25-\mathrm{yr}, 30-\mathrm{min}$ & 100-yr, 1440-min \\
\hline \multicolumn{9}{|l|}{ a Percent of paved area converted to PPSs } \\
\hline \multicolumn{9}{|l|}{ b Percent of available space used for ITs } \\
\hline \multicolumn{9}{|c|}{${ }^{\mathrm{c}}$ Percent of available space used for IT cells } \\
\hline \multicolumn{9}{|l|}{ d Percent of available space used for CSW } \\
\hline \multicolumn{9}{|l|}{ e Percent of buildings with GRs } \\
\hline \multicolumn{9}{|c|}{${ }^{\mathrm{f}}$ Percent of residential homes with RH systems } \\
\hline \multicolumn{9}{|c|}{${ }^{\mathrm{g}}$ Design storm for SWR sizing } \\
\hline${ }^{\mathrm{h}}$ Design storm for detention pond siz & & & & & & & & \\
\hline
\end{tabular}

The climate change stormwater footprint fuzzy numbers are based on the $5^{\text {th }}$ percentile, median, and $95^{\text {th }}$ percentile of RCP 2.6 and RCP 8.5. All possible system configurations are ranked based on the Fuzzy-TOPSIS algorithm.

Although criteria weight vectors in fuzzy TOPSIS are often also fuzzy numbers, often calculated based on linguistic variables from multiple decision makers using analytic hierarchy process (Chen 
2000), the OWSWPF is not intended as a multi-stakeholder framework. Therefore, criteria weights are entered as crisp values.

Once the fuzzy decision matrix $(\widetilde{D})$ has been populated with data produced from the historical and climate change runoff simulations, the matrix is then normalized as $\tilde{R}=\left[\tilde{r}_{i j}\right]$, where

$$
\begin{aligned}
& \tilde{r}_{i j}=\left(\frac{a_{i j}}{c^{*}{ }_{j}}, \frac{b_{i j}}{c^{*}{ }_{j}}, \frac{c_{i j}}{c^{*}{ }_{j}}\right) \text { and } c^{*}{ }_{j}=\max _{i}\left[c_{i j}\right] \quad \text { (benefit criteria) } \\
& \tilde{r}_{i j}=\left(\frac{a^{-} j}{c_{i j}}, \frac{a^{-}{ }_{j}}{b_{i j}}, \frac{a^{-}{ }_{j}}{a_{i j}}\right) \text { and } a^{-}{ }_{j}={ }_{i}^{\min }\left[a_{i j}\right] \quad \text { (cost criteria) }
\end{aligned}
$$

A weighted normalized fuzzy decision matrix $\left(\tilde{V}=\left(\tilde{v}_{i j}\right)\right)$ is then calculated, where $\tilde{v}_{i j}=\tilde{r}_{i j} x w_{j}$. Next, the fuzzy positive ideal solution (FPIS) $\left(A^{*}\right)$ and fuzzy negative ideal solution (FNIS) $\left(A^{-}\right)$ are calculated as follows:

$$
\begin{aligned}
& A^{*}=\left(\tilde{v}_{1}^{*}, \tilde{v}_{2}^{*}, \ldots, \tilde{v}_{n}^{*}\right) \text { where: } \\
& \tilde{v}_{j}^{*}=(c, c, c) \text { such that: } \\
& c=\max _{i}\left\{c_{i j}^{\prime \prime}\right\}, \quad i=1,2, \ldots, m ; j=1,2, \ldots, n
\end{aligned}
$$$$
\text { Equation 3-22 }
$$

and

$$
\begin{aligned}
& A^{-}=\left(\tilde{v}_{1}^{-}, \tilde{v}_{2}^{-}, \ldots, \tilde{v}_{n}^{-}\right) \text {where: } \\
& \tilde{v}_{j}^{-}=(a, a, a) \text { such that: } \\
& a=\min _{i}\left\{a_{i j}^{\prime \prime}\right\}, \quad i=1,2, \ldots, m ; j=1,2, \ldots, n
\end{aligned}
$$$$
\text { Equation 3-23 }
$$

Distances from each alternative and the FPIS $\left(d_{i}^{*}\right)$ and FNIS $\left(d_{i}^{-}\right)$are then calculated as:

$$
\begin{array}{ll}
d_{i}^{*}=\sum_{j=1}^{n} d_{v}\left(\tilde{v}_{i j}, \tilde{v}_{j}^{*}\right), & i=1,2, \ldots, m \\
d_{i}^{-}=\sum_{j=1}^{n} d_{v}\left(\tilde{v}_{i j}, \tilde{v}_{j}^{-}\right), & i=1,2, \ldots, m
\end{array}
$$

Distances between two triangular fuzzy numbers $(\tilde{a}, \tilde{b})$ are calculated using the vertex method as follows:

$$
d(\tilde{a}, \tilde{b})=\sqrt{\left.\frac{1}{3}\left[\left(a-a^{\prime}\right)^{2}+\left(b-b^{\prime}\right)^{2}+\left(c-c^{\prime}\right)^{2}\right)\right]}
$$

Finally, alternatives are ranked based on closeness coefficient $\left(C C_{i}\right)$ calculated for each alternative as follows: 


$$
C C_{i}=\frac{d_{i}^{-}}{d_{i}^{-}+d_{i}^{*}}, \quad i=1,2, \ldots, m
$$

\subsubsection{MCDM method 2 - Fuzzy clustering}

The Fuzzy-TOPSIS analysis ranks the stormwater management strategies based on parametric values of total community stormwater footprints and life cycle costs for three different climate scenarios. As another MCDM method, a Fuzzy-clustering analysis (FCA) can be used to cluster together those stormwater management scenarios with similar characteristics. The FCA clusters the stormwater management scenarios based on average values of blue water footprints, grey water footprints, and life cycle costs to identify the management scenarios that perform best in terms of intended stormwater management objectives (e.g., pollution reduction vs. water scarcity). Green water footprints are excluded from this analysis, as the primary objective of the FCA is distinguish between those systems that have greatest impact on annual pollutant loads and runoff and infiltration volumes.

The following description of FCA is based on (Hu et al. 2018).Prior to completing the fuzzy clustering analysis (FCA), the average BWF, GyWF, and LCCs for each infrastructure scenario were normalized to a scale from 0 to 1 . The FCA algorithm requires that each data point in the dataset be assigned a degree of membership (DOM) to very formed cluster. The DOM indicates that each data point is at least in some part connected to each one of the formed clusters with a different level of association. The presence of the DOM of each point for each cluster is what distinguishes FCA from traditional (crisp) clustering algorithms (e.g., $k$-means clustering). The DOM feature of FCA is capable of addressing fuzzy uncertainties in (e.g., precipitation patterns, future climate variability, and life cycle costs ) in stormwater management planning. Fuzzy $c$ means is a commonly adopted and well accepted fuzzy clustering algorithm ( $\mathrm{Hu}$ et al. 2018; Liu et al. 2016).

The fuzzy $c$-means algorithm classifies data points for a dataset $X=\left(x_{1}, x_{2}, \ldots, x_{n}\right)$ composed of $n$ data points into predefined $p$ clusters based on measured similarities among the data points. Each cluster is assigned a center $e_{j}(j \in[1, p])$, and the Euclidean distance $d_{i j}$ between each data point $x_{i}$ and each $e_{j}$, respectively, can be calculated as:

$$
d_{i j}=\left\|x_{i}-e_{j}\right\|
$$

Equation 3-28 
In this study, each stormwater management infrastructure scenario was considered as a data point defined by three-dimensional values $(a, b, c)$ (i.e., the normalized blue water footprint, grey water footprint, and life cycle costs). As opposed to total water footprints, blue and grey water footprints were used as clustering dimensions to further differentiate between those systems which balance water volumes more naturally and those systems which perform well in terms of urban stormwater pollutant removal. The Euclidean distance between data point $x_{i}\left(a_{i}, b_{i}, c_{i}\right)$ and $e_{j}\left(a_{j}, b_{j}, c_{j}\right)$ in a three-dimensional space was calculated as:

$$
d_{i j}=\sqrt{\left(a_{i}-a_{j}\right)^{2}+\left(b_{i}-b_{j}\right)^{2}+\left(c_{i}-c_{j}\right)^{2}}
$$

To initiate the fuzzy $c$-means algorithm, random centers (often with a value of zero) are selected for the clusters. A DOM $\mu_{j}\left(x_{i}\right)$ can be calculated as a measure of the similarity between a data point $x_{i}$ and the $j^{\text {th }}$ cluster, based on the calculated $d_{i j}$ :

$$
\mu_{j}\left(x_{i}\right)=\frac{\left(\frac{1}{d_{i j}}\right)^{2 /(\zeta-1)}}{\sum_{k=1}^{p}\left(\frac{1}{d_{i k}}\right)^{2 /(\zeta-1)}}
$$

Equation 3-30

where $\zeta$ is a fuzzification parameter determining the degree of fuzziness between clusters. A higher value of $\zeta$ will lead to increased inter-cluster fuzziness. $\zeta$ most commonly takes values between 1.25 and 2 (Cox 2005; Hu et al. 2018; Sadiq et al. 2007). For the purpose of this study, the $\zeta$ value was set at 2 . The parameter $d_{i k}$ is the Euclidean distance between $x_{i}$ and the center of each respective cluster $\left(k^{\text {th }}\right)$. New cluster centers can then be calculated as:

$$
e^{\prime}{ }_{j}=\frac{\sum_{i}\left[\mu_{j}\left(x_{i}\right)\right]^{\zeta} x_{i}}{\sum_{i}\left[\mu_{j}\left(x_{i}\right)\right]^{\zeta}}
$$

$\mu_{j}\left(x_{i}\right)$ is then updated based on the new $e_{j}^{\prime}, \mu_{j}\left(x_{i}\right)$. This iterative process will continue until the minimum objective function $J$ is achieved:

$$
J=\sum_{i=1}^{n} \sum_{j=1}^{p}\left[\mu_{j}\left(x_{i}\right)\right]^{\zeta} d_{i j}^{2} ; \quad p \leq n
$$

Equation 3-32

\subsection{Summary}

Resilient and effective stormwater management has the potential to affect all four major water scarcity risks identified by the OECD (scarcity, floods, pollution, and freshwater ecosystem resilience) (OECD 2013). To address the knowledge gaps and limited capabilities of current stormwater infrastructure planning tools in mitigating these risks, the OWSWPF is proposed. The OWSWPF is the deployment of a one water approach framework for identifying the optimal mix of low impact development, reuse, and traditional stormwater infrastructure for a new urban 
community development. Uncertainty attributed to both stochastic variability and epistemic uncertainty are considered in the framework. A combination of historical and predicted climate change precipitation patterns is considered in the framework, allowing Canadian decision makers to not only plan for the present, but the future as well.

The final ranking of system configurations by the OWSWPF can help decision makers identify which stormwater management strategies have the most cost-effective positive impact on a community's stormwater footprint. The rankings, clusters and water balance equations for each of the top-ranked system configurations can help stormwater infrastructure decision makers come identify the optimal stormwater management strategy. Although the OWSWPF was specifically developed for Canadian stormwater infrastructure planners, the framework could be adopted by any jurisdiction on the planet. 


\section{FRAMEWORK IMPLEMENTATION}

\subsection{Case Study Descriptions}

Two case study demonstrations of the OWSWPF were performed for two Western-Canadian cities: Calgary, Alberta (AB); and Kelowna, British Columbia (BC). These case studies were selected to emphasize and contrast the impact of decision-maker priorities and objectives with regard to stormwater volume and pollutant management. Calgary represents a case study where decision makers may be more interested in reducing pollutant loads, while Kelowna represents a case study where decision makers may be more interested in reducing anthropogenic water use.

Furthermore, both cities have experienced historic flooding within the past decade, and have similar average total annual precipitation (within $\sim 8 \%$ ) but with different distribution patterns throughout the year. The two case studies represent two different Canadian climate regions.

\subsection{Calgary (AB, Canada)}

Calgary is the largest city in $\mathrm{AB}$ and sits approximately $80 \mathrm{~km}$ east of the Rocky Mountain front ranges in the foothills and prairies of the southern portion of the province. Many of Calgary's neighbourhoods are nestled along the banks of the Bow and Elbow Rivers, with their confluence within the city. The Bow River has been recognized as one of the leading trout fisheries in North America, but recent growth of the City of Calgary has resulted in increased pressures on the river's ecosystems and fish habitat (Trout Unlimited Canada 2018). According to the City of Calgary, Calgarians use an average of 214L per capita of water per day in their households. In 2016, 174 billion litres of water were withdrawn from the Bow and Elbow Rivers for anthropogenic water use in Calgary. This withdrawn volume is well below the 213 billion litre benchmark established in 2003 (City of Calgary 2018).

Calgary is classified as having a warm-summer humid continental climate as per the KöppenGeiger climate classification system (Peel et al. 2007) and part of the Prairies Canadian climatic region according to Environment Canada (Environment Canada 1998).

Between 1981 and 2010, Calgary's average precipitation was $419 \mathrm{~mm}$ of annual precipitation (326 $\mathrm{mm}$ of rain and $129 \mathrm{~cm}$ of snowfall), and experienced five months of year with average temperatures below $0^{\circ} \mathrm{C}$ (Environment and Climate Change Canada 2018). Many parts of the City of Calgary currently sit on top of the sediments of Glacial Lake Calgary. The glacial lake, present 
during the Laurentide ice sheet, left behind a silty clay-heavy soil underlying most of Calgary (Fisher 1999).

\subsubsection{Precipitation simulation results}

The OWSWPF precipitation simulation results for Calgary are summarized in Table 4-1. More detailed results are available in Appendix C. The average simulated historical annual precipitation, annual rainfall, and annual snowfall values from the 30 simulated years are within $1.5 \%, 0.4 \%$, and $6.0 \%$ of observed historical averages (between 1981 and 2010), respectively. Although the maximum rainfall depth of all simulated years is 13\% higher than observed values between 1981 and 2010, this value is similar to the rainfall depths observed just east of Calgary during the Southern Alberta floods of 2013 (Alberta Environment and Sustainable Resource Development 2015).

The RCP 2.6 climate change scenario simulation resulted in an average annual decrease of 3.5\% in total precipitation, but an increase of $11.7 \%$ in annual rainfall (i.e., a smaller percentage of the precipitation is predicted to be in the form of snowfall). The largest rainfall event for RCP 2.6 increased by $23.3 \%$ to $132 \mathrm{~mm}$. The RCP 8.5 climate change scenario simulation resulted in a $3.1 \%$ increase in average total annual precipitation with a dramatic $14.1 \%$ increase in annual rainfall and an average snowfall decrease of $48.3 \%$. The maximum depth rainfall event for RCP 8.5 is 126 $\mathrm{mm}$, with smaller, more frequent storm events predicted to increase in depth. The results for the RCP 2.6 and RCP 8.5 scenarios are in line with predicted changes based on the IDF tables (Simonovic et al. 2018), annual snowpack change, and annual precipitation change (Government of Canada 2018b). Figure 4-1 is visual comparison of observed and simulated average monthly precipitation values for Calgary.

Table 4-1: Annual precipitation statistics for precipitation simulations based on historical data.

\begin{tabular}{|c|c|c|c|c|c|c|c|c|}
\hline Year & \multicolumn{2}{|c|}{$\begin{array}{l}\text { Annual Precipitation } \\
\qquad(\mathrm{mm})\end{array}$} & \multicolumn{2}{|c|}{$\begin{array}{l}\text { Annual Rainfall } \\
\text { (mm) }\end{array}$} & \multicolumn{2}{|c|}{$\begin{array}{l}\text { Annual Snowfall } \\
\qquad(\mathrm{cm})\end{array}$} & \multicolumn{2}{|c|}{$\begin{array}{l}\text { Max depth rainfall } \\
(\mathrm{mm})\end{array}$} \\
\hline Observed & avg: 418.8 & & avg: 326.4 & & avg: 128.8 & & $\max : 95.3$ & \\
\hline Simulation (Historical) $^{\mathrm{a}}$ & avg: 424.9 & $+1.5 \%$ & vg: 327.8 & $+0.4 \%$ & avg: 136.5 & $+6.0 \%$ & $\max : 107$ & $+12.6 \%$ \\
\hline Simulation (RCP 2.6) & avg: 410.1 & $-3.5 \%$ & avg: 366.2 & $+11.7 \%$ & avg: 92.6 & $-32.2 \%$ & $\max : 132$ & $+23.3 \%$ \\
\hline Simulation (RCP 8.5$)^{\mathrm{b}}$ & avg: 438.1 & $+3.1 \%$ & avg: 373.9 & $+14.1 \%$ & avg: 70.6 & $-48.3 \%$ & $\max : 126$ & $+17.8 \%$ \\
\hline
\end{tabular}

a: percent change relative to observed historical data

b: percent change relative to simulated historical data 


\subsubsection{Fuzzy TOPSIS results}

The criteria selected for the Fuzzy-TOPSIS algorithm are primarily reflective of LCCs and resiliency to climate change (as defined by the total community stormwater footprint under current climate conditions, RCP 2.6, and RCP 8.5). To reflect the decision-making context of this demonstration, four weighting schemes for different decision scenarios were developed (Table 4-2). These climate change-oriented decision scenarios were applied to both the Calgary and Kelowna case studies.

Table 4-3 outlines the ranking and closeness coefficients of all 35 infrastructure mix scenarios for each of the decision weighting scenarios outlined in Table 4-2 for Calgary. Figure 4-1 and Figure 4-2 are visual representations of the Fuzzy-TOPSIS results for Calgary.

Table 4-2: Weighting schemes for decision scenarios

\begin{tabular}{llllll}
\hline & & \multicolumn{4}{c}{ Weighting Scenarios } \\
\cline { 3 - 5 } Criteria & $\begin{array}{l}\text { Climate change } \\
\text { scenario }\end{array}$ & Neutral & Pro-economic & $\begin{array}{l}\text { Pessimistic } \\
\text { about climate } \\
\text { change }\end{array}$ & $\begin{array}{l}\text { Optimistic } \\
\text { about climate } \\
\text { change }\end{array}$ \\
\hline LCC & All & 0.25 & 0.5 & 0.25 & 0.25 \\
TCSWF & Current & 0.25 & 0.17 & 0.2 & 0.2 \\
& RCP 2.6 & 0.25 & 0.17 & 0.05 & 0.5 \\
& RCP 8.5 & 0.25 & 0.17 & 0.5 & 0.05 \\
\hline
\end{tabular}

LCC: life cycle cost; TCSWF: total community stormwater footprint

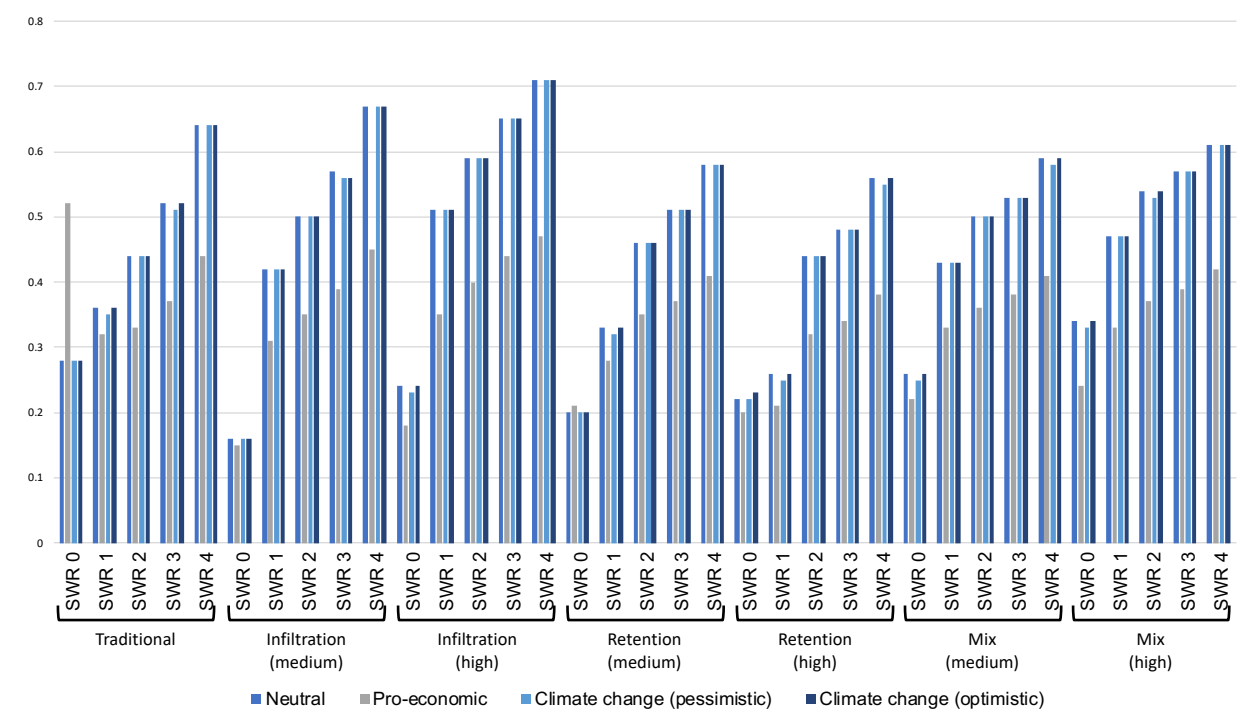

Figure 4-1:Closeness coefficients for stormwater infrastructure scenarios in Calgary. 


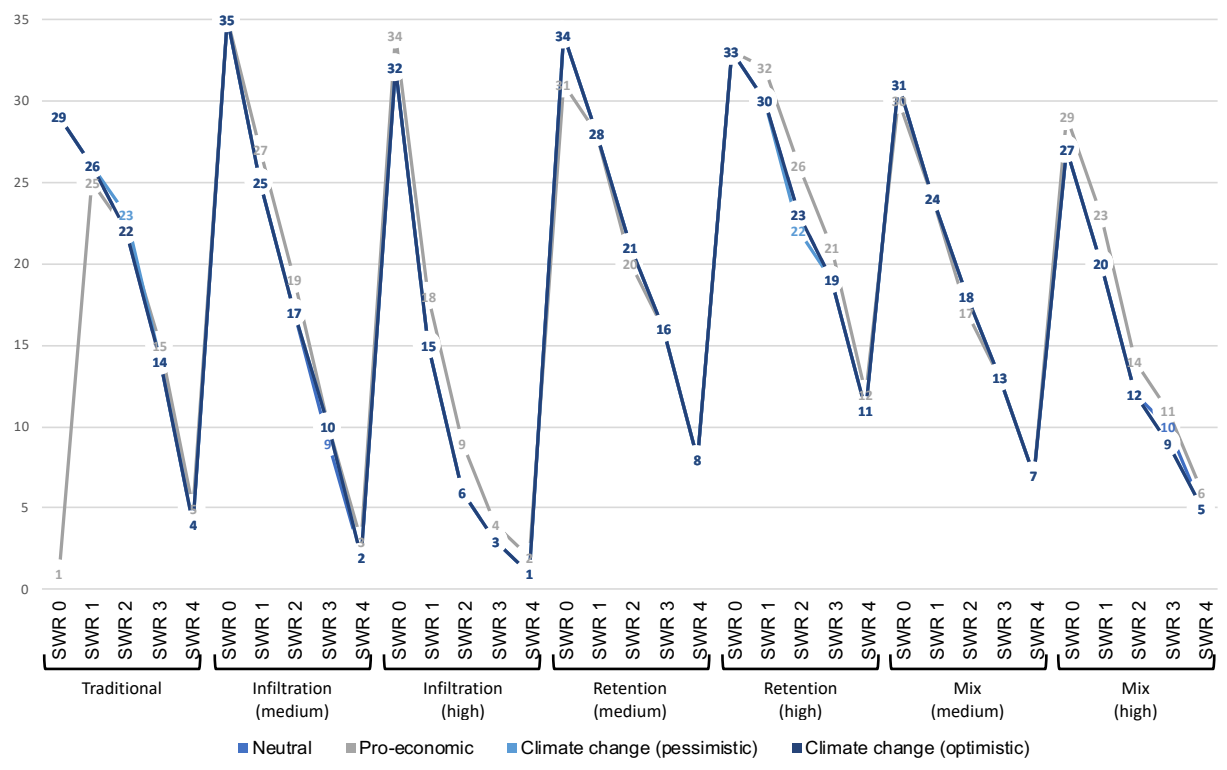

Figure 4-2:Change in ranking results for all infrastructure and weighting scenarios for Calgary.

The FCA process was carried out using the statistical computing software $\mathrm{R}^{\mathrm{TM}}$ (version 1.0.136). Kernel density estimation (KDE) plots, a non-parametric method for estimating the probability density function of random variables, are seen in Figure 4-3 for Calgary under the current climate scenario.

\subsubsection{Fuzzy clustering analysis}

For Calgary, the LCC KDE reveals a relatively symmetric normal distribution (p-value of 0.72 for Anderson-Darling test) around the mean of $\$ 23.3 \mathrm{M}$, with minimum and maximum values of $\$ 2.2 \mathrm{M}$ and $\$ 50.2 \mathrm{M}$, respectively. As the 35 infrastructure scenarios represent various degrees of infrastructure complexity and management, this normal distribution of LCCs is expected. The GyWFs for Calgary are found to follow a lognormal distribution (p-value of 0.09 for AndersonDarling test) around a mean of $318 \mathrm{~K} \mathrm{~m}^{3}$, with minimum and maximum values of $43 \mathrm{~K} \mathrm{~m}$ and $2,488 \mathrm{~K} \mathrm{~m}^{3}$, respectively. As the majority of infrastructure scenarios $(86 \%)$ contain varying degrees of LID and SWR (86\%), this lognormal distribution in GyWFs is also expected (i.e., LID and SWR are effective means of controlling stormwater pollutants). An outlier can also be seen in the KDE for GyWFs. This outlier represents the only scenario with no LID or SWR components. The trimodal distribution of the BWFs is reflective of the three different mixes of traditional, SWR, and LID infrastructure represented by the 35 scenarios. These three mixes are found to be normally distributed when separated and are represented by the three peaks of the trimodal distribution as: 
Table 4-3: Infrastructure mix rankings and closeness coefficients for different weighting scenarios for Calgary.

\begin{tabular}{|c|c|c|c|c|c|c|c|c|}
\hline \multirow[b]{2}{*}{ Infrastructure alternatives } & \multicolumn{2}{|c|}{ Neutral } & \multirow{2}{*}{$\begin{array}{l}\text { Pro- } \\
\text { economic } \\
\text { CC } \\
\end{array}$} & \multicolumn{2}{|c|}{$\begin{array}{l}\text { Pessimistic about climate } \\
\text { change }\end{array}$} & \multicolumn{3}{|c|}{$\begin{array}{l}\text { Optimistic about } \\
\text { climate change }\end{array}$} \\
\hline & $\mathrm{CC}$ & Rank & & Rank & $\mathrm{CC}$ & Rank & $\mathrm{CC}$ & Rank \\
\hline Traditional (SWR 0) & 0.28 & 29 & 0.52 & 1 & 0.28 & 29 & 0.28 & 29 \\
\hline Traditional (SWR 1) & 0.36 & 26 & 0.32 & 25 & 0.35 & 26 & 0.36 & 26 \\
\hline Traditional (SWR 2) & 0.44 & 22 & 0.33 & 22 & 0.44 & 23 & 0.44 & 22 \\
\hline Traditional + (SWR 3) & 0.52 & 14 & 0.37 & 15 & 0.51 & 14 & 0.52 & 14 \\
\hline Traditional + (SWR 4) & 0.64 & 4 & 0.44 & 5 & 0.64 & 4 & 0.64 & 4 \\
\hline Traditional + LID (Inf-med) (SWR0) & 0.16 & 35 & 0.15 & 35 & 0.16 & 35 & 0.16 & 35 \\
\hline Traditional + LID (Inf-med) (SWR1) & 0.42 & 25 & 0.31 & 27 & 0.42 & 25 & 0.42 & 25 \\
\hline Traditional + LID (Inf-med) (SWR2) & 0.50 & 17 & 0.35 & 19 & 0.50 & 17 & 0.50 & 17 \\
\hline Traditional + LID (Inf-med) (SWR3) & 0.57 & 9 & 0.39 & 10 & 0.56 & 10 & 0.56 & 10 \\
\hline Traditional + LID (Inf-med) (SWR4) & 0.67 & 2 & 0.45 & 3 & 0.67 & 2 & 0.67 & 2 \\
\hline Traditional + LID (Inf-high) (SWR0) & 0.24 & 32 & 0.18 & 34 & 0.23 & 32 & 0.24 & 32 \\
\hline Traditional + LID (Inf-high) (SWR1) & 0.51 & 15 & 0.35 & 18 & 0.51 & 15 & 0.51 & 15 \\
\hline Traditional + LID (Inf-high) (SWR2) & 0.59 & 6 & 0.40 & 9 & 0.59 & 6 & 0.59 & 6 \\
\hline Traditional + LID (Inf-high) (SWR3) & 0.65 & 3 & 0.44 & 4 & 0.65 & 3 & 0.65 & 3 \\
\hline Traditional + LID (Inf-high) (SWR4) & 0.71 & 1 & 0.47 & 2 & 0.71 & 1 & 0.71 & 1 \\
\hline $\begin{array}{l}\text { Traditional + LID (Ret-med) } \\
\text { (SWR0) }\end{array}$ & 0.20 & 34 & 0.21 & 31 & 0.20 & 34 & 0.20 & 34 \\
\hline Traditional + LID (Ret-med) & & & & & & & & \\
\hline $\begin{array}{l}\text { (SWR1) } \\
\text { Traditional + LID (Ret-med) }\end{array}$ & 0.33 & 28 & 0.28 & 28 & 0.32 & 28 & 0.33 & 28 \\
\hline $\begin{array}{l}\text { (SWR2) } \\
\text { Traditional + LID (Ret-med) }\end{array}$ & 0.46 & 21 & 0.35 & 20 & 0.46 & 21 & 0.46 & 21 \\
\hline $\begin{array}{l}\text { (SWR3) } \\
\text { Traditional + LID (Ret-med) }\end{array}$ & 0.51 & 16 & 0.37 & 16 & 0.51 & 16 & 0.51 & 16 \\
\hline $\begin{array}{l}\text { (SWR4) } \\
\text { Traditional + LID (Ret-high) }\end{array}$ & 0.58 & 8 & 0.41 & 8 & 0.58 & 8 & 0.58 & 8 \\
\hline $\begin{array}{l}\text { (SWR0) } \\
\text { Traditional + LID (Ret-high) }\end{array}$ & 0.22 & 33 & 0.20 & 33 & 0.22 & 33 & 0.23 & 33 \\
\hline $\begin{array}{l}\text { (SWR1) } \\
\text { Traditional + LID (Ret-high) }\end{array}$ & 0.26 & 30 & 0.21 & 32 & 0.25 & 30 & 0.26 & 30 \\
\hline $\begin{array}{l}\text { (SWR2) } \\
\text { Traditional + LID (Ret-high) }\end{array}$ & 0.44 & 23 & 0.32 & 26 & 0.44 & 22 & 0.44 & 23 \\
\hline $\begin{array}{l}\text { (SWR3) } \\
\text { Traditional + LID (Ret-high) }\end{array}$ & 0.48 & 19 & 0.34 & 21 & 0.48 & 19 & 0.48 & 19 \\
\hline $\begin{array}{l}\text { (SWR4) } \\
\text { Traditional + LID (Mix-med) }\end{array}$ & 0.56 & 11 & 0.38 & 12 & 0.55 & 11 & 0.56 & 11 \\
\hline $\begin{array}{l}\text { (SWR0) } \\
\text { Traditional + LID (Mix-med) }\end{array}$ & 0.26 & 31 & 0.22 & 30 & 0.25 & 31 & 0.26 & 31 \\
\hline (SWR1) & 0.43 & 24 & 0.33 & 24 & 0.43 & 24 & 0.43 & 24 \\
\hline $\begin{array}{l}\text { Traditional + LID (Mix-med) } \\
\text { (SWR2) }\end{array}$ & 0.50 & 18 & 0.36 & 17 & 0.50 & 18 & 0.50 & 18 \\
\hline $\begin{array}{l}\text { Traditional + LID (Mix-med) } \\
\text { (SWR3) }\end{array}$ & 0.53 & 13 & 0.38 & 13 & 0.53 & 13 & 0.53 & 13 \\
\hline $\begin{array}{l}\text { Traditional + LID (Mix-med) } \\
\text { (SWR4) }\end{array}$ & 0.59 & 7 & 0.41 & 7 & 0.58 & 7 & 0.59 & 7 \\
\hline $\begin{array}{l}\text { Traditional + LID (Mix-high) } \\
\text { (SWR0) }\end{array}$ & 0.34 & 27 & 0.24 & 29 & 0.33 & 27 & 0.34 & 27 \\
\hline $\begin{array}{l}\text { Traditional + LID (Mix-high) } \\
\text { (SWR1) }\end{array}$ & 0.47 & 20 & 0.33 & 23 & 0.47 & 20 & 0.47 & 20 \\
\hline $\begin{array}{l}\text { Traditional + LID (Mix-high) } \\
\text { (SWR2) }\end{array}$ & 0.54 & 12 & 0.37 & 14 & 0.53 & 12 & 0.54 & 12 \\
\hline $\begin{array}{l}\text { Traditional + LID (Mix-high) } \\
\text { (SWR3) }\end{array}$ & 0.57 & 10 & 0.39 & 11 & 0.57 & 9 & 0.57 & 9 \\
\hline $\begin{array}{l}\text { Traditional + LID (Mix-high) } \\
\text { (SWR4) }\end{array}$ & 0.61 & 5 & 0.42 & 6 & 0.61 & 5 & 0.61 & 5 \\
\hline
\end{tabular}


- $\quad 1^{\text {st }}$ peak; $\mathrm{n}=4 ; \mathrm{p}$-value for Anderson-Darling test $=0.50 ; \mathrm{SWR}$ and no LID

- $\quad 2^{\text {nd }}$ peak; $n=24 ; \mathrm{p}$-value for Anderson-Darling test $=0.40$; various levels of LID and SWR

- $\quad 3^{\text {rd }}$ peak; $\mathrm{n}=7 ; \mathrm{p}$-value for Anderson-Darling test $=0.13$; LID with no SWR

The relatively small deviations between climate scenarios seen in the KDEs is not representative of a small change precipitation (as the KDEs are produced using normalized values for each climate scenario), but rather are reflective of the fact that there is little deviation in pros and cons of systems between climate scenarios. For example, if under current climate conditions a system is seen to be excellent at controlling pollutant loads but poor and controlling water volumes, the same will be observed under RCP 8.5, but to a different degree.

Prior to completing the FCA, users are required to identify the optimum number of clusters for the analysis. The optimum number can be identified by evaluating the change of within-group sum of squares by changing the number of clusters. The optimal number of clusters is generally selected when the decrease of within-group sum of squares is not apparent when compared to the previous number (Hu et al. 2018). This small change between within-group sum of squares can be seen in Figure 4-4. Six clusters marks the inflection point, or leveling off, of change in within-group sum of squares.

A matrix scatterplot was used to identify the common characteristics among each of the six clusters (Figure 4-5). Table 4-5 outlines the linguistic divisions of performance used to evaluate the common and predominant traits amongst all six clusters for both Calgary and Kelowna. These divisions are often made based on quartile breaks, minimum/maximum values, and other statistics (Hu et al. 2018), but no such values were shared between the Calgary and Kelowna case study demonstrations. Therefore, a simple five-way equal division was adopted to enable more meaningful comparison between case studies.

As seen in

Table 4-6, although associated with higher costs, Clusters 3 and 6 offer no superior benefits to other clusters. Therefore, Clusters 3 and 6 have been categorized as non-beneficial clusters. Although cluster 4 may be used by some decision makers, clusters 1, 2, and 5 appear to be the most promising clusters.

\subsubsection{Aggregate fuzzy decision making}

It is important to reiterate that the BWF in this study does not reflect the hydraulic performance of LID technologies, but is a reflection of the total water volumes diverted or redirected back to 
natural water resources. Although it is assumed that infrastructure scenarios with high penetration LID BMPs will results in a more natural runoff hydrograph, this is not considered as part of the scope of this decision-making framework.

As previously mentioned, the Calgary decision makers may be more interested in adopting those infrastructure mixes that best support continuous pollutant reduction (i.e., cluster 1 or 5). As only low to moderate cost options were included in this aggregate analysis (i.e., clusters 1 and 5) and the fact that most Paris Agreement-signing nations are not making adequate reductions in GHGs, the ranks for the pessimistic about climate change weighting scenario from the Fuzzy-TOPSIS results were considered. Resiliency was calculated as the difference between the current climate fuzzy numbers for the total water footprint and the RCP 8.5 climate fuzzy numbers for the total water footprint.

Table 4-4 outlines the infrastructure scenarios present in clusters 1 and 5, for Calgary.

Table 4-4: Data required for performing aggregate decision making considering both FCA and Fuzzy-TOPSIS results and resiliency for Calgary.

\begin{tabular}{|c|c|c|c|c|c|c|c|c|c|c|c|c|}
\hline \multicolumn{4}{|c|}{ Fuzzy-clustering } & \multicolumn{6}{|c|}{ Fuzzy-TOPSIS } & \multicolumn{3}{|l|}{ Description } \\
\hline Cluster & LCC & BWF & GyWF & Rank & TWF & & LCC & Resiliency* & Rank & LID & SWR & Det \\
\hline \multirow[t]{5}{*}{1} & 23.6 & 244 & 544 & 32 & $\begin{array}{l}(292, \\
1238)\end{array}$ & 783 , & $\begin{array}{l}(19.3,23.7, \\
28.1)\end{array}$ & $(73,228,367)$ & 5 & IB (high) & 0.0 & 13.1 \\
\hline & 25.0 & 229 & 148 & 20 & $\begin{array}{l}(199, \\
589)\end{array}$ & 392, & $\begin{array}{l}(20.6,24.9, \\
29.3)\end{array}$ & $(12,67,142)$ & 4 & $\begin{array}{l}\text { Mix } \\
\text { (high) }\end{array}$ & 1.2 & 7.9 \\
\hline & 27.5 & 220 & 101 & 12 & $\begin{array}{l}(194, \\
513)\end{array}$ & 338 & $\begin{array}{l}(22.5,27.5, \\
32.7)\end{array}$ & $(13,44,106)$ & 3 & & 2.4 & 7.3 \\
\hline & 29.9 & 218 & 83 & 9 & $\begin{array}{l}(190, \\
477)\end{array}$ & 320 & $\begin{array}{l}(24.0,30.1, \\
35.3)\end{array}$ & $(13,30,99)$ & 2 & & 3.5 & 7.0 \\
\hline & 34.6 & 216 & 58 & 5 & $\begin{array}{l}(185, \\
426)\end{array}$ & 200 & $\begin{array}{l}(27.3,34.5, \\
41.9)\end{array}$ & $(11,19,77)$ & 1 & & 5.5 & 6.3 \\
\hline \multirow[t]{7}{*}{5} & 25.0 & 165 & 164 & 17 & $\begin{array}{l}(171, \\
647)\end{array}$ & 345 , & $(19,25,31)$ & $(17,62,180)$ & 7 & IB (med) & 5.4 & 12.0 \\
\hline & 30.3 & 169 & 245 & 10 & $\begin{array}{l}(160, \\
555)\end{array}$ & 301, & $(22,30,38)$ & $(15,46,150)$ & 6 & & 7.7 & 11.4 \\
\hline & 30.9 & 193 & 141 & 15 & $\begin{array}{l}(173, \\
617)\end{array}$ & 337, & $(25,31,36)$ & $(15,51,159)$ & 5 & IB (high) & 3.2 & 12.1 \\
\hline & 25.8 & 187 & 85 & 8 & $\begin{array}{l}(186, \\
462)\end{array}$ & 321 , & $(17,26,34)$ & $(13,31,87)$ & 1 & RB (med) & 7.7 & 6.7 \\
\hline & 23.7 & 204 & 144 & 19 & $\begin{array}{l}(199, \\
583)\end{array}$ & 381 , & $(18,24,29)$ & $(16,66,123)$ & 4 & RB (high) & 3.6 & 17.1 \\
\hline & 31.0 & 202 & 93 & 11 & $\begin{array}{l}(190, \\
483)\end{array}$ & 331, & $(23,31,39)$ & $(14,32,104)$ & 3 & & 6.7 & 6.6 \\
\hline & 25.1 & 195 & 82 & 7 & $\begin{array}{l}(185, \\
461)\end{array}$ & 314 & $(19,25,32)$ & $(14,31,94)$ & 2 & $\begin{array}{l}\text { Mix } \\
\text { (high) }\end{array}$ & 5.9 & 6.5 \\
\hline
\end{tabular}

Note: LCCs are measured in CAD millions; water footprints are measured in thousands of $\mathrm{m}^{3}$; SWR and detention volumes are measured in thousands of $\mathrm{m}^{3}$. IB: infiltration-based; RB: retention-based; Mix: mix of IB and RB; Det: detention. Terms in parentheses refer to penetration of LID technologies. 
Although all options outlined in clusters 1 and 5 are cost-effective options for Calgary, one option will be investigated in more detail in the following section. Based on the results of the FuzzyTOPSIS, Fuzzy clustering, and resiliency analyses, the option consisting of a mix of retention and infiltration-based LID technologies (high penetration), a SWR scheme of 5,937 $\mathrm{m}^{3}$, and a detention basin of $37,622 \mathrm{~m}^{3}$ was investigated. This option was selected based on the following:

- Member of the cluster identified as having excellent pollutant control and moderate water volume control for moderate costs

- Highest rank within the cluster in terms of total water footprint and LCCs

- Second highest rank within the cluster in terms of resiliency to climate change

- Third lowest cost option within cluster 5

Table 4-5: Levels of performance corresponding to different index ranges.

\begin{tabular}{lrrr}
\hline Level & \multicolumn{1}{c}{ LCC } & \multicolumn{1}{c}{ BWF } & \multicolumn{1}{c}{ GyWF } \\
\hline Low (L) & $(0.8,1.00]$ & $(0.8,1.00]$ & $(0.8,1.00]$ \\
Medium-low (ML) & $(0.6,0.8]$ & $(0.6,0.8]$ & $(0.6,0.8]$ \\
Medium (M) & $(0.4,0.6]$ & $(0.4,0.6]$ & $(0.4,0.6]$ \\
Medium-high (MH) & $(0.2,0.4]$ & $(0.2,0.4]$ & $(0.2,0.4]$ \\
High (H) & {$[0,0.2]$} & {$[0,0.2]$} & {$[0,0.2]$} \\
\hline
\end{tabular}

Note: $\mathrm{LCC}=$ life cycle costs; BWF = blue water footprint; GyWF = grey water footprint; All

indices were normalized to a scale of 0 to 1 .

Table 4-6: Cluster characteristics for Calgary.

\begin{tabular}{|c|c|c|c|c|}
\hline Cluster & LCC & BWF & GyWF & Description \\
\hline 1 & $\begin{array}{l}\text { Range: } \mathrm{ML} \text { to } \\
\mathrm{M} \\
\text { Predominant: } \mathrm{M}\end{array}$ & $\begin{array}{l}\text { Range: L to ML } \\
\text { Predominant: } \\
\text { ML }\end{array}$ & $\begin{array}{l}\text { Range: } \mathrm{H} \\
\text { Predominant: } \mathrm{H}\end{array}$ & $\begin{array}{l}\text { Excellent pollutant control and poor to moderate water } \\
\text { volume control for moderate costs }\end{array}$ \\
\hline 2 & $\begin{array}{l}\text { Range: } \mathrm{M} \text { to } \\
\mathrm{MH} \\
\text { Predominant: } \mathrm{M}\end{array}$ & $\begin{array}{l}\text { Range: } \mathrm{H} \\
\text { Predominant: } \mathrm{H}\end{array}$ & $\begin{array}{l}\text { Range: } \mathrm{MH} \text { to } \mathrm{H} \\
\text { Predominant: } \mathrm{H}\end{array}$ & $\begin{array}{l}\text { Moderate to excellent pollutant control and water volumes } \\
\text { for low to moderate costs }\end{array}$ \\
\hline 3 & $\begin{array}{l}\text { Range: } \mathrm{L} \text { to } \mathrm{ML} \\
\text { Predominant: } \mathrm{L}\end{array}$ & $\begin{array}{l}\text { Range: } \mathrm{M} \text { to } \\
\mathrm{MH} \\
\text { Predominant: } \\
\mathrm{M}\end{array}$ & $\begin{array}{l}\text { Range: } \mathrm{MH} \text { to } \mathrm{H} \\
\text { Predominant: } \mathrm{H}\end{array}$ & $\begin{array}{l}\text { Excellent at controlling pollutants, moderate at water } \\
\text { volumes, for high costs }\end{array}$ \\
\hline 4 & $\begin{array}{l}\text { Range: } \mathrm{M} \text { to } \mathrm{H} \\
\text { Predominant: } \\
\mathrm{MH}\end{array}$ & $\begin{array}{l}\text { Range: L } \\
\text { Predominant: L }\end{array}$ & $\begin{array}{l}\text { Range: } \mathrm{M} \text { to } \mathrm{H} \\
\text { Predominant: } \\
\mathrm{MH}\end{array}$ & $\begin{array}{l}\text { Poor control of water volumes, moderate pollutant control } \\
\text { at low to moderate cost }\end{array}$ \\
\hline 5 & $\begin{array}{l}\text { Range: } \mathrm{ML} \text { to } \\
\mathrm{M} \\
\text { Predominant: } \mathrm{M}\end{array}$ & $\begin{array}{l}\text { Range: } M \text { to } \\
\text { MH } \\
\text { Predominant: } \\
\text { M }\end{array}$ & $\begin{array}{l}\text { Range: } \mathrm{H} \\
\text { Predominant: } \mathrm{H}\end{array}$ & $\begin{array}{l}\text { Excellent pollutant control and moderate water volume } \\
\text { control for moderate costs }\end{array}$ \\
\hline 6 & $\begin{array}{l}\text { Range: } \mathrm{L} \text { to } \mathrm{ML} \\
\text { Predominant: } \mathrm{L}\end{array}$ & $\begin{array}{l}\text { Range: } \mathrm{M} \text { to } \mathrm{H} \\
\text { Predominant: } \\
\mathrm{M}\end{array}$ & $\begin{array}{l}\text { Range: } \mathrm{H} \\
\text { Predominant: } \mathrm{H}\end{array}$ & $\begin{array}{l}\text { Excellent pollutant control with moderate water volume } \\
\text { control at high costs }\end{array}$ \\
\hline
\end{tabular}



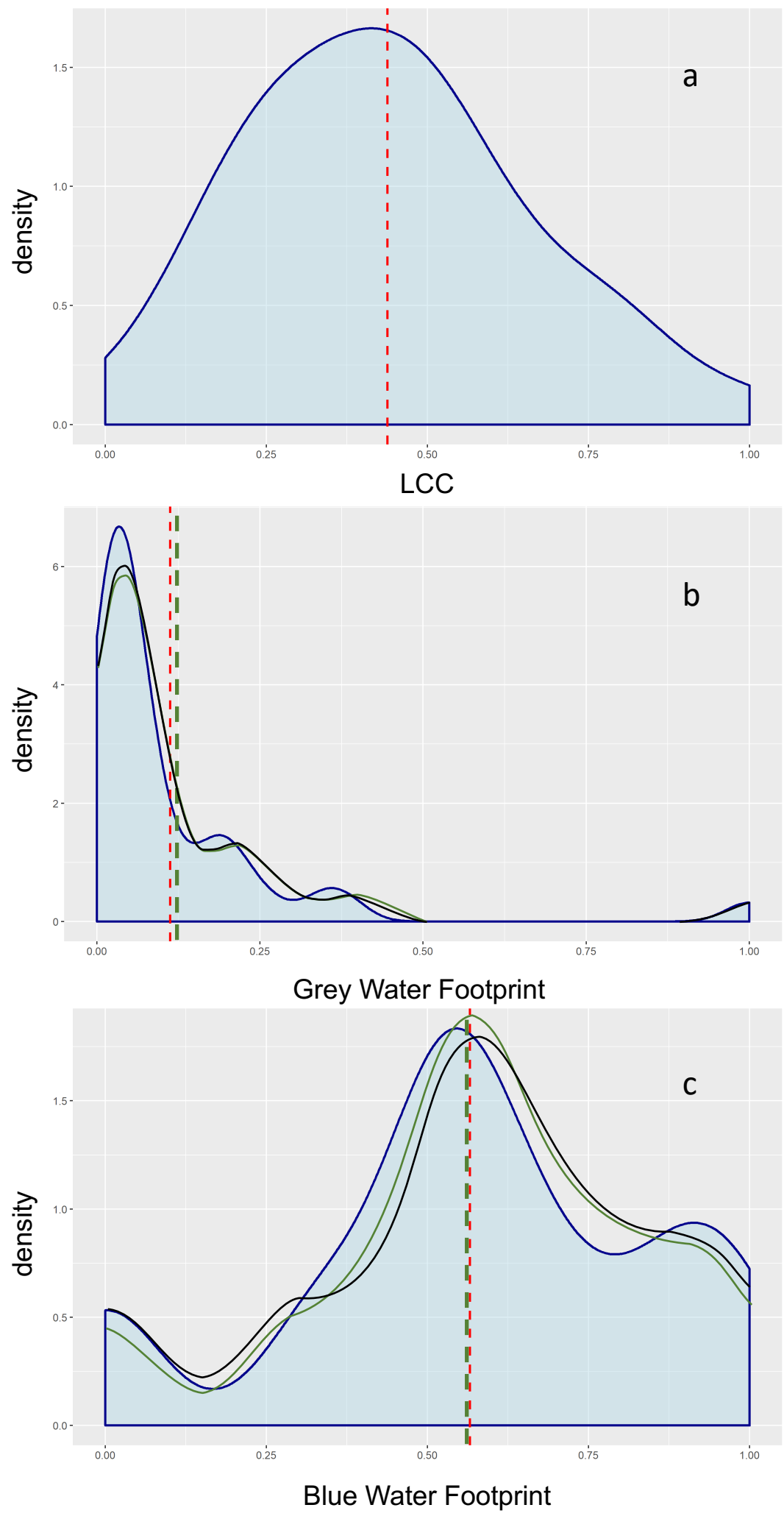

Figure 4-3:The kernel density estimation (KDE) of (a) life cycle costs (LCC); (b) grey water footprints; and (c) blue water footprints for the Calgary case study demonstration. The blue KDE with red line represents the current climate, green represents RCP 2.6, and black represents RCP 8.5. Dashed lines indicate averages. 


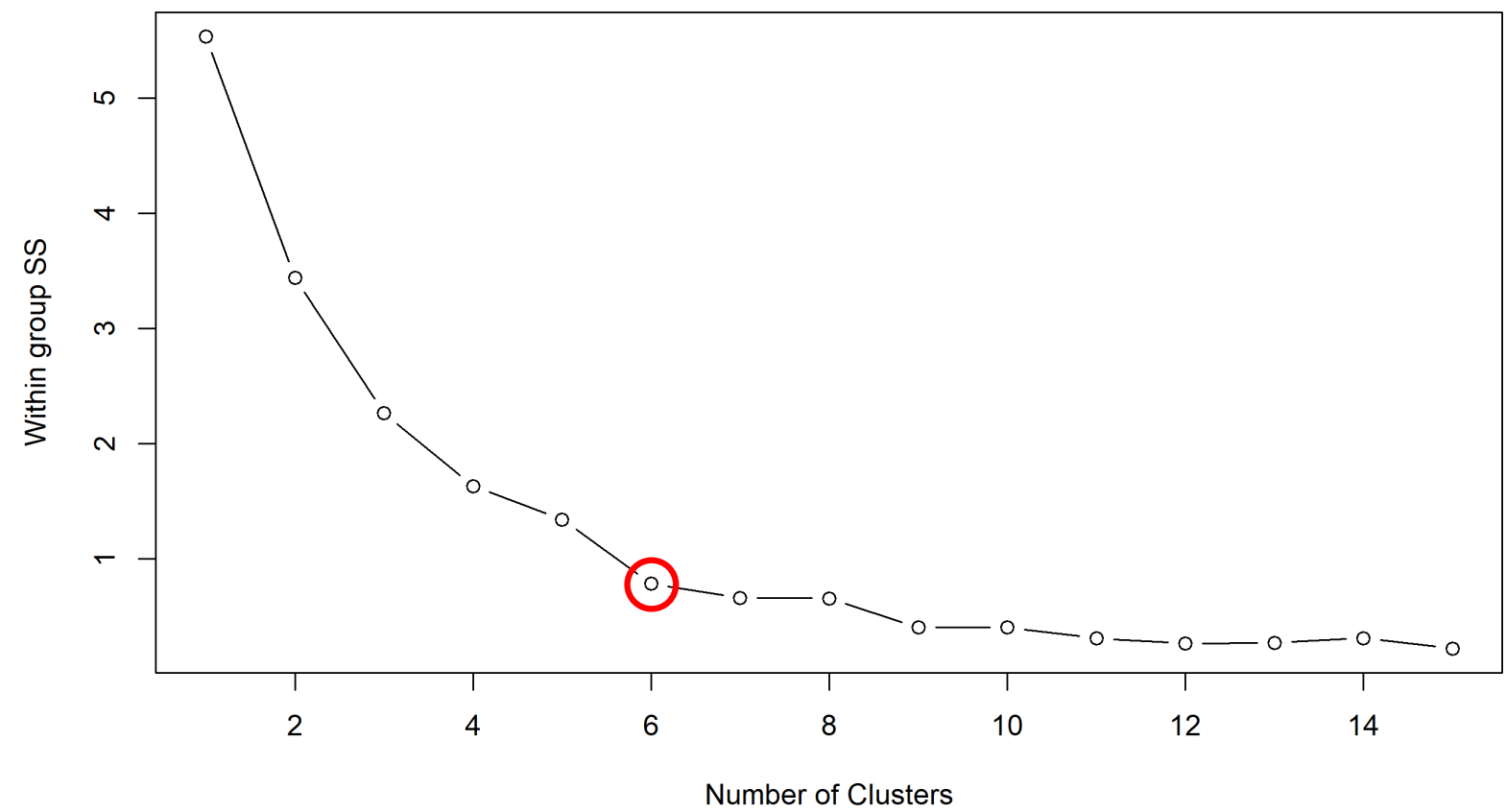

Figure 4-4: The variation of within-group sum of squares (SS) with change in cluster number for Calgary.

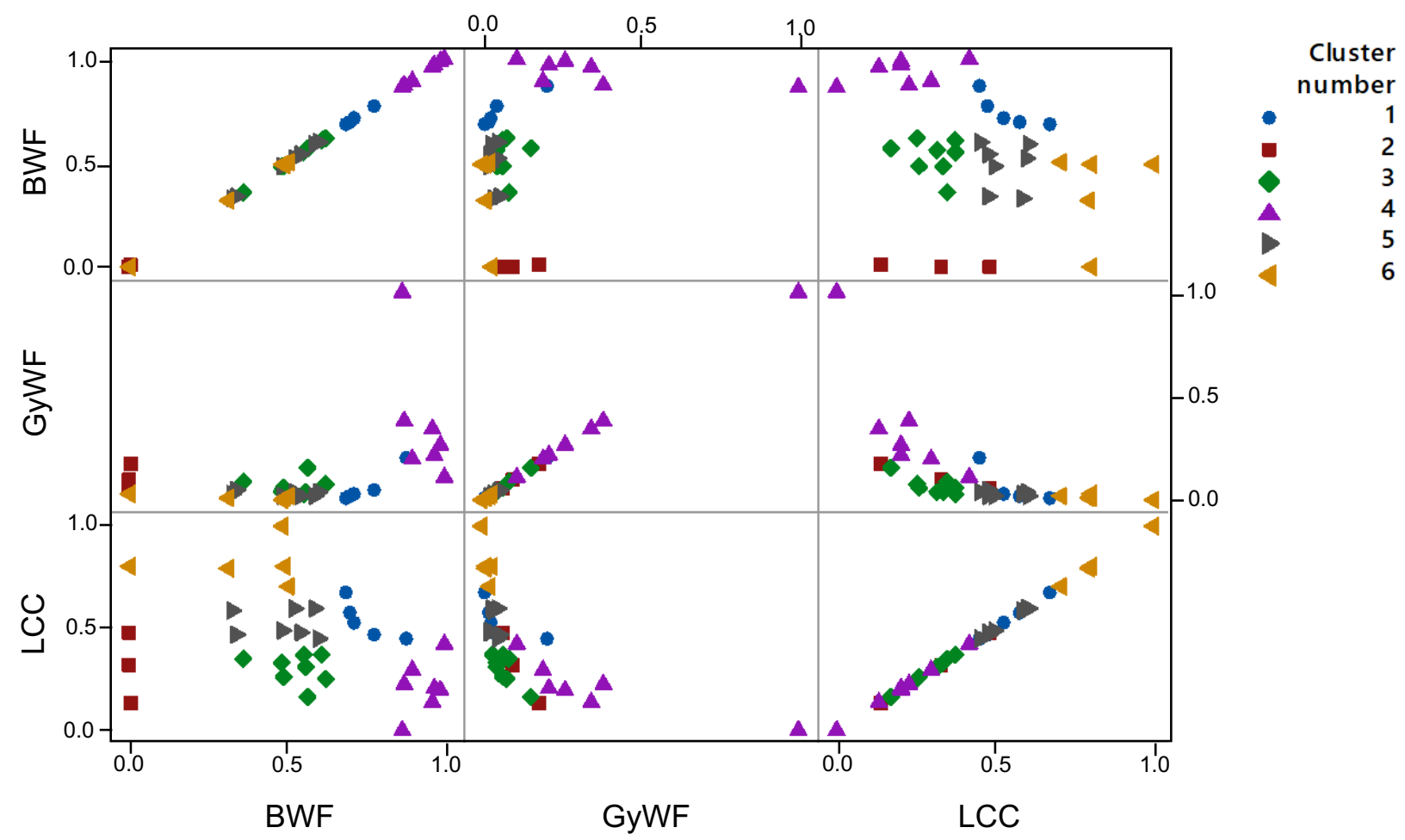

Figure 4-5: Matrix scatterplot of FCA for Calgary. 


\subsubsection{Detailed analysis of selected option}

A water balance equation (WBE) can be used as simple method for describing the flow of water in and out of a system by relying on the principles of conversation of mass in a closed system. Water balance equations can be customized to reflect the types of flows that are desired to be represented. Water balance equations have been used as a simple method of quantifying the flow of precipitation through systems by many researchers (Jing et al. 2018; Starry et al. 2016). The WBEs generated in this research are used to outline the flow of water through system components in terms of precipitation, infiltration, evapotranspiration, reuse, and conveyance. The WBE represents these four parameters not only for the entire community, but also for each individual BMP, stormwater reuse system, and conveyance-based system components.

Figure 4-6 is visual representations of the WBE for the selected infrastructure scenario for Kelowna. Three WBEs are captured in each WBE schematic, performance for the $05^{\text {th }}$ percentile, $50^{\text {th }}$ percentile, and $95^{\text {th }}$ percentile years in terms of total precipitation. For Kelowna, the total annual precipitation of the selected years are 348, 441, and $488 \mathrm{~mm}$, respectively. Figure 4-6a is the WBE under historical precipitation patterns, and Figure 4-6b is the WBE under RCP 8.5. As a form of basic validation of the WBE capabilities of the OWSWPF, the sum of evapotranspiration, infiltration, runoff, and SWR volumes minus irrigation is within $5 \%$ of the total volume of precipitated water. This small difference is attributed to the volume of water retained in LID and SWR infrastructure components at the end of each annual simulation. As the OWSWPF is a planning framework and not a design tool, this small difference is negligible in terms of decision making.

In terms of SWR performance, greater annual precipitation values result in greater volumes of reusable stormwater. This relationship is observed for both historical and RCP 8.5 climate scenarios. An inverse relationship between annual AWU and annual precipitation is also observed for all three years in both climate scenarios. As expected, the increased volume of reusable stormwater can be attributed to the increase in runoff volumes also observed as annual precipitation increases. 

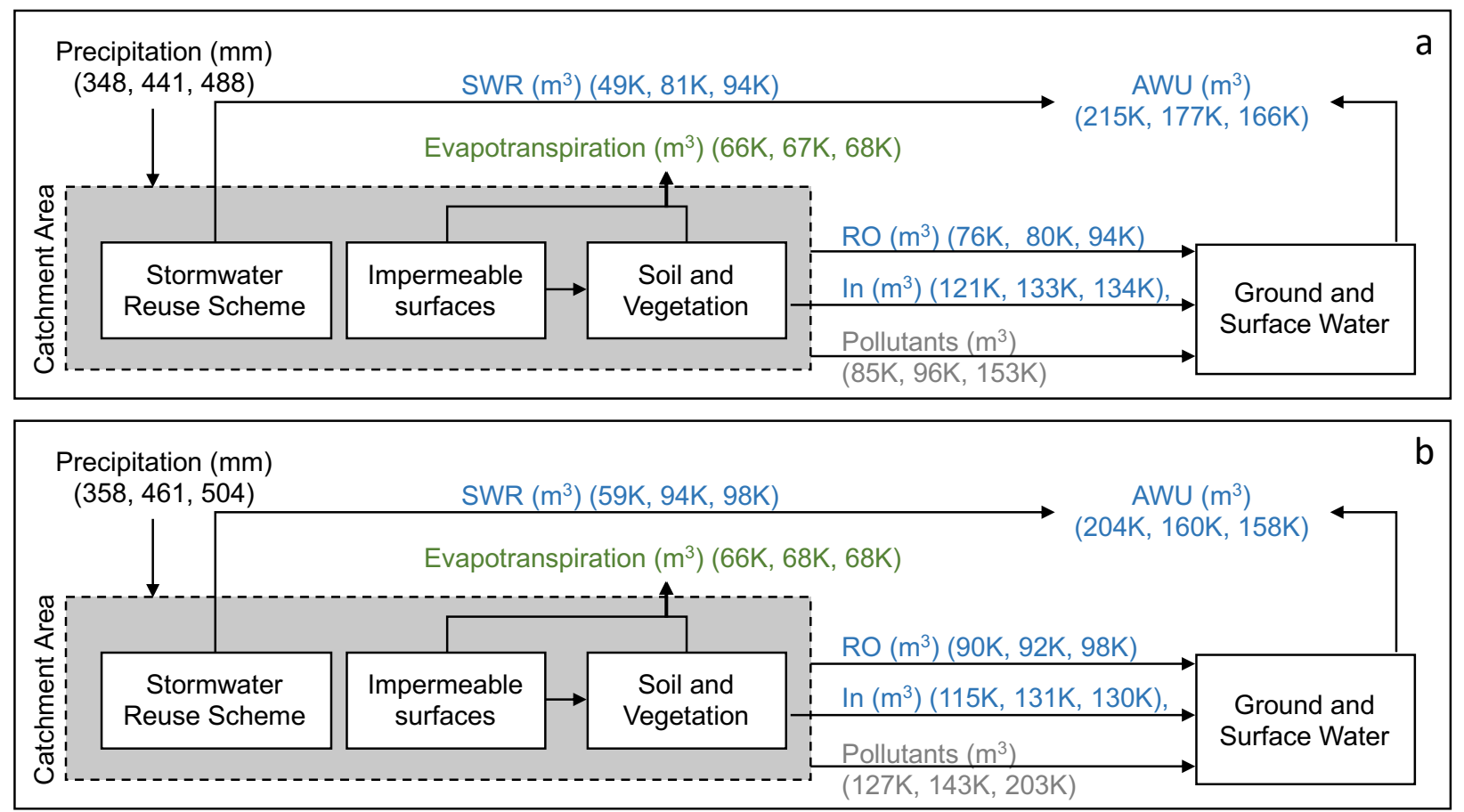

Figure 4-6: Visual representation of WBEs for historical climate norms (a) and RCP 8.5 (b) for Calgary. Values in parentheses represent the calculate values for three different annual precipitation amounts.

The impact of selecting a simplistic model for calculating evapotranspiration is also apparent when examining Figure 4-17. The Blaney-Criddle method for calculating evapotranspiration relies on only latitude, and average daily temperature to calculate total EVT. This simplistic model combined with the fact that many irrigation models in the OWSWPF are precipitation dependent (i.e., less rain results in more irrigation, resulting in very similar EVT volumes) results in less interannual variability in EVT volumes despite differences in total annual precipitation.

Despite varying levels of total annual precipitation observed in both climate scenarios, the annual infiltration capacity of the system appears to be approximately $130 \mathrm{~K}$ to $134 \mathrm{~K}$, as total annual precipitation values ranging from $441 \mathrm{~mm}$ to $504 \mathrm{~mm}$ resulted in roughly the same values of annual infiltrated volumes.

To further investigate the relationships between annual rainfall and system performance, a regression was performed to identify their numerical relationships (Figure 4-7). With an $\mathrm{R}^{2}$ value of 0.69 , an exponential relationship between annual precipitation and total water footprint was identified. As the selected infrastructure scenario relies on a mix of both LID and SWR infrastructure components, this relationship is not unexpected. As each of the components are 
limited in terms of volume and treatment capacity, the components are also limited in terms of performance.

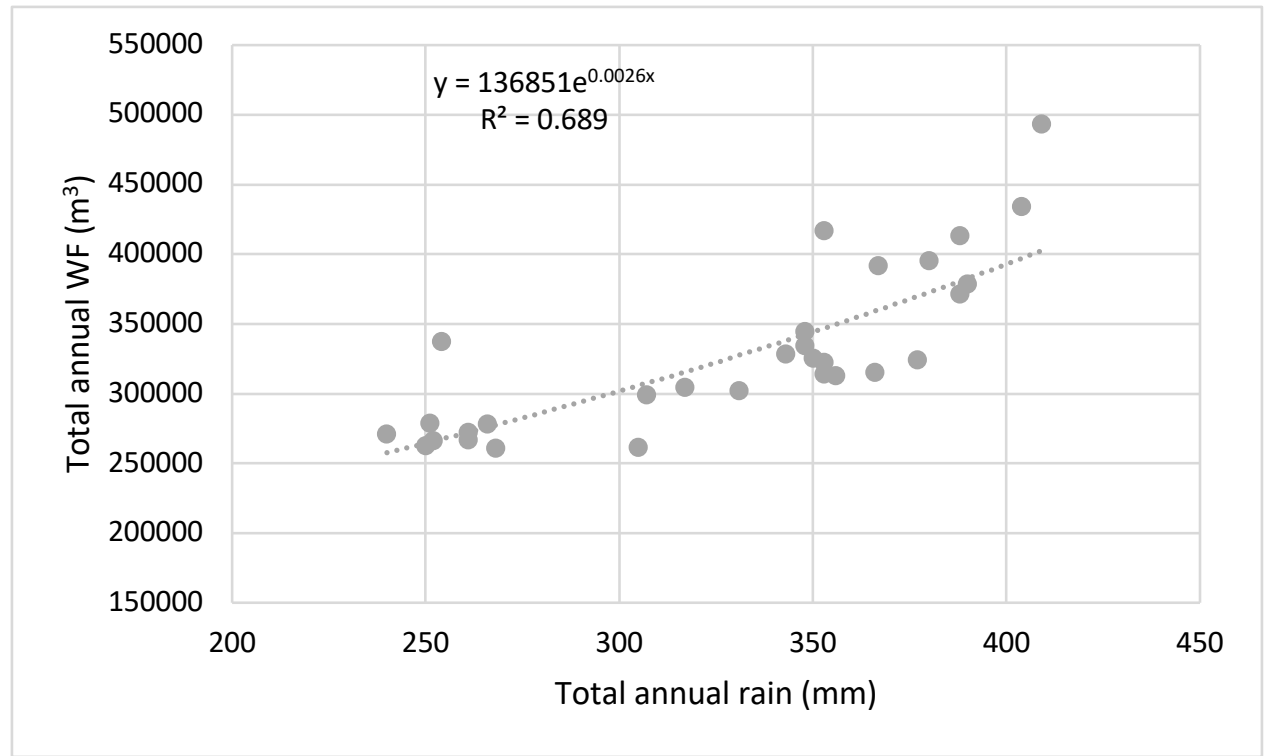

Figure 4-7: Total annual water footprint vs. total annual rainfall for Calgary.

Upon initial investigation of the GWF values, there appears to be a "breakthrough" point at which the pollutant treatment performance of LID and SWR components become overrun and a increases in annual precipitation result in non-proportional increases to GWF values. To further investigate this relationship, an analysis of the relationship between annual precipitation and GWFs was completed (Figure 4-8). After plotting both values on a scatterplot, the "breakthrough" point at which the system becomes overwhelmed in terms of pollutant control appears to be around 475 $\mathrm{mm}$ of total annual precipitation. This breakthrough value is not a problem under historical climate norms (where $\sim 80 \%$ of annual precipitation simulations are below this value), but it becomes an issue when considering RCP 8.5 (where $\sim 40 \%$ of annual precipitation simulations are above this value. As the OWSWPF sizes infrastructure components based on historical IDF tables, this case study offers evidence that stormwater planners are required to size their infrastructure according to predicted changes in IDF tables.

The following paragraph outlines the detailed assessment of the LCC results for the Calgary case study. In terms of the triangular fuzzy number used for the Fuzzy TOPSIS decision-making algorithm, the results for the selected infrastructure scenario are $(\$ 18.6 \mathrm{M} ; \$ 24.8 \mathrm{M} ; \$ 31.9 \mathrm{M})$. This represents a large range in possible costs from $\$ 18.6 \mathrm{M}$ to $\$ 31.9 \mathrm{M}$. Figure $4-9$ is set of boxplots representing the results of the Monte Carlo-based life cycle costs. When further investigating the 
data displayed in Figure 4-9, it can be seen that the SWR scheme is responsible for a larger portion of LCC in terms of capital costs, operations and maintenance, and decommissioning. The remainder of the costs are distributed between the LID (i.e., green roofs, rain barrels, permeable pavement systems, bioretention cells, infiltration trenches, and constructed stormwater wetlands) and detention infrastructure components incorporated in this scenario. Although a CSW is included in this infrastructure scenario $\left(1,576 \mathrm{~m}^{2}\right)$, its size is relatively small due to the fact that the upstream LID components greatly reduce runoff volumes and therefore contribute to the CSW's small size. As a result the LCCs for the CSW are only visible in the pie charts if the size is increased (i.e., the CSW does not cost much). For this selected infrastructure scenario (SWR volume of 5,936 $\mathrm{m}^{3}$ ), a SWR scheme is able to provide $49-98 \mathrm{~m}^{3}$ of reusable water to offset AWU volumes for $\$ 1.71 / \mathrm{m}^{3}$ $-\$ 3.42 / \mathrm{m}^{3}$ per hectare. This results in an effective reusable stormwater volume of $8.3-16.5 \mathrm{~m}^{3}$ per metre cube of installed capacity. This increase is retained runoff was capable of reducing the size of the detention facility by $\sim 54 \%$ compared to a traditional community (no LID or SWR).

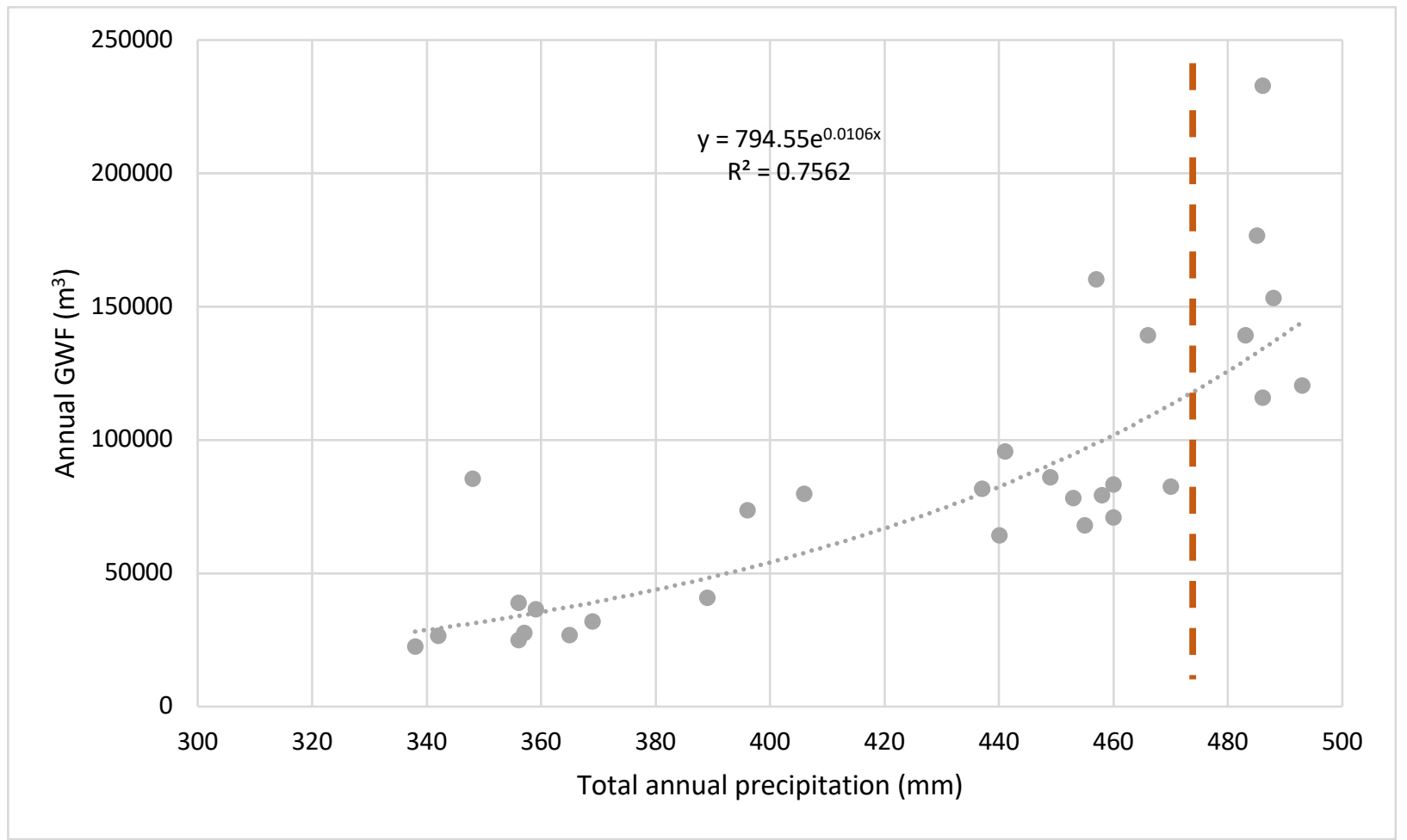

Figure 4-8: Annual GWF vs. total annual precipitation for Calgary. Red deashed line represents the pollutant breakthrough point. 


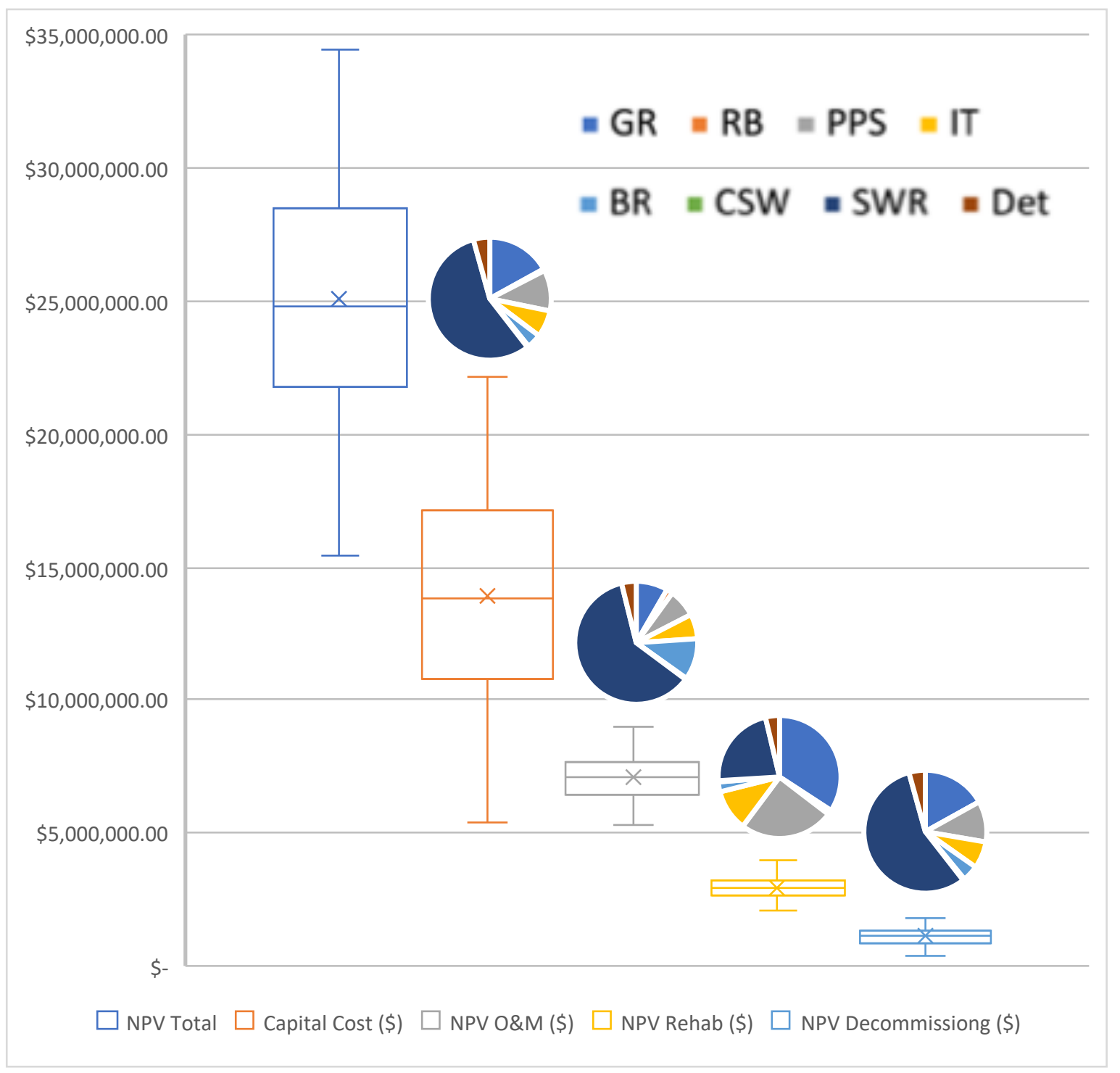

Figure 4-9: Boxplots of Monte Carlo-based life cycle costs for Calgary. All values in net present value. Pie charts represent the ratio of each infrastructure component for each life cycle cost category.

\subsection{Kelowna (BC, Canada)}

Kelowna, BC, the largest city in the Okanagan Valley in BC, is well known for its hot summers and temperate winters (City of Kelowna 2017). The residents of the Okanagan Valley have the unfortunate reputation of being some of the highest per capita water users in the province of BC (Okanagan Basin Water Board 2015), with an average daily water use of $675 \mathrm{~L}$ per person per day, increasing to $\sim 1,000 \mathrm{~L}$ per person per day in the summer months (Okanagan Basin Water Board 2015). These values are much higher than the provincial average of $490 \mathrm{~L} /$ day and the national 
average of $329 \mathrm{~L} /$ day (Okanagan Basin Water Board 2015). These values point to an excellent opportunity for alternative water management strategies, including the possibility of stormwater capture, treatment and reuse.

Kelowna is classified as a cold semi-arid environment according to the Köppen-Geiger climate classification (Peel et al. 2007) and part of the South British Columbia Mountains Canadian climatic region according to Environment Canada (Environment Canada 1998). With $387 \mathrm{~mm}$ of annual precipitation $(311 \mathrm{~mm}$ as rainfall and $89 \mathrm{~cm}$ of snowfall), and four months of year with average temperatures near or below $0^{\circ} \mathrm{C}$ (Government of Canada 2017), any potential stormwater reuse schemes would have to address the relatively low annual rainfall and months with freezing temperatures.

Kelowna soils have developed in deep, medium to moderately coarse-textured glacial till deposits which are usually capped with sandy to loamy, surface deposits that are generally 10 to $30 \mathrm{~cm}$ in thickness. Although surface soils are well drained, subsoils are dense and compact and may limit infiltration (Gough et al. 1994).

Table 4-7:Average monthly climate normals for Calgary and Kelowna (1981-2010)

\begin{tabular}{lllllllllllllll}
\hline & Parameter & Jan & Feb & Mar & Apr & May & Jun & Jul & Aug & Sep & Oct & Nov & Dec & Annual \\
\hline Calgary & Temp $\left({ }^{\circ} \mathrm{C}\right)$ & -7.1 & -5.4 & -1.6 & 4.6 & 9.7 & 13.7 & 16.5 & 15.8 & 11.0 & 5.2 & -2.4 & -6.8 & 4.4 \\
& Precip (mm) & 9.4 & 9.4 & 17.8 & 25.2 & 56.8 & 94.0 & 65.5 & 57.0 & 45.1 & 15.3 & 13.1 & 10.2 & 418.8 \\
\multirow{3}{*}{ Kelowna } & $\operatorname{Temp~}\left({ }^{\circ} \mathrm{C}\right)$ & -2.5 & -0.9 & 4.1 & 8.4 & 12.8 & 16.6 & 19.5 & 19.1 & 13.9 & 7.3 & 1.6 & -2.6 & 8.1 \\
& $\operatorname{Precip~}(\mathrm{mm})$ & 31.0 & 19.0 & 21.6 & 29.1 & 40.2 & 45.9 & 37.2 & 32.1 & 32.4 & 29.2 & 36.7 & 32.6 & 386.9 \\
\hline
\end{tabular}

Both case studies shared the same control variable values to enable meaningful comparison of results. A full outline of control variable inputs is available in Appendix C.

\subsubsection{Precipitation simulation results}

The OWSWPF precipitation simulation results for Kelowna are summarized in Table 4-8. More detailed results are available in Appendix B. The average simulated historical annual precipitation, annual rainfall, and annual snowfall values from the 30 simulated years are within 3.3\%, 3.8\%, and 3.1\% of observed historical averages (between 1981 and 2010), respectively. The RCP 2.6 climate change scenario simulation resulted in an average annual decrease of $3.7 \%$ in total precipitation, but an increase of $17.4 \%$ in annual rainfall (i.e., a smaller percentage of the precipitation is predicted to be in the form of snowfall). The largest rainfall event for RCP 2.6 
increased by $12.5 \%$ to $35.9 \mathrm{~mm}$. The RCP 8.5 climate change scenario simulation resulted in a $13.2 \%$ increase in average total annual precipitation with a dramatic $14.1 \%$ increase in annual

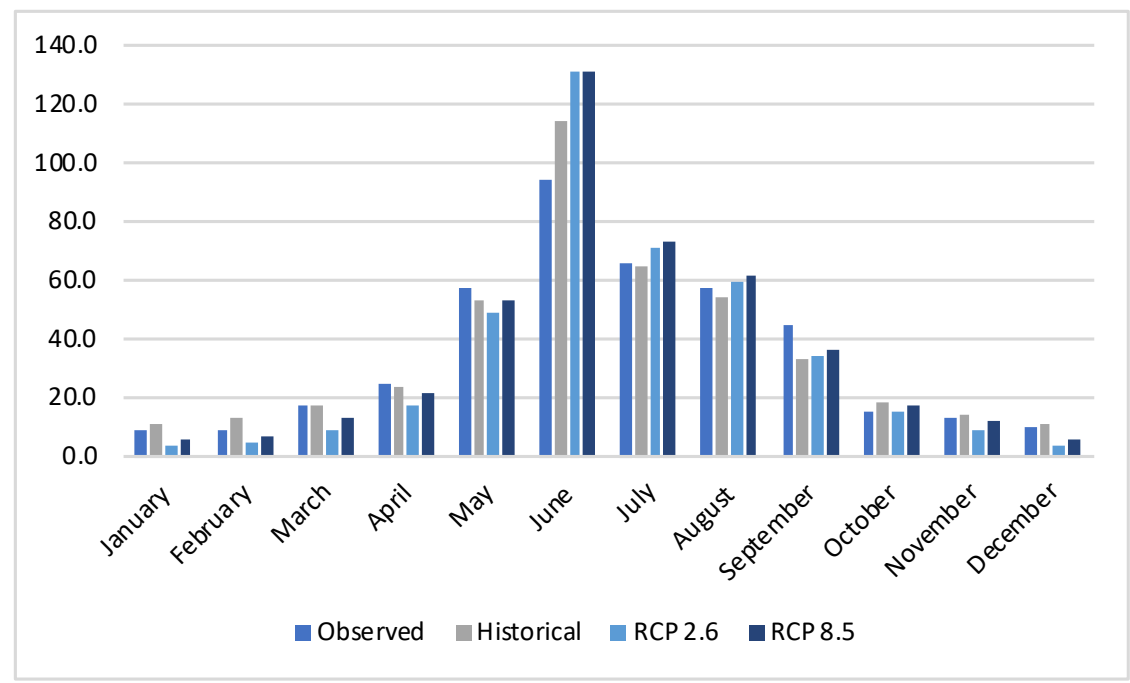

Figure 4-10: Average monthly precipitation values generated by the OWSWPF for current (Historical) and predicted climate change (RCP 2.6 and RCP 8.5) and observed historical averages (Observed) for Calgary.

rainfall and an average snowfall decrease of 53.1\%. The maximum depth rainfall event for RCP 8.5 is $42.9 \mathrm{~mm}$, with smaller, more frequent storm events predicted to increase in depth. The results for the RCP 2.6 and RCP 8.5 scenarios are in line with predicted changes based on the IDF tables (Simonovic et al. 2018), annual snowpack change, and annual precipitation change (Government of Canada 2018b). Figure 4-11 is a visual comparison of observed and simulated average monthly precipitation values for Calgary.

Table 4-8: Annual precipitation statistics for precipitation simulations based on historical data.

\begin{tabular}{|c|c|c|c|c|c|c|c|c|}
\hline \multirow[t]{2}{*}{ Year } & \multicolumn{2}{|c|}{$\begin{array}{l}\text { Annual Precipitation } \\
(\mathrm{mm})\end{array}$} & \multicolumn{2}{|c|}{$\begin{array}{l}\text { Annual Rainfall } \\
\text { (mm) }\end{array}$} & \multicolumn{2}{|c|}{$\begin{array}{l}\text { Annual Snowfall } \\
\qquad(\mathrm{cm})\end{array}$} & \multicolumn{2}{|c|}{$\begin{array}{l}\text { Max depth rainfall } \\
\text { (mm) }\end{array}$} \\
\hline & avg: 387.0 & & avg: 311.3 & & avg: 89.0 & & $\max : 33.8$ & \\
\hline Simulation (Historical) ${ }^{\mathrm{a}}$ & avg: 399.8 & $+3.3 \%$ & avg: 323.1 & $+3.8 \%$ & avg: 91.8 & $+3.1 \%$ & $\max : 31.9$ & $-5.6 \%$ \\
\hline Simulation (RCP 2.6) & avg: 384.9 & $-3.7 \%$ & avg: 379.2 & $+17.4 \%$ & avg: 62.8 & $-31.6 \%$ & $\max : 35.9$ & $+12.5 \%$ \\
\hline Simulation (RCP 8.5$)^{\mathrm{b}}$ & avg: 452.4 & $+13.2 \%$ & avg: 448.5 & $+38.8 \%$ & avg: 43.1 & $-53.1 \%$ & $\max : 42.9$ & $+34.5 \%$ \\
\hline
\end{tabular}

a: percent change relative to observed historical data

b: percent change relative to simulated historical data 


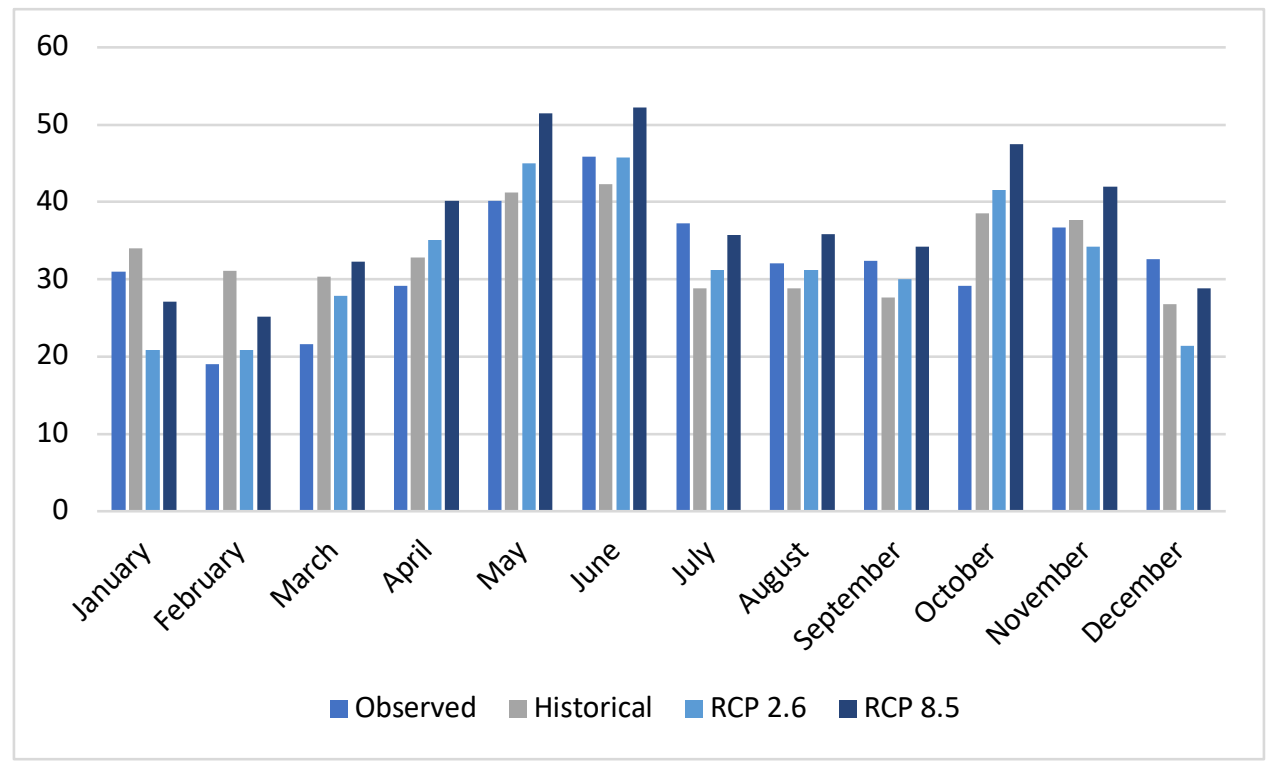

Figure 4-11: Average monthly precipitation values generated by the OWSWPF for current (Historical) and predicted climate change (RCP 2.6 and RCP 8.5) and observed historical averages (Observed) for Kelowna.

\subsubsection{Fuzzy TOPSIS results}

Table 4-9 outlines the ranking and closeness coefficients of all 35 infrastructure mix scenarios for each of the decision weighting scenarios outlined in Table 4-2 for Kelowna. Figure 4-12 and Figure 4-13 are visual representations of the Fuzzy-TOPSIS results for Kelowna. A full fuzzy decision matrix for the Fuzzy-TOPSIS algorithm is available in Appendix C for both Calgary and Kelowna.

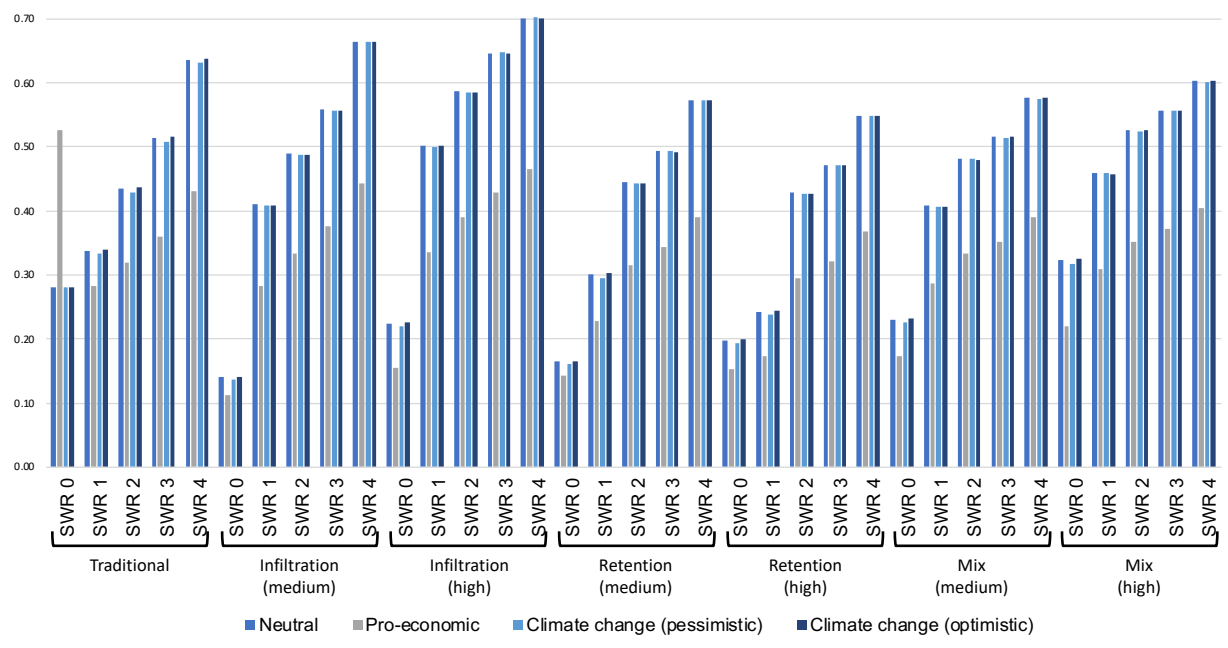

Figure 4-12: Closeness coefficients for stormwater infrastructure scenarios in Kelowna. 


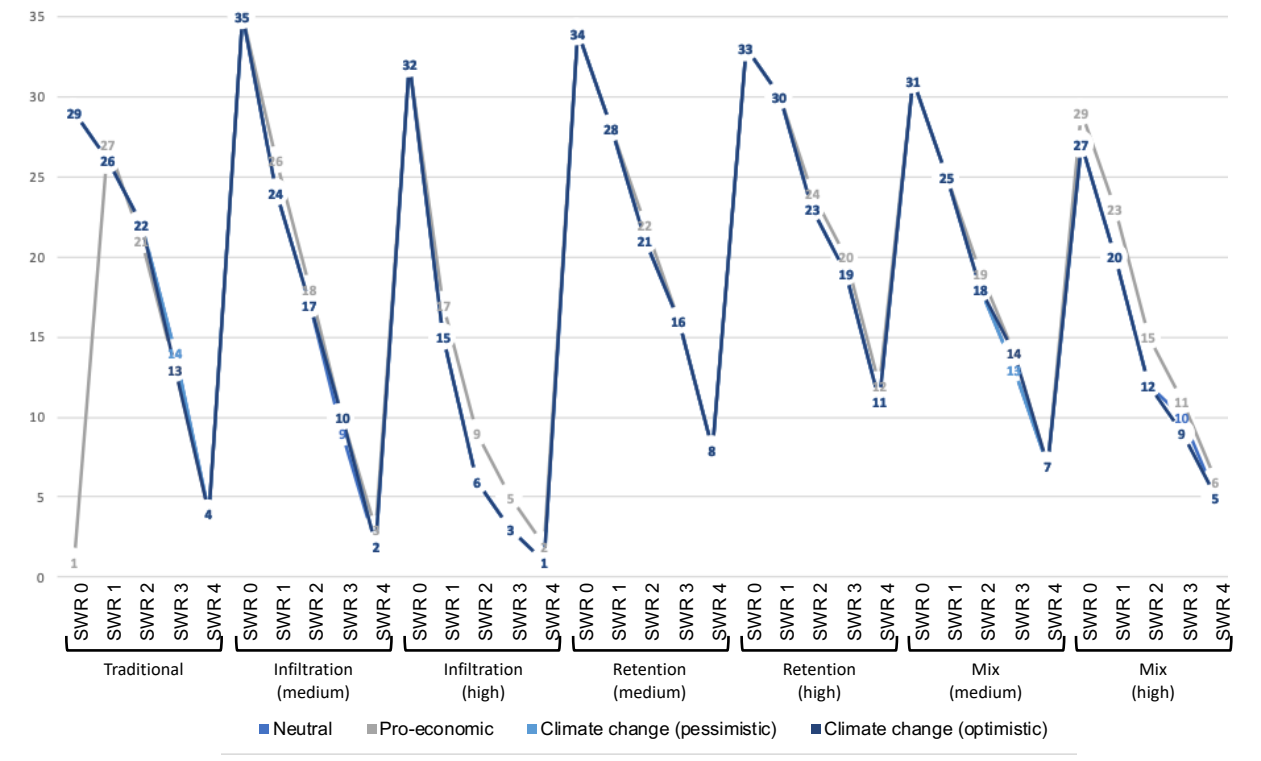

Figure 4-13: Change in ranking results for all infrastructure and weighting scenarios for Kelowna.

Except for the pro-economic scenario weighting scenario, SWR infrastructure was incorporated into all the top-ranked infrastructure scenarios for both case studies. It can be clearly seen that SWR has a significant effect on system performance. The lowest ranked infrastructure options as per the Fuzzy-TOPSIS algorithm are those lacking and SWR components. SWR's strong effects on results are attributed to its combined ability to cost-effectively remove pollutants and offset anthropogenic water use. The largest deviation in ranking and closeness coefficients is observed between the pro-economic and the other three weighting scenarios. Although there is slight deviation between the neutral, optimistic, pessimistic weighting scenarios, in general these three scenarios tracked the same trends in terms of ranks and closeness coefficients. Although slight variations exist between the Calgary and Kelowna case studies in terms of Fuzzy-TOPSIS results, intra-scenario trends in performance and climate resilience are very similar for both case studies.

\subsubsection{Fuzzy clustering analysis}

For Kelowna, the LCC KDE reveals a normal distribution (p-value of 0.90 for Anderson-Darling test) around the mean of $\$ 18.4 \mathrm{M}$, with minimum and maximum values of $\$ 0.9 \mathrm{M}$ and $\$ 39.6 \mathrm{M}$, respectively. As the 35 infrastructure scenarios represent various degrees of infrastructure complexity and management, this normal distribution of LCCs is expected. It is important to note that the average LCCs for Kelowna are roughly $20 \%$ lower than the average for the Calgary case study. These lower LCCs are due to the differences in sizing attributed to hydrologic-based sizing 
Table 4-9: Infrastructure mix rankings and closeness coefficients for different weighting scenarios for Kelowna.

\begin{tabular}{|c|c|c|c|c|c|c|c|c|}
\hline \multirow[b]{2}{*}{ Infrastructure alternatives } & \multicolumn{2}{|c|}{ Neutral } & \multicolumn{2}{|c|}{ Pro-economic } & \multicolumn{2}{|c|}{$\begin{array}{l}\text { Pessimistic about } \\
\text { climate change }\end{array}$} & \multicolumn{2}{|c|}{$\begin{array}{l}\text { Optimistic about } \\
\text { climate change }\end{array}$} \\
\hline & $\mathrm{CC}$ & Rank & $\mathrm{CC}$ & Rank & $\mathrm{CC}$ & Rank & $\mathrm{CC}$ & Rank \\
\hline Traditional (SWR 0) & 0.28 & 29 & 0.53 & 1 & 0.28 & 29 & 0.28 & 29 \\
\hline Traditional (SWR 1) & 0.34 & 26 & 0.28 & 27 & 0.33 & 26 & 0.34 & 26 \\
\hline Traditional (SWR 2) & 0.44 & 22 & 0.32 & 21 & 0.43 & 22 & 0.44 & 22 \\
\hline Traditional + (SWR 3) & 0.51 & 14 & 0.36 & 13 & 0.51 & 14 & 0.52 & 13 \\
\hline Traditional + (SWR 4) & 0.64 & 4 & 0.43 & 4 & 0.63 & 4 & 0.64 & 4 \\
\hline Traditional + LID (Inf-med) (SWR0) & 0.14 & 35 & 0.11 & 35 & 0.14 & 35 & 0.14 & 35 \\
\hline Traditional + LID (Inf-med) (SWR1) & 0.41 & 24 & 0.28 & 26 & 0.41 & 24 & 0.41 & 24 \\
\hline Traditional + LID (Inf-med) (SWR2) & 0.49 & 17 & 0.33 & 18 & 0.49 & 17 & 0.49 & 17 \\
\hline Traditional + LID (Inf-med) (SWR3) & 0.56 & 9 & 0.38 & 10 & 0.56 & 10 & 0.56 & 10 \\
\hline Traditional + LID (Inf-med) (SWR4) & 0.66 & 2 & 0.44 & 3 & 0.66 & 2 & 0.66 & 2 \\
\hline Traditional + LID (Inf-high) (SWR0) & 0.22 & 32 & 0.16 & 32 & 0.22 & 32 & 0.23 & 32 \\
\hline Traditional + LID (Inf-high) (SWR1) & 0.50 & 15 & 0.34 & 17 & 0.50 & 15 & 0.50 & 15 \\
\hline Traditional + LID (Inf-high) (SWR2) & 0.59 & 6 & 0.39 & 9 & 0.59 & 6 & 0.59 & 6 \\
\hline Traditional + LID (Inf-high) (SWR3) & 0.65 & 3 & 0.43 & 5 & 0.65 & 3 & 0.65 & 3 \\
\hline Traditional + LID (Inf-high) (SWR4) & 0.70 & 1 & 0.47 & 2 & 0.70 & 1 & 0.70 & 1 \\
\hline $\begin{array}{l}\text { Traditional + LID (Ret-med) } \\
\text { (SWR0) }\end{array}$ & 0.16 & 34 & 0.14 & 34 & 0.16 & 34 & 0.17 & 34 \\
\hline Traditional + LID (Ret-med) & & & & & & & & \\
\hline $\begin{array}{l}\text { (SWR1) } \\
\text { Traditional + LID (Ret-med) }\end{array}$ & 0.30 & 28 & 0.23 & 28 & 0.29 & 28 & 0.30 & 28 \\
\hline (SWR2) & 0.44 & 21 & 0.32 & 22 & 0.44 & 21 & 0.44 & 21 \\
\hline $\begin{array}{l}\text { Traditional + LID (Ret-med) } \\
\text { (SWR3) }\end{array}$ & 0.49 & 16 & 0.34 & 16 & 0.49 & 16 & 0.49 & 16 \\
\hline $\begin{array}{l}\text { Traditional + LID (Ret-med) } \\
\text { (SWR4) }\end{array}$ & 0.57 & 8 & 0.39 & 8 & 0.57 & 8 & 0.57 & 8 \\
\hline $\begin{array}{l}\text { Traditional + LID (Ret-high) } \\
\text { (SWR0) }\end{array}$ & 0.20 & 33 & 0.15 & 33 & 0.19 & 33 & 0.20 & 33 \\
\hline Traditional + LID (Ret-high) & & & & & & & & \\
\hline $\begin{array}{l}\text { (SWR1) } \\
\text { Traditional + LID (Ret-high) }\end{array}$ & 0.24 & 30 & 0.17 & 30 & 0.24 & 30 & 0.24 & 30 \\
\hline (SWR2) & 0.43 & 23 & 0.29 & 24 & 0.43 & 23 & 0.43 & 23 \\
\hline $\begin{array}{l}\text { Traditional + LID (Ret-high) } \\
\text { (SWR3) }\end{array}$ & 0.47 & 19 & 0.32 & 20 & 0.47 & 19 & 0.47 & 19 \\
\hline $\begin{array}{l}\text { Traditional + LID (Ret-high) } \\
\text { (SWR4) }\end{array}$ & 0.55 & 11 & 0.37 & 12 & 0.55 & 11 & 0.55 & 11 \\
\hline $\begin{array}{l}\text { Traditional + LID (Mix-med) } \\
\text { (SWR0) }\end{array}$ & 0.23 & 31 & 0.17 & 31 & 0.23 & 31 & 0.23 & 31 \\
\hline $\begin{array}{l}\text { Traditional + LID (Mix-med) } \\
\text { (SWR1) }\end{array}$ & 0.41 & 25 & 0.29 & 25 & 0.41 & 25 & 0.41 & 25 \\
\hline $\begin{array}{l}\text { Traditional + LID (Mix-med) } \\
\text { (SWR2) }\end{array}$ & 0.48 & 18 & 0.33 & 19 & 0.48 & 18 & 0.48 & 18 \\
\hline $\begin{array}{l}\text { Traditional + LID (Mix-med) } \\
\text { (SWR3) }\end{array}$ & 0.52 & 13 & 0.35 & 14 & 0.51 & 13 & 0.52 & 14 \\
\hline $\begin{array}{l}\text { Traditional + LID (Mix-med) } \\
\text { (SWR4) }\end{array}$ & 0.58 & 7 & 0.39 & 7 & 0.58 & 7 & 0.58 & 7 \\
\hline Traditional + LID (Mix-high) & & & & & & & & \\
\hline (SWR0) & 0.32 & 27 & 0.22 & 29 & 0.32 & 27 & 0.32 & 27 \\
\hline Traditional + LID (Mix-high) & & & & & & & & \\
\hline (SWR1) & 0.46 & 20 & 0.31 & 23 & 0.46 & 20 & 0.46 & 20 \\
\hline $\begin{array}{l}\text { Traditional + LID (Mix-high) } \\
\text { (SWR2) }\end{array}$ & 0.53 & 12 & 0.35 & 15 & 0.52 & 12 & 0.53 & 12 \\
\hline Traditional + LID (Mix-high) & & & & & & & & \\
\hline (SWR3) & 0.56 & 10 & 0.37 & 11 & 0.56 & 9 & 0.56 & 9 \\
\hline $\begin{array}{l}\text { Traditional + LID (Mix-high) } \\
\text { (SWR4) }\end{array}$ & 0.60 & 5 & 0.40 & 6 & 0.60 & 5 & 0.60 & 5 \\
\hline
\end{tabular}


of stormwater infrastructure (e.g., SWR, CSW, and detention components). For example, detention basins are sized based on a 100-year return period storm. In Calgary this storm has a depth of $103.14 \mathrm{~mm}$, while in Kelowna this storm only has a depth of $40.75 \mathrm{~mm}$. The GyWFs for Calgary were not found to follow a normal, log, hyperbolic, or exponential distribution. The GyWFs for Kelowna have a mean value of $133.9 \mathrm{~K} \mathrm{~m}^{3}$, a median of $40.9 \mathrm{~K} \mathrm{~m}^{3}$, a minimum of $12.5 \mathrm{~K} \mathrm{~m}^{3}$, and a maximum of $1.63 \mathrm{M} \mathrm{m}^{3}$. The average GyWF for Kelowna is only $42 \%$ of the average GyWF of Calgary. This clear difference in pollutant loads is attributed to the fact that Kelowna experiences a greater amount of small precipitation events more evenly distributed throughout the year, as opposed to the heavy rainfall season experienced in summer months in Calgary. The results are indicative of the fact that LID and SWR components perform better when experiencing smaller rainfall events. As with Calgary, the GyWF KDE for Kelowna is representative of the fact that most infrastructure scenarios have at least some degree of SWR of LID, with the only completely traditional infrastructure scenario seen as an outlier. In contrast with trimodal distribution seen in BWFs of the Calgary case study, the bimodal distribution seen in the BWF KDE for Kelowna is representative of the following normally distributed groups:

- $\quad 1^{\text {st }}$ peak; $\mathrm{n}=4 ; \mathrm{p}$-value for Anderson-Darling test $=0.70 ; \mathrm{SWR}$ and no LID

- $2^{\text {nd }}$ peak; $\mathrm{n}=31 ; \mathrm{p}$-value for Anderson-Darling test $=0.34$; various levels of LID and SWR, and only LID

The same division between the SWR-only and LID plus SWR infrastructure scenarios seen in the Calgary case study is not observed in the Kelowna case study. This lack of a third division is an indication that adding SWR to LID in Kelowna does not greatly alter its performance in terms of the BWF. As opposed to the Calgary case study, the deviation seen in the KDEs for Kelowna is much greater. This is attributed to the fact that the simulation results show a much greater change in both annual precipitation and maximum depth of storm events for Kelowna for RCP 8.5 (13.2\% change in annual precipitation and $34.5 \%$ change in maximum storm depth) as opposed to the relatively small change for Calgary $(3.1 \%$ change in annual precipitation and $17.8 \%$ change in maximum storm depth).

As was also observed in the Calgary case study, six clusters marks the inflection point, or leveling off, of change in within-group sum of squares for Kelowna. 

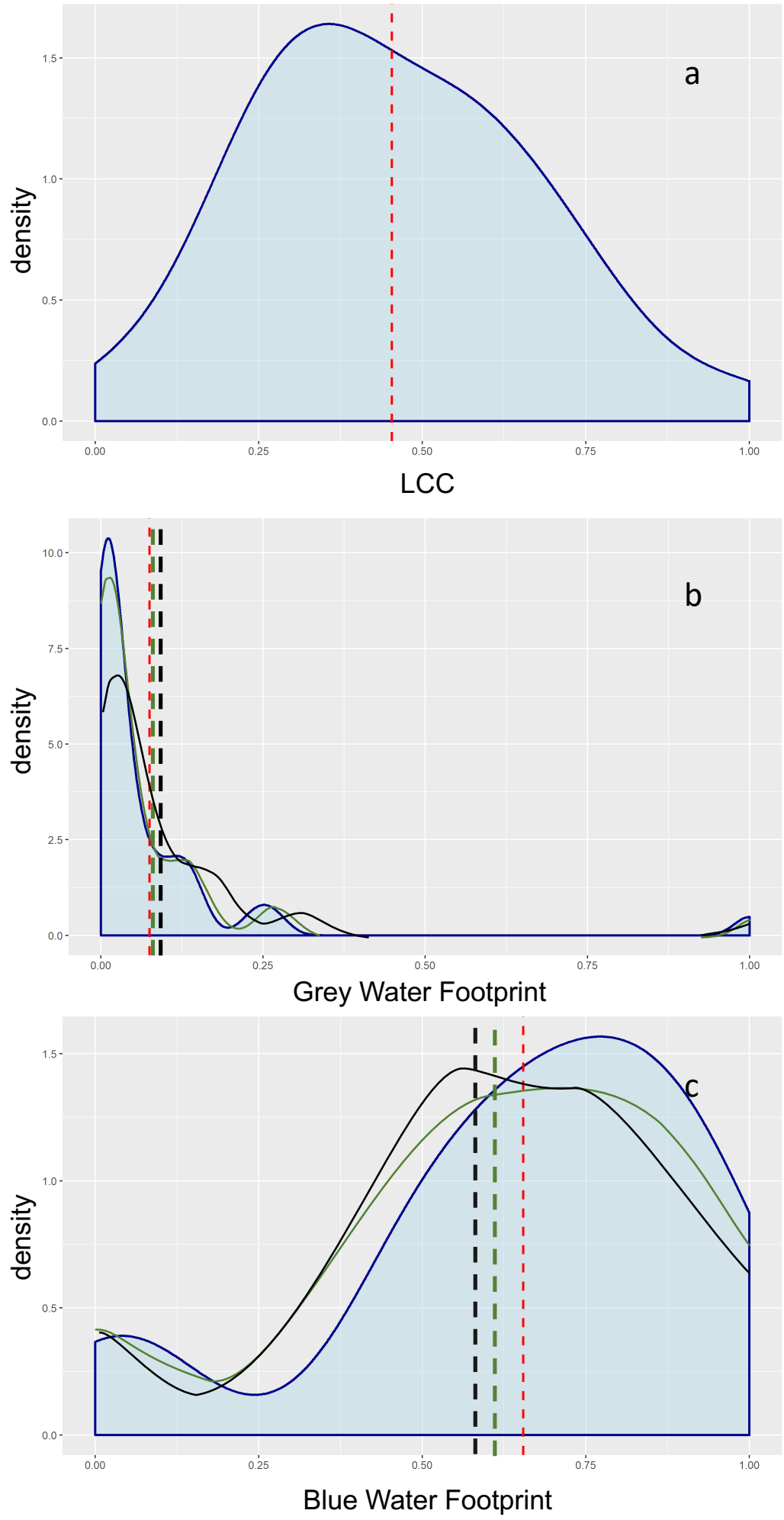

Figure 4-14: The kernel density estimation (KDE) of (a) life cycle costs (LCC); (b) grey water footprints; and (c) blue water footprints for the Kelowna case study demonstration. The blue KDE with red line represents the current climate, green represents RCP 2.6, and black represents RCP 8.5. Dashed lines indicate averages. 


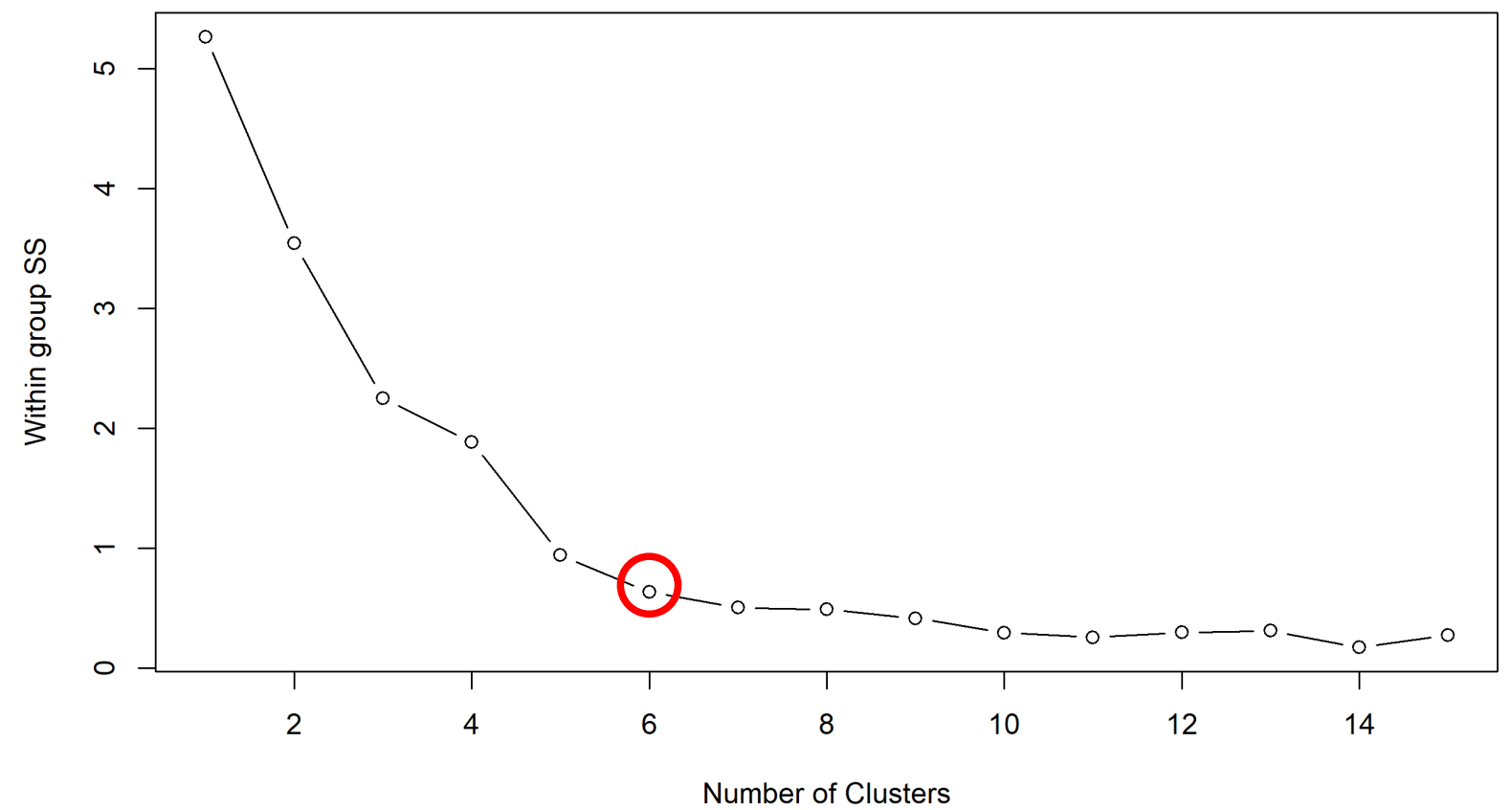

Figure 4-15: The variation of within-group sum of squares (SS) with change in cluster number for Kelowna.

Table 4-10: Cluster characteristics for Kelowna.

\begin{tabular}{|c|c|c|c|c|}
\hline Cluster & LCC & BWF & GyWF & Description \\
\hline 1 & $\begin{array}{l}\text { Range: } \mathrm{MH} \text { to } \\
\mathrm{H} \\
\text { Predominant: } \\
\text { MH }\end{array}$ & $\begin{array}{l}\text { Range: } \mathrm{L} \text { to } \mathrm{ML} \\
\text { Predominant: } \mathrm{L}\end{array}$ & $\begin{array}{l}\text { Range: } \mathrm{H} \\
\text { Predominant: } \mathrm{H}\end{array}$ & $\begin{array}{l}\text { Excellent at controlling pollutants and poor control of water } \\
\text { volumes for moderate costs. }\end{array}$ \\
\hline 2 & $\begin{array}{l}\text { Range: } M \text { to } \\
\text { MH } \\
\text { Predominant: } \\
\text { M }\end{array}$ & $\begin{array}{l}\text { Range: } \mathrm{M} \\
\text { Predominant: } \\
\mathrm{M}\end{array}$ & $\begin{array}{l}\text { Range: } \mathrm{H} \\
\text { Predominant: } \mathrm{H}\end{array}$ & $\begin{array}{l}\text { Excellent at controlling pollutants and moderate control of } \\
\text { water volumes for moderate costs. }\end{array}$ \\
\hline 3 & $\begin{array}{l}\text { Range: } \mathrm{L} \text { to } \mathrm{ML} \\
\text { Predominant: }\end{array}$ & $\begin{array}{l}\text { Range: ML to } \\
\mathrm{M} \\
\text { Predominant: } \\
\text { ML }\end{array}$ & $\begin{array}{l}\text { Range: } \mathrm{H} \\
\text { Predominant: } \mathrm{H}\end{array}$ & $\begin{array}{l}\text { Excellent at controlling pollutants and moderate control of } \\
\text { water volumes for high costs. }\end{array}$ \\
\hline 4 & $\begin{array}{l}\text { Range: } \mathrm{M} \text { to } \\
\mathrm{MH} \\
\text { Predominant: } \\
\mathrm{M}\end{array}$ & $\begin{array}{l}\text { Range: } \mathrm{L} \text { to } \mathrm{M} \\
\text { Predominant: }\end{array}$ & $\begin{array}{l}\text { Range: } \mathrm{H} \\
\text { Predominant: } \mathrm{H}\end{array}$ & $\begin{array}{l}\text { Excellent at controlling pollutants and poor to moderate } \\
\text { control of water volumes for moderate. }\end{array}$ \\
\hline 5 & $\begin{array}{l}\text { Range: } \mathrm{M} \text { to } \mathrm{H} \\
\text { Predominant: } \\
\mathrm{MH}\end{array}$ & $\begin{array}{l}\text { Range: } \mathrm{H} \\
\text { Predominant: } \mathrm{H}\end{array}$ & $\begin{array}{l}\text { Range: } \mathrm{MH} \text { to } \\
\mathrm{H} \\
\text { Predominant: } \mathrm{H}\end{array}$ & $\begin{array}{l}\text { Excellent at controlling water volumes and excellent control } \\
\text { of pollutants for low to moderate costs. }\end{array}$ \\
\hline 6 & $\begin{array}{l}\text { Range: } \mathrm{MH} \text { to } \\
\mathrm{H} \\
\text { Predominant: } \\
\mathrm{MH}\end{array}$ & $\begin{array}{l}\text { Range: } \mathrm{L} \text { to } \mathrm{ML} \\
\text { Predominant: } \\
\text { N/A }\end{array}$ & $\begin{array}{l}\text { Range: } \mathrm{L} \text { to } \mathrm{H} \\
\text { Predominant: } \\
\mathrm{MH}\end{array}$ & $\begin{array}{l}\text { Poor control of water volumes and a range in pollutant } \\
\text { control for low to moderate costs }\end{array}$ \\
\hline
\end{tabular}




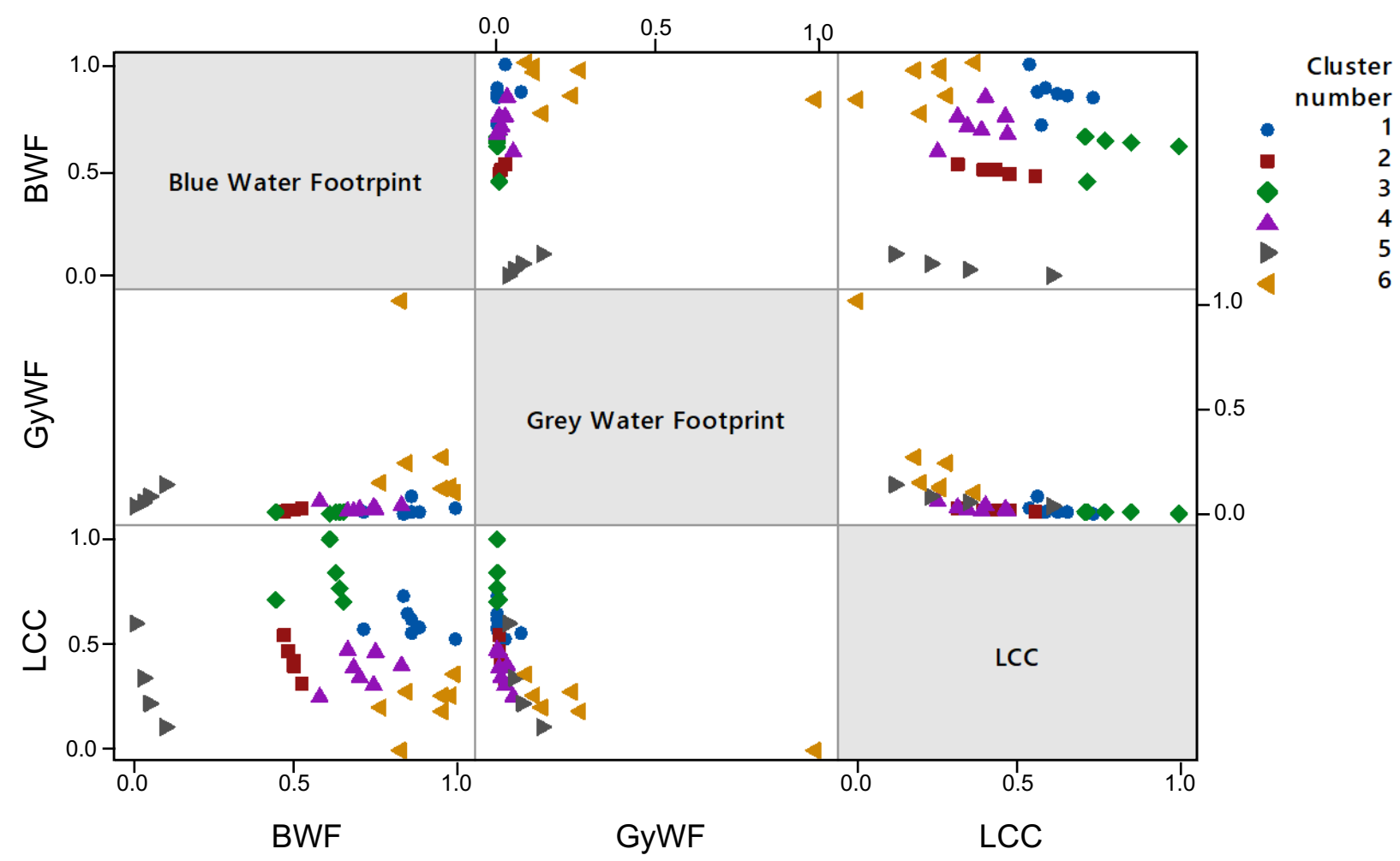

Figure 4-16: Matrix scatterplot of FCA for Kelowna.

As an aggregate decision-making method, the results from the FCA, the Fuzzy-TOPSIS analysis, and a simplistic analysis of resiliency to climate change were all considered to identify the best option for both Calgary and Kelowna. Table 4-11 outlines the advantages and disadvantages associated with both decision-making algorithms used in this analysis.

Table 4-11: Advantages and disadvantages of associated with MCDM algorithms used in this study.

\begin{tabular}{|c|c|c|}
\hline Method & Advantage & Disadvantage \\
\hline $\begin{array}{l}\text { Fuzzy } \\
\text { TOPSIS }\end{array}$ & $\begin{array}{l}\text { Considers uncertainty in model results via fuzzy } \\
\text { numbers as input to algorithm. }\end{array}$ & $\begin{array}{l}\text { Relying on the total water footprint does not allow for } \\
\text { objective-based decision support (e.g., lack of } \\
\text { distinction between blue and grey water) }\end{array}$ \\
\hline $\begin{array}{l}\text { Fuzzy } \\
\text { clustering }\end{array}$ & $\begin{array}{l}\text { Considers fuzziness with regard to degree of } \\
\text { membership between clusters. } \\
\text { Distinction between blue and grey water allows decision } \\
\text { makers to make objective-based decisions (e.g., blue vs. } \\
\text { grey water footprint performance). }\end{array}$ & $\begin{array}{l}\text { Mean values used to run algorithm do not capture } \\
\text { ranges in system performance }\end{array}$ \\
\hline
\end{tabular}




\subsubsection{Aggregate fuzzy decision making}

As previously mentioned, the Kelowna decision makers may be more interested in adopting those infrastructure mixes that best support a reduction in anthropogenic effects on water volumes (i.e., cluster 2 via SWR). As only low to moderate cost options were included in this aggregate analysis (i.e., cluster 2) and the fact that most Paris Agreement-signing nations are not making adequate reductions in GHGs, the ranks for the pessimistic about climate change weighting scenario from the Fuzzy-TOPSIS results were considered for the Kelowna aggregate decision-making analysis. Table 4-12 outlines the infrastructure scenarios present in clusters 1 and 5, for Calgary.

Table 4-12: Data required for performing aggregate decision making considering both FCA and Fuzzy-TOPSIS results and resiliency for Kelowna.

\begin{tabular}{|c|c|c|c|c|c|c|c|c|c|c|c|}
\hline \multicolumn{4}{|c|}{ Fuzzy clustering } & \multicolumn{3}{|c|}{ Fuzzy-TOPSIS } & \multicolumn{2}{|l|}{ Resiliency } & \multicolumn{3}{|c|}{ Description } \\
\hline Cluster & LCC & BWF & GyWF & Rank & TWF & LCC & Resiliency* & Rank & LID & SWR & Det \\
\hline \multirow[t]{4}{*}{5} & 5.1 & 117 & 469 & 26 & $\begin{array}{l}(218,617, \\
1091)\end{array}$ & $\begin{array}{l}(3.2,5.2, \\
7.2)\end{array}$ & $(42,173,310)$ & 4 & None & 1.9 & 4.9 \\
\hline & 9.5 & 116 & 271 & 22 & $\begin{array}{l}(176,426, \\
772)\end{array}$ & $\begin{array}{l}(5.5,9.3 \\
13.5)\end{array}$ & $(26,112,215)$ & 3 & & 3.9 & 4.5 \\
\hline & 14.2 & 117 & 190 & 14 & $\begin{array}{l}(154,351, \\
627)\end{array}$ & $\begin{array}{l}(7.9,14.0, \\
20.6)\end{array}$ & $(23,77,168)$ & 2 & & 6.1 & 4.1 \\
\hline & 24.1 & 117 & 108 & 4 & $\begin{array}{l}(135,280, \\
488)\end{array}$ & $\begin{array}{l}(13.0,24.4, \\
35.2)\end{array}$ & $(11,49,118)$ & 1 & & 10.4 & 3.4 \\
\hline
\end{tabular}

Note: LCCs are measured in CAD millions; water footprints are measured in thousands of $\mathrm{m}^{3}$; $\mathrm{SWR}$ and detention volumes are measured in thousands of $\mathrm{m}^{3}$. IB: infiltration-based; RB: retention-based; Mix: mix of IB and RB; Det: detention. Terms in parentheses refer to penetration of LID technologies.

* resiliency calculated as the difference between the TWF for current climate conditions and RCP 8.5 conditions. The subtraction of a fuzzy number: $A-B=\left(a_{1}-b_{1}, a_{2}-b_{2}, a_{3}-b_{3}\right)$.

Although all four options outlined in the $4^{\text {th }}$ cluster (SWR) are cost-effective options for Kelowna, one option will be investigated in more detail in the following section. Based on the results of the Fuzzy TOPSIS, Fuzzy clustering, and resiliency analyses, the option consisting of a SWR scheme with a volume of $6,056 \mathrm{~m}^{3}$ and a detention basin of $23,893 \mathrm{~m}^{3}$ was investigated. This option was selected based on the following:

- Member of the cluster identified as having the best performance in terms of blue and grey water for low to moderate costs

- Second highest rank within the cluster in terms of total water footprint and LCCs

- Second highest rank within the cluster in terms of resiliency to climate change

- Best performing option under $\$ 20 \mathrm{M}$ 


\subsubsection{Detailed analysis of selected option}

Figure 4-17 is visual representations of the WBE for the selected infrastructure scenario for Kelowna. Three WBEs are captured in each WBE schematic, performance for the $05^{\text {th }}$ percentile, $50^{\text {th }}$ percentile, and $95^{\text {th }}$ percentile years in terms of total precipitation. For Kelowna, the total annual precipitation of the selected years are 355,407 , and $421 \mathrm{~mm}$, respectively. Figure $4-17 \mathrm{a}$ is the WBE under historical precipitation patterns, and Figure 4-17b is the WBE under RCP 8.5.
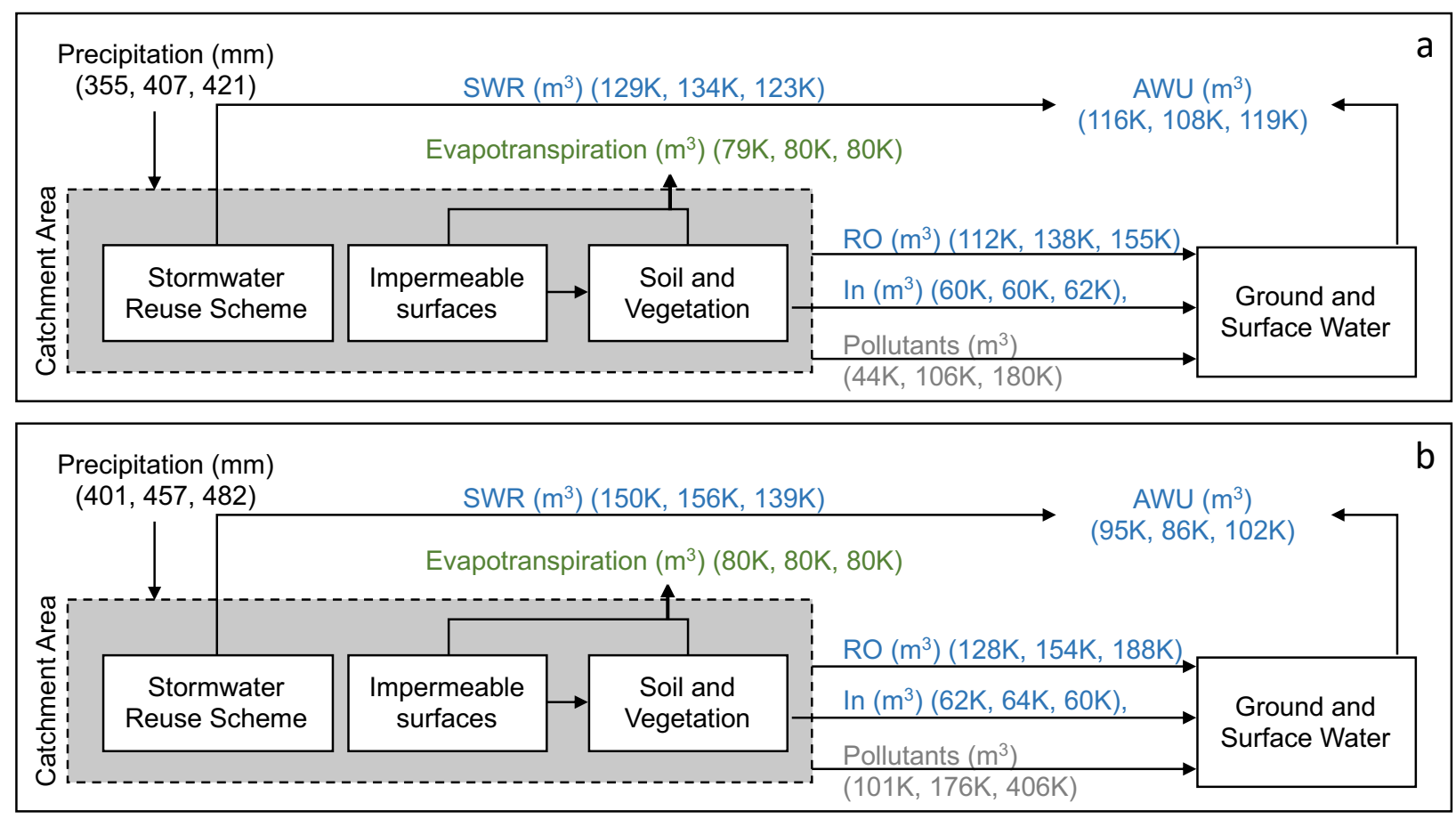

Figure 4-17: Visual representation of WBEs for historical climate norms (a) and RCP 8.5 (b) for Kelowna. Values in parentheses represent the calculate values for three different annual precipitation amounts.

In terms of SWR performance, it can be seen that an increase in annual rainfall alone does not automatically result in an increase in reusable stormwater. For example, if the annual rainfall is largely composed of snowfall or a small number of very large rainfall events, the SWR scheme is not able to leverage this rainfall as easily if it were to occur in the form of many small rainfall events. In fact, based on Figure 4-17b, the smallest volume of water consumed for anthropogenic purposes under RCP 8.5 is the $50^{\text {th }}$ percentile annual rainfall year $(457 \mathrm{~mm})$. In general, the SWR scheme was shown to be more effective at reducing the total AWU under RCP 8.5, despite the fact that it was hydrologically sized using historical rainfall data. In both climate scenarios (historical 
climate norms and RCP 8.5), the years with more precipitation did not perform as well as those years with low to moderate precipitation.

In general, the results show that as annual precipitation increases, so do runoff volumes. This same relationship is not shared between the infiltration volumes and annual precipitation. This is due to the fact that the SCS curve number method does not proportionally increase infiltration volumes as a function of precipitation depth for tight soils (i.e., silty-clay soils were selected for the Kelowna case study).

Upon further investigating the pollutant loads (represented by the GyWF), it appears that the SWR reuse scheme is not able to appropriately manage pollutants once annual precipitation values go above $\sim 450 \mathrm{~mm}$. This can be attributed to the fact that the SWR scheme represents a finite volume of storage capacity. If the system is constantly full, it is not able to capture any more runoff and therefore will not intercept any extra pollutants.

To further investigate the relationships between annual rainfall and system performance, a linear regression was performed to identify their numerical relationships. Although a linear regression was performed and plotted in Figure 4-18, there does not appear to be a numerical relationship between the total annual WF and total annual rainfall $\left(\mathrm{R}^{2}=0.133\right)$. This lack of a relationship is attributed to the many underlying precipitation phenomena not captured in the simple metric of total annual rainfall (e.g., diversity inter- and intra-monthly distribution of rainfall). It may also be inferred that the system's heavy reliance on a SWR scheme is capable of decoupling the intuitively-assumed relationship of annual precipitation and the community's stormwater footprint.

As seen in Figure 4-19, the same breakthrough of pollutants above a certain annual precipitation threshold was not observed in the Kelowna case study. It is interpreted that due to the system's complete reliance on SWR (i.e., no LID) and the relatively even distribution of annual precipitation, the SWR in this case study is more effective at attenuating runoff volumes and pollutants for a greater portion of rainfall events.

The following paragraph outlines the detailed assessment of the LCC results for the Kelowna case study. In terms of the triangular fuzzy number used for the Fuzzy TOPSIS decision-making algorithm, the results for the selected infrastructure scenario are $(\$ 7,930,792 ; \$ 14,043,085$; $\$ 20,599,937)$. This represents a large range in possible costs from $\$ 7.9 \mathrm{M}$ to $\$ 20.6 \mathrm{M}$. Figure $4-20$ 
is set of boxplots representing the results of the Monte Carlo-based life cycle costs. When further investigating the data displayed in Figure 4-20, is can be seen that the SWR scheme is responsible

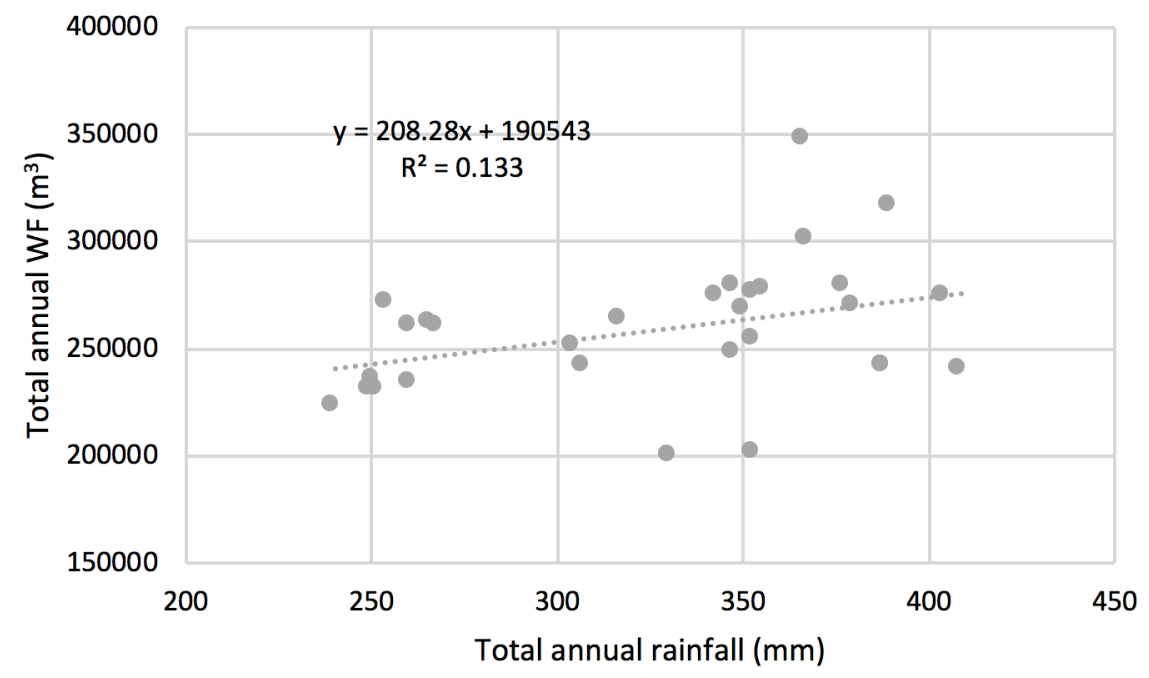

Figure 4-18:Total annual water footprint vs. total annual rainfall for Kelowna.

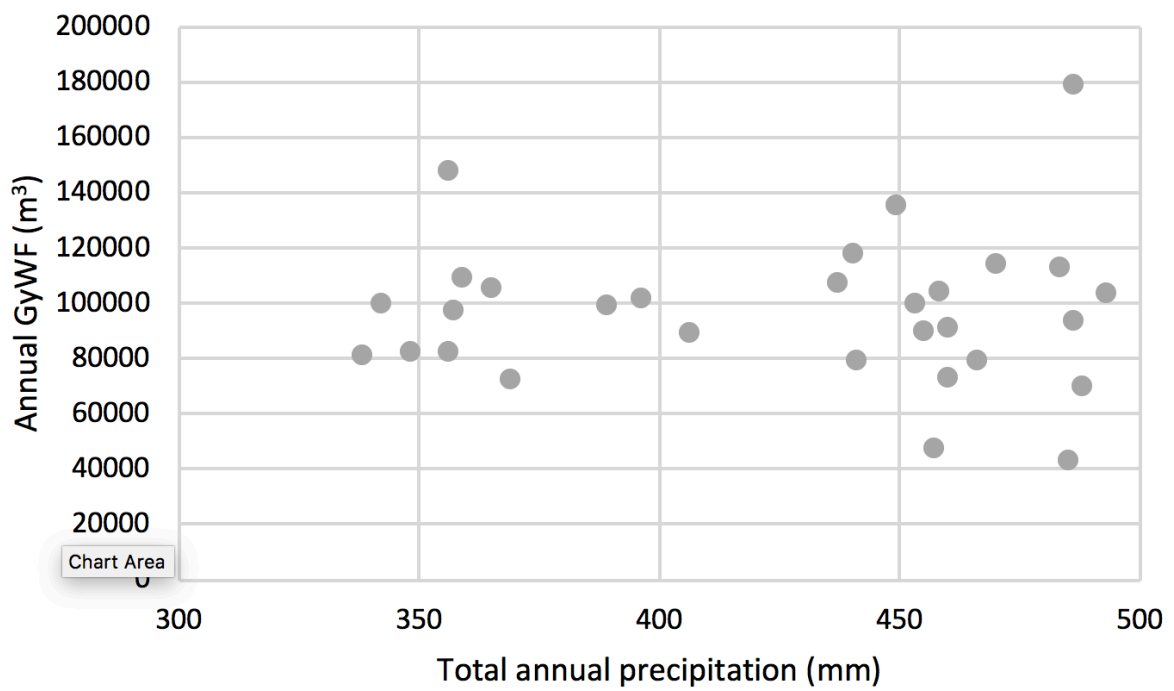

Figure 4-19: Annual grey water footprint vs. total annual precipitation for Kelowna.

for a larger portion of LCC in terms of capital costs, operations and maintenance, rehabilitation, and decommissioning. Although SWR is an effective method for controlling stormwater volumes and pollutant loads, these services come at a cost. For this selected infrastructure scenario (SWR volume of $6,056 \mathrm{~m}^{3}$ ), a SWR scheme is able to provide $123-156 \mathrm{~m}^{3}$ of reusable water to offset AWU volumes for $\$ 1.09 / \mathrm{m}^{3}-\$ 1.38 / \mathrm{m}^{3}$ per hectare. This results in an effective reusable 
stormwater volume of $20.3-25.8 \mathrm{~m}^{3}$ per metre cube of installed capacity. This increase in retained runoff of the SWR system was capable of reducing the size of the detention facility by $\sim 40 \%$ compared to a traditional community (no LID or SWR).

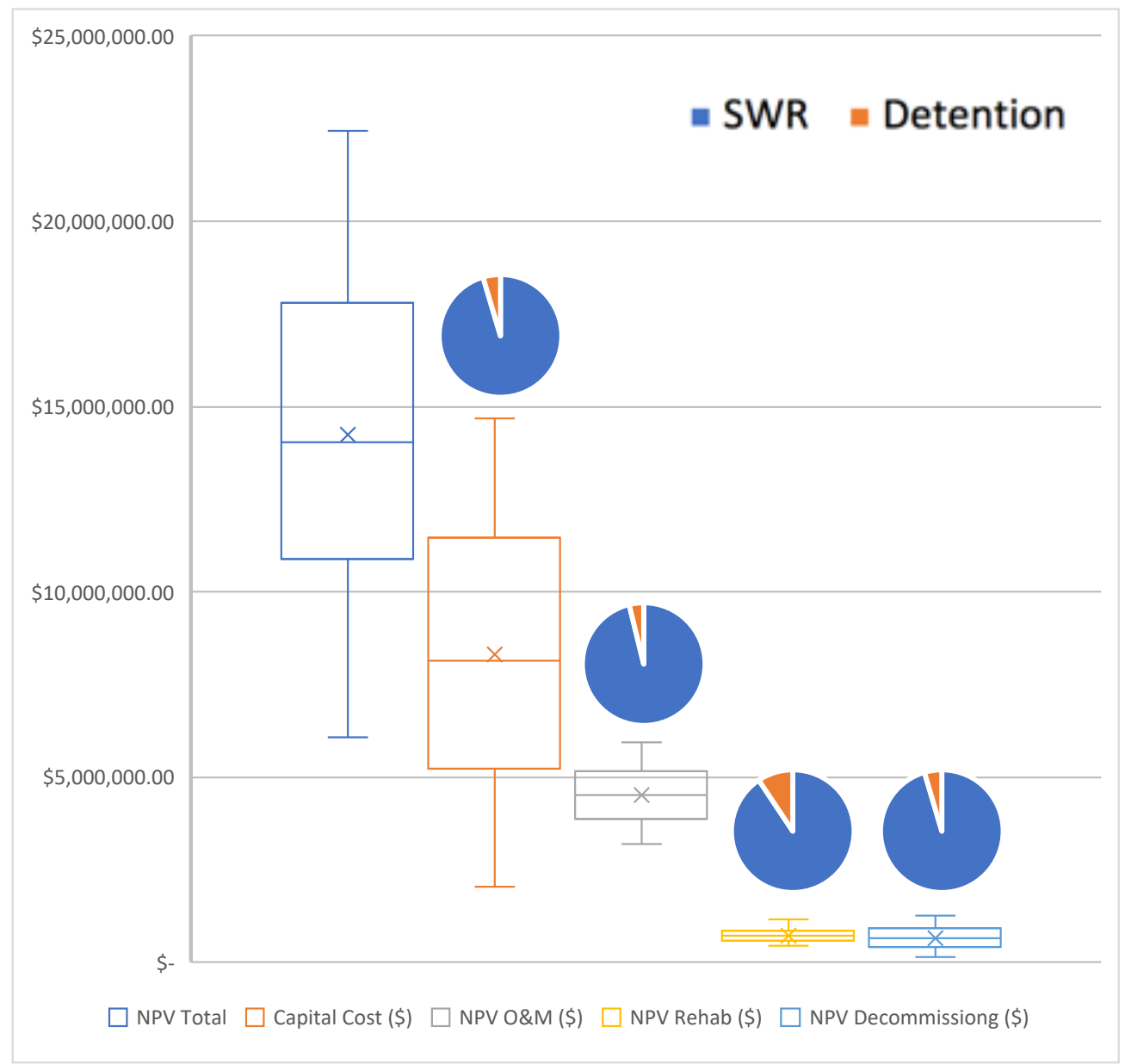

Figure 4-20: Boxplots of Monte Carlo-based life cycle costs for Kelowna. All values in net present value. Pie charts represent the ratio of each infrastructure component for each life cycle cost category.

\subsection{Summary}

The two case study demonstrations performed for Calgary, AB and Kelowna, BC represent two sites with similar total annual precipitation (419 mm for Calgary and $387 \mathrm{~mm}$ for Kelowna, 8\% difference). Although both locations have similar historical annual precipitation, the inter- and intra-annual distribution of this precipitation in the form of small and large rainfall and snowfall events was found to have a drastic impact on the selection of an optimal stormwater management strategy. An aggregate decision support analysis was performed using the OWSWPF to consider region-specific decision-making objectives of stormwater planners. Due to the water quality objectives of stormwater planners and the prominent peak in summer precipitation in the Calgary 
case study, a mix of LID, SWR, and detention infrastructure was identified as the optimal infrastructure scenario for Calgary. As a result of the relatively even distribution of annual precipitation throughout the year, limited number of cold weather months, and water availability concerns in the Okanagan Valley, the optimal infrastructure scenario for Kelowna relied heavily on a SWR scheme and detention infrastructure. Due to the even distribution of intra-annual precipitation in Kelowna, the cost of SWR was 36-68\% cheaper than Calgary in terms of $\$ / \mathrm{m}^{3}$ of reusable stormwater collected. Due to the increase in TWFs between the historical and climate change scenarios, both case study demonstrations provide evidence that stormwater planners should consider future storm volumes when sizing hydrologically-based infrastructure components (e.g., SWR, detention, green roofs). The case study demonstrations showed that the OWSWPF is a novel approach for identifying the optimal stormwater management approach and associated planning metrics for a new mixed-use urban community. 


\section{CONCLUSIONS}

\subsection{Assumptions and limitations}

It is important to reiterate the fact that the One Water StormWater Planning Framework (OWSWPF) is a planning framework. This is an important consideration when interpreting results and outputs. Although the framework's outputs are very specific (e.g., the volume of detention basins to the closest integer) these outputs should be used as approximations for infrastructure mixes. The uncertainty intrinsic to many of the control variables (e.g., LID BMP pollutant reduction performance, runoff curve numbers, soil porosity) results in non-exact design parameters. Users wishing to proceed from the planning metrics provided by the OWSWPF can use the provided outputs as a stepping stone to further, more detailed design and hydraulic-based practices (e.g., USEPA's SWMM).

The OWSWPF relies heavily on the previous work of others (e.g., runoff, infiltration, and evapotranspiration models). The equations adopted by the OWSWPF models have been shown time and time again to be effective methods for modelling urban runoff at a coarse scale, such as is required by this study. For example, the SCS curve number method is an effective means of estimating runoff volumes for a specific storm event, but this method will not provide users with hydraulic characteristics of that runoff (e.g., velocity and flows). Furthermore, as the OWSWPF is not a hydraulic modelling tool, it is not effective at modelling flood events and does not provide users with any hydraulic-based flood outputs. The outputs of the framework are intended to be used as guiding metrics for the detailed design and flood modelling of a proposed system.

The water use and reuse profiles outlined in the OWSWPF do not consider uncertainty or variation. To this end, the user must assume that water use and reuse is predictable and stable. This assumption is obviously not true. Although this assumption may has less significant consequences for household and commercial water use, as these are supplied by the water utility, there are greater impacts for assessing the performance of the modelled SWR schemes. The OWSWPF assumes that a client for the non-potable runoff has been procured and that all captured and runoff is eventually used. This may not be the case in reality, and therefore, further post-OWSWPF modelling of SWR schemes should be conducted. 


\subsection{Contributions}

The three most significant contributions to the scientific and engineering community made by the work outlined in this thesis are as follows:

1. An in-depth critical literature review of LID BMPs and their respective pollutant removal performance. Not only did this review identify the most commonly studied pollutants, it has provided the applied science and engineering community with ranges in performance values that can be used in stochastic modelling of BMPs.

2. The concept of water footprinting was adapted to stormwater management planning for the very first time. This novel combination of has provided a new perspective for long-term stormwater planning that allows planners to simultaneously consider water volume and pollutant implications of stormwater management strategies.

3. A new multi-criteria, multi-period framework for stormwater management planning was introduced (the OWSWPF). This framework was developed to address the knowledge gaps of existing stormwater management planning and design tools. The framework incorporated water footprinting and climate change resiliency to identify the optimal mix of traditional, reuse, and LID stormwater infrastructure during the planning phase of a new community. The scope and capabilities of the framework was entirely novel.

\subsection{Summary}

The developed model (OWSWPF) effectively addresses many of the current challenges in stormwater planning outlined in Chapter 2 and Chapter 3 of this thesis. The long-term, continuous modelling of urban runoff and associated pollutants using a one water approach can provide stormwater infrastructure planners with an alternative perspective to the current flood mitigation and risk reduction paradigm. Although flood-focused decision making should not be discontinued, the cumulative effects benefits of long-term continuous performance provided by LID and SWR infrastructure should be integrated into decision support services for stormwater planners.

The case studies performed in Chapter 4 show that decision makers should take a customized approach to stormwater infrastructure adoption as opposed to commonly-adopted ad-hoc approaches. Identifying the best mix of infrastructure during the planning stage can ensure that the most-effective infrastructure components for a specific site and community conditions are identified early on in the planning process. Considering climate change and the long-term, continuous performance of stormwater infrastructure can avoid costly changes or refurbishments 
during the infrastructure's life and ensure that levels of service are maintained when extensive climate change occurs.

\subsection{Conclusions}

For a specific case study, the OWSWPF can provide decision makers with many metrics to support their decision-making needs. In terms of knowledge that can be extracted from the two case studies performed in this thesis for all stormwater planners, the following phenomena were observed:

1. Stormwater reuse is a cost-effective strategy for managing both urban stormwater volumes and pollutants and can provide an alternative source of non-potable water. This research shows that stormwater reuse infrastructure can even be integrated in areas classified as semi-arid.

2. Those designs relying more heavily on hydrologic-based infrastructure components perform more reliably under different precipitation patterns and climate change scenarios than those systems sized based on limiting factors (e.g., soil type limiting the storage capacity of infiltration-based best management practices). Therefore, this research supports the continued use of return period storm sizing of urban stormwater infrastructure.

3. A one-size-fits-all approach to stormwater management is ill-advised, and stormwater planners should transition to a planning framework that considers site-specific precipitation patterns, soil conditions, climate change, and land use planning prior to performing the detailed design of a community's stormwater infrastructure.

4. A one water approach to stormwater infrastructure planning during the planning stage of a community can provide community planners and developers with the necessary data to procure a stormwater reuse client (e.g., seasonal volume-based data for reusable urban stormwater availability). Having this information during the planning phase of a community can support meaningful integration of all water systems.

5. As predicted climate change is location specific and the resiliency of stormwater infrastructure is a function of this change, climate change will not have the same impact on stormwater infrastructure throughout Canada. Ergo, infrastructure resiliency requires different consideration for different locations.

6. Some locations are able to effectively leverage multiple different stormwater solutions to fulfill their objectives (e.g., LID or SWR), whereas for other locations, a single stormwater management strategy performs much better than others (e.g., only SWR). 


\subsection{Recommendations}

\subsubsection{Robust evapotranspiration model}

As mentioned in the Detailed analysis of selected options section in Chapter 4, the overly simplistic Blaney-Criddle method for estimating evapotranspiration should be updated to incorporate a model that more accurately reflects temporal (daily) changes in evapotranspiration. Although this would enable the OWSWPF to more accurately model evapotranspiration, the data requirements for other models often involve wind speeds, humidity conditions, and other metrics not currently included in the OWSWPF (DehghaniSanij et al. 2004). Not only would the inclusion of such data increase the data requirements for users, but there is a lack of Canada-wide predictions for changes in many of the variables due to climate change, therefore, making the climate change prediction portion of the OWSWPF difficult to model.

\subsubsection{BMP performance uncertainty}

As mentioned in Chapter 2, large ranges in BMP pollutant treatment performance have been observed by many researchers, with some BMPS even displaying negative treatment performance values. BMP treatment performance in this study was considered to be static. Updating the OWSWPF to handle stochastic-based BMP treatment performance would provide better realworld modelling of BMPs but would also add to the complexity of the MCDM inputs and interpreting results. Nevertheless, these hurdles could be overcome and such improvements to the framework could be made.

\subsubsection{Human health risk assessment}

In any type of reclaimed or reused water scheme it is imperative that some form of human health risk assessment be performed (National Blue Ribbon Commission for Onsite Non-potable Water Systems 2017). Incorporation of risk-based decision support metrics within the OWSWPF would drastically increase the abilities of the framework's capabilities in terms of decision support. The proposed addition would require more robust water use and reuse models and the addition of a quantitative microbial risk assessment module. A risk-based framework such as the one proposed by the National Water Research Institute (Sharvelle et al. 2017) could be integrated within the OWSWPF to address the human health risk-based needs of SWR planning. 


\section{Bibliography}

Abebe, Y., Kabir, G., and Tesfamariam, S. (2018). "Assessing urban areas vulnerability to pluvial flooding using GIS applications and Bayesian Belief Network model." Journal of Cleaner Production, Elsevier Ltd, 174, 1629-1641.

Ahiablame, L. M., Engel, B. A., and Chaubey, I. (2012). "Effectiveness of low impact development practices: Literature review and suggestions for future research." Water, Air, and Soil Pollution, 223(7), 4253-4273.

Al-ali， D. (2015). "DEVELOPMENT OF A MULTI-CRITERIA DECISION-MAKING FRAMEWORK FOR THE IMPLEMENTATION OF STORMWATER by.” $p H D$.

Al-Rubaei, A. M., Engström, M., Viklander, M., and Blecken, G. T. (2016). "Long-term hydraulic and treatment performance of a 19-year old constructed stormwater wetland-Finally maturated or in need of maintenance?” Ecological Engineering, Elsevier B.V., 95, 73-82.

Alberta Environment and Sustainable Resource Development. (2015). "Precipitation Map (June 19-22, 2013)."

Alsubih, M., Arthur, S., Wright, G., and Allen, D. (2017). "Experimental study on the hydrological performance of a permeable pavement." Urban Water Journal, Taylor \& Francis, 14(4), 427434.

Amin, M. T., Kim, T., Amin, M. N., and Han, M. Y. (2013). "Effects of catchment, first-flush, storage conditions, and time on microbial quality in rainwater harvesting systems." Water environment research : a research publication of the Water Environment Federation, 85(12), 2317-29.

Anderson, B. S., Phillips, B. M., Voorhees, J. P., Siegler, K., and Tjeerdema, R. (2016). "Bioswales reduce contaminants associated with toxicity in urban storm water." Environmental Toxicology and Chemistry, 35(12), 3124-3134.

Angel, S., Parent, J., Civco, D. L., and Blei, A. M. (2011). Making Room for a Planet of Cities.

Ascione, F., Bianco, N., de' Rossi, F., Turni, G., and Vanoli, G. P. (2013). "Green roofs in European climates. Are effective solutions for the energy savings in air-conditioning?" Applied Energy, 104, 845-859.

Ávila, C., Salas, J. J., Martín, I., Aragón, C., and García, J. (2013). "Integrated treatment of combined sewer wastewater and stormwater in a hybrid constructed wetland system in southern Spain and its further reuse." Ecological Engineering, Elsevier B.V., 50, 13-20. 
Al Bakri, D., Rahman, S., and Bowling, L. (2008). "Sources and management of urban stormwater pollution in rural catchments, Australia.” Journal of Hydrology, 356(3-4), 299-311.

Berger, M., Pfister, S., and Motoshita, M. (2016). "Water Footprinting in Life Cycle Assessment: How to Count the Drops and Assess the Impacts?" Special Types of Life Cycle Assessment, $73-114$.

Bick, I. A., Bardhan, R., and Beaubois, T. (2018). "Applying fuzzy logic to open data for sustainable development decision-making: a case study of the planned city Amaravati." Natural Hazards, Springer Netherlands, 91(3), 1317-1339.

Brown, R. A., and Borst, M. (2015). "Nutrient infiltrate concentrations from three permeable pavement types.” Journal of Environmental Management, Elsevier Ltd, 164, 74-85.

Brown, R. A., and Hunt, W. F. (2011). "Impacts of Media Depth on Effluent Water Quality and Hydrologic Performance of Undersized Bioretention Cells." Journal of Irrigation and Drainage Engineering, 137(3), 132-143.

Brown, R. A., Line, D. E., and Hunt, W. F. (2012). "LID Treatment Train: Pervious Concrete with Subsurface Storage in Series with Bioretention and Care with Seasonal High Water Tables." Journal of Environmental Engineering, 138(6), 689-697.

Brunetti, G., Šimůnek, J., and Piro, P. (2016). "A Comprehensive Analysis of the Variably Saturated Hydraulic Behavior of a Green Roof in a Mediterranean Climate." Vadose Zone Journal, 15(9), 1-17.

Buffam, I., Mitchell, M. E., and Durtsche, R. D. (2016). "Environmental drivers of seasonal variation in green roof runoff water quality.” Ecological Engineering, Elsevier B.V., 91, 506514.

Canada Mortgage and Housing Corporation. (2017). "Downspout Disconnection | CMHC." $<$ https://www.cmhc-schl.gc.ca/en/inpr/su/waho/waho_014.cfm> (Nov. 28, 2017).

Canada Weather Stats. (2018). "Canada Weather Stats.” <https://www.weatherstats.ca/> (Sep. 30, 2018).

Canadian Society of Civil Engineers. (2016). "Canadian Infrastructure Report Card: Informing the Future." $1-164$.

Carpenter, D. D., and Hallam, L. (2010). "Influence of Planting Soil Mix Characteristics on Bioretention Cell Design and Performance.” Journal of Hydrologic Engineering, 15(6), 404416. 
Chahar, B. R., Graillot, D., and Gaur, S. (2012). "Storm-Water Management through Infiltration Trenches.” Journal of Irrigation and Drainage Engineering, 138(3), 274-281.

Chang, N. B., Islam, M. K., and Wanielista, M. P. (2012). "Floating wetland mesocosm assessment of nutrient removal to reduce ecotoxicity in stormwater ponds." International Journal of Environmental Science and Technology, 9(3), 453-462.

Chen, C. T. (2000). "Extensions of the TOPSIS for group decision-making under fuzzy environment." Fuzzy Sets and Systems, 114(1), 1-9.

Chen, L., Zhi, X., Shen, Z., Dai, Y., and Aini, G. (2018). “Comparison between snowmelt-runoff and rainfall-runoff nonpoint source pollution in a typical urban catchment in Beijing, China." Environmental Science and Pollution Research, Environmental Science and Pollution Research, 25(3), 2377-2388.

Chen, Z., Ngo, H. H., and Guo, W. (2016a). "Environmental and Ecological Impacts/Benefits." Urban Water Reuse Hanbook, S. Eslamian, ed., Taylor \& Francis.

Chen, Z., Ngo, H. H., and Guo, W. (2016b). "Water Reuse Environmental Benefits." Urban Water Reuse Handbook, 209-217.

Chhipi-shrestha, G., Hewage, K., and Sadiq, R. (2017). "Water - Energy - Carbon Nexus Modeling for Urban Water Systems: System Dynamics Approach.” Jourmal of Water Resource Planning and Management, 143(Stillwell 2015), 1-11.

Choi, K. S., Lee, S. G., and Jang, J. R. (2016). "Vegetative Filter Strip (Vfs) Applications for Runoff and Pollution Management in the Saemangeum Area of Korea." Irrigation and Drainage, 65, 168-174.

Chong, M. N., Sidhu, J., Aryal, R., Tang, J., Gernjak, W., Escher, B., and Toze, S. (2013). “Urban stormwater harvesting and reuse: A probe into the chemical, toxicology and microbiological contaminants in water quality." Environmental Monitoring and Assessment, 185(8), 66456652 .

Chowdhury, R. K., Sharvelle, S. E., Beecham, S., and Emirates, A. (2016). "Greywater quality changes in a permeable pavement reservoir." Proceedings of the Institution of Civil Engineers, 169(WM4), 190-198.

City of Calgary. (2018). "Water efficiency." The City of Calgary, $<$ http://www.calgary.ca/UEP/Water/Pages/Water-conservation/Water-efficiency.aspx> (Oct. 30, 2018). 
City of Toronto. (2017). "Mandatory Downspout Disconnection." City of Toronto, $<$ https://www.toronto.ca/services-payments/water-environment/managing-rain-meltedsnow/basement-flooding/mandatory-downspout-disconnection/> (Nov. 28, 2017).

City of Vancouver. (2018). "Citywide Integrated Rainwater Management Plan.” RedDot CMS, $<$ http://vancouver.ca/home-property-development/city-wide-integrated-stormwatermanagement-plan.aspx $>$ (Apr. 10, 2018).

City of Windsor. (2017). "Downspout (Eavestrough) Disconnection." $<$ https://www.citywindsor.ca/residents/maintenanceandfieldservices/Sewers/Pages/Downspout-Disconnection.aspx $>$ (Nov. 28, 2017).

Clary, J., Jones, J., Leisenring, M., Hobson, P., and Strecker, E. (2017). Final Report International Stormwater BMP Database - 2016 Summary Statistics. Water Environment \& Reuse Foundation.

CNLA. (2017). Life Cycle Cost Analysis Of Natural On-site Stormwater Management Methods.

CNT. (n.d.). "Green Values National Stormwater Management Calculator." $<$ http://greenvalues.cnt.org/national/cost_detail.php> (Aug. 7, 2018).

Cox, E. (2005). "Fuzzy Clustering." Fuzzy Modeling and Genetic Algorithms for Data Mining and Exploration, Elsevier, 207-263.

Dabbaghain, M., Hewage, K., Reza, B., Culver, K., and Sadiq, R. (2013). "Sustainability performance assessment of green roof systems using fuzzy-analytical hierarchy process (FAHP).” International Journal of Sustainable Building Technology and Urban Dvelopment, 260-276.

David, N., Leatherbarrow, J. E., Yee, D., and McKee, L. J. (2015). "Removal Efficiencies of a Bioretention System for Trace Metals, PCBs, PAHs, and Dioxins in a Semiarid Environment." Journal of Environmental Engineering, 141(6), 1-8.

DeBusk, K. M., and Wynn, T. M. (2011). "Storm-Water Bioretention for Runoff Quality and Quantity Mitigation.” Journal of Environmental Engineering, 137(9), 800-808.

DehghaniSanij, H., Yamamoto, T., and Rasiah, V. (2004). "Assessment of evapotranspiration estimation models for use in semi-arid environments." Agricultural Water Management, 64(2), 91-106.

Department of Environmental Quality. (2003). "Biofilters For Stormwater Discharge Pollution Removal Bioswales, Vegetative Buffers, and Constructed Wetlands For Stormwater 
Discharge Pollution Removal Guidance for using Bioswales, Vegetative Buffers, and Constructed." < $<$ htp://www.oregon.gov/deq/FilterPermitsDocs/biofiltersV2.pdf> (Oct. 12, 2017).

Domene, E., and Saur1, D. (2006). "Urbanisation and Water Consumption : Influencing Factors in the Metropolitan Region of Barcelona Urbanisation and Water Consumption : Influencing Factors in the Metropolitan Region of Barcelona.” Urban Studies, 43(August 2016), 16051623.

Drake, J., Bradford, A., and Van Seters, T. (2014a). "Stormwater quality of spring-summer-fall effluent from three partial-infiltration permeable pavement systems and conventional asphalt pavement." Journal of Environmental Management, 139, 69-79.

Drake, J., Bradford, A., and Van Seters, T. (2014b). "Hydrologic Performance of Three PartialInfiltration Permeable Pavements in a Cold Climate over Low Permeability Soil." Journal of Hydrologic Engineering, 19(9), 04014016.

Dunnett, N., and Kingsbury, N. (2004). Planting Green Roofs and Living Walls. Timber Press, Portland.

Dvorak, B., and Volder, A. (2010). "Green roof vegetation for North American ecoregions: A literature review." Landscape and Urban Planning, Elsevier B.V., 96(4), 197-213.

Elliott, S., Meyer, M. H., Sands, G. R., and Horgan, B. (2011). "Water Quality Characteristics of Three Rain Gardens Located Within the Twin Cities Metropolitan Area, Minnesota." Cities and the Environment, 4(1), 1-15.

Emerson, C. H., Wadzuk, B. M., and Traver, R. G. (2010). "Hydraulic evolution and total suspended solids capture of an infiltration trench.” Hydrological Processes, 24(8), 10081014.

Environment and Climate Change Canada. (2018). "Canadian Climate Normals." $<$ http://climate.weather.gc.ca/climate_normals/index_e.html> (Sep. 30, 2018).

Environment Canada. (1998). "Climate Trends and Variations Bulletin for Canada."

Farreny, R., Morales-Pinzón, T., Guisasola, A., Tayà, C., Rieradevall, J., and Gabarrell, X. (2011). "Roof selection for rainwater harvesting: Quantity and quality assessments in Spain." Water Research, 45(10), 3245-3254.

Fisher, T. G. (1999). "Sedimentology, stratigraphy, and geomorphology of glacial Lake Calgary at Cochrane, Alberta, Canada." (1986). 
Flanagan, K., Branchu, P., Ramier, D., and Gromaire, M. C. (2017). "Evaluation of the relative roles of a vegetative filter strip and a biofiltration swale in a treatment train for road runoff." Water Science and Technology, 75(4), 987-997.

Fletcher, T. D., Andrieu, H., and Hamel, P. (2013). "Understanding, management and modelling of urban hydrology and its consequences for receiving waters: A state of the art." Advances in Water Resources, Elsevier Ltd, 51, 261-279.

Fletcher, T. D., Shuster, W., Hunt, W. F., Ashley, R., Butler, D., Arthur, S., Trowsdale, S., Barraud, S., Semadeni-Davies, A., Bertrand-Krajewski, J. L., Mikkelsen, P. S., Rivard, G., Uhl, M., Dagenais, D., and Viklander, M. (2015). "SUDS, LID, BMPs, WSUD and more - The evolution and application of terminology surrounding urban drainage." Urban Water Journal, Taylor \& Francis, 12(7), 525-542.

Fletcher, T., Duncan, H., Poelsma, P., and Lloyd, S. (2005). "Stormwater Flow and Quality and the Effectiveness of Non-proprietary Stormwater Treatment Measures : A Review and Gap Analysis.”(January 2005).

Food and Agriculture Organization of the United States. (n.d.). "CHAPTER 3: CROP WATER NEEDS." <http://www.fao.org/docrep/S2022E/s2022e07.htm> (Sep. 30, 2018).

Forasteé, J. A., and Hirschman, D. (2010). "Low Impact Development 2010: Redefining Water in the City." Proceedings of the 2010 International Low Impact Development Conference, (Endreny 2004).

Forgione, E. R. (2015). "The fate and transport of chloride in a constructed stormwater wetland." Villanova University.

Fox, G. A., Matlock, E. M., Guzman, J. A., Sahoo, D., and Stunkel, K. B. (2011). "Load Reduction from Runoff by Vegetative Filter Strips: A Laboratory-Scale Study.” Journal of Environment Quality, 40(3), 980-988.

Fulazzaky, M. A., Khamidun, M. H., and Yusof, B. (2013). "Sediment traps from synthetic construction site stormwater runoff by grassed filter strip." Journal of Hydrology, Elsevier B.V., 502, 53-61.

Furlong, C., De Silva, S., Gan, K., Guthrie, L., and Considine, R. (2017). "Risk management, financial evaluation and funding for wastewater and stormwater reuse projects." Journal of Environmental Management, Elsevier Ltd, 191, 83-95.

García-Serrana, M., Gulliver, J. S., and Nieber, J. L. (2017). “Infiltration capacity of roadside filter 
strips with non-uniform overland flow." Journal of Hydrology, 545, 451-462.

Garofalo, G., Palermo, S., Principato, F., Theodosiou, T., and Piro, P. (2016). "The influence of hydrologic parameters on the hydraulic efficiency of an extensive green roof in Mediterranean area." Water (Switzerland), 8(2), 1-21.

Gough, N. A., Hughes-Games, G. A., and Nikkel, D. C. (1994). Soil Management Handbook For The Okanagan And Similkameen Valleys.

Gouri, R. L., and Srinivas, V. V. (2017). “A fuzzy approach to reliability based design of storm water drain network." Stochastic Environmental Research and Risk Assessment, Springer Berlin Heidelberg, 31(5), 1091-1106.

Government of Canada. (2017a). "The Energy-Water Nexus." $<$ http://www.horizons.gc.ca/en/content/energy-water-nexus> (Mar. 20, 2018).

Government of Canada. (2017b). "Water availability: indicator initiative." $<$ https://www.canada.ca/en/environment-climate-change/services/wateroverview/quantity/availability-indicator-initiative.html> (Apr. 10, 2018).

Government of Canada. (2017c). "CMIP5 graphics and tables." <http://climatescenarios.canada.ca/index.php?page $=$ download-cmip5> $($ Apr. 5, 2018).

Government of Canada. (2018a). "Environment and Climate Change Canada." $<$ http://climate.weather.gc.ca/glossary_e.html $>$ (Apr. 10, 2018).

Government of Canada. (2018b). "CMIP5 graphics and tables." <http://climatescenarios.canada.ca/index.php?page $=$ download-cmip5 $>$ (Oct. 3, 2018).

Guo, J. C. Y., and Luu, T. M. (2015). “Operation of Cap Orifice in a Rain Garden.” Journal of Hydrologic Engineering, 20(10), 06015002.

Gwenzi, W., Dunjana, N., Pisa, C., Tauro, T., and Nyamadzawo, G. (2015). "Water quality and public health risks associated with roof rainwater harvesting systems for potable supply: Review and perspectives." Sustainability of Water Quality and Ecology, Elsevier B.V., 6, $107-118$.

Habibiandehkordi, R., Quinton, J. N., and Surridge, B. W. J. (2014). "Enhancing soluble phosphorus removal within buffer strips using industrial by-products." Environmental Science and Pollution Research, 12257-12269.

Hager, J., Hu, G., Sadiq, R., and Hewage, K. (2018). "Performance of low impact development best management practices: a critical review." Environmental Reviews, 27(1), 17-42. 
doi:10.1139/er-2018-0048

Haider, H., Hewage, K., Umer, A., Ruparathna, R., Chhipi-Shrestha, G., Culver, K., Holland, M., Kay, J., and Sadiq, R. (2018). "Sustainability assessment framework for small-sized urban neighbourhoods: An application of fuzzy synthetic evaluation." Sustainable Cities and Society, Elsevier, 36(May 2017), 21-32.

Hartung, E. W. (2017). "Aging bioretention cells: do they still function to improve water quality?" Kent State University.

Heilweil, V. M., and Watt, D. E. (2011). "Trench infiltration for managed aquifer recharge to permeable bedrock." Hydrological Processes, 25(1), 141-151.

Helmers, M. J., Zhou, X., Asbjornsen, H., Kolka, R., Tomer, M. D., and Cruse, R. M. (2012). "Sediment Removal by Prairie Filter Strips in Row-Cropped Ephemeral Watersheds." Journal of Environment Quality, 41(5), 1531-1539.

Hood, A., Chopra, M., and Wanielista, M. (2013). “Assessment of biosorption activated media under roadside swales for the removal of phosphorus from stormwater." Water (Switzerland), $5(1), 53-66$.

Hossain, F., Chang, N.-B., and Wanielista, M. (2009). "Modeling kinetics and isotherms of functionalized filter media for nutrient removal from stormwater dry ponds." Environmental science \& technology, 33(2), 482-489.

Hsieh, C., and Davis, A. P. (2005). "Evaluation and Optimization of Bioretention Media for Treatment of Urban Storm Water Runoff." Journal of Environmental Engineering, 131(11), $1521-1531$.

Hu, G., Kaur, M., Hewage, K., and Sadiq, R. (2018). Fuzzy Clustering Analysis of Hydraulic Fracturing Additives for Environmental and Human Health Risk Mitigation.

Huang, J., Valeo, C., He, J., and Chu, A. (2016). “Three Types of Permeable Pavements in Cold Climates: Hydraulic and Environmental Performance." Journal of Environmental Engineering, 142(6), 04016025.

Humphrey, C., Chaplinski, N., O’Driscoll, M., Kelley, T., and Richards, S. (2014). "Nutrient and Escherichia coli Attentuation in a Constructed Stormwater Wetland in the North Carolina Coastal Plain." Environment and Natural Resources Research, 4(3), 12-22.

Hunt, W. F., Davis, A. P., and Traver, R. G. (2012). "Meeting Hydrologic and Water Quality Goals through Targeted Bioretention Design.” Journal of Environmental Engineering, 138(6), 698- 
707.

Hunt, W. F., Hathaway, J. M., Winston, R. J., and Jadlocki, S. J. (2010). "Runoff Volume Reduction by a Level Spreader-Vegetated Filter Strip System in Suburban Charlotte, N.C.” Journal of Hydrologic Engineering, 15(6), 499-503.

Hussain, A., and Berndtsson, J. C. (2012). "Microbiological runoff water quality from a green roof and in an open stormwater system." Journal of Water Management and Research, 68, 247254.

Hwang, C.-L., and Yoon, K. (1981). Multiple Attribute Decision Making: Methods and Applications A State-of-the-Art Survey.

HydroCAD Software Solutions. (2018). "The Simple Method to Calculate Urban Stormwater Loads." 1-10.

Imran, H. M., Akib, S., and Karim, M. R. (2013). "Permeable pavement and stormwater management systems: a review." Environmental Technology, Taylor \& Francis, 34(18), 2649-2656.

International Organization for Standardardization. (2014). "ISO 14046:2014 - Environmental management -- Water footprint -- Principles, requirements and guidelines." $<$ https://www.iso.org/standard/43263.html > (Apr. 10, 2018).

IPCC. (2014). "Climate Change 2014 Synthesis Report Summary Chapter for Policymakers.” Ipcc, $1-31$.

Iqbal, H., Garcia-Perez, M., and Flury, M. (2015). "Effect of biochar on leaching of organic carbon, nitrogen, and phosphorus from compost in bioretention systems." Science of the Total Environment, Elsevier B.V., 521-522, 37-45.

Isoken, H. I., and Osemwengie, O. V. (2016). "On-site Assessment of Environmental and Sanitary Qualities of Rainwater Harvesting System ( RWH ) in a Rural Community in Benin City, Nigeria." Journal of Applied Sciences and Environmental Management, 20(2), 320-324.

Jato-Espino, D., Rodriguez-Hernandez, J., Andrés-Valeri, V. C., and Ballester-Muñoz, F. (2014). "A fuzzy stochastic multi-criteria model for the selection of urban pervious pavements." Expert Systems with Applications, Elsevier Ltd, 41(15), 6807-6817.

Jia, H., Wang, X., Ti, C., Zhai, Y., Field, R., Tafuri, A. N., Cai, H., and Yu, S. L. (2015). "Field monitoring of a LID-BMP treatment train system in China." Environmental Monitoring and Assessment, 187(6), 1-18. 
Jiang, W., Sha, A., Xiao, J., Li, Y., and Huang, Y. (2015). "Experimental study on filtration effect and mechanism of pavement runoff in permeable asphalt pavement." Construction and Building Materials, 102-110.

Jing, X., Zhang, S., Zhang, J., Wang, Y., Wang, Y., and Yue, T. (2018). “Analysis and Modelling of Stormwater Volume Control Performance of Rainwater Harvesting Systems in Four Climatic Zones of China.” Water Resources Management, Water Resources Management, C. Kamali, M., Delkash, M., and Tajrishy, M. (2017). "Evaluation of permeable pavement responses to urban surface runoff." Journal of Environmental Management, Elsevier Ltd, 187, 43-53.

Karczmarczyk, A., Baryla, A., and Bus, A. (2014). "Effect of P-reactive drainage aggregates on green roof runoff quality." Water (Switzerland), 6(9), 2575-2589.

Kayhanian, M., and Chai, L. (2011). "Hydraulic performance simulation of fully permeable highway shoulder." World Environmental and Water Resources Congress 2011: Bearing Knowledge for Sustainability - Proceedings of the 2011 World Environmental and Water Resources Congress, American Society of Civil Engineers (ASCE), 3489-3498.

Kenway, S., Gregory, A., and McMahon, J. (2011). “Urban water mass balance analysis.” Journal of Industrial Ecology, 15(5), 693-706.

Khan, U. T., Valeo, C., Chu, A., and van Duin, B. (2012a). "Bioretention cell efficacy in cold climates: Part 2 - water quality performance." Canadian Journal of Civil Engineering, 39(11), 1222-1233.

Khan, U. T., Valeo, C., Chu, A., and van Duin, B. (2012b). "Bioretention cell efficacy in cold climates: Part 1 - hydrologic performance." Canadian Journal of Civil Engineering, 39(11), $1210-1221$.

Kim, M. H., Sung, C. Y., Li, M. H., and Chu, K. H. (2012). "Bioretention for stormwater quality improvement in Texas: Removal effectiveness of Escherichia coli." Separation and Purification Technology, Elsevier B.V., 84, 120-124.

Knight, E. M. P., Hunt, W. F., and Winston, R. J. (2013). "Side-by-side evaluation of four level spreader-vegetated filter strips and a swale in eastern North Carolina." Journal of Soil and Water Conservation, 68(1), 60-72.

Kuoppamäki, K., Hagner, M., Lehvävirta, S., and Setälä, H. (2016). "Biochar amendment in the green roof substrate affects runoff quality and quantity." Ecological Engineering, Elsevier B.V., 88, 1-9. 
De Kwaadsteniet, M., Dobrowsky, P. H., Van Deventer, A., Khan, W., and Cloete, T. E. (2013). "Domestic rainwater harvesting: Microbial and chemical water quality and point-of-use treatment systems." Water, Air, and Soil Pollution, 224(7), 1-19.

Lafrance, P., Caron, E., and Bernard, C. (2013). "Impact of grass filter strips length on exported dissolved masses of metolachlor, atrazine and deethylatrazine: A four-season study under natural rain conditions." Soil Use and Management, 29(1), 87-97.

Larson, R. A., and Safferman, S. I. (2012). "Field Application of Farmstead Runoff to Vegetated Filter Strips: Surface and Subsurface Water Quality Assessment.” Journal of Environmental Quality, 41(2), 592-603.

Lee, J. G., Selvakumar, A., Alvi, K., Riverson, J., Zhen, J. X., Shoemaker, L., and Lai, F. hsiung. (2012a). "A watershed-scale design optimization model for stormwater best management practices." Environmental Modelling and Software, Elsevier Ltd, 37, 6-18.

Lee, J. Y., Bak, G., and Han, M. (2012b). "Quality of roof-harvested rainwater - Comparison of different roofing materials." Environmental Pollution, Elsevier Ltd, 162, 422-429.

Lee, J. Y., Yang, J. S., Han, M., and Choi, J. (2010). "Comparison of the microbiological and chemical characterization of harvested rainwater and reservoir water as alternative water resources." Science of the Total Environment, Elsevier B.V., 408(4), 896-905.

Leroy, M. charlotte, Portet-Koltalo, F., Legras, M., Lederf, F., Moncond'huy, V., Polaert, I., and Marcotte, S. (2016). "Performance of vegetated swales for improving road runoff quality in a moderate traffic urban area." Science of the Total Environment, Elsevier B.V., 566-567.

Lewellyn, C., Quetti, K., Wadzuk, B. M., and Traver, R. G. (2015). “An Extremely Undersized Infiltration Trench 10 Years Later." International Low Impact Development Conference 2015, (Pwd 2011), 133-141.

Li, H., and Davis, A. P. (2016). "Water Quality Improvement through Reductions of Pollutant Loads Using Bioretention.” Journal of Environmental Engineering, 135(8), 567-576.

Li, J., Jiang, C., Lei, T., and Li, Y. (2016). "Experimental study and simulation of water quality purification of urban surface runoff using non-vegetated bioswales." Ecological Engineering, Elsevier B.V., 95, 706-713.

Li, M.-H., Sung, C. Y., Kim, M. H., and Chu, K.-H. (2011). "Assessing Performance of Bioretention Boxes in Hot and Semiarid Regions." Transportation Research Record: Journal of the Transportation Research Board, 2262(1), 155-163. 
Lim, K. J., Engel, B. A., Muthukrishnan, S., and Harbor, J. (2006). "Effects of initial abstraction and urbanization on estimated runoff using $\mathrm{CN}$ technology." Journal of the American Water Resources Association, 42(3), 629-643.

Liu, A., Carroll, S., Dawes, L., and Goonetilleke, A. (2017). "Monitoring of a mixed land use catchment for pollutant source characterisation." Environmental Monitoring and Assessment, Environmental Monitoring and Assessment, 189(7), 336, 1-10.

Liu, J., and Davis, A. P. (2014). "Phosphorus speciation and treatment using enhanced phosphorus removal bioretention." Environmental Science and Technology, 48(1), 607-614.

Liu, L., Li, X., Xia, G., Jin, J., and Chen, G. (2016). "Spatial fuzzy clustering approach to characterize flood risk in urban storm water drainage systems." Natural Hazards, Springer Netherlands, 83(3), 1469-1483.

Lizárraga-Mendiola, L., Vázquez-Rodríguez, G., Lucho-Constantino, C., Bigurra-Alzati, C., Beltrán-Hernández, R., Ortiz-Hernández, J., and López-León, L. (2017). "Hydrological Design of Two Low-Impact Development Techniques in a Semi-Arid Climate Zone of Central Mexico." Water, 9(8), 561, 1-18.

Locatelli, L., Mark, O., Mikkelsen, P. S., Arnbjerg-Nielsen, K., Wong, T., and Binning, P. J. (2015). "Determining the extent of groundwater interference on the performance of infiltration trenches." Journal of Hydrology, Elsevier B.V., 529, 1360-1372.

LSRCA. (2016). "LID Treatment Train Tool." < https://www.lsrca.on.ca/Pages/LIDTTTool.aspx> (Mar. 28, 2018).

Lucas, R., and Babatunde, A. O. (2017). "Influence of Key Design and Operating Variables on Dynamics of Pollutant Removal in Experimental Stormwater Constructed Wetlands.” Journal of Environmental Engineering (United States), 143(7), 1-11.

Lucas, R., Earl, E. R., Babatunde, A. O., and Bockelmann-Evans, B. N. (2015). "Constructed wetlands for stormwater management in the UK: a concise review." Civil Engineering and Environmental Systems, 32(3), 251-268.

Lucke, T., Ansaf Kachchu Mohamed, M., and Tindale, N. (2014). "Pollutant Removal and Hydraulic Reduction Performance of Field Grassed Swales during Runoff Simulation Experiments." Water, 6, 1887-1904.

Lynch, J., Fox, L. J., Owen, J. S., and Sample, D. J. (2015). "Evaluation of commercial floating treatment wetland technologies for nutrient remediation of stormwater." Ecological 
Engineering, Elsevier B.V., 75, 61-69.

Ma, Y. (2013). "WATERSHED-LEVEL ANALYSIS OF URBAN RAINGARDEN PERFORMANCE SCIENCE." University of Missouri-Kansas City.

Mackintosh, T. J., Davis, J. A., and Thompson, R. M. (2015). "The influence of urbanisation on macroinvertebrate biodiversity in constructed stormwater wetlands." Science of the Total Environment, Elsevier B.V., 536, 527-537.

Mangangka, I. R. (2017). "Modelling the Hydraulic Processes on Constructed Stormwater Wetland." Civil Engineering Dimension, 19(1), 21-28.

Mangangka, I. R., Liu, A., Egodawatta, P., and Goonetilleke, A. (2015a). "Performance characterisation of a stormwater treatment bioretention basin." Journal of Environmental Management, Elsevier Ltd, 150, 173-178.

Mangangka, I. R., Liu, A., Egodawatta, P., and Goonetilleke, A. (2015b). "Sectional analysis of stormwater treatment performance of a constructed wetland." Ecological Engineering, Elsevier B.V., 77, 172-179.

Maniquiz-Redillas, M. C., and Kim, L.-H. (2016). "Evaluation of the capability of low-impact development practices for the removal of heavy metal from urban stormwater runoff." Environmental technology, Taylor \& Francis, 3330(March), 1-8.

Maniquiz, M. C., Lee, S. Y., and Kim, L. H. (2010). "Long-Term Monitoring of Infiltration Trench for Nonpoint Source Pollution Control." Water Air and Soil Pollution, 212(1-4), 13-26.

Mateleska, K. (2016). Memorandum: Methodology for developing cost estimates for Opti-Tool.

McArdle, P., Gleeson, J., Hammond, T., Heslop, E., Holden, R., and Kuczera, G. (2011). "Centralised urban stormwater harvesting for potable reuse." Water Science and Technology, 63(1), 16-24.

McIntyre, J. K., Edmunds, R. C., Redig, M. G., Mudrock, E. M., Davis, J. W., Incardona, J. P., Stark, J. D., and Scholz, N. L. (2016). "Confirmation of Stormwater Bioretention Treatment Effectiveness Using Molecular Indicators of Cardiovascular Toxicity in Developing Fish.” Environmental Science and Technology, 50(3), 1561-1569.

Meera, V., and Mansoor Ahammed, M. (2006). "Water quality of rooftop rainwater harvesting systems: A review." Journal of Water Supply: Research and Technology - AQUA, 55(4), 257268.

Melville, A. D. (2016). “Assessment of a Mycorrhizal Fungi Application to Treat Stormwater in 
an Urban Bioswale." Portland State University.

Mendez, C. B., Klenzendorf, J. B., Afshar, B. R., Simmons, M. T., Barrett, M. E., Kinney, K. A., and Kirisits, M. J. (2011). "The effect of roofing material on the quality of harvested rainwater." Water Research, Elsevier Ltd, 45(5), 2049-2059.

Minnesota Environment and Natural Resources Trust Fund. (2013). Hydrologic Soil Group Knowledge Matrix.

Minnesota Pollution Control Agency. (2000). Minnesota Urban Small Sites BMP Manual. Minnesota.

Minnesota Pollution Control Agency. (2016). "Overview for pretreatment vegetated filter strips." $<$ https://stormwater.pca.state.mn.us/index.php?title=Overview_for_pretreatment_vegetated _filter_strips> (Nov. 26, 2017).

Minnesota Pollution Control Agency. (2018a). "Design infiltration rates - Minnesota Stormwater Manual.” $\quad<$ https://stormwater.pca.state.mn.us/index.php?title=Design_infiltration_rates $>$ (Sep. 30, 2018).

Minnesota Pollution Control Agency. (2018b). "Design criteria for stormwater ponds - Minnesota Stormwater Manual." $<$ https://stormwater.pca.state.mn.us/index.php?title=Design_criteria_for_stormwater_ponds $>$ (Sep. 30, 2018).

Mitsch, W. J., and Gosselink, J. G. (2001). Wetlands (third edition). John Wiley and Sons Inc., New York.

Morales-Pinzón, T., García-Serna, M. I., and Flórez-Calderón, M. T. (2015). “Quality of rainwater harvesting in urban systems: Case study in Colombia." Water Practice and Technology, $10(3), 424-431$.

Morales-Torres, A., Escuder-Bueno, I., Andrés-Doménech, I., and Perales-Momparler, S. (2016a). "Decision Support Tool for energy-efficient, sustainable and integrated urban stormwater management." Environmental Modelling \& Software, 84, 518-528.

Morales-Torres, A., Escuder-Bueno, I., Andrés-Doménech, I., and Perales-Momparler, S. (2016b). "Decision Support Tool for energy-efficient, sustainable and integrated urban stormwater management." Environmental Modelling and Software, 84, 518-528.

Morgan, S., Alyaseri, I., and Retzlaff, W. (2011). "Suspended solids in and turbidity of runoff from green roofs.” International Journal of Phytoremediation, 13(SUPPL.1), 179-193. 
Morgan, S., Celik, S., and Retzlaff, W. (2013). "Green Roof Storm-Water Runoff Quantity and Quality." Journal of Environmental Engineering, 139(2), 471-478.

Müller, K., Trolove, M., James, T. K., and Rahman, A. (2004). "Herbicide loss in runoff: Effects of herbicide properties, slope, and rainfall intensity." Australian Journal of Soil Research, 42(1), 17-27.

Muller, T. (2017). "Forensic Analysis of an Aged Infiltration Trench and Evaluation of Its Retrofit." ProQuest Dissertations and Theses, Villanova University.

Nagase, A., and Dunnett, N. (2011). "The relationship between percentage of organic matter in substrate and plant growth in extensive green roofs." Landscape and Urban Planning, Elsevier B.V., 103(2), 230-236.

National Academies of Sciences, E. \& M. (2016). Using Graywater and Stormwater to Enhance Local Water Supplies.

National Blue Ribbon Commission for Onsite Non-potable Water Systems. (2017). A Guidebook for Developing and Implementing Regulations for Onsite Non-potable Water Systems.

Nilsson, E., and Stigsson, A. (2012). "Pollutant Removal Efficiencies and Flow Detention of Infiltration Trenches.” Chalmers University of Technology.

Norrstrom, A. C. (2005). "Metal mobility by de-icing salt from an infiltration trench for highway runoff." Applied Geochemistry, 20(10), 1907-1919.

O’Hogain, S., McCarton, L., McIntyre, N., Pender, J., and Reid, A. (2011). "Physicochemical and microbiological quality of water from a pilot domestic rainwater harvesting facility in Ireland." Water and Environment Journal, 25(4), 489-494.

O’Neill, B. C., Tebaldi, C., Van Vuuren, D. P., Eyring, V., Friedlingstein, P., and Sanderson, B. M. (2016). "The scnenario model intercomparison project (ScenarioMIP) for CMIP6." Geoscientific Model Development, 9(9), 4461-3482.

OECD. (2013). Water Security for Better Lives.

OECD. (2015). Water and Cities Ensuring Sustainable Futures.

Olechnowicz, B., and Weinerowska-Bords, K. (2014). "Impact of urbanization on stormwater runoff from a small urban catchment: Gdańsk Małomiejska basin case study." Archives of Hydroengineering and Environmental Mechanics, 61(3-4), 141-162.

Pan, Q., Chhipi-Shrestha, G., Zhou, D., Zhang, K., Hewage, K., and Sadiq, R. (2018). "Evaluating water reuse applications under uncertainty: generalized intuitionistic fuzzy-based approach.” 
Stochastic Environmental Research and Risk Assessment, Springer Berlin Heidelberg, 32(4), 1099-1111.

Paulson, C., Stephens, L., and Broley, W. (2017). Blueprint for One Water.

Paus, K. H., Muthanna, T. M., and Braskerud, B. C. (2015). "The hydrological performance of bioretention cells in regions with cold climates: seasonal variation and implications for design." Hydrology Research, nh2015084, (47)2, 291-304

Peak, S., and Gil, K. (2016). "Correlation analysis of factors affecting removal efficiency in vegetative filter strips.” Environmental Earth Sciences, Springer Berlin Heidelberg, 75(1), 18.

Peel, M. C., Finlayson, B. L., and McMahon, T. A. (2007). "Updated $\{\{$ World Map $\}\}$ of the $\{\{$ Köppen $\}\}-\{\{$ Geiger Climate Classification $\}\} . ” H y d r o l$. Earth Systm. Sci. Discuss., 4, 439473.

Petit-Boix, A., Sevigné-Itoiz, E., Rojas-Gutierrez, L. A., Barbassa, A. P., Josa, A., Rieradevall, J., and Gabarrell, X. (2015). "Environmental and economic assessment of a pilot stormwater infiltration system for flood prevention in Brazil.” Ecological Engineering, Elsevier B.V., 84, 194-201.

Qin, H. peng, Li, Z. xi, and Fu, G. (2013). "The effects of low impact development on urban flooding under different rainfall characteristics." Journal of Environmental Management, $129,577-585$.

Rahman, S., Khan, M. T. R., Akib, S., Che, N., Biswas, S. K., and Shirazi, S. M. (2014). "Sustainability of Rain Water Harvesting System in Terms of Water Quality : A Case Study." The Scientific World, 2(2014), 10-17.

Randall, M. T., and Bradford, A. (2013). "Bioretention gardens for improved nutrient removal." Water Quality Research Journal of Canada, 48(4), 372-386.

Rhea, L., Jarnagin, T., Hogan, D., Loperfido, J. V., and Shuster, W. (2015). "Effects of urbanization and stormwater control measures on streamflows in the vicinity of Clarksburg, Maryland, USA.” Hydrological Processes, 29(20), 4413-4426.

Richards, P. J., Farrell, C., Tom, M., Williams, N. S. G., and Fletcher, T. D. (2015). "Vegetable raingardens can produce food and reduce stormwater runoff." Urban Forestry and Urban Greening, Elsevier GmbH., 14(3), 646-654.

Roseen, R., Ballestero, T., Houle, J., Avelleneda, P., Briggs, J., Fowler, G., and Wildey, R. (2009). 
"Seasonal Performance Variations for Storm-Water Management Systems in Cold Climate Conditions." Journal of Environmental Engineering, 135(3), 128-137.

Roseen, R. M., Ballestero, T. P., Houle, J. J., Briggs, J. F., and Houle, K. M. (2012). "Water quality and hydrologic performance of a porous asphalt pavement as a storm-water treatment strategy in a cold climate." Journal of Environmental Engineering (United States), American Society of Civil Engineers (ASCE), 138(1), 81-89.

Roy-Poirier, A., Champagne, P., and Filion, Y. (2010). "Review of Bioretention System Research and Design: Past, Present, and Future.” Journal of Environmental Engineering, 136(9), 878889.

Ruparathna, R., Hewage, K., and Sadiq, R. (2017). "Economic evaluation of building energy retrofits: A fuzzy based approach.” Energy and Buildings, Elsevier B.V., 139, 395-406.

Sadiq, R., Rodriguez, M. J., Imran, S. A., and Najjaran, H. (2007). “Communicating human health risks associated with disinfection by-products in drinking water supplies : a fuzzy-based approach." Stochastic Environmental Research and Risk Assessment, 21(4), 341-353.

Sansalone, J., Kuang, X., Ying, G., and Ranieri, V. (2012). "Filtration and clogging of permeable pavement loaded by urban drainage.” Water Research, Elsevier Ltd, 46(20), 6763-6774.

Schets, F. M., Italiaander, R., van den Berg, H. H. J. L., and de Roda Husman, A. M. (2010). "Rainwater harvesting: Quality assessment and utilization in The Netherlands." Journal of Water and Health, 8(2), 224-235.

Schmitt, N., Wanko, A., Laurent, J., Bois, P., Molle, P., and Mosé, R. (2015). “Constructed wetlands treating stormwater from separate sewer networks in a residential Strasbourg urban catchment area: Micropollutant removal and fate." Journal of Environmental Chemical Engineering, Elsevier B.V., 3(4), 2816-2824.

Scholz, M., and Yazdi, S. K. (2009). "Treatment of Road Runoff by a Combined Storm Water Treatment, Detention and Infiltration System.” Water Air and Soil Pollution, 198, 55-64.

Scientific and Technical Advisory Panel of the Global Environment Facility. (2014). "Sustainable Urbanization Policy Brief: Proliferation of Urban Centres, their Impact on the World's Environmant and the Potential Role of the GEF. Report to the 5th GEF Assembly, México May 2014."

Segismundo, E. Q., Kim, L. H., Jeong, S. M., and Lee, B. S. (2017). “A laboratory study on the filtration and clogging of the sand-bottom ash mixture for stormwater infiltration filter 
media." Water (Switzerland), 9(1), 1-18.

Seto, K. C., Dhakal, S., Bigio, A., Blanco, H., Delgado, G. C., Dewar, D., Huang, L., Inaba, A., Kansal, A., Lwasa, S., McMahon, J., Müller, D., Murakami, J., Nagrenda, H., and Ramaswami, A. (2014). "Human Settlements, Infrastructure, and Spatial Planning.” Climate Change 2014: Mitigation of Climate Change. Contribution of Working Group III to the Fifth Assessment Report of the Intergovernmental Panel on Climate Change, 923-1000.

Shafique, M., and Kim, R. (2015). "Low impact development practices: A review of current research and recommendations for future directions." Ecological Chemistry and Engineering $S, 22(4), 543-563$.

Sharvelle, S., Ashbolt, N., Clerico, E., Hultquist, R., Leverenz, H., and Olivieri, A. (2017). RiskBased Framework for the Development of Public Health Guidance for Decentralized NonPotable Water Systems.

Shuster, W. D., Lye, D., De La Cruz, A., Rhea, L. K., O’Connell, K., and Kelty, A. (2013). "Assessment of residential rain barrel water quality and use in Cincinnati, Ohio1." Journal of the American Water Resources Association, 49(4), 753-765.

Simonovic, S. P., Schardong, A., Gaur, A., and Sandink, D. (2018). "IDF_CC Tool 3.0." $<$ https://www.idf-cc-uwo.ca/home.aspx> (Sep. 30, 2018).

Sims, A. W., Robinson, C. E., Smart, C. C., Voogt, J. A., Hay, G. J., Lundholm, J. T., Powers, B., and O'Carroll, D. M. (2016). "Retention performance of green roofs in three different climate regions." Journal of Hydrology, Elsevier B.V., 542, 115-124.

Stagge, J. H. (2006). "Field evaluation of hydrologic and water quality benefits of grass swales for managing highway runoff." University of Maryland.

Stagge, J. H., Davis, A. P., Jamil, E., and Kim, H. (2012). "Performance of grass swales for improving water quality from highway runoff.” Water Research, Elsevier Ltd, 46(20), 67316742.

Starry, O., Lea-Cox, J., Ristvey, A., and Cohan, S. (2016). "Parameterizing a Water-Balance Model for Predicting Stormwater Runoff from Green Roofs." Journal of Hydrologic Engineering, 21(12), 04016046.

Tang, N. yuan, Li, T., and Ge, J. (2016). "Assessing ability of a wet swale to manage road runoff: A case study in Hefei, China.” Journal of Central South University, 23(6), 1353-1362.

Tang, P., Yu, B., Zhou, Y., Zhang, Y., and Li, J. (2017). "Clogging development and hydraulic 
performance of the horizontal subsurface flow stormwater constructed wetlands: a laboratory study." Environmental Science and Pollution Research, Environmental Science and Pollution Research, 24(10), 9210-9219.

Taylor, A. (2005). "Structural Stormwater Quality BMP Cost / Size Relationship Information From the Literature.” (September 2000), 1-16.

Teemusk, A., and Mander, Ü. (2011). "The Influence of Green Roofs on Runoff Water Quality: A Case Study from Estonia.” Water Resources Management, 25(14), 3699-3713.

Thode, A. G. (2013). "Evaluation of the farm lane bioretention research facility stormwater treatment performance." Michigan State University.

Thorpe, D., and Zhuge, Y. (2010). "Advantages and disadvantages in using permeable concrete pavement as a pavement construction material." Association of Researchers in Construction Management, ARCOM 2010 - Proceedings of the 26th Annual Conference, (July 2014), 1341-1350.

Toronto and Region Conservation Authority. (2012). "Stormwater Management Criteria." (August), 1-126.

Tota-Maharaj, K., and Scholz, M. (2010). "Efficiency of permeable pavement systems for the removal of urban runoff pollutants under varying environmental conditions." Environmental Progress and Sustainable Energy, John Wiley and Sons Inc., 29(3), 358-369.

Trout Unlimited Canada. (2018). "Bow River Chapter.” < https://tucanada.org/bow-river-chapter/> (Oct. 30, 2018).

U.S. Environmental Protection Agency. (2000). "Low Impact Development (LID): A Literature Review." (October), 41.

Uda, M., Van Seters, T., Graham, C., and Rocha, L. (2013). Assessment of Life Cycle Costs for Low Impact Development Stormwater Management Practices.

UNEP. (2016). GEO-6 Regional Assessment for North America. Nairobi, Kenya.

Unger, I. M., Goyne, K. W., Kremer, R. J., and Kennedy, A. C. (2013). "Microbial community diversity in agroforestry and grass vegetative filter strips." Agroforestry Systems, 87(2), 395402.

United Nations. (2014). World Urbanization Prospects. Undesa.

USDA. (1986). Urban Hydrology for Small Watersheds TR-55. USDA Natural Resource Conservation Service Conservation Engeneering Division Technical Release 55. 
USEPA. (1999). Storm Water Technology Fact Sheet - Porous Pavement.

USEPA. (2001). National Menu of Best Management Practices (BMPs) for Stormwater.

USEPA. (2009). Green Infrastructure in Arid and Semi-Arid Climates - Adapting innovative stormwater management techniques to the water-limited West.

USEPA. (2013). Rainwater Harvesting: Conservation, Credit, Codes, and Cost Literature Review and Case Studies.

USEPA. (2016a). "National Nonpoint Source Program — a catalyst for water quality improvements."

USEPA. (2016b). Storm Water Management Model Reference Manual Volume III - Water Quality.

USEPA. (2017a). "Green Infrastructure and Urban Stormwater Impacts." $<$ https://www.epa.gov/green-infrastructure/green-infrastructure-and-urban-stormwaterimpacts $>$ (Oct. 15, 2017).

USEPA. (2017b). "Urban Runoff: Low Impact Development." < https://www.epa.gov/nps/urbanrunoff-low-impact-development> (Dec. 18, 2017).

USEPA. (2017c). "Soak Up the Rain: Disconnect / Redirect Downspouts."

USEPA. (2018a). "Storm Water Management Model (SWMM)." <https://www.epa.gov/waterresearch/storm-water-management-model-swmm\#capabilities> (Mar. 26, 2018).

USEPA. (2018b). "National Stormwater Calculator." <https://www.epa.gov/waterresearch/national-stormwater-calculator> (Mar. 26, 2018).

Vacca, K., Komlos, J., and Wadzuk, B. M. (2016). "Phosphorus Removal in Constructed Stormwater Wetland Mesocosms Amended with Water Treatment Residuals." Water Environment Research, 88(9), 898-906.

Vanuytrecht, E., Van Mechelen, C., Van Meerbeek, K., Willems, P., Hermy, M., and Raes, D. (2014). "Runoff and vegetation stress of green roofs under different climate change scenarios." Landscape and Urban Planning, Elsevier B.V., 122, 68-77.

Vialle, C., Sablayrolles, C., Lovera, M., Huau, M. C., Jacob, S., and Montrejaud-Vignoles, M. (2012). "Water Quality Monitoring and Hydraulic Evaluation of a Household Roof Runoff Harvesting System in France." Water Resources Management, 26(8), 2233-2241.

Vijayaraghavan, K., and Badavane, A. (2017). "Preparation of growth substrate to improve runoff quality from green roofs: physico-chemical characterization, sorption and plant-support experiments." Urban Water Journal, Taylor \& Francis, 14(8), 804-810. 
Vijayaraghavan, K., and Joshi, U. M. (2014). "Can green roof act as a sink for contaminants? A methodological study to evaluate runoff quality from green roofs." Environmental Pollution, Elsevier Ltd, 194, 121-129.

Vijayaraghavan, K., Joshi, U. M., and Balasubramanian, R. (2012). "A field study to evaluate runoff quality from green roofs." Water Research, Elsevier Ltd, 46(4), 1337-1345.

Walker, C., Tondera, K., and Lucke, T. (2017). "Stormwater treatment evaluation of a Constructed Floating Wetland after two years operation in an urban catchment." Sustainability (Switzerland), 9(10), 1-10.

Wang, Y., Montas, H. J., Brubaker, K. L., Leisnham, P. T., Shirmohammadi, A., Chanse, V., and Rockler, A. K. (2017). “A Diagnostic Decision Support System for BMP Selection in Small Urban Watershed." Water Resources Management, Water Resources Management, 31(5), $1649-1664$.

Wenger, S. J., Roy, A. H., Jackson, C. R., Bernhardt, E. S., Carter, T. L., Filoso, S., Gibson, C. A., Hession, W. C., Kaushal, S. S., Martí, E., Meyer, J. L., Palmer, M. A., Paul, M. J., Purcell, A. H., Ramírez, A., Rosemond, A. D., Schofield, K. A., Sudduth, E. B., and Walsh, C. J. (2009). "Twenty-six key research questions in urban stream ecology: an assessment of the state of the science." Journal of the North American Benthological Society, 28(4), 10801098.

Wild, T. C., Henneberry, J., and Gill, L. (2017). “Comprehending the multiple 'values' of green infrastructure - Valuing nature-based solutions for urban water management from multiple perspectives.” Environmental Research, Elsevier Inc., 158(July), 179-187.

Winston, R. J., Anderson, A. R., and Hunt, W. F. (2017). "Modeling Sediment Reduction in Grass Swales and Vegetated Filter Strips Using Particle Settling Theory.” Journal of Environmental Engineering, 143(1), 04016075.

Winston, R. J., Hunt III, W. F., and Osmond, D. L. (2011a). "Field Evaluation of Four Level Spreader - Vegetative Filter Strips to Improve Urban Storm-Water Quality.” Journal of Irrigation and Drainage Engineering, 137(March), 170-182.

Winston, R. J., Hunt, W. F., Kennedy, S. G., Wright, J. D., and Lauffer, M. S. (2012). "Field Evaluation of Storm-Water Control Measures for Highway Runoff Treatment." Journal of Environmental Engineering, 138(1), 101-111.

Winston, R. J., Hunt, W. F., and Lord, W. G. (2011b). “Thermal Mitigation of Urban Storm Water 
by Level Spreader - Vegetative Filter Strips.” Journal of Environmental Engineering, 137(8), $707-716$.

Winston, R. J., Hunt, W. F., and Wright, J. D. (2010a). "Evaluation of Roadside Filter Strips, Dry Swales, Wet Swales, and Porous Friction Course for Stormwater Treatment." Proceedings of the 2010 International Low Impact Development Conference, 1258-1269.

Winston, R. J., Lauffer, M. S., Narayanaswamy, K., McDaniel, A. H., Lipscomb, B. S., Nice, A. J., and Hunt, W. F. (2015). "Comparing Bridge Deck Runoff and Stormwater Control Measure Quality in North Carolina." Journal of Environmental Engineering, 141(1), 04014045 .

Winston, R. J., Luell, S. K., and Hunt, W. F. (2010b). "Retrofitting with bioretention and a bioswale to treat bridge deck stormwater runoff." Green Streets and Highways 2010: An Interactive Conference on the State of the Art and How to Achieve Sustainable Outcomes Proceedings of the Green Streets and Highways 2010 Conference, 389, 147-162.

Wolman, A. (1965). “The metabolism of cities.” Scientific American, 179-190.

Wu, Z., McKay, J., and Keremane, G. (2012). "Issues affecting community attitudes and intended behaviours in stormwater reuse: A case study of Salisbury, South Australia." Water (Switzerland), 4(4), 835-847.

Xiao, Q., and McPherson, E. G. (2011). "Performance of engineered soil and trees in a parking lot bioswale." Urban Water Journal, 8(4), 241-253.

Xiao, Q., McPherson, E., Zhang, Q., Ge, X., and Dahlgren, R. (2017). "Performance of Two Bioswales on Urban Runoff Management.” Infrastructures, 2(4), 12, 1-14.

Xu, C., Hong, J., Jia, H., Liang, S., and Xu, T. (2017). "Life cycle environmental and economic assessment of a LID-BMP treatment train system: A case study in China." Journal of Cleaner Production, 149, 227-237.

Yergeau, S., and Obropta, C. (2013). "Preliminary Field Evaluation of Soil Compaction in Rain Gardens.” Journal of Environmental Engineering, 139(September), 1233-1236.

Yu, J., Park, K., and Kim, Y. (2012). "Characteristics of pollutants behavior in a stormwater constructed wetland during dry days." Frontiers of Environmental Science and Engineering in China, 6(5), 649-657.

Yu, J., Yu, H., and Xu, L. (2013). "Performance evaluation of various stormwater best management practices." Environmental Science and Pollution Research, 20(9), 6160-6171. 
Zhang, L., Gao, S., Wei, B., Li, Y., Li, H., Wang, L., and Ye, B. (2017). "Effects of Urbanization on Rural Drinking Water Quality in Beijing, China.” Sustainability, 9(12), 461.

Zhang, Q., Wang, X., Hou, P., Wan, W., Li, R., Ren, Y., and Ouyang, Z. (2014). "Quality and seasonal variation of rainwater harvested from concrete, asphalt, ceramic tile and green roofs in Chongqing, China." Journal of Environmental Management, Elsevier Ltd, 132, 178-187.

Zhang, S., and Guo, Y. (2014). "SWMM Simulation of the Storm Water Volume Control Performance of Permeable Pavement Systems." Journal of Hydrologic Engineering, 19(1994), 1-8.

Zounemat-Kermani, M., Scholz, M., and Tondar, M. M. (2015). "Hydrodynamic modelling of free water-surface constructed storm water wetlands using a finite volume technique." Environmental Technology (United Kingdom), 36(20), 2532-2547. 


\section{Appendices}

\section{Appendix A: Detailed reports of reviewed LID BMP studies}

Table A-1: Quantitative and qualitative effects of permeable pavement systems on urban stormwater runoff.

\begin{tabular}{|c|c|c|c|c|c|c|c|c|c|c|c|c|c|c|c|c|c|c|}
\hline \multirow{3}{*}{\begin{tabular}{l}
\multicolumn{1}{c}{ Study } \\
(Ahiablame et \\
al. 2012)
\end{tabular}} & \multirow{3}{*}{$\begin{array}{c}\text { Hydrologic } \\
\text { Quantity } \\
48 \text { to } 97\end{array}$} & \multicolumn{2}{|c|}{ Solids } & \multicolumn{3}{|c|}{ Metals } & \multicolumn{4}{|c|}{ Nutrients } & \multicolumn{2}{|c|}{ Hydrocarbons } & \multirow{2}{*}{$\begin{array}{c}\text { Dissolved } \\
\text { ions } \\
\mathrm{Cl}^{-}\end{array}$} & \multicolumn{3}{|c|}{ Pathogens } & \multicolumn{2}{|c|}{$\begin{array}{l}\text { Oxidizing } \\
\text { Pollutants }\end{array}$} \\
\hline & & TSS & TDS & $\mathbf{P b}$ & $\mathrm{Cu}$ & Zn & \multicolumn{2}{|c|}{ Nitrogen } & \multicolumn{2}{|c|}{ Phosphorous } & TPH & PAH & & TC & FC & $\begin{array}{c}E . \\
\text { coli }\end{array}$ & BOD & COD \\
\hline & & $\begin{array}{l}47 \text { to } \\
93\end{array}$ & - & $\begin{array}{l}31 \text { to } \\
97\end{array}$ & $\begin{array}{l}43 \text { to } \\
97\end{array}$ & $\begin{array}{l}62 \text { to } \\
97\end{array}$ & $\mathrm{TN}$ & $\begin{array}{l}32 \text { to } \\
99\end{array}$ & $\mathrm{TP}$ & $\begin{array}{l}-3 \text { to } \\
99\end{array}$ & $\begin{array}{l}83 \text { to } \\
97\end{array}$ & - & - & - & $\begin{array}{l}71 \text { to } \\
97\end{array}$ & - & - & - \\
\hline $\begin{array}{l}\text { (Shafique and } \\
\text { Kim 2015) }\end{array}$ & 50 to 93 & $\begin{array}{l}58 \text { to } \\
97\end{array}$ & - & $\begin{array}{l}74 \text { to } \\
99\end{array}$ & $\begin{array}{l}20 \text { to } \\
98\end{array}$ & $\begin{array}{l}73 \text { to } \\
95\end{array}$ & $\begin{array}{l}\mathrm{NH}_{3-}^{-} \\
\mathrm{N}\end{array}$ & $\begin{array}{l}75 \text { to } \\
85\end{array}$ & $\mathrm{TP}$ & $\begin{array}{l}10 \text { to } \\
78\end{array}$ & & - & & - & $\begin{array}{l}73 \text { to } \\
95\end{array}$ & - & - & - \\
\hline $\begin{array}{l}\text { (Tota- } \\
\text { Maharaj and } \\
\text { Scholz 2010) }\end{array}$ & - & 91 & - & - & - & - & $\begin{array}{l}\mathrm{NO}_{3-} \\
\mathrm{N} \\
\mathrm{NH}_{3-}^{-} \\
\mathrm{N}\end{array}$ & $\begin{array}{l}41 \text { to } \\
63 \\
70 \text { to } \\
96\end{array}$ & OPP & 78 & - & - & - & $\begin{array}{l}98 \text { to } \\
99\end{array}$ & - & $\begin{array}{l}98 \text { to } \\
99\end{array}$ & 88 & - \\
\hline $\begin{array}{l}\text { (Kayhanian } \\
\text { and Chai } \\
\text { 2011) }\end{array}$ & $\sim 100$ & - & - & - & - & - & - & & - & & - & - & - & - & - & - & - & - \\
\hline $\begin{array}{l}\text { (Roseen et al. } \\
2012 \text { ) }\end{array}$ & 90 to $100^{*}$ & $\sim 100^{*}$ & - & - & - & $\sim 100^{*}$ & $\begin{array}{l}\mathrm{NO}_{3-} \\
\mathrm{N}\end{array}$ & $-50^{*}$ & $\mathrm{TP}$ & $42 *$ & $\sim 100^{*}$ & - & $0 *$ & - & - & - & - & - \\
\hline $\begin{array}{l}\text { (Jiang et al. } \\
2015 \text { ) }\end{array}$ & - & 90 & - & 98 & $\begin{array}{l}20 \text { to } \\
100\end{array}$ & 90 & $\begin{array}{l}\mathrm{NH}_{3-}^{-} \\
\mathrm{N}\end{array}$ & 34 & $\mathrm{TP}$ & $\begin{array}{l}5 \text { to } \\
87\end{array}$ & $\sim 100$ & - & 6 & - & - & - & $\begin{array}{l}50 \text { to } \\
55\end{array}$ & $\begin{array}{l}50 \text { to } \\
55\end{array}$ \\
\hline $\begin{array}{l}\text { (Sansalone et } \\
\text { al. 2012) }\end{array}$ & - & 50 & - & - & - & - & - & & - & & - & - & - & - & - & - & - & - \\
\hline $\begin{array}{l}\text { (Alsubih et al. } \\
\text { 2017) }\end{array}$ & 40 to 92 & - & - & - & - & - & - & & - & & - & - & - & - & - & - & - & - \\
\hline $\begin{array}{l}\text { (Kamali et al. } \\
\text { 2017) }\end{array}$ & $\sim 100$ & - & - & - & - & - & $\begin{array}{l}\mathrm{NO}_{3-} \\
\mathrm{N}\end{array}$ & $\begin{array}{l}-17 \text { to } \\
-6\end{array}$ & OPP & $\begin{array}{l}9 \text { to } \\
38\end{array}$ & - & - & - & - & - & - & - & - \\
\hline & & & & & & & $\begin{array}{l}\mathrm{NH}_{3-} \\
\mathrm{N}\end{array}$ & $\begin{array}{l}57 \text { to } \\
79\end{array}$ & & & & & & & & & & \\
\hline $\begin{array}{l}\text { (Drake et al. } \\
\text { 2014a) }\end{array}$ & - & 80 & - & - & $\begin{array}{l}65 \text { to } \\
93\end{array}$ & 90 & $\mathrm{TN}$ & 47 & $\mathrm{TP}$ & 75 & $\sim 100$ & - & 0 & - & - & - & - & - \\
\hline $\begin{array}{l}\text { (Drake et al. } \\
2014 b \text { ) }\end{array}$ & 43 & - & - & - & - & - & - & & - & & - & - & - & - & - & - & - & - \\
\hline $\begin{array}{l}\text { (Chowdhury } \\
\text { et al. 2016) }\end{array}$ & - & - & $\begin{array}{l}-33 \text { to }- \\
17\end{array}$ & - & - & - & $\begin{array}{l}\mathrm{NO}_{3-} \\
\mathrm{N} \\
\mathrm{NH}_{3-} \\
\mathrm{N}\end{array}$ & $\begin{array}{l}-27 \text { to } \\
-9 \\
68 \text { to } \\
99\end{array}$ & - & & - & - & - & 0 & - & - & - & $\begin{array}{l}40 \text { to } \\
96\end{array}$ \\
\hline
\end{tabular}




\begin{tabular}{|c|c|c|c|c|c|c|c|c|c|c|c|c|c|c|c|c|c|c|}
\hline \multirow[b]{2}{*}{ Study } & \multirow{2}{*}{$\begin{array}{c}\text { Hydrologic } \\
\text { Quantity }\end{array}$} & \multicolumn{2}{|c|}{ Solids } & \multicolumn{3}{|c|}{ Metals } & \multicolumn{4}{|c|}{ Nutrients } & \multicolumn{2}{|c|}{ Hydrocarbons } & \multirow{2}{*}{$\begin{array}{c}\text { Dissolved } \\
\text { ions } \\
\mathrm{Cl}^{-}\end{array}$} & \multicolumn{3}{|c|}{ Pathogens } & \multicolumn{2}{|c|}{$\begin{array}{l}\text { Oxidizing } \\
\text { Pollutants }\end{array}$} \\
\hline & & TSS & TDS & $\mathbf{P b}$ & $\mathrm{Cu}$ & Zn & & ogen & Pho & horous & TPH & PAH & & TC & FC & $\begin{array}{c}E . \\
\text { coli }\end{array}$ & BOD & COD \\
\hline $\begin{array}{l}\text { Range in } \\
\text { values }\end{array}$ & 19 to 100 & $\begin{array}{l}47 \text { to } \\
100\end{array}$ & $\begin{array}{l}-33 \text { to } \\
17\end{array}$ & $\begin{array}{l}31 \text { to } \\
99\end{array}$ & $\begin{array}{l}20 \text { to } \\
100\end{array}$ & $\begin{array}{l}62 \text { to } \\
100\end{array}$ & $\begin{array}{l}\mathrm{TN} \\
\mathrm{NO}_{3}- \\
\mathrm{N} \\
\mathrm{NH}_{3}- \\
\mathrm{N}\end{array}$ & $\begin{array}{l}0 \text { to } \\
99 \\
-50 \text { to } \\
63 \\
34 \text { to } \\
96\end{array}$ & $\begin{array}{l}\text { TP } \\
\text { OPP }\end{array}$ & $\begin{array}{l}-3 \text { to } \\
99 \\
9 \text { to } \\
38\end{array}$ & $\begin{array}{l}83 \text { to } \\
100\end{array}$ & - & 0 to 6 & $\begin{array}{l}0 \text { to } \\
99\end{array}$ & $\begin{array}{l}71 \text { to } \\
97\end{array}$ & $\begin{array}{l}98 \text { to } \\
99\end{array}$ & $\begin{array}{l}50 \text { to } \\
88\end{array}$ & $\begin{array}{l}40 \text { to } \\
96\end{array}$ \\
\hline
\end{tabular}

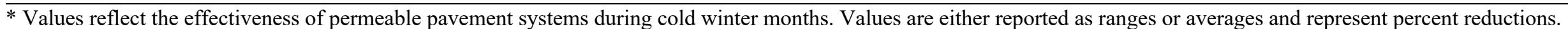


Table A-2: Quantitative and qualitative effects of infiltration trenches on urban stormwater runoff.

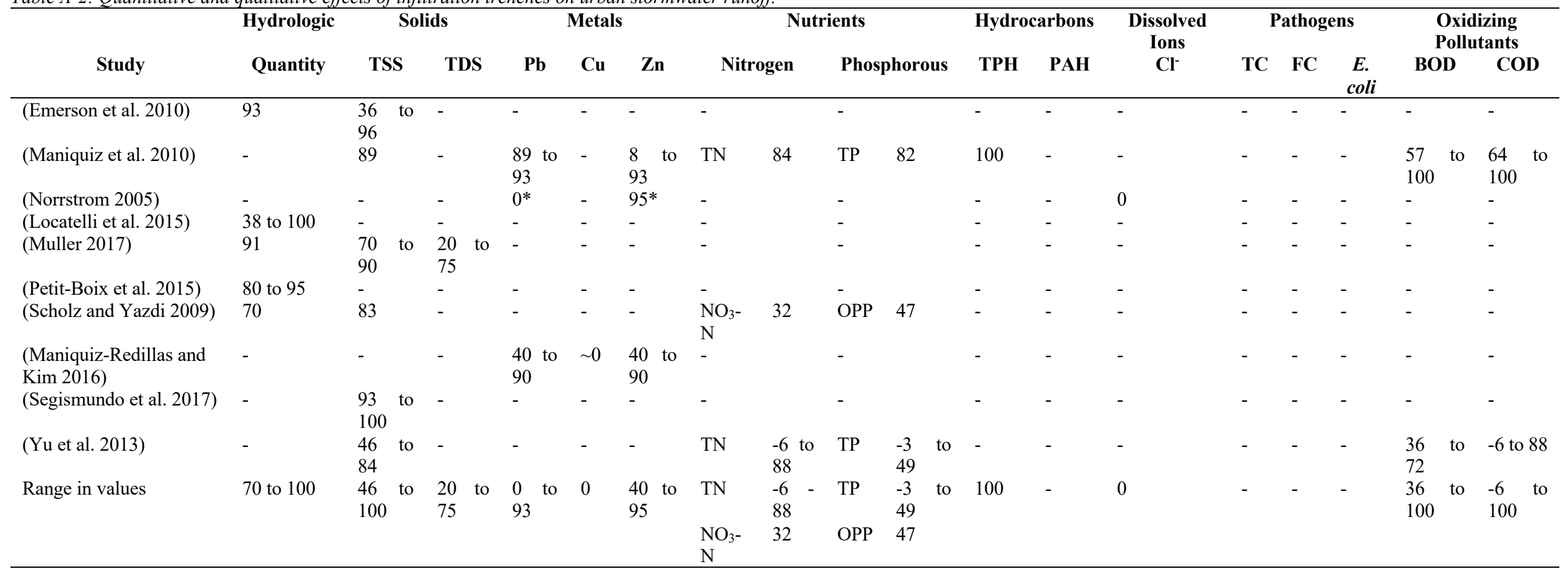

* Values reflect the effectiveness of infiltration trenches during cold winter months. Values are either reported as ranges or averages and represent percent reductions. 
Table A-3: Quantitative and qualitative effects of bioswales on urban stormwater runoff.

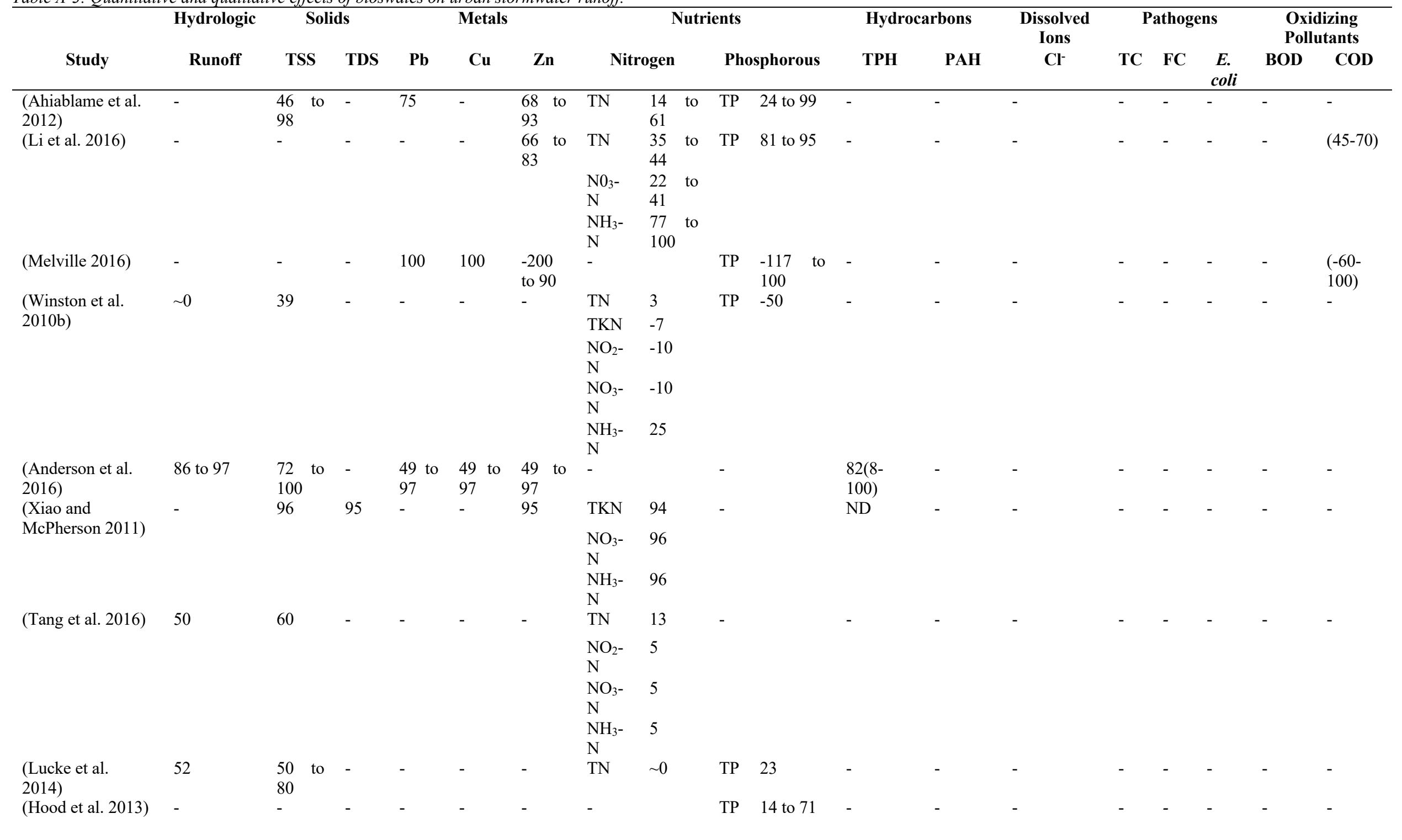




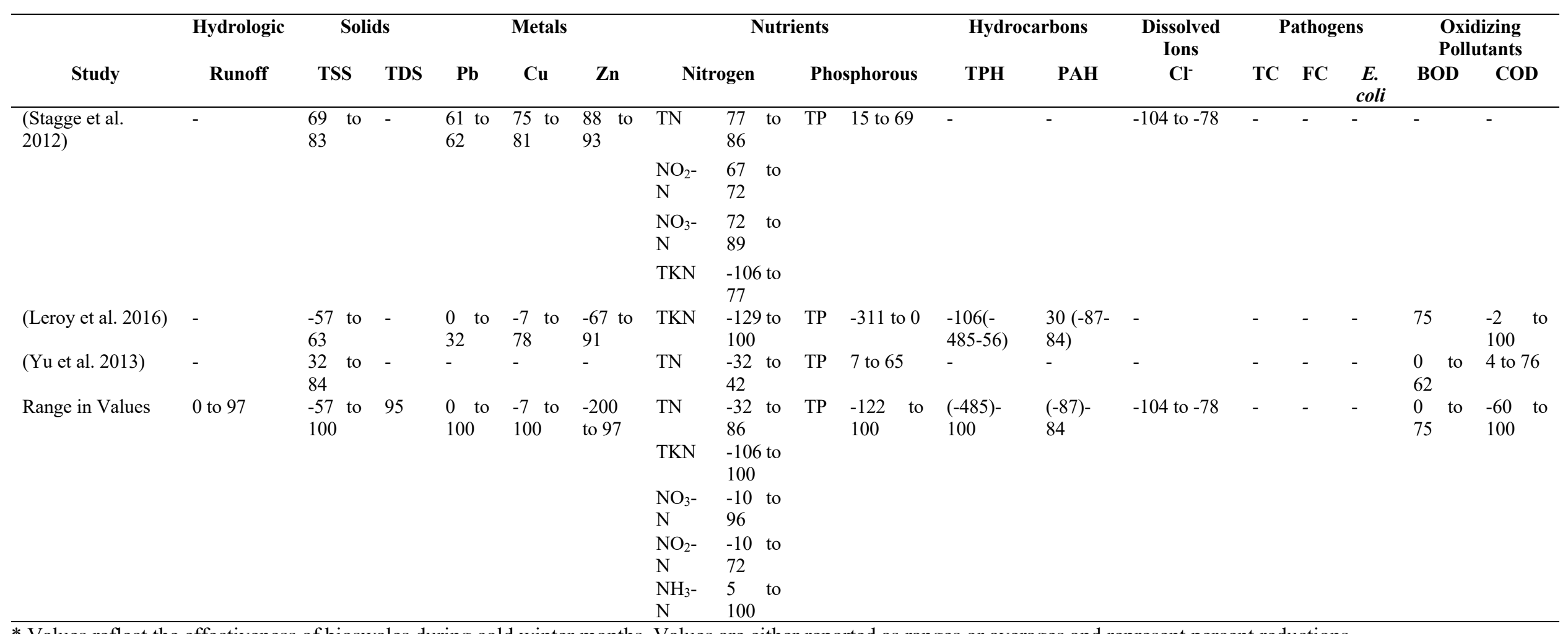

* Values reflect the effectiveness of bioswales during cold winter months. Values are either reported as ranges or averages and represent percent reductions. 
Table A-4: Quantitative and qualitative effects of bioretention cells on urban stormwater runoff

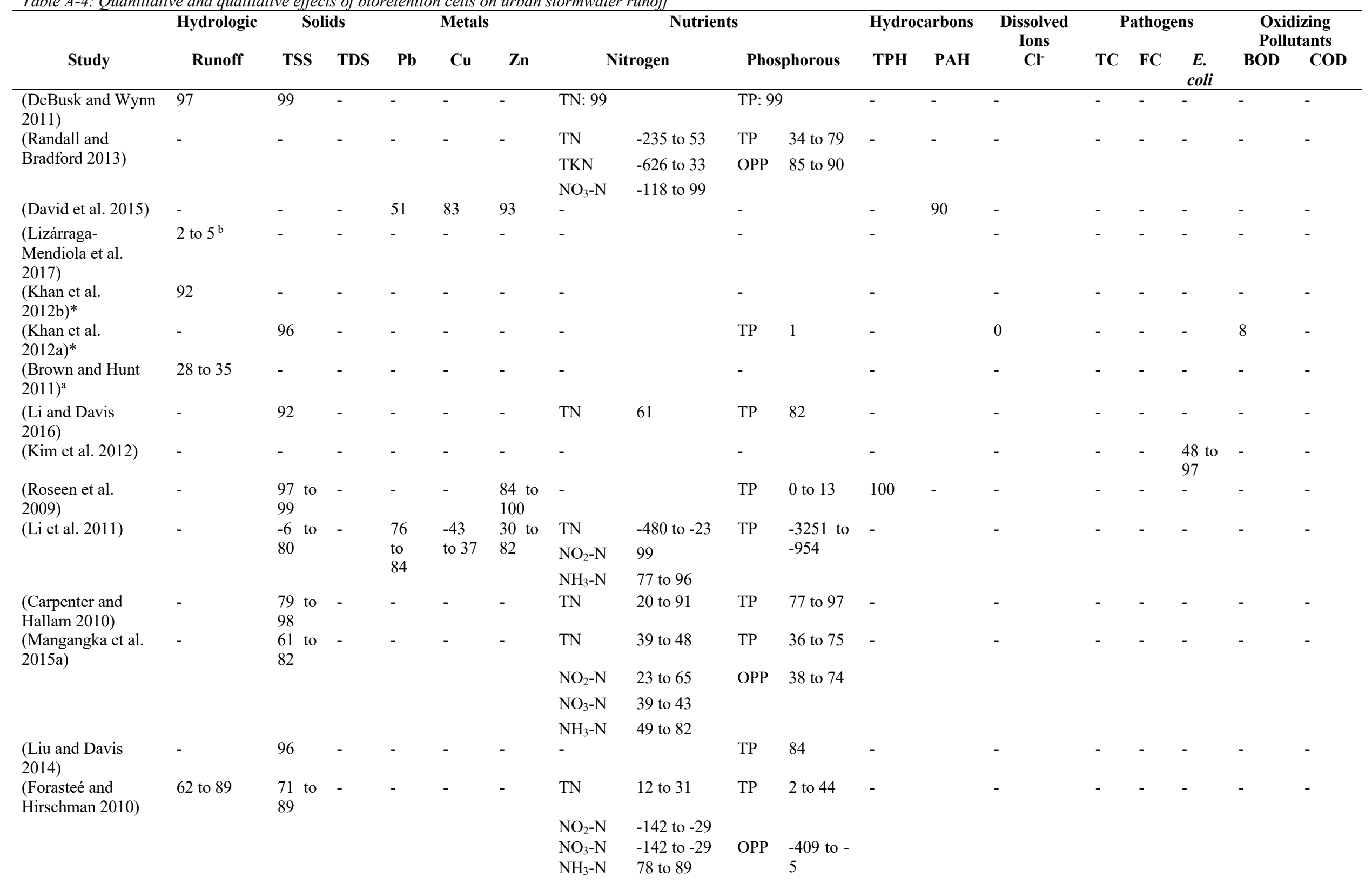


Table A-4: Quantitative and qualitative effects of bioretention cells on urban stormwater runoff

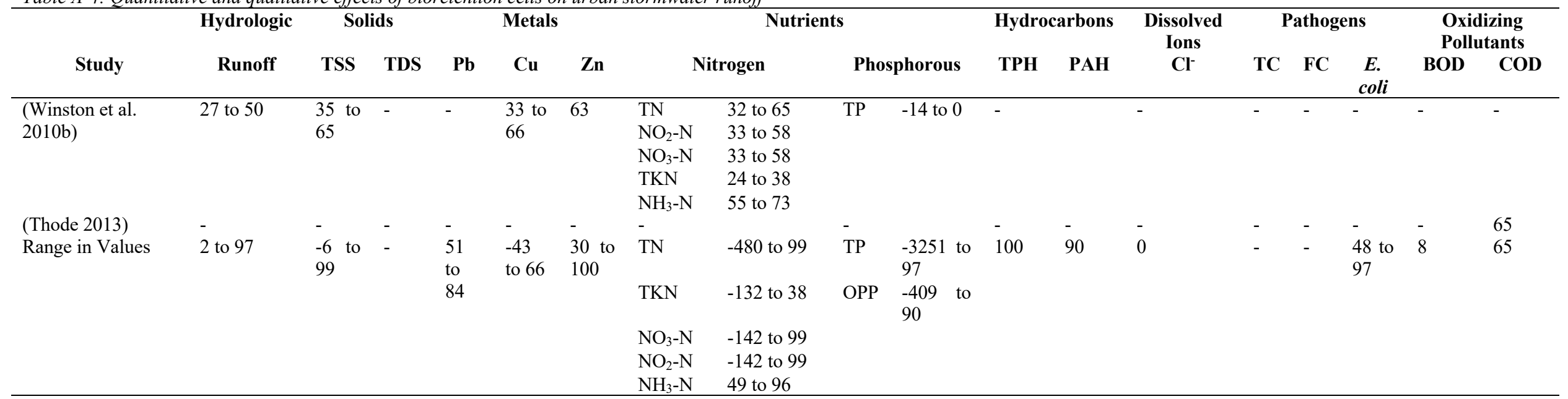

* Values reflect the effectiveness of bioretention cells during cold winter months. Values are either reported as ranges or averages and represent percent reductions.

${ }^{a}$ Intentionally undersized to highlight effects of improper design

${ }^{b}$ Values are very low because the BMP to drainage area ratio is only $1 \%$. 
Table A-5: Quantitative and qualitative effects of buffer/filter strips on urban stormwater runoff.

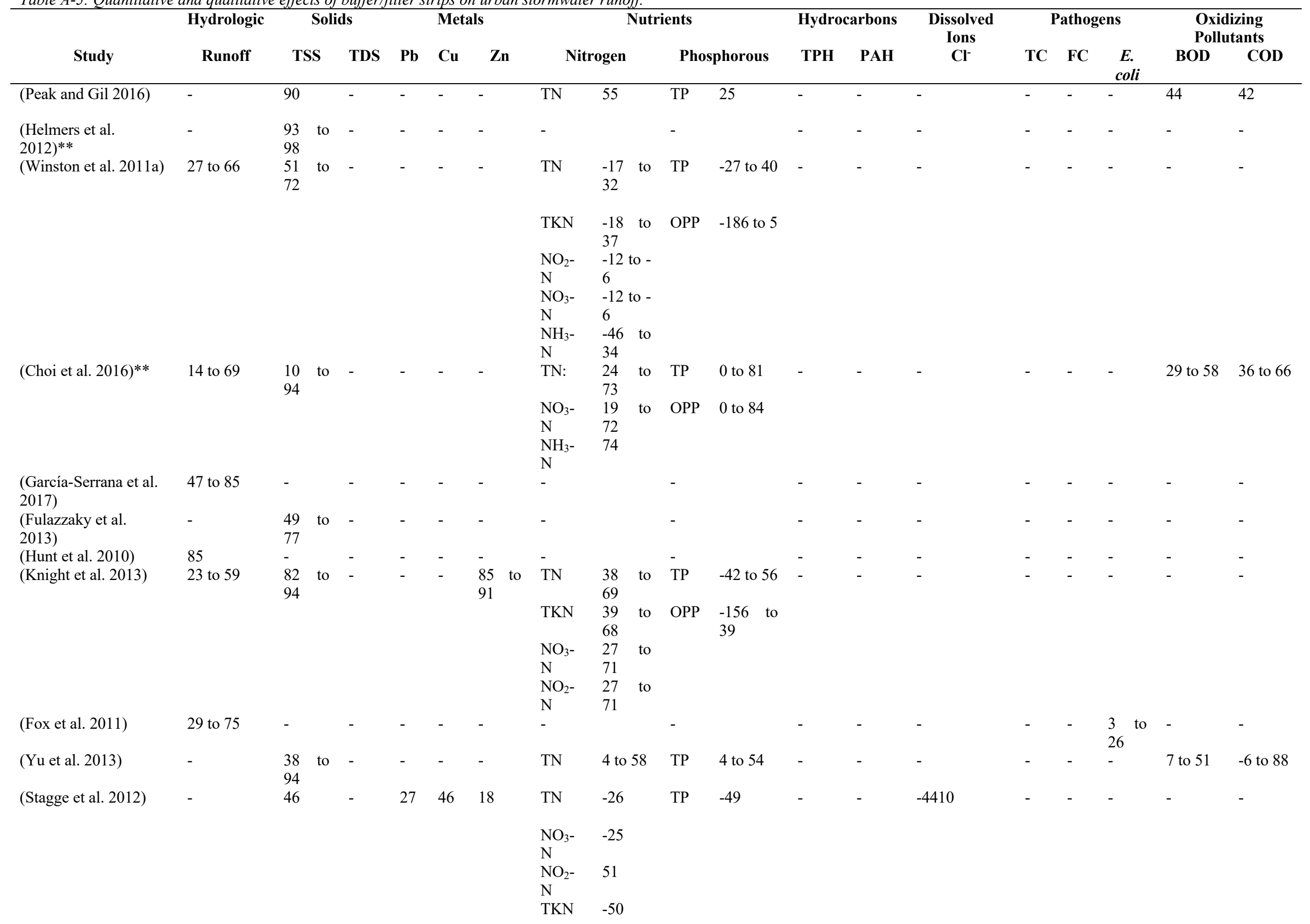


Table A-5: Quantitative and qualitative effects of buffer/filter strips on urban stormwater runoff.

\begin{tabular}{|c|c|c|c|c|c|c|c|c|c|c|c|c|c|c|c|c|c|c|}
\hline \multirow{3}{*}{$\begin{array}{c}\text { Study } \\
\text { Range in Values }\end{array}$} & \multirow{3}{*}{$\begin{array}{c}\text { Hydrologic } \\
\text { Runoff } \\
14 \text { to } 85\end{array}$} & \multicolumn{2}{|c|}{ Solids } & \multicolumn{3}{|c|}{ Metals } & \multicolumn{4}{|c|}{ Nutrients } & \multicolumn{2}{|c|}{ Hydrocarbons } & \multirow{3}{*}{$\begin{array}{c}\begin{array}{c}\text { Dissolved } \\
\text { Ions } \\
\text { Cl}^{-}\end{array} \\
-4410\end{array}$} & \multicolumn{3}{|c|}{ Pathogens } & \multicolumn{2}{|c|}{$\begin{array}{l}\text { Oxidizing } \\
\text { Pollutants }\end{array}$} \\
\hline & & TSS & TDS & \multirow{2}{*}{$\begin{array}{c}\mathbf{P b} \\
27\end{array}$} & \multirow{2}{*}{$\begin{array}{l}\mathrm{Cu} \\
46\end{array}$} & $\mathbf{Z n}$ & \multicolumn{2}{|c|}{ Nitrogen } & \multicolumn{2}{|c|}{ Phosphorous } & \multirow{2}{*}{$\begin{array}{c}\text { TPH } \\
-\end{array}$} & РAH & & TC & FC & $\begin{array}{c}E . \\
\text { coli }\end{array}$ & BOD & COD \\
\hline & & $\begin{array}{ll}10 & \text { to } \\
98 & \end{array}$ & - & & & $\begin{array}{ll}18 & \text { to } \\
91 & \end{array}$ & $\mathrm{TN}$ & $\begin{array}{ll}-26 & \text { to } \\
73 & \end{array}$ & & & & - & & - & - & $\begin{array}{l}3 \\
26\end{array}$ to & 7 to 58 & -6 to 88 \\
\hline & & & & & & & TKN & $\begin{array}{l}-50 \text { to } \\
68\end{array}$ & OPP & $\begin{array}{l}-186 \text { to } \\
39\end{array}$ & & & & & & & & \\
\hline & & & & & & & $\begin{array}{l}\mathrm{NO}_{3-} \\
\mathrm{N} \\
\mathrm{NO}_{2-} \\
\mathrm{N} \\
\mathrm{NH}_{3-} \\
\mathrm{N}\end{array}$ & $\begin{array}{l}-25 \text { to } \\
72 \\
(-12)- \\
71 \\
(-46)- \\
74\end{array}$ & & & & & & & & & & \\
\hline
\end{tabular}

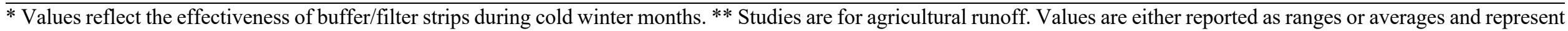
percent reductions. 
Table A-6: Quantitative and qualitative effects of constructed stormwater wetlands on urban stormwater runoff.

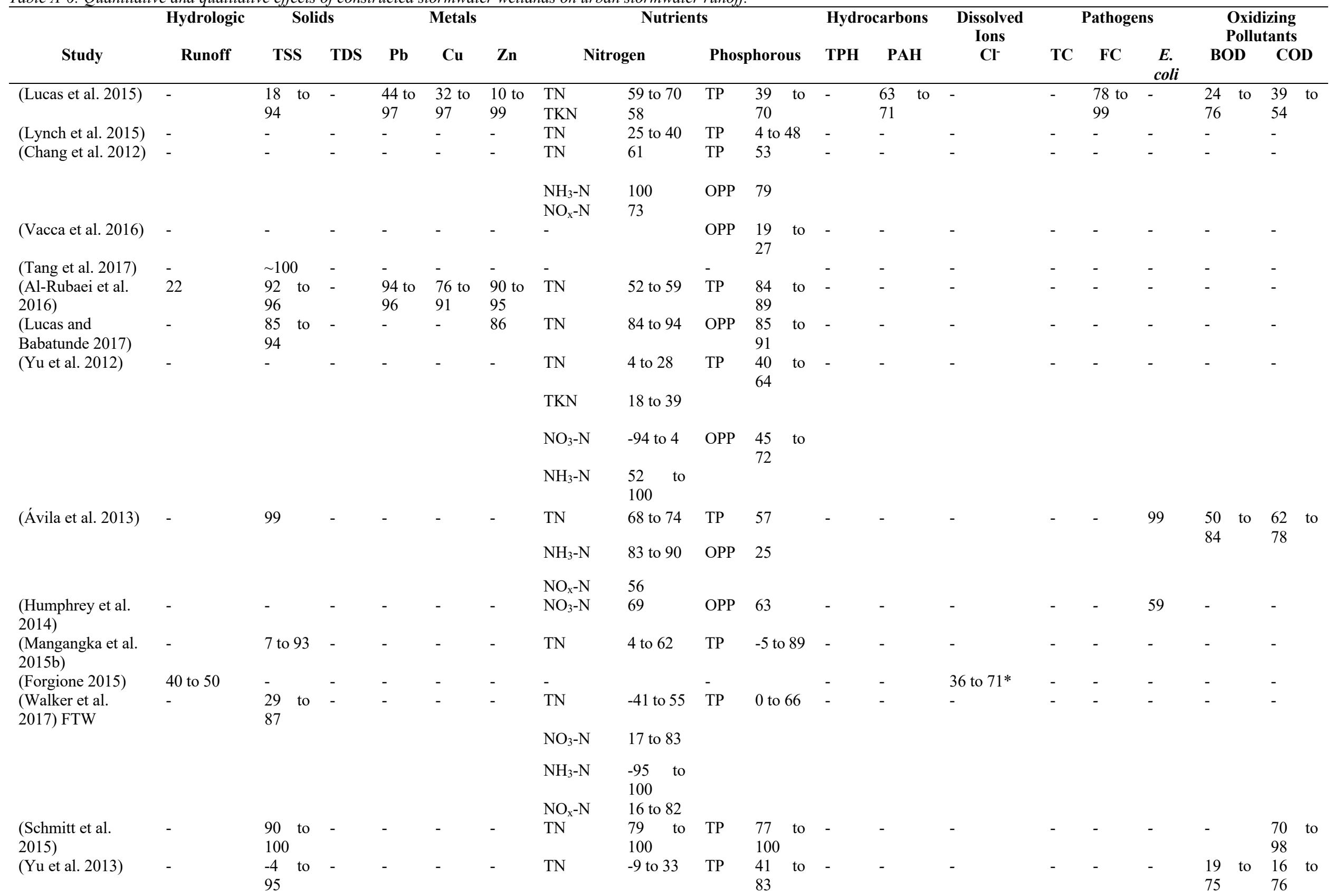




\begin{tabular}{|c|c|c|c|c|c|c|c|c|c|c|c|c|c|c|c|c|c|c|c|}
\hline \multirow{3}{*}{$\begin{array}{c}\text { Study } \\
\text { Range in Values }\end{array}$} & \multirow{3}{*}{$\begin{array}{c}\begin{array}{c}\text { Hydrologic } \\
\text { Runoff }\end{array} \\
22 \text { to } 50\end{array}$} & \multicolumn{2}{|c|}{ Solids } & \multicolumn{3}{|c|}{ Metals } & \multicolumn{5}{|c|}{ Nutrients } & \multicolumn{2}{|c|}{ Hydrocarbons } & \multirow{3}{*}{\begin{tabular}{|c|c|c|c|c|}
$\begin{array}{c}\text { Dissolved } \\
\text { Ions } \\
\mathbf{C l}^{-}\end{array}$ \\
36 to 71
\end{tabular}} & \multicolumn{3}{|c|}{ Pathogens } & \multicolumn{2}{|c|}{$\begin{array}{l}\text { Oxidizing } \\
\text { Pollutants }\end{array}$} \\
\hline & & TSS & TDS & \multirow{3}{*}{$\begin{array}{l}\text { Pb } \\
44 \text { to } \\
97\end{array}$} & \multirow{3}{*}{$\begin{array}{l}\mathbf{C u} \\
32 \text { to } \\
97\end{array}$} & \multirow{3}{*}{$\begin{array}{l}\mathbf{Z n} \\
10 \text { to } \\
99\end{array}$} & \multicolumn{2}{|c|}{ Nitrogen } & \multicolumn{3}{|c|}{ Phosphorous } & \multirow{3}{*}{$\begin{array}{l}\text { TPH } \\
-\end{array}$} & PAH & & \multirow{2}{*}{$\begin{array}{l}\text { TC } \\
-\end{array}$} & \multirow{3}{*}{$\begin{array}{l}\text { FC } \\
78 \text { to } \\
99\end{array}$} & \multirow{3}{*}{$\begin{array}{c}\begin{array}{c}E . \\
\text { coli }\end{array} \\
59 \text { to } \\
99\end{array}$} & BOD & COD \\
\hline & & -4 to & - & & & & $\mathrm{TN}$ & -41 & TP & 0 & to & & 63 & & & & & 19 to & 16 to \\
\hline & & 100 & & & & & & 100 & & 100 & & & 71 & & & & & 84 & 98 \\
\hline & & & & & & & TKN & 18 to 58 & OPP & $\begin{array}{l}19 \\
91\end{array}$ & to & & & & & & & & \\
\hline & & & & & & & $\mathrm{NO}_{3}-\mathrm{N}$ & -94 to 83 & & & & & & & & & & & \\
\hline & & & & & & & $\mathrm{NO}_{x}-\mathrm{N}$ & 16 to 82 & & & & & & & & & & & \\
\hline & & & & & & & $\mathrm{NH}_{3}-\mathrm{N}$ & $\begin{array}{ll}-95 & \text { to } \\
100 & \end{array}$ & & & & & & & & & & & \\
\hline
\end{tabular}

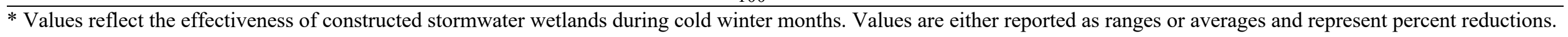


Table A-7: Concentrations of pollutants in rainwater harvesting storage vessels.

\begin{tabular}{|c|c|c|c|c|c|c|c|c|c|c|c|c|c|c|c|c|c|}
\hline \multirow{3}{*}{\begin{tabular}{l}
\multicolumn{1}{c}{ Study } \\
(De \\
Kwaadsteniet \\
et al. 2013)
\end{tabular}} & \multirow{2}{*}{$\begin{array}{r}\text { Soli } \\
\text { TSS } \\
(\mathrm{mg} / \mathrm{L}) \\
-\end{array}$} & \multicolumn{2}{|l|}{ lids } & \multicolumn{2}{|l|}{ Metals } & \multicolumn{4}{|c|}{ Nutrients } & \multicolumn{2}{|c|}{ Hydrocarbons } & \multirow{2}{*}{$\begin{array}{c}\text { Dissolved } \\
\text { Ions } \\
\mathrm{Cl}^{-} \\
(\mathrm{mg} / \mathrm{L})\end{array}$} & \multicolumn{3}{|c|}{ Pathogens } & \multicolumn{2}{|c|}{$\begin{array}{l}\text { Oxidizing } \\
\text { Pollutant }\end{array}$} \\
\hline & & $\begin{array}{c}\text { TDS } \\
(\mathrm{mg} / \mathrm{L})\end{array}$ & $\begin{array}{c}\mathrm{Pb} \\
(\mathrm{mg} / \mathrm{L})\end{array}$ & $\begin{array}{c}\mathrm{Cu} \\
(\mathrm{mg} / \mathrm{L})\end{array}$ & $\begin{array}{c}\mathrm{Zn} \\
(\mathrm{mg} / \mathrm{L})\end{array}$ & & $\begin{array}{l}\text { ogen } \\
\text { s/L) }\end{array}$ & $\begin{array}{r}\text { Phos } \\
\text { (n }\end{array}$ & $\begin{array}{l}\text { horous } \\
\text { g/L) }\end{array}$ & $\begin{array}{c}\text { TPH } \\
(\mathrm{mg} / \mathrm{L})\end{array}$ & $\begin{array}{c}\text { PAH } \\
(\mathbf{m g} / \mathbf{L})\end{array}$ & & $\begin{array}{c}\text { TC } \\
(\mathrm{cfu} / \mathbf{1 0 0} \\
\mathrm{mL})\end{array}$ & $\begin{array}{c}\text { FC } \\
(\mathrm{cfu} / 100 \\
\mathrm{mL})\end{array}$ & $\begin{array}{c}\text { E. coli } \\
(\mathrm{cfu} / 100 \\
\mathrm{mL})\end{array}$ & $\begin{array}{c}\text { BOD } \\
(\mathrm{mg} / \mathrm{L})\end{array}$ & $\begin{array}{c}\text { COD } \\
(\mathrm{mg} / \mathrm{L})\end{array}$ \\
\hline & & - & $\begin{array}{l}0.0002 \\
\text { to } 0.041\end{array}$ & $\begin{array}{l}0.001 \\
\text { to } 0.06\end{array}$ & $\begin{array}{l}0.009 \\
\text { to } 1.8\end{array}$ & $\begin{array}{l}\mathrm{NO}_{2-} \\
\mathrm{N} \\
\mathrm{NO}_{3-} \\
\mathrm{N} \\
\mathrm{NH}_{3-} \\
\mathrm{N}\end{array}$ & $\begin{array}{l}0.006 \\
\text { to } 0.1 \\
1.2 \text { to } \\
7.0 \\
0.007 \\
\text { to } 1.4\end{array}$ & $\begin{array}{l}\text { TP } \\
\text { OPP }\end{array}$ & $\begin{array}{l}0.25 \\
0.09 \text { to } \\
1.3\end{array}$ & - & - & & - & & - & - & - \\
\hline $\begin{array}{l}\text { (Mendez et al. } \\
\text { 2011) }\end{array}$ & $\begin{array}{l}10 \text { to } \\
150\end{array}$ & - & $\begin{array}{l}0.0007 \\
\text { to } \\
0.0086\end{array}$ & - & $\begin{array}{l}0.001 \\
\text { to } \\
0.023\end{array}$ & $\begin{array}{l}\mathrm{NO}_{2-} \\
\mathrm{N} \\
\mathrm{NO}_{3-} \\
\mathrm{N}\end{array}$ & $\begin{array}{l}0.01 \\
\text { to } \\
0.06 \\
0.3 \text { to } \\
4.7\end{array}$ & - & & - & - & - & 64 to 353 & 37 to 253 & - & - & - \\
\hline $\begin{array}{l}\text { (Lee et al. } \\
2012 b \text { ) }\end{array}$ & $\begin{array}{ll}20 & \text { to } \\
40 & \end{array}$ & - & $\begin{array}{l}0.03 \text { to } \\
0.05\end{array}$ & $\begin{array}{l}0.01 \text { to } \\
0.04\end{array}$ & $\begin{array}{l}0.02 \text { to } \\
0.08\end{array}$ & $\begin{array}{l}\mathrm{NO}_{3-} \\
\mathrm{N}\end{array}$ & $\begin{array}{l}0.1 \text { to } \\
0.4\end{array}$ & & & & - & & 0 to 20 & & 0 to 4 & & \\
\hline $\begin{array}{l}\text { (Shuster et al. } \\
\text { 2013) }\end{array}$ & - & - & - & - & - & - & & - & & - & - & - & $\begin{array}{l}1930 \text { to } \\
112000\end{array}$ & & $\begin{array}{ll}47 & \text { to } \\
8300\end{array}$ & - & - \\
\hline $\begin{array}{l}\text { (O'Hogain et } \\
\text { al. 2011) }\end{array}$ & 0 to 12 & $\begin{array}{l}45 \text { to } \\
124\end{array}$ & $\begin{array}{l}0.0057 \\
\text { to } 0.136\end{array}$ & - & - & $\begin{array}{l}\mathrm{NO}_{3-} \\
\mathrm{N} \\
\mathrm{NO}_{2-} \\
\mathrm{N} \\
\mathrm{NH}_{3-} \\
\mathrm{N}\end{array}$ & $\begin{array}{l}0.2 \text { to } \\
2.1 \\
0 \text { to } \\
0.2 \\
0 \text { to } \\
0.3\end{array}$ & - & & - & - & - & 0 to 563 & 0 to 10 & 0 to 2.1 & - & - \\
\hline $\begin{array}{l}\text { (Schets et al. } \\
\text { 2010) }\end{array}$ & - & - & - & - & - & - & & - & & - & - & - & $\begin{array}{ll}15 & \text { to } \\
3818 & \end{array}$ & - & 2 to 1934 & - & - \\
\hline $\begin{array}{l}\text { (Farreny et al. } \\
\text { 2011) }\end{array}$ & 6 & - & - & - & - & $\begin{array}{l}\mathrm{NO}_{3-} \\
\mathrm{N}: \\
\mathrm{NO}_{2-} \\
\mathrm{N} \\
\mathrm{NH}_{3-} \\
\mathrm{N}\end{array}$ & $\begin{array}{l}1.44 \\
\text { to } \\
1.96 \\
0.08 \\
\text { to } \\
0.18 \\
0.43 \\
\text { to } \\
0.57\end{array}$ & OPP & $\begin{array}{l}0.18 \text { to } \\
0.46\end{array}$ & - & - & 6.5 to 11.2 & - & - & - & & \\
\hline $\begin{array}{l}\text { (Vialle et al. } \\
\text { 2012) }\end{array}$ & - & - & - & - & - & $\begin{array}{l}\mathrm{TN} \\
\mathrm{NO}_{3-} \\
\mathrm{N} \\
\mathrm{NH}_{3-}- \\
\mathrm{N}\end{array}$ & $\begin{array}{l}1.7 \\
2.8 \\
\\
0.58\end{array}$ & $\begin{array}{l}\text { TP } \\
\text { OPP }\end{array}$ & $\begin{array}{l}<0.1 \\
0.17\end{array}$ & - & - & 0.3 & - & - & - & $<3$ & $<30$ \\
\hline $\begin{array}{l}\text { (Rahman et al. } \\
\text { 2014) }\end{array}$ & - & $\begin{array}{ll}20 & \text { to } \\
90 & \end{array}$ & - & - & - & $\begin{array}{l}\mathrm{NH}_{3-} \\
\mathrm{N}\end{array}$ & $\begin{array}{l}0.1 \text { to } \\
1.4\end{array}$ & - & & - & - & - & 0 to 380 & 0 to 340 & - & $\begin{array}{l}0.02 \text { to } \\
0.18\end{array}$ & - \\
\hline
\end{tabular}




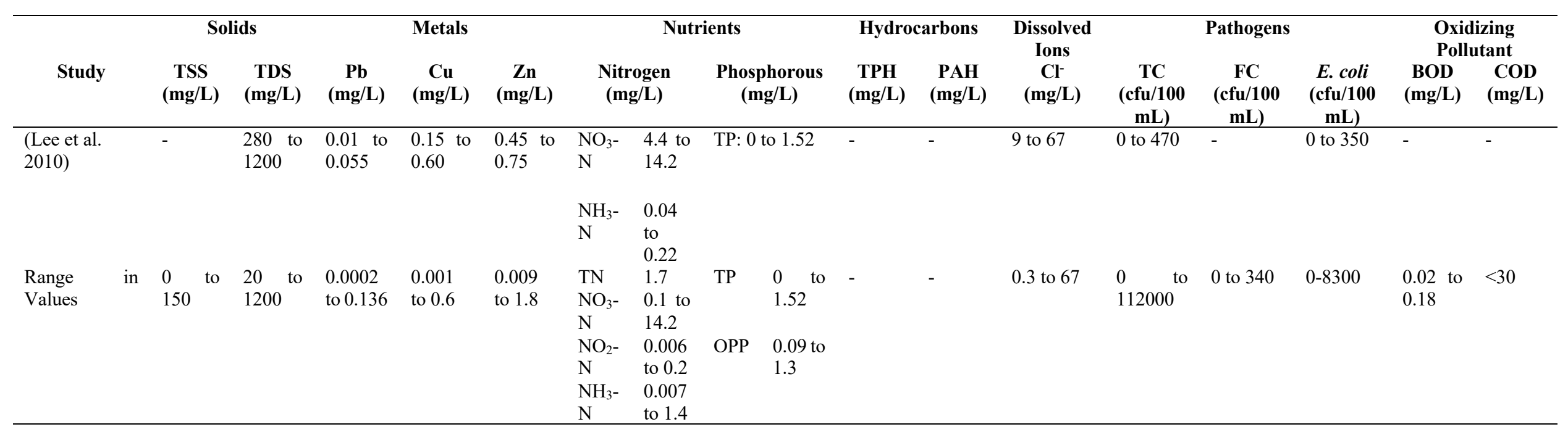




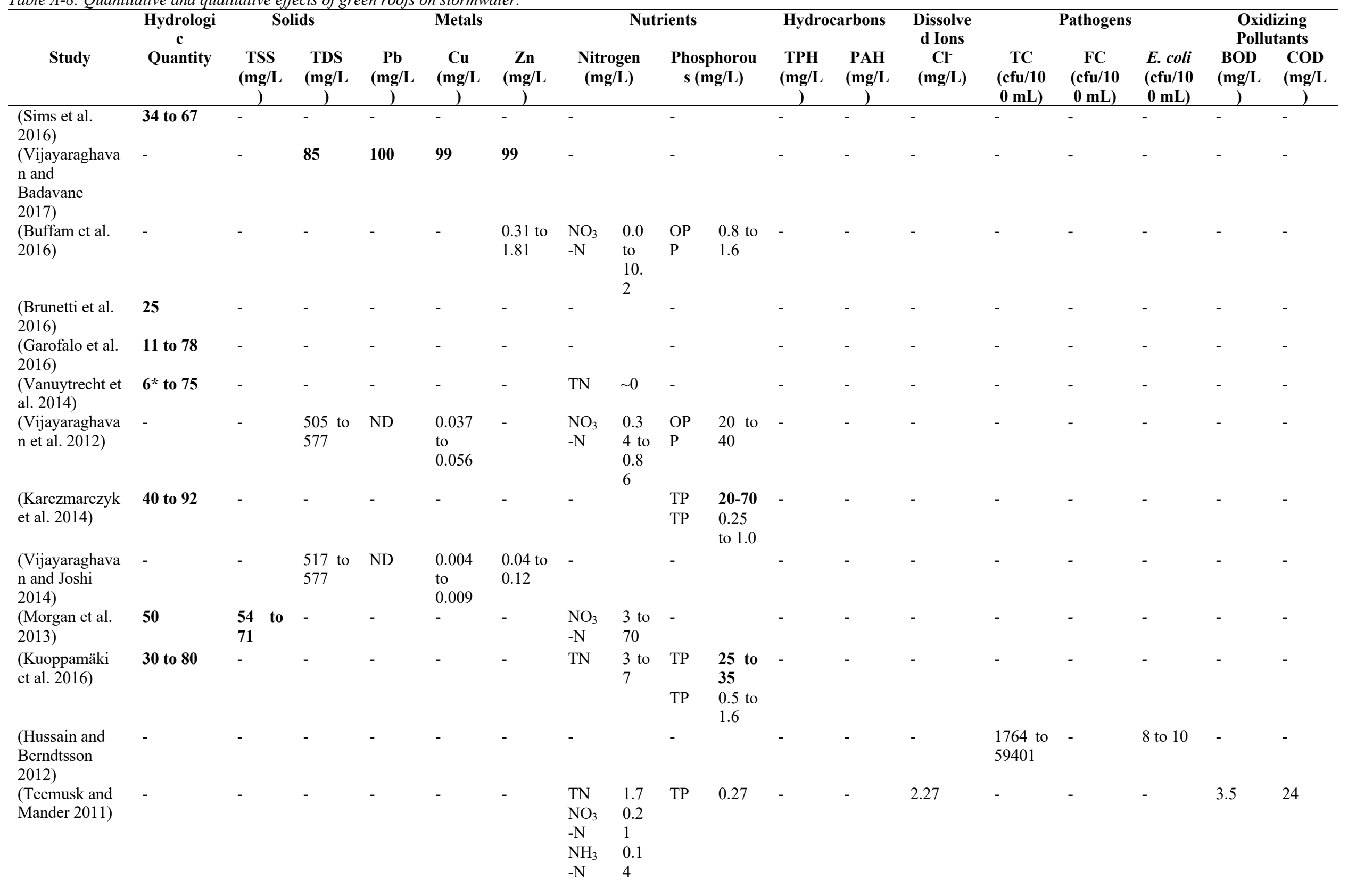




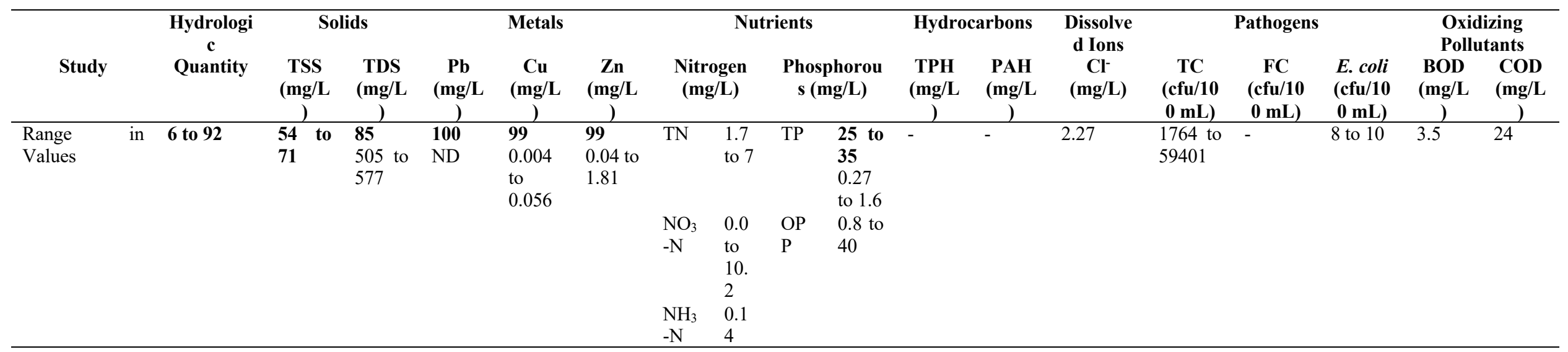

Bold values represent percent reductions, all other values are in $\mathrm{mg} / \mathrm{L}$. 


\begin{tabular}{|c|c|c|c|c|c|c|c|c|c|}
\hline BMP & Function & $\begin{array}{l}\text { BMP } \\
\text { Category }\end{array}$ & Pros & Cons & $\begin{array}{l}\text { Factors Affecting } \\
\text { Performance }\end{array}$ & $\begin{array}{l}\text { Land } \\
\text { Requirements }\end{array}$ & $\begin{array}{l}\text { Maintenance } \\
\text { requirements }\end{array}$ & $\begin{array}{l}\text { Potential } \\
\text { Nutrient } \\
\text { Exporter }\end{array}$ & $\begin{array}{l}\text { Cold Climate } \\
\text { Functionality }\end{array}$ \\
\hline $\begin{array}{l}\text { Permeable } \\
\text { Pavement } \\
\text { Systems }\end{array}$ & $\begin{array}{l}\text { Increase } \\
\text { infiltration rates } \\
\text { and capacities of } \\
\text { typically non- } \\
\text { permeable } \\
\text { surfaces }\end{array}$ & $\begin{array}{l}\text { Infiltration- } \\
\text { based }\end{array}$ & $\begin{array}{l}\text { - Runoff reduction } \\
\text { - Groundwater recharge } \\
\text { - Filters pollutants } \\
\text { - Less storm sewer } \\
\text { infrastructure } \\
\text { - Reduced heat island } \\
\text { effect } \\
\text { - Improved road safety }\end{array}$ & $\begin{array}{l}\text { - Installation complexity } \\
\text { - Prone to clogging } \\
\text { - Higher failure rates } \\
\text { - Potential groundwater } \\
\text { contamination } \\
\text { - Some building codes } \\
\text { may not permit PPSs } \\
\text { - Effectiveness decreases } \\
\text { if underlying soil is not } \\
\text { able to dry out }\end{array}$ & $\begin{array}{l}\text { - Surface infiltration } \\
\text { rate } \\
\text { - Shape and volume } \\
\text { - Infiltration and } \\
\text { exfiltration capacity } \\
\text { - Stormwater } \\
\text { sediment discharge } \\
\text { characteristics } \\
\text { - Construction and } \\
\text { maintenance }\end{array}$ & Low & Moderate & No & Yes \\
\hline $\begin{array}{l}\text { Infiltration } \\
\text { Trenches }\end{array}$ & $\begin{array}{l}\text { Induce higher } \\
\text { rates of } \\
\text { infiltration }\end{array}$ & $\begin{array}{l}\text { Infiltration- } \\
\text { based }\end{array}$ & $\begin{array}{l}\text { - Reduced runoff } \\
\text { volumes } \\
\text { - Groundwater recharge } \\
\text { - Filters pollutants } \\
\text { - Appropriate for small } \\
\text { sites } \\
\text { - Can be utilized where } \\
\text { space is limited }\end{array}$ & $\begin{array}{l}\text { - Require proper siting } \\
\text { and design } \\
\text { - Potential need for } \\
\text { pretreatment } \\
\text { - Poor performance in } \\
\text { low conductivity } \\
\text { soil/high water tables } \\
\text { - Possible groundwater } \\
\text { contamination } \\
\text { - Susceptible to clogging }\end{array}$ & $\begin{array}{l}\text { - Hydraulic } \\
\text { conductivity of } \\
\text { surrounding soils } \\
\text { - Depth to the water } \\
\text { table } \\
\text { - Area/storage } \\
\left(\mathrm{m}^{2} / \mathrm{m}^{3}\right) \text { ratio } \\
\text { - Infiltrated water } \\
\text { quality } \\
\text { - Rainfall } \\
\text { characteristics } \\
\text { - Maintenance } \\
\text { practices } \\
\text { - Surrounding } \\
\text { topography }\end{array}$ & Low & High & No & Yes \\
\hline Bioswales & $\begin{array}{l}\text { Act as drainage } \\
\text { courses that trap, } \\
\text { transport, and } \\
\text { treat stormwater } \\
\text { runoff }\end{array}$ & $\begin{array}{l}\text { Infiltration- } \\
\text { based }\end{array}$ & $\begin{array}{l}\text { - Very basic design } \\
\text { requirements } \\
\text { - Reduced runoff } \\
\text { velocities } \\
\text { - Cost-effective } \\
\text { - Many possible } \\
\text { applications } \\
\text { - Performance } \\
\text { maintained in low } \\
\text { conductivity soil/high } \\
\text { water tables } \\
\text { - Simultaneous }\end{array}$ & $\begin{array}{l}\text { - Low infiltration rates } \\
\text { - Potential nutrient and } \\
\text { chloride exporter } \\
\text { - Steep and low grades } \\
\text { reduce functionality }\end{array}$ & $\begin{array}{l}\text { - Length and width } \\
\text { - Slope } \\
\text { - Vegetation cover } \\
\text { (type and density) } \\
\text { - Soil characteristics } \\
\text { - Pollutant properties } \\
\text { - Ratio of catchment } \\
\text { area to BS area } \\
\text { - Filter media } \\
\text { - Maintenance } \\
\text { practices }\end{array}$ & Low & Low & Yes & Yes \\
\hline
\end{tabular}




\begin{tabular}{|c|c|c|c|c|c|c|c|c|c|}
\hline BMP & Function & $\begin{array}{l}\text { BMP } \\
\text { Category }\end{array}$ & Pros & Cons & $\begin{array}{l}\text { Factors Affecting } \\
\text { Performance }\end{array}$ & $\begin{array}{l}\text { Land } \\
\text { Requirements }\end{array}$ & $\begin{array}{l}\text { Maintenance } \\
\text { requirements }\end{array}$ & $\begin{array}{l}\text { Potential } \\
\text { Nutrient } \\
\text { Exporter }\end{array}$ & $\begin{array}{l}\text { Cold Climate } \\
\text { Functionality }\end{array}$ \\
\hline $\begin{array}{l}\text { Bioretention } \\
\text { Cells }\end{array}$ & $\begin{array}{l}\text { Designed to } \\
\text { exploit the } \\
\text { benefits of } \\
\text { stormwater } \\
\text { attenuation and } \\
\text { water quality } \\
\text { improvements } \\
\text { attributed to } \\
\text { natural processes } \\
\text { of soils and } \\
\text { vegetation }\end{array}$ & $\begin{array}{l}\text { Retention- } \\
\text { based }\end{array}$ & $\begin{array}{l}\text { - High tolerance to } \\
\text { changing hydrologic } \\
\text { regimes } \\
\text { - Significant stormwater } \\
\text { volume reduction } \\
\text { - Ease of integration in } \\
\text { urban environments } \\
\text { - Stormwater retention } \\
\text { and treatment capabilities } \\
\text { - Relatively fast draining } \\
\text { periods } \\
\text { - Aesthetic benefits }\end{array}$ & $\begin{array}{l}\text { - Prone to clogging } \\
\text { - Labour-intensive } \\
\text { maintenance - } \\
\text { Accumulated pollutants } \\
\text { may breakthrough and } \\
\text { leach } \\
\text { - Inconsistent removal of } \\
\text { nutrient pollutants } \\
\text { - Potential for } \\
\text { groundwater } \\
\text { contamination }\end{array}$ & $\begin{array}{l}\text { - Storage volume } \\
\text { - Maintenance } \\
\text { practices } \\
\text { - Rainfall } \\
\text { characteristics } \\
\text { - Inflow water } \\
\text { characteristics } \\
\text { - Antecedent dry } \\
\text { days } \\
\text { - Vegetation type } \\
\text { - Road salting } \\
\text { activities }\end{array}$ & Moderate & High & Yes & No consensus \\
\hline $\begin{array}{l}\text { Buffer/Filter } \\
\text { Strips }\end{array}$ & $\begin{array}{l}\text { Act as a barrier } \\
\text { between areas of } \\
\text { non-point source } \\
\text { pollution and } \\
\text { natural water } \\
\text { bodies }\end{array}$ & $\begin{array}{l}\text { Infiltration- } \\
\text { based }\end{array}$ & $\begin{array}{l}\text { - Low maintenance and } \\
\text { construction costs } \\
\text { - Pollutant reduction } \\
\text { - Stormwater conveyance } \\
\text { - Ease of installation and } \\
\text { design } \\
\text { - Diversity of possible } \\
\text { siting locations } \\
\text { - Performance } \\
\text { maintained in high water } \\
\text { tables } \\
\text { - Possible pretreatment } \\
\text { for other BMPs } \\
\text { - Habitat for a diversity } \\
\text { of animals }\end{array}$ & $\begin{array}{l}\text { - Low infiltration rates } \\
\text { - Steep and low grades } \\
\text { both reduce functionality }\end{array}$ & $\begin{array}{l}\text { - Vegetation } \\
\text { coverage, } \\
\text { - Length } \\
\text { - Cross-sectional } \\
\text { shape } \\
\text { - Retention time } \\
\text { - Slope } \\
\text { - Type of vegetation } \\
\text { - Soil conductivity } \\
\text { - Width }\end{array}$ & Moderate & Low & Yes & No consensus \\
\hline $\begin{array}{l}\text { Constructed } \\
\text { Stormwater } \\
\text { Wetlands }\end{array}$ & $\begin{array}{l}\text { Artificial } \\
\text { ecosystems } \\
\text { constructed to } \\
\text { simultaneously } \\
\text { store and treat } \\
\text { stormwater } \\
\text { runoff using } \\
\text { vegetative } \\
\text { filtration and } \\
\text { settling processes }\end{array}$ & $\begin{array}{l}\text { Retention- } \\
\text { based }\end{array}$ & $\begin{array}{l}\text { - Significant reductions } \\
\text { in peak flows and runoff } \\
\text { volumes } \\
\text { - Water quality } \\
\text { improvements } \\
\text { - Habitat for a diversity } \\
\text { of animals } \\
\text {-Ability to maintain } \\
\text { continuous flows } \\
\text { - Greater flood protection } \\
\text { than other BMPs } \\
\text { - Groundwater recharge } \\
\text { - Mechanically simple } \\
\text { design }\end{array}$ & $\begin{array}{l}\text { - Large volume flows } \\
\text { may have to be bypassed } \\
\text { to preserve vegetation } \\
\text { - Lack of flexibility in } \\
\text { system retrofitting once } \\
\text { constructed }\end{array}$ & $\begin{array}{l}\text { - Antecedent dry } \\
\text { days } \\
\text { - System } \\
\text { configuration } \\
\text { - Hydraulic } \\
\text { conditions } \\
\text { - Influent } \\
\text { characteristics } \\
\text { - Primary media type } \\
\text { - Soil types } \\
\text { - Vegetation type } \\
\text { - Retention time }\end{array}$ & High & Low & No & Yes \\
\hline
\end{tabular}




\begin{tabular}{|c|c|c|c|c|c|c|c|c|c|}
\hline BMP & Function & $\begin{array}{l}\text { BMP } \\
\text { Category }\end{array}$ & Pros & Cons & $\begin{array}{l}\text { Factors Affecting } \\
\text { Performance }\end{array}$ & $\begin{array}{l}\text { Land } \\
\text { Requirements }\end{array}$ & $\begin{array}{l}\text { Maintenance } \\
\text { requirements }\end{array}$ & $\begin{array}{l}\text { Potential } \\
\text { Nutrient } \\
\text { Exporter }\end{array}$ & $\begin{array}{l}\text { Cold Climate } \\
\text { Functionality }\end{array}$ \\
\hline $\begin{array}{l}\text { Raingardens } \\
\text { and } \\
\text { Downspout } \\
\text { Disconnection }\end{array}$ & $\begin{array}{l}\text { To increase } \\
\text { infiltration rates } \\
\text { and volumes of } \\
\text { roof-surface } \\
\text { runoff }\end{array}$ & $\begin{array}{l}\text { Infiltration- } \\
\text { based }\end{array}$ & $\begin{array}{l}\text { - Ability to significantly } \\
\text { reduce runoff } \\
\text { - Ease of integration with } \\
\text { lot-level landscape } \\
\text { - Relatively short } \\
\text { draining periods } \\
\text { - Aesthetic benefits } \\
\text { (raingarden) } \\
\text { - Potential source of } \\
\text { homegrown food } \\
\text { (raingarden) }\end{array}$ & $\begin{array}{l}\text { - Poor performance in } \\
\text { soils with low } \\
\text { conductivity }\end{array}$ & $\begin{array}{l}\text { - Lot size of the } \\
\text { property } \\
\text { - Soil characteristics } \\
\text { - Grade of the } \\
\text { property } \\
\text { - Proximity to } \\
\text { buildings }\end{array}$ & Low & Low & No & No consensus \\
\hline $\begin{array}{l}\text { Rain } \\
\text { Harvesting }\end{array}$ & $\begin{array}{l}\text { Reduce runoff } \\
\text { from roof } \\
\text { surfaces and } \\
\text { provide an } \\
\text { auxiliary source } \\
\text { of non-potable } \\
\text { water }\end{array}$ & $\begin{array}{l}\text { Retention- } \\
\text { based }\end{array}$ & $\begin{array}{l}\text { - Reduced burden on } \\
\text { public water supplies } \\
\text { - Low cost of installation } \\
\text { and maintenance } \\
\text { - Reduced water } \\
\text { expenses } \\
\text { - Simple deployment of } \\
\text { untreated water for non- } \\
\text { potable uses }\end{array}$ & $\begin{array}{l}\text { - Storage constraints } \\
\text { - Water quality risks } \\
\text { - Lack of research on the } \\
\text { role of social factors }\end{array}$ & $\begin{array}{l}\text { - Land use practices } \\
\text { - Weather patterns } \\
\text { - Storage system } \\
\text { material } \\
\text { - Roof slope } \\
\text { - Roofing material } \\
\text { - Maintenance } \\
\text { practices }\end{array}$ & Low & $\begin{array}{l}\text { Low- } \\
\text { Moderate }\end{array}$ & No & No \\
\hline Green Roofs & $\begin{array}{l}\text { Increase the } \\
\text { retention } \\
\text { capacity of } \\
\text { traditional } \\
\text { roofing materials } \\
\text { and reduce roof- } \\
\text { surface runoff }\end{array}$ & $\begin{array}{l}\text { Retention- } \\
\text { based }\end{array}$ & $\begin{array}{l}\text { - Reduced runoff } \\
\text { - Potential building } \\
\text { insulation benefits } \\
\text { - Decreased urban heat } \\
\text { island effect } \\
\text { - Increased urban } \\
\text { biodiversity } \\
\text { - Aesthetic benefits }\end{array}$ & $\begin{array}{l}\text { - Structural building } \\
\text { limitations } \\
\text { - Potentially requires } \\
\text { supplemental watering } \\
\text { - Larger upfront } \\
\text { constructions costs } \\
\text { - Possible issues due to } \\
\text { improper selection of } \\
\text { vegetation }\end{array}$ & $\begin{array}{l}\text { - Choice of substrate } \\
\text { - Substrate thickness } \\
\text { - Number of layers } \\
\text { - Vegetation type } \\
\text { - Percentage of roof } \\
\text { covered } \\
\text { - Roof slope } \\
\text { - Antecedent dry } \\
\text { days } \\
\text { - Rainfall } \\
\text { characteristics } \\
\text { - Presence of a } \\
\text { drainage/storage } \\
\text { layer }\end{array}$ & Low & $\begin{array}{l}\text { Low- } \\
\text { Moderate }\end{array}$ & Yes & Yes \\
\hline
\end{tabular}




\section{Appendix B: Original life cycle costing data}

Table B-1: Original life cycle costing data.

\begin{tabular}{|c|c|c|c|c|c|c|c|c|c|c|c|c|c|c|c|c|}
\hline & Capital Costs & & & & & Annual Mai & intenance $\mathrm{Co}$ & & & & $\begin{array}{l}\text { Rehabil } \\
\text { Require } \\
\text { (years) }\end{array}$ & $\begin{array}{l}\text { litation } \\
\text { ed }\end{array}$ & Rehab costs & & $\begin{array}{l}\text { Decommis } \\
\text { costs }\end{array}$ & ssioning \\
\hline Study & $\begin{array}{l}\text { (Mateleska } \\
\text { 2016) }\end{array}$ & $\begin{array}{l}\text { (Uda et al. } \\
2013 \text { ) }\end{array}$ & $\begin{array}{l}\text { (CNLA } \\
\text { 2017) }\end{array}$ & (CNT n.d.) & $\begin{array}{l}\text { (Fletcher et } \\
\text { al. 2005) }\end{array}$ & $\begin{array}{l}\text { (Mateleska } \\
\text { 2016) }\end{array}$ & $\begin{array}{l}\text { (Uda et al. } \\
\text { 2013) }\end{array}$ & $\begin{array}{l}\text { (CNLA } \\
\text { 2017) }\end{array}$ & $\begin{array}{l}\text { (CNT } \\
\text { n.d.) }\end{array}$ & $\begin{array}{l}\text { (USEPA } \\
2001)\end{array}$ & $\begin{array}{l}\text { (Uda } \\
\text { et al. } \\
2013)\end{array}$ & $\begin{array}{l}\text { (CNT } \\
\text { n.d.) }\end{array}$ & $\begin{array}{l}\text { (Uda et al. } \\
2013 \text { ) }\end{array}$ & $\begin{array}{l}\text { (CNT } \\
\text { n.d.) }\end{array}$ & $\begin{array}{l}\text { (Taylor } \\
2005 \text { ) }\end{array}$ & $\begin{array}{l}\text { No } \\
\text { source }\end{array}$ \\
\hline Bioretention & $\$ 749.00 / \mathrm{m}^{3}$ & $\begin{array}{l}\$ 282.77 / \mathrm{m}^{2}- \\
\$ 366.83 / \mathrm{m}^{2}\end{array}$ & $\$ 71.36 / \mathrm{m}^{2}$ & - & - & $\$ 0.67 / \mathrm{m}^{2}$ & $\begin{array}{l}\$ 8.36 / \mathrm{m}^{2} \\
- \\
\$ 8.42 / \mathrm{m}^{2 \mathrm{~d}}\end{array}$ & $\$ 17.19 / \mathrm{m}^{2}$ & - & - & 25 & - & $\$ 66.36 / \mathrm{m}^{2}$ & - & $\begin{array}{l}39 \% \text { of } \\
\mathrm{CC}\end{array}$ & - \\
\hline $\begin{array}{l}\text { Infiltration } \\
\text { trench }\end{array}$ & $\$ 302.31 / \mathrm{m}^{3}$ & $\begin{array}{l}\$ 310.82 / \mathrm{m}^{2}- \\
\$ 513.25 / \mathrm{m}^{2}\end{array}$ & - & - & $\begin{array}{l}\$ 77.89 / \mathrm{m}^{3} \\
- \\
\$ 103.85 / \mathrm{m}^{3}\end{array}$ & - & $\begin{array}{l}\$ 0.84 / \mathrm{m}^{2} \\
- \\
\$ 14.39 / \mathrm{m}^{2}\end{array}$ & - & - & $\begin{array}{l}5-20 \% \\
\mathrm{CC}\end{array}$ & - & - & - & - & $\begin{array}{l}35 \% \text { of } \\
\mathrm{CC}\end{array}$ & - \\
\hline $\begin{array}{l}\text { Permeable } \\
\text { Pavement }\end{array}$ & $\begin{array}{l}\$ 257.84 / \mathrm{m}^{3} \\
- \\
\$ 875.74 / \mathrm{m}^{3^{*}}\end{array}$ & $\begin{array}{l}\$ 59.74 / \mathrm{m}^{2}- \\
\$ 73.35 / \mathrm{m}^{2}\end{array}$ & $\$ 16.68 / \mathrm{m}^{2}$ & - & - & $\$ 0.38 / \mathrm{m}^{2}$ & $\begin{array}{l}\$ 0.49 / \mathrm{m}^{2}- \\
\$ 0.53 / \mathrm{m}^{2}\end{array}$ & $\$ 0.87 / \mathrm{m}^{2}$ & - & - & 30 & - & $\$ 52.93 / \mathrm{m}^{2}$ & - & - & $35 \%$ \\
\hline $\begin{array}{l}\text { Stormwater } \\
\text { reuse costs }\end{array}$ & - & $\begin{array}{l}\$ 2031.40 / \mathrm{m}^{3} \\
- \\
\$ 2361.32 / \mathrm{m}^{3}\end{array}$ & - & $\begin{array}{l}\$ 270.00 / \mathrm{m}^{3} \\
- \\
\$ 1210.00 / \mathrm{m}^{3}\end{array}$ & - & - & $\$ 37.17 / \mathrm{m}^{3}$ & - & $\begin{array}{l}0.00- \\
\$ 0.02 / \mathrm{L}\end{array}$ & - & 40 & $20-50$ & $\$ 298.44 / \mathrm{m}^{3}$ & - & - & $35 \%$ \\
\hline $\begin{array}{l}\text { Constructed } \\
\text { Wetland }\end{array}$ & $\$ 329.59 / \mathrm{m}^{3}$ & - & $\$ 33.56 / \mathrm{m}^{2}$ & - & - & $\$ 1.08 / \mathrm{m}^{2}$ & - & $\$ 0.09 / \mathrm{m}^{2}$ & - & - & - & - & - & - & $\begin{array}{l}38 \% \text { of } \\
\mathrm{CC}\end{array}$ & - \\
\hline Rain barrels & - & - & - & $\begin{array}{l}\$ 0.29 / \mathrm{L} \quad \text { to } \\
\$ 1.13 / \mathrm{L}\end{array}$ & & - & - & - & $\$ 0.00 / \mathrm{L}$ & - & - & 20 & - & $\begin{array}{l}\$ 0.29 / \mathrm{L} \\
\text { to } \\
\$ 1.13 / \mathrm{L}\end{array}$ & $\mathrm{n} / \mathrm{a}$ & $\mathrm{n} / \mathrm{a}$ \\
\hline $\begin{array}{l}\text { Dry pond or } \\
\text { detention } \\
\text { basin }\end{array}$ & $\$ 113.32 / \mathrm{m}^{3}$ & - & $\$ 38.42 / \mathrm{m}^{2}$ & - & - & $\$ 0.84 / \mathrm{m}^{2}$ & - & $\$ 0.53 / \mathrm{m}^{2}$ & - & - & - & - & - & - & - & $35 \%$ \\
\hline
\end{tabular}




\section{Appendix C: Case study demonstration - detailed data}

Table C-1: Community-related inputs for case studies.

\begin{tabular}{|c|c|}
\hline $\begin{array}{l}\text { User-defined control variable } \\
\text {. }\end{array}$ & Value \\
\hline Total areal size of community (ha) & 80 \\
\hline Percent of community covered in residential lots (\%) & 46 \\
\hline $\begin{array}{l}\text { Percent of community covered with surface waters } \\
\text { excluding BMPs (e.g., lake, river) (\%) }\end{array}$ & 6 \\
\hline Percent of community covered in roadways/walkways (\%) & 12 \\
\hline Percent of community covered in parking lots $(\%)$ & 9 \\
\hline Percent of community covered in commercial areas (\%) & 21 \\
\hline $\begin{array}{l}\text { Percent of community covered in green spaces (e.g., parks) } \\
(\%)\end{array}$ & 6 \\
\hline $\begin{array}{l}\text { Percent of green spaces available for water-based } \\
\text { infrastructure (e.g., constructed stormwater wetland) (\%) }\end{array}$ & 20 \\
\hline Community Stormwater Reuse Volume Profile ( $\left.\mathrm{m}^{3} / \mathrm{day}\right)^{*}$ & 2019 \\
\hline User-defined observed variables & Value \\
\hline Soil type & $\begin{array}{l}\text { Silty clay (Calgary) } \\
\text { Silty clay loam (Kelowna) }\end{array}$ \\
\hline
\end{tabular}

* This value is the same for all months with average daily temperatures above $0^{\circ} \mathrm{C}$.

Table C-2: Pre-development inputs.

\begin{tabular}{ll}
\hline User-defined observed variables & Value \\
\hline Land cover description & Meadow - continuous grass, protected from \\
& grazing and generally mowed for hay. \\
Average grade & Average $\left(2^{\circ}-7^{\circ}\right)$ \\
\hline
\end{tabular}

Table C-3: Residential lot inputs

\begin{tabular}{ll}
\hline User-defined control variable & Value \\
\hline Number of residential lots & 1300 \\
Percent of lots covered in buildings (\%) & 60 \\
Percent of lots covered in impermeable surfaces (e.g., & \\
driveways, stone patio) (\%) & 20 \\
Percent of lot covered in lawns/gardens (\%) & 20 \\
Average rain harvesting volume (L) & 210 \\
Number of dry days before watering lawn & 4 \\
Residential daily water use (L/household/day) & 404 \\
\hline
\end{tabular}


Table C-4: Commercial lot inputs.

\begin{tabular}{ll}
\hline User-defined control variable & Value \\
\hline Number of commercial units & 25 \\
Percent of lots covered in buildings (\%) & 70 \\
Percent of lots covered in impermeable surfaces (e.g., & 30 \\
walkways) (\%) & \\
Commercial daily water use (L/business/day) & 2019 \\
\hline
\end{tabular}

Table C-5:Runoff capture and distribution inputs.

\begin{tabular}{ll}
\hline User-defined control variable & Value \\
\hline Percent of post-lot runoff directed to streets/walkways (\%) & 25 \\
Percent of post-lot runoff directed directly to sewers (\%) & 75 \\
Percent of pretreatment train runoff directed to constructed & 50 \\
stormwater wetland (\%) & \\
Percent of pretreatment train runoff directed to stormwater & 50 \\
reuse scheme (\%) & \\
\hline
\end{tabular}


Table C-6: Annual precipitation statistics for precipitation simulations based on historical data for Calgary.

\begin{tabular}{|c|c|c|c|c|}
\hline Year & $\begin{array}{l}\text { Annual Precipitation } \\
\qquad(\mathrm{mm})\end{array}$ & $\begin{array}{l}\text { Annual Rainfall } \\
\text { (mm) }\end{array}$ & $\begin{array}{l}\text { Annual Snowfall } \\
(\mathrm{cm})\end{array}$ & $\begin{array}{c}\text { Max depth rainfall } \\
\text { (mm) }\end{array}$ \\
\hline 1 & 460 & 348 & 153 & 101 \\
\hline 2 & 486 & 409 & 110 & 99 \\
\hline 3 & 389 & 305 & 123 & 31 \\
\hline 4 & 369 & 268 & 138 & 33 \\
\hline 5 & 488 & 388 & 142 & 61 \\
\hline 6 & 449 & 350 & 139 & 32 \\
\hline 7 & 365 & 261 & 145 & 30 \\
\hline 8 & 493 & 390 & 150 & 74 \\
\hline 9 & 356 & 251 & 147 & 32 \\
\hline 10 & 406 & 317 & 125 & 59 \\
\hline 11 & 470 & 377 & 128 & 29 \\
\hline 12 & 457 & 353 & 145 & 88 \\
\hline 13 & 485 & 404 & 109 & 107 \\
\hline 14 & 460 & 353 & 150 & 36 \\
\hline 15 & 359 & 261 & 141 & 31 \\
\hline 16 & 357 & 252 & 148 & 32 \\
\hline 17 & 466 & 367 & 141 & 98 \\
\hline 18 & 356 & 266 & 131 & 33 \\
\hline 19 & 440 & 331 & 145 & 32 \\
\hline 20 & 441 & 348 & 130 & 48 \\
\hline 21 & 486 & 388 & 135 & 35 \\
\hline 22 & 437 & 343 & 134 & 57 \\
\hline 23 & 338 & 250 & 123 & 31 \\
\hline 24 & 348 & 254 & 132 & 86 \\
\hline 25 & 455 & 356 & 142 & 30 \\
\hline 26 & 453 & 366 & 124 & 48 \\
\hline 27 & 342 & 240 & 147 & 31 \\
\hline 28 & 483 & 380 & 148 & 56 \\
\hline 29 & 458 & 353 & 145 & 34 \\
\hline 30 & 396 & 307 & 126 & 34 \\
\hline Simulation & avg: 424.9 & avg: 327.8 & avg: 136.5 & $\max : 107$ \\
\hline Observed & avg: 418.8 & avg: 326.4 & avg: 128.8 & $\max : 95.3$ \\
\hline Difference & $+1.5 \%$ & $+0.4 \%$ & $+6.0 \%$ & $+12.6 \%$ \\
\hline
\end{tabular}


Table C-7: Annual precipitation statistics for precipitation simulations for RCP 2.6 for Calgary.

\begin{tabular}{|c|c|c|c|c|}
\hline Year & $\begin{array}{l}\text { Annual Precipitation } \\
(\mathrm{mm})\end{array}$ & $\begin{array}{l}\text { Annual Rainfall } \\
\text { (mm) }\end{array}$ & $\begin{array}{l}\text { Annual Snowfall } \\
(\mathrm{cm})\end{array}$ & $\begin{array}{l}\text { Max depth rainfall } \\
(\mathrm{mm})\end{array}$ \\
\hline 1 & 441 & 390 & 101 & 123 \\
\hline 2 & 504 & 468 & 74 & 120 \\
\hline 3 & 365 & 329 & 88 & 33 \\
\hline 4 & 345 & 300 & 93 & 41 \\
\hline 5 & 484 & 441 & 100 & 73 \\
\hline 6 & 435 & 391 & 94 & 37 \\
\hline 7 & 333 & 286 & 98 & 35 \\
\hline 8 & 487 & 442 & 105 & 90 \\
\hline 9 & 318 & 269 & 98 & 36 \\
\hline 10 & 396 & 356 & 84 & 72 \\
\hline 11 & 458 & 416 & 86 & 34 \\
\hline 12 & 455 & 406 & 95 & 110 \\
\hline 13 & 504 & 467 & 71 & 132 \\
\hline 14 & 441 & 394 & 105 & 43 \\
\hline 15 & 329 & 287 & 99 & 33 \\
\hline 16 & 327 & 278 & 98 & 36 \\
\hline 17 & 461 & 416 & 95 & 119 \\
\hline 18 & 326 & 287 & 92 & 37 \\
\hline 19 & 414 & 365 & 95 & 39 \\
\hline 20 & 432 & 389 & 86 & 60 \\
\hline 21 & 484 & 441 & 91 & 44 \\
\hline 22 & 426 & 384 & 92 & 69 \\
\hline 23 & 310 & 271 & 84 & 37 \\
\hline 24 & 330 & 287 & 89 & 106 \\
\hline 25 & 438 & 392 & 96 & 35 \\
\hline 26 & 456 & 417 & 85 & 61 \\
\hline 27 & 306 & 260 & 101 & 33 \\
\hline 28 & 475 & 426 & 99 & 68 \\
\hline 29 & 440 & 392 & 96 & 41 \\
\hline 30 & 379 & 340 & 87 & 41 \\
\hline Simulation & avg: 410.1 & avg: 366.2 & avg: 92.6 & $\max : 132$ \\
\hline \multicolumn{5}{|l|}{ Historical } \\
\hline Simulation & avg: 424.9 & avg: 327.8 & avg: 136.5 & $\max : 107$ \\
\hline Difference & $-3.5 \%$ & $+11.7 \%$ & $-32.2 \%$ & $+23.3 \%$ \\
\hline
\end{tabular}


Table C-8: Annual precipitation statistics for precipitation simulations for RCP 8.5 for Calgary.

\begin{tabular}{|c|c|c|c|c|}
\hline Year & $\begin{array}{l}\text { Annual Precipitation } \\
(\mathrm{mm})\end{array}$ & $\begin{array}{l}\text { Annual Rainfall } \\
(\mathrm{mm})\end{array}$ & $\begin{array}{l}\text { Annual Snowfall } \\
(\mathrm{cm})\end{array}$ & $\begin{array}{c}\text { Max depth rainfall } \\
(\mathrm{mm})\end{array}$ \\
\hline 1 & 472 & 397 & 74 & 117 \\
\hline 2 & 521 & 468 & 55 & 115 \\
\hline 3 & 399 & 346 & 70 & 35 \\
\hline 4 & 372 & 306 & 70 & 39 \\
\hline 5 & 504 & 441 & 80 & 69 \\
\hline 6 & 463 & 398 & 72 & 37 \\
\hline 7 & 365 & 296 & 74 & 34 \\
\hline 8 & 511 & 445 & 83 & 86 \\
\hline 9 & 356 & 285 & 73 & 36 \\
\hline 10 & 421 & 362 & 64 & 69 \\
\hline 11 & 490 & 429 & 65 & 33 \\
\hline 12 & 480 & 408 & 70 & 106 \\
\hline 13 & 519 & 464 & 52 & 126 \\
\hline 14 & 470 & 402 & 82 & 41 \\
\hline 15 & 359 & 296 & 79 & 35 \\
\hline 16 & 359 & 286 & 73 & 37 \\
\hline 17 & 486 & 419 & 72 & 114 \\
\hline 18 & 359 & 302 & 73 & 38 \\
\hline 19 & 448 & 376 & 70 & 41 \\
\hline 20 & 461 & 398 & 65 & 57 \\
\hline 21 & 505 & 442 & 70 & 44 \\
\hline 22 & 452 & 391 & 71 & 66 \\
\hline 23 & 342 & 284 & 64 & 37 \\
\hline 24 & 358 & 294 & 67 & 103 \\
\hline 25 & 472 & 404 & 72 & 34 \\
\hline 26 & 476 & 419 & 65 & 57 \\
\hline 27 & 340 & 273 & 78 & 35 \\
\hline 28 & 506 & 435 & 75 & 65 \\
\hline 29 & 472 & 402 & 71 & 39 \\
\hline 30 & 408 & 350 & 68 & 39 \\
\hline Simulation & avg: 438.1 & avg: 373.9 & avg: 70.6 & $\max : 126$ \\
\hline \multicolumn{5}{|l|}{ Historical } \\
\hline Simulation & avg: 424.9 & avg: 327.8 & avg: 136.5 & $\max : 107$ \\
\hline Difference & $+3.1 \%$ & $+14.1 \%$ & $-48.3 \%$ & $+17.8 \%$ \\
\hline
\end{tabular}


Table C-9: Average monthly precipitation values generated by the OWSWPF for current (Historical) and predicted climate change (RCP 2.6 and RCP 8.5) and observed historical averages (Observed) for Calgary.

\begin{tabular}{lrrrrrrrrrrrr}
\hline & Jan & \multicolumn{1}{c}{ Feb } & Mar & Apr & May & Jun & Jul & Aug & Sep & Oct & Nov & Dec \\
\hline Observed (mm) & 9.4 & 9.4 & 17.8 & 25.2 & 56.8 & 94.0 & 65.5 & 57.0 & 45.1 & 15.3 & 13.1 & 10.2 \\
Historical (mm) & 10.9 & 12.9 & 17.0 & 23.7 & 52.8 & 114.3 & 64.4 & 53.6 & 32.7 & 18.0 & 13.8 & 10.9 \\
RCP 2.6 (mm) & 3.9 & 4.8 & 9.4 & 17.5 & 49.0 & 130.9 & 71.2 & 59.7 & 34.5 & 15.6 & 9.3 & 4.3 \\
RCP 8.5 (mm) & 5.4 & 6.8 & 13.6 & 21.3 & 53.5 & 131.0 & 73.3 & 61.0 & 36.1 & 17.7 & 12.4 & 6.1 \\
\hline
\end{tabular}

Table C-10: Annual precipitation statistics for precipitation simulations based on historical data for Kelowna.

\begin{tabular}{|c|c|c|c|c|}
\hline Year & $\begin{array}{l}\text { Annual Precipitation } \\
(\mathrm{mm})\end{array}$ & $\begin{array}{l}\text { Annual Rainfall } \\
\text { (mm) }\end{array}$ & $\begin{array}{l}\text { Annual Snowfall } \\
(\mathrm{cm})\end{array}$ & $\begin{array}{l}\text { Max depth rainfall } \\
\text { (mm) }\end{array}$ \\
\hline 1 & 372 & 290 & 98 & 15 \\
\hline 2 & 399 & 333 & 80 & 13 \\
\hline 3 & 377 & 297 & 98 & 22 \\
\hline 4 & 412 & 345 & 82 & 27 \\
\hline 5 & 408 & 322 & 103 & 15 \\
\hline 6 & 418 & 337 & 97 & 15 \\
\hline 7 & 407 & 326 & 98 & 14 \\
\hline 8 & 403 & 321 & 96 & 28 \\
\hline 9 & 411 & 323 & 105 & 15 \\
\hline 10 & 426 & 351 & 89 & 22 \\
\hline 11 & 397 & 315 & 99 & 20 \\
\hline 12 & 421 & 333 & 104 & 15 \\
\hline 13 & 387 & 317 & 82 & 32 \\
\hline 14 & 420 & 344 & 93 & 21 \\
\hline 15 & 392 & 323 & 83 & 16 \\
\hline 16 & 420 & 342 & 94 & 22 \\
\hline 17 & 403 & 329 & 87 & 28 \\
\hline 18 & 420 & 329 & 106 & 26 \\
\hline 19 & 356 & 284 & 90 & 13 \\
\hline 20 & 405 & 327 & 93 & 27 \\
\hline 21 & 407 & 344 & 74 & 21 \\
\hline 22 & 379 & 299 & 94 & 14 \\
\hline 23 & 386 & 303 & 98 & 14 \\
\hline 24 & 407 & 336 & 84 & 15 \\
\hline 25 & 424 & 356 & 82 & 20 \\
\hline 26 & 421 & 343 & 93 & 31 \\
\hline 27 & 356 & 294 & 74 & 25 \\
\hline 28 & 416 & 328 & 102 & 18 \\
\hline 29 & 355 & 289 & 80 & 18 \\
\hline 30 & 390 & 311 & 98 & 25 \\
\hline Simulation & avg: 399.8 & avg: 323.1 & avg: 91.8 & $\max : 31.9$ \\
\hline Observed & avg: 387.0 & avg: 311.3 & avg: 89.0 & $\max : 33.8$ \\
\hline Difference & $+3.3 \%$ & $+3.8 \%$ & $+3.1 \%$ & $-5.6 \%$ \\
\hline
\end{tabular}


Table C-11: Annual precipitation statistics for precipitation simulations for RCP 2.6 for Kelowna.

\begin{tabular}{|c|c|c|c|c|}
\hline Year & $\begin{array}{l}\text { Annual Precipitation } \\
(\mathrm{mm})\end{array}$ & $\begin{array}{l}\text { Annual Rainfall } \\
\text { (mm) }\end{array}$ & $\begin{array}{l}\text { Annual Snowfall } \\
(\mathrm{cm})\end{array}$ & $\begin{array}{c}\text { Max depth rainfall } \\
\text { (mm) }\end{array}$ \\
\hline 1 & 352 & 346 & 67 & 16 \\
\hline 2 & 392 & 387 & 54 & 14 \\
\hline 3 & 358 & 352 & 67 & 23 \\
\hline 4 & 404 & 398 & 57 & 29 \\
\hline 5 & 389 & 383 & 69 & 16 \\
\hline 6 & 400 & 394 & 68 & 17 \\
\hline 7 & 389 & 382 & 67 & 15 \\
\hline 8 & 385 & 379 & 67 & 32 \\
\hline 9 & 391 & 384 & 72 & 16 \\
\hline 10 & 415 & 409 & 61 & 23 \\
\hline 11 & 379 & 373 & 68 & 22 \\
\hline 12 & 400 & 393 & 72 & 16 \\
\hline 13 & 377 & 372 & 54 & 36 \\
\hline 14 & 410 & 405 & 61 & 24 \\
\hline 15 & 379 & 374 & 58 & 18 \\
\hline 16 & 405 & 399 & 65 & 23 \\
\hline 17 & 393 & 387 & 57 & 31 \\
\hline 18 & 398 & 391 & 72 & 29 \\
\hline 19 & 342 & 336 & 60 & 14 \\
\hline 20 & 389 & 383 & 64 & 29 \\
\hline 21 & 399 & 394 & 51 & 23 \\
\hline 22 & 361 & 355 & 64 & 20 \\
\hline 23 & 365 & 359 & 68 & 16 \\
\hline 24 & 396 & 390 & 57 & 17 \\
\hline 25 & 415 & 409 & 57 & 22 \\
\hline 26 & 409 & 403 & 64 & 34 \\
\hline 27 & 348 & 344 & 51 & 29 \\
\hline 28 & 393 & 387 & 69 & 20 \\
\hline 29 & 342 & 337 & 56 & 19 \\
\hline 30 & 374 & 368 & 67 & 29 \\
\hline RCP 2.6 Simulation & avg: 384.9 & avg: 379.2 & avg: 62.8 & $\max : 35.9$ \\
\hline \multicolumn{5}{|l|}{ Historical } \\
\hline Simulation & avg: 399.8 & avg: 323.1 & avg: 91.8 & $\max : 31.9$ \\
\hline Difference & $-3.7 \%$ & $+17.4 \%$ & $-31.6 \%$ & $+12.5 \%$ \\
\hline
\end{tabular}


Table C-12: Annual precipitation statistics for precipitation simulations for RCP 8.5 for Kelowna.

\begin{tabular}{|c|c|c|c|c|}
\hline Year & $\begin{array}{c}\text { Annual Precipitation } \\
(\mathrm{mm})\end{array}$ & $\begin{array}{c}\text { Annual Rainfall } \\
(\mathrm{mm})\end{array}$ & $\begin{array}{c}\text { Annual Snowfall } \\
(\mathrm{cm})\end{array}$ & $\begin{array}{c}\text { Max depth rainfall } \\
(\mathrm{mm})\end{array}$ \\
\hline 1 & 415 & 411 & 46 & 18 \\
\hline 2 & 458 & 455 & 38 & 16 \\
\hline 3 & 423 & 418 & 46 & 27 \\
\hline 4 & 473 & 470 & 40 & 33 \\
\hline 5 & 457 & 453 & 48 & 18 \\
\hline 6 & 472 & 468 & 46 & 21 \\
\hline 7 & 457 & 453 & 47 & 17 \\
\hline 8 & 455 & 451 & 44 & 38 \\
\hline 9 & 460 & 455 & 50 & 18 \\
\hline 10 & 485 & 481 & 43 & 26 \\
\hline 11 & 445 & 440 & 49 & 25 \\
\hline 12 & 471 & 467 & 49 & 18 \\
\hline 13 & 443 & 440 & 36 & 43 \\
\hline 14 & 480 & 476 & 42 & 28 \\
\hline 15 & 446 & 442 & 41 & 21 \\
\hline 16 & 476 & 472 & 45 & 26 \\
\hline 17 & 460 & 457 & 39 & 36 \\
\hline 18 & 470 & 465 & 48 & 32 \\
\hline 19 & 403 & 399 & 41 & 16 \\
\hline 20 & 458 & 453 & 45 & 34 \\
\hline 21 & 466 & 463 & 34 & 26 \\
\hline 22 & 425 & 421 & 43 & 24 \\
\hline 23 & 431 & 427 & 46 & 18 \\
\hline 24 & 465 & 461 & 39 & 20 \\
\hline 25 & 486 & 482 & 39 & 25 \\
\hline 26 & 482 & 479 & 41 & 40 \\
\hline 27 & 406 & 403 & 35 & 32 \\
\hline 28 & 465 & 461 & 46 & 22 \\
\hline 29 & 401 & 398 & 40 & 21 \\
\hline 30 & 441 & 436 & 46 & 33 \\
\hline RCP 8.5 Simulation & avg: 452.4 & avg: 448.5 & avg: 43.1 & $\max : 42.9$ \\
\hline \multicolumn{5}{|l|}{ Historical } \\
\hline Simulation & avg: 399.8 & avg: 323.1 & avg: 91.8 & $\max : 31.9$ \\
\hline Difference & $+13.2 \%$ & $+38.8 \%$ & $-53.1 \%$ & $+34.5 \%$ \\
\hline
\end{tabular}


Table C-13: Average monthly precipitation values generated by the OWSWPF for current (Historical) and predicted climate change (RCP 2.6 and RCP 8.5) and observed historical averages (Observed) for Kelowna.

\begin{tabular}{lllllllllllll}
\hline & Jan & Feb & Mar & Apr & May & Jun & Jul & Aug & Sep & Oct & Nov & Dec \\
\hline Observed (mm) & 31.0 & 19.0 & 21.6 & 29.1 & 40.2 & 45.9 & 37.2 & 32.1 & 32.4 & 29.2 & 36.7 & 32.6 \\
Historical (mm) & 34.0 & 31.1 & 30.3 & 32.8 & 41.2 & 42.3 & 28.8 & 28.8 & 27.6 & 38.5 & 37.7 & 26.8 \\
RCP 2.6 (mm) & 20.9 & 20.8 & 27.9 & 35.1 & 45.0 & 45.7 & 31.2 & 31.2 & 30.0 & 41.5 & 34.2 & 21.4 \\
RCP 8.5 (mm) & 27.1 & 25.2 & 32.3 & 40.2 & 51.5 & 52.2 & 35.7 & 35.8 & 34.2 & 47.5 & 42.0 & 28.8 \\
\hline
\end{tabular}


Table C-14: Fuzzy decision matrix for Calgary case study.

\begin{tabular}{|c|c|c|c|c|c|c|c|c|c|c|c|c|}
\hline \multirow[b]{2}{*}{$\begin{array}{l}\text { Scenario } \\
\text { Number }\end{array}$} & \multicolumn{3}{|c|}{ Water Footprint (Current) } & \multicolumn{3}{|c|}{ Water Footprint (RCP 2.6) } & \multicolumn{3}{|c|}{ Water Footprint (RCP 8.5) } & \multicolumn{3}{|c|}{ Life Cycle Costs (\$) } \\
\hline & P05 & P50 & P95 & P05 & P50 & P95 & P05 & P50 & P95 & P05 & P50 & P95 \\
\hline \multirow{3}{*}{1} & & 270767 & 347162 & 185463 & 299061 & 397932 & 213805 & 328622 & 419462 & & & \\
\hline & 1830201 & 7 & 2 & 8 & 9 & 4 & 9 & 6 & 2 & $2,034,100.15$ & $2,233,203.81$ & $2,440,723.22$ \\
\hline & & & 109124 & & & 137070 & & & 140114 & & & $11,814,576.7$ \\
\hline \multirow[t]{2}{*}{2} & 218195 & 617387 & 9 & 236961 & 728251 & 5 & 260673 & 790591 & 1 & $5,794,124.96$ & $9,049,754.88$ & 0 \\
\hline & & & & & & & & & & $10,538,349.6$ & $18,009,796.3$ & $25,060,697.7$ \\
\hline 3 & 176435 & 426438 & 771990 & 186943 & 486858 & 968586 & 202894 & 538827 & 986595 & 4 & 9 & 2 \\
\hline & & & & & & & & & & $14,630,909.2$ & $25,254,404.6$ & $36,530,155.6$ \\
\hline 4 & 153538 & 351336 & 626736 & 163714 & 394521 & 777790 & 176633 & 428790 & 794635 & 6 & 1 & 4 \\
\hline & & & & & & & & & & $22,312,881.3$ & $41,118,965.9$ & $58,313,586.4$ \\
\hline 5 & 135072 & 279927 & 487870 & 140400 & 305459 & 582797 & 146398 & 329016 & 605512 & 1 & 3 & 8 \\
\hline & & 120868 & 180810 & & 143220 & 221963 & & 155124 & 229693 & $10,775,604.6$ & $13,165,844.9$ & $15,136,491.4$ \\
\hline 6 & 459158 & 7 & 7 & 501761 & 2 & 1 & 567332 & 7 & 0 & 6 & 0 & 1 \\
\hline & & & & & & 100927 & & & 100481 & $15,238,608.3$ & $18,943,922.2$ & $22,579,379.1$ \\
\hline 7 & 188158 & 434118 & 789720 & 196409 & 484798 & 6 & 207678 & 524220 & 9 & 4 & 9 & 2 \\
\hline & & & & & & & & & & $18,693,461.4$ & $24,828,725.8$ & $30,931,897.3$ \\
\hline 8 & 171433 & 345111 & 647061 & 178201 & 384308 & 827067 & 188677 & 406637 & 826775 & 5 & 1 & 6 \\
\hline & & & & & & & & & & $21,804,368.1$ & $30,432,476.2$ & $38,467,079.4$ \\
\hline 9 & 159936 & 301272 & 555414 & 165271 & 328658 & 704848 & 175208 & 347514 & 705094 & 7 & 0 & 7 \\
\hline & & & & & & & & & & $27,760,290.9$ & $40,741,297.0$ & $53,275,041.1$ \\
\hline 10 & 147711 & 251391 & 472374 & 148440 & 266170 & 567683 & 154443 & 278845 & 576128 & 6 & 5 & 9 \\
\hline & & & 123821 & & & 156433 & & 101127 & 160538 & $19,334,654.8$ & $23,654,910.5$ & $28,074,418.5$ \\
\hline 11 & 291577 & 783602 & 2 & 319190 & 938113 & 5 & 364165 & 5 & 4 & 6 & 7 & 0 \\
\hline & & & & & & & & & & $25,371,623.2$ & $30,866,442.8$ & $36,341,120.4$ \\
\hline 12 & 173186 & 337234 & 616818 & 176653 & 365537 & 778288 & 188107 & 387951 & 776119 & 4 & 4 & 5 \\
\hline & & & & & & & & & & $28,678,258.0$ & $36,298,715.1$ & $43,755,307.7$ \\
\hline 13 & 161019 & 290687 & 515719 & 163483 & 303880 & 647327 & 173821 & 320883 & 646249 & 2 & 2 & 2 \\
\hline & & & & & & & & & & $31,322,350.7$ & $40,845,071.4$ & $50,598,863.8$ \\
\hline 14 & 155024 & 265152 & 470327 & 154752 & 273661 & 568983 & 163267 & 284910 & 572252 & 2 & 7 & 3 \\
\hline & & & & & & & & & & $37,220,046.5$ & $50,314,240.2$ & $63,593,478.4$ \\
\hline 15 & 154389 & 243047 & 408106 & 153861 & 239675 & 490014 & 160205 & 252006 & 493711 & 5 & 7 & 5 \\
\hline & & 119345 & 154326 & & 131571 & 177554 & & 145373 & 186753 & & & $10,610,264.8$ \\
\hline 16 & 470144 & 8 & 2 & 509353 & 9 & 1 & 573907 & 1 & 8 & $6,596,399.06$ & $8,637,510.12$ & 8 \\
\hline & & & & & & 113679 & & & 118063 & & $10,400,886.2$ & $12,474,779.5$ \\
\hline 17 & 259239 & 672663 & 955886 & 275716 & 764740 & 7 & 312839 & 834342 & 1 & $8,291,880.26$ & 3 & 8 \\
\hline & & & & & & & & & & $11,124,226.3$ & $14,691,649.2$ & $18,365,393.8$ \\
\hline 18 & 204011 & 428546 & 637290 & 211476 & 477436 & 760552 & 222479 & 506755 & 767992 & 0 & 8 & 8 \\
\hline & & & & & & & & & & $13,417,510.8$ & $18,120,325.2$ & $23,376,927.1$ \\
\hline 19 & 196975 & 373093 & 557655 & 202523 & 414374 & 660978 & 212224 & 435267 & 669053 & 1 & 9 & 5 \\
\hline & & & & & & & & & & $17,390,891.1$ & $25,910,758.1$ & $34,006,833.9$ \\
\hline 20 & 185801 & 321327 & 462492 & 190497 & 334330 & 541147 & 198962 & 352050 & 549980 & 1 & 9 & 0 \\
\hline & & & 130525 & & 110801 & 155970 & & 120751 & 162204 & & $11,747,750.6$ & $14,208,083.5$ \\
\hline 21 & 360260 & 975355 & 4 & 397249 & 8 & 3 & 452228 & 0 & 7 & $9,187,923.12$ & 7 & 7 \\
\hline & & & 110264 & & & 131853 & & & 136021 & $12,535,541.2$ & $16,405,896.1$ & $20,042,121.0$ \\
\hline 22 & 296199 & 795216 & 9 & 320508 & 910713 & 5 & 366849 & 987313 & 7 & 4 & 0 & 2 \\
\hline & & & & & & & & & & $16,035,953.2$ & $20,100,569.7$ & $24,637,396.6$ \\
\hline 23 & 204743 & 427350 & 659196 & 212714 & 487982 & 794608 & 223204 & 512959 & 797793 & 3 & 3 & 1 \\
\hline & & & & & & & & & & $18,157,322.2$ & $23,598,197.8$ & $29,405,690.7$ \\
\hline 24 & 199173 & 381069 & 583463 & 204817 & 424964 & 703178 & 214780 & 446901 & 706257 & 2 & 6 & 0 \\
\hline & & & & & & & & & & $22,989,428.9$ & $30,812,265.3$ & $39,091,221.1$ \\
\hline 25 & 189588 & 331341 & 483019 & 194443 & 343015 & 580571 & 203592 & 363012 & 586612 & 4 & 2 & 0 \\
\hline & & & 113155 & & & 136075 & & 100778 & 141485 & & $11,943,709.8$ & $14,099,831.6$ \\
\hline 26 & 329650 & 821053 & 6 & 356862 & 925215 & 6 & 402871 & 5 & 1 & $9,752,511.43$ & 0 & 0 \\
\hline & & & & & & & & & & $11,880,600.2$ & $14,432,031.9$ & $16,665,428.4$ \\
\hline 27 & 209320 & 459466 & 690369 & 218723 & 516972 & 852105 & 234339 & 545934 & 863692 & 6 & 4 & 5 \\
\hline & & & & & & & & & & $14,044,225.6$ & $17,346,524.3$ & $20,775,696.9$ \\
\hline 28 & 197722 & 376581 & 574340 & 203507 & 418242 & 692611 & 213420 & 439450 & 699683 & 4 & 7 & 7 \\
\hline & & & & & & & & & & $15,611,356.6$ & $20,104,043.1$ & $24,460,720.5$ \\
\hline 29 & 193158 & 348136 & 530618 & 198227 & 378537 & 633121 & 208131 & 402372 & 640581 & 3 & 4 & 2 \\
\hline & & & & & & & & & & $18,683,863.3$ & $24,849,388.4$ & $31,894,799.2$ \\
\hline 30 & 185043 & 314350 & 461129 & 188997 & 322880 & 546916 & 198596 & 345463 & 554926 & 6 & 0 & 6 \\
\hline & & & & & & 101335 & & & 104460 & $18,307,280.5$ & $22,327,331.2$ & $26,552,180.3$ \\
\hline 31 & 242112 & 571023 & 824645 & 257112 & 658244 & 7 & 287253 & 709006 & 5 & 5 & 8 & 7 \\
\hline & & & & & & & & & & $20,624,291.0$ & $24,938,690.4$ & $29,339,778.8$ \\
\hline 32 & 199335 & 391727 & 588798 & 206349 & 437124 & 724704 & 216426 & 458995 & 730623 & 9 & 2 & 7 \\
\hline & & & & & & & & & & $22,538,143.4$ & $27,507,196.3$ & $32,673,777.9$ \\
\hline 33 & 193751 & 337946 & 512725 & 196498 & 357044 & 614336 & 207110 & 381742 & 619071 & 6 & 3 & 8 \\
\hline & & & & & & & & & & $24,044,861.1$ & $30,096,601.0$ & $35,340,889.5$ \\
\hline 34 & 190498 & 320374 & 477100 & 192727 & 332588 & 569793 & 203265 & 350435 & 575753 & 2 & 8 & 6 \\
\hline & & & & & & & & & & $27,289,264.7$ & $34,517,279.5$ & $41,877,023.8$ \\
\hline 35 & 185025 & 299999 & 425533 & 186255 & 301676 & 496562 & 196039 & 319091 & 502847 & 1 & 9 & 4 \\
\hline
\end{tabular}


Table C-15: Fuzzy decision matrix for Kelowna case study.

\begin{tabular}{|c|c|c|c|c|c|c|c|c|c|c|c|c|}
\hline \multirow[b]{2}{*}{ Scenario } & \multicolumn{3}{|c|}{ Water Footprint (Current) } & \multicolumn{3}{|c|}{ Water Footprint (RCP 2.6) } & \multicolumn{3}{|c|}{ Water Footprint (RCP 8.5) } & \multicolumn{2}{|l|}{ Life Cycle Costs } & \multirow[b]{2}{*}{ P95 } \\
\hline & P05 & P50 & P95 & P05 & $\mathrm{P} 50$ & P95 & P05 & $\mathrm{P} 50$ & P95 & P05 & P50 & \\
\hline 1 & 1830201 & 2707677 & 3471622 & 1854638 & 2990619 & 3979324 & 2138059 & 3286226 & 4194622 & $802,134.85$ & $875,127.12$ & $954,336.72$ \\
\hline 2 & 218195 & 617387 & 1091249 & 236961 & 728251 & 1370705 & 260673 & 790591 & 1401141 & $3,196,832.07$ & $5,230,524.39$ & $7,194,506.10$ \\
\hline 3 & 176435 & 426438 & 771990 & 186943 & 486858 & 968586 & 202894 & 538827 & 986595 & $5,487,785.19$ & $9,332,500.35$ & $13,523,843.88$ \\
\hline 4 & 153538 & 351336 & 626736 & 163714 & 394521 & 777790 & 176633 & 428790 & 794635 & $7,930,792.44$ & $14,043,085.36$ & $20,599,937.32$ \\
\hline 5 & 135072 & 279927 & 487870 & 140400 & 305459 & 582797 & 146398 & 329016 & 605512 & $13,000,956.41$ & $24,425,681.49$ & $35,213,024.04$ \\
\hline 6 & 459158 & 1208687 & 1808107 & 501761 & 1432202 & 2219631 & 567332 & 1551247 & 2296930 & $9,497,748.26$ & $11,708,521.00$ & $13,837,048.51$ \\
\hline 7 & 188158 & 434118 & 789720 & 196409 & 484798 & 1009276 & 207678 & 524220 & 1004819 & $13,035,738.52$ & $16,043,526.71$ & $19,132,815.76$ \\
\hline 8 & 171433 & 345111 & 647061 & 178201 & 384308 & 827067 & 188677 & 406637 & 826775 & $14,978,754.71$ & $19,091,397.29$ & $23,087,001.68$ \\
\hline 9 & 159936 & 301272 & 555414 & 165271 & 328658 & 704848 & 175208 & 347514 & 705094 & $16,712,736.58$ & $22,231,790.91$ & $27,553,058.88$ \\
\hline 10 & 147711 & 251391 & 472374 & 148440 & 266170 & 567683 & 154443 & 278845 & 576128 & $20,407,160.14$ & $28,152,535.58$ & $36,884,545.77$ \\
\hline 11 & 291577 & 783602 & 1238212 & 319190 & 938113 & 1564335 & 364165 & 1011275 & 1605384 & $18,104,615.59$ & $22,407,376.35$ & $26,721,749.28$ \\
\hline 12 & 173186 & 337234 & 616818 & 176653 & 365537 & 778288 & 188107 & 387951 & 776119 & $22,740,827.91$ & $28,072,047.72$ & $33,744,933.05$ \\
\hline 13 & 161019 & 290687 & 515719 & 163483 & 303880 & 647327 & 173821 & 320883 & 646249 & $24,605,294.08$ & $30,780,481.50$ & $36,618,529.36$ \\
\hline 14 & 155024 & 265152 & 470327 & 154752 & 273661 & 568983 & 163267 & 284910 & 572252 & $26,696,083.57$ & $33,746,787.18$ & $40,720,429.26$ \\
\hline 15 & 154389 & 243047 & 408106 & 153861 & 239675 & 490014 & 160205 & 252006 & 493711 & $30,199,764.67$ & $39,704,513.09$ & $48,999,194.57$ \\
\hline 16 & 470144 & 1193458 & 1543262 & 509353 & 1315719 & 1775541 & 573907 & 1453731 & 1867538 & $5,943,197.43$ & $7,787,567.44$ & $9,605,096.53$ \\
\hline 17 & 259239 & 672663 & 955886 & 275716 & 764740 & 1136797 & 312839 & 834342 & 1180631 & $6,552,993.02$ & $8,569,010.53$ & $10,365,440.93$ \\
\hline 18 & 204011 & 428546 & 637290 & 211476 & 477436 & 760552 & 222479 & 506755 & 767992 & $8,048,712.25$ & $10,571,506.18$ & $13,015,825.06$ \\
\hline 19 & 196975 & 373093 & 557655 & 202523 & 414374 & 660978 & 212224 & 435267 & 669053 & $9,829,633.16$ & $12,815,388.06$ & $16,146,341.24$ \\
\hline 20 & 185801 & 321327 & 462492 & 190497 & 334330 & 541147 & 198962 & 352050 & 549980 & $12,614,986.76$ & $17,383,091.60$ & $22,340,160.09$ \\
\hline 21 & 360260 & 975355 & 1305254 & 397249 & 1108018 & 1559703 & 452228 & 1207510 & 1622047 & $8,381,665.32$ & $10,954,005.78$ & $13,485,339.59$ \\
\hline 22 & 296199 & 795216 & 1102649 & 320508 & 910713 & 1318535 & 366849 & 987313 & 1360217 & $11,236,483.86$ & $14,859,737.17$ & $18,844,738.92$ \\
\hline 23 & 4743 & 427350 & 659196 & 212714 & 487982 & 794608 & 223204 & 512959 & 797793 & $12,565,448.41$ & $16,365,308.89$ & $20,151,169.25$ \\
\hline 24 & 199173 & 381069 & 583463 & 204817 & 424964 & 703178 & 214780 & 446901 & 706257 & $14,508,103.17$ & $18,620,381.38$ & $22,889,343.92$ \\
\hline 25 & 189588 & 331341 & 483019 & 194443 & 343015 & 580571 & 203592 & 363012 & 586612 & $17,478,711.76$ & $23,066,835.98$ & $28,583,077.29$ \\
\hline 26 & 329650 & 821053 & 1131556 & 356862 & 925215 & 1360756 & 402871 & 1007785 & 1414851 & $8,940,705.78$ & $11,032,134.89$ & $13,212,755.76$ \\
\hline 27 & 209320 & 459466 & 690369 & 218723 & 516972 & 852105 & 234339 & 545934 & 863692 & $10,442,678.41$ & $12,790,458.17$ & $15,180,491.64$ \\
\hline 28 & 197722 & 376581 & 574340 & 203507 & 418242 & 692611 & 213420 & 439450 & 699683 & $11,560,741.61$ & $14,165,809.23$ & $16,924,991.97$ \\
\hline 29 & 193158 & 348136 & 530618 & 198227 & 378537 & 633121 & 208131 & 402372 & 640581 & $12,836,078.83$ & $15,876,441.86$ & $19,017,987.82$ \\
\hline 30 & 185043 & 314350 & 461129 & 188997 & 322880 & 546916 & 198596 & 345463 & 554926 & $14,660,186.00$ & $18,967,561.20$ & $23,594,098.22$ \\
\hline 31 & 242112 & 571023 & 824645 & 257112 & 658244 & 1013357 & 287253 & 709006 & 1044605 & $17,042,993.36$ & $21,464,300.90$ & $25,466,792.84$ \\
\hline 32 & 199335 & 391727 & 588798 & 206349 & 437124 & 724704 & 216426 & 458995 & 730623 & $19,095,474.91$ & $23,450,616.69$ & $27,914,707.97$ \\
\hline 33 & 193751 & 337946 & 512725 & 196498 & 357044 & 614336 & 207110 & 381742 & 619071 & $20,501,033.89$ & $24,860,529.46$ & $29,414,785.37$ \\
\hline 34 & 190498 & 320374 & 477100 & 192727 & 332588 & 569793 & 203265 & 350 & 575 & $21,244,696.82$ & $26,166,425.14$ & $30,645,281.95$ \\
\hline 35 & 185025 & 299999 & 425533 & 186255 & 301676 & 496562 & 196039 & 319091 & 502847 & $23,403,251.69$ & $29,391,260.79$ & $34,601,756.52$ \\
\hline
\end{tabular}

